\author{
M. Reeves \\ C. $\boldsymbol{W}$. Francis \\ J. O. Duguid
}

Environmental Sciences Division

Publication No. 1105 


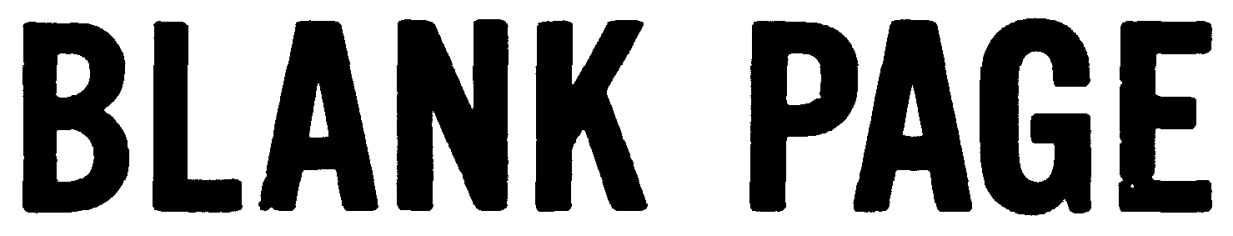




\section{Printed in the United States of America Available from National Technical information Service} U.S. Department of Commerce 5285 Port Royal Road. Springfield. Virginia 22161

Price. Printed Cop; \$9.00: Microfiche \$3 00

\footnotetext{
Tris sepor: was prepared as ar: account of work soonsored by ar agercy a the u ted

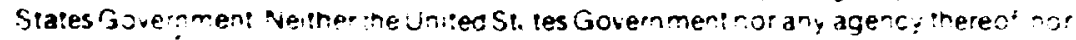
any ot the:r emoloyees ar iractors subcontraciors or tretremoloyees makes an,

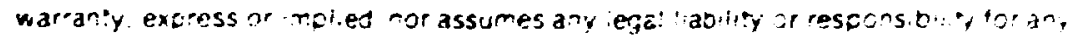

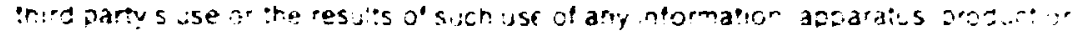

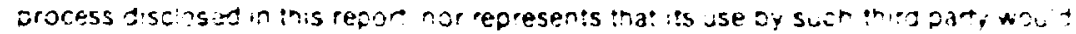
not intregos privateiy owned : $7^{\text {hr:s }}$
} 
ORNL-5337

Dist. Category UC-70

Coatract No. w-7405-eas-26

COMPUTER SCIENCES DIVISION

ENVIRONMENT AL SCIENCES DIVISION

\title{
QUANTITATIVE ANALYSIS OF SOIL CHROMATOGRAPHY \\ I. WATER AND RADIONUCLIDE TRANSPORT
}

\author{
M. Reeves \\ Computer Sziences Division \\ C. W. Francis \\ Environmental Sciences Division \\ J. O. Duguid \\ Environmental Sciences Division
}

Environmental Sciences Division

Publication No. II0S

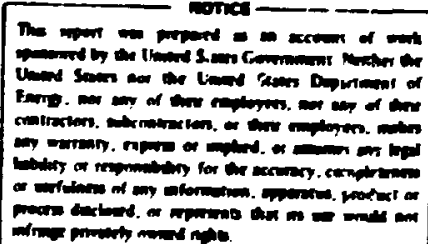

Date Published: Decenber 1977

OAK RIDGE NATIONAI. LABORATORY

Oak Ridge. Tennessce $\mathbf{3 7 8 . 2 0}$ operaled by UNION CARBIDE CORPORATION

for the DEPARTMENT OF ENERGYY 


\section{CONTENTS}

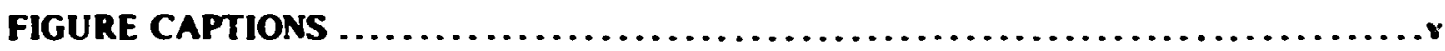

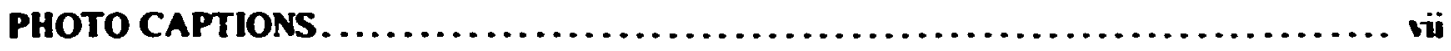

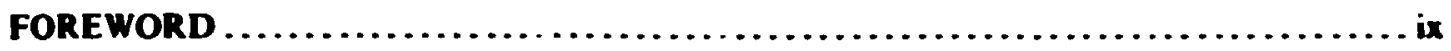

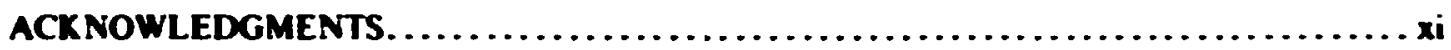

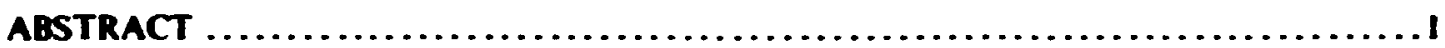

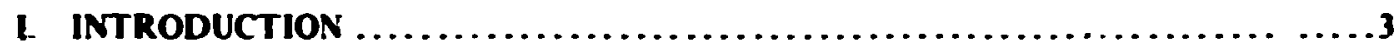

II. EXPERIMENTAL SOIL CHROMATOGRAPHY $\ldots \ldots \ldots \ldots \ldots \ldots \ldots \ldots \ldots \ldots \ldots \ldots \ldots \ldots \ldots \ldots$

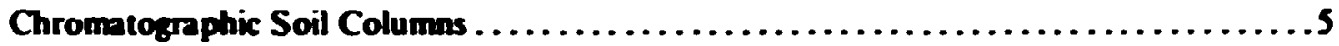

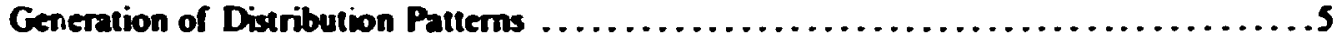

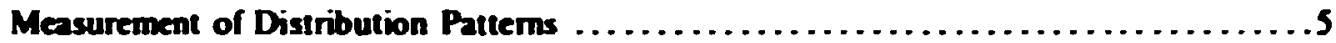

Movement of the Eluting Solution................................. 10

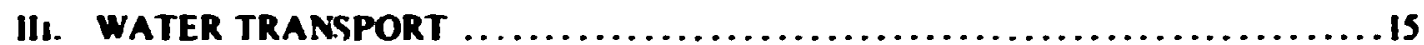

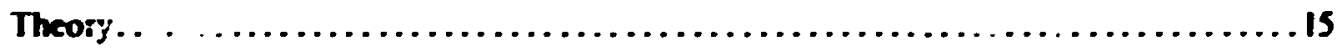

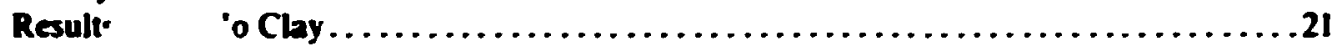

Para $\quad$ on of Soil Preperties ...................................

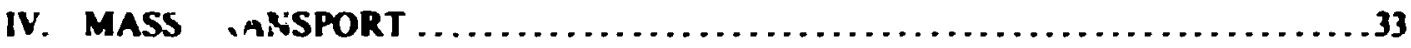

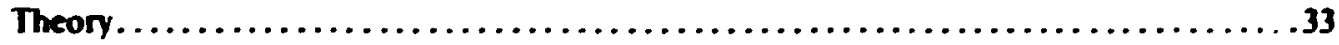

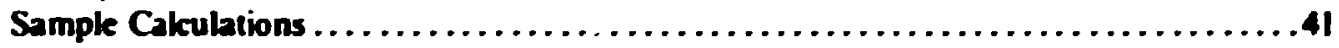

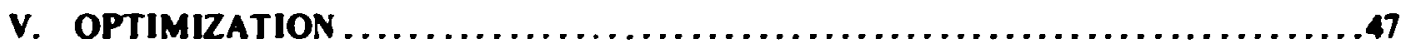

Introduction ................................................. 4

Optimal Search .................................................47

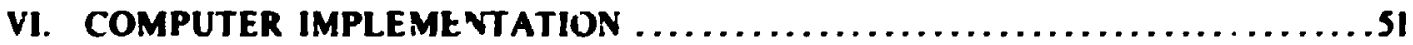

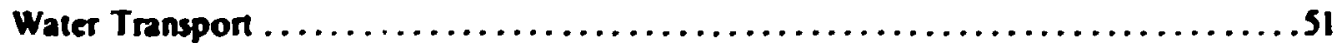

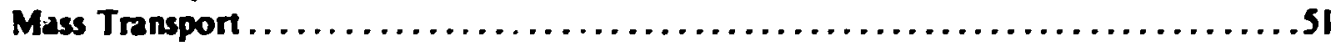

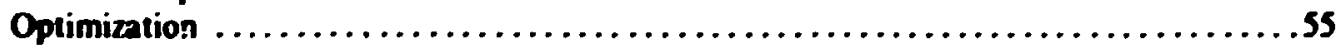

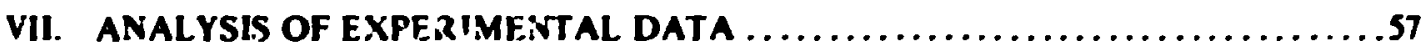

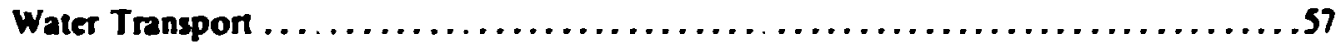

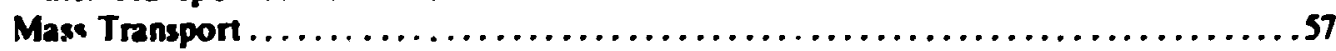

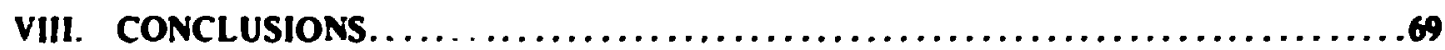

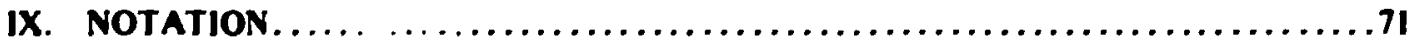

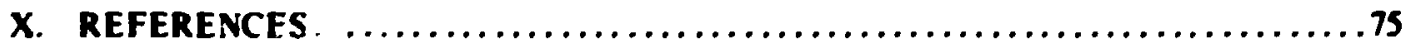

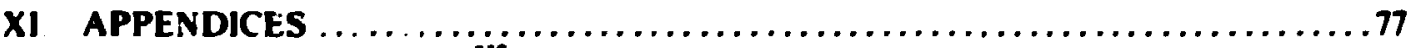

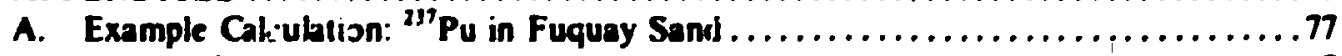

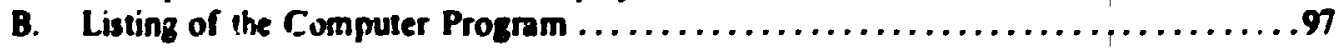

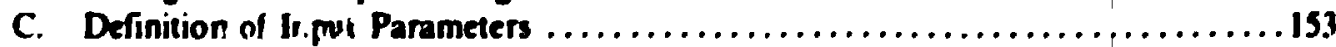

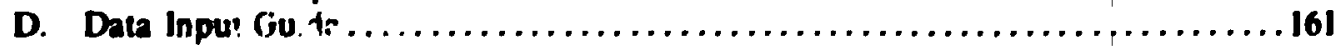




\section{FIGURE CAPTIONS}

Fiz. 1. Mobility of "Sr in Fuquay sand for an eluting solution containing $200 \mathrm{ppm} \mathrm{Ca} . \ldots . .11$

Fig. 2. Mobility of "Sr in Captina sih loam for an chuting solution containing 200 ppm Ca .. 12

Fie 3. Water-front movement with respect to time...........................

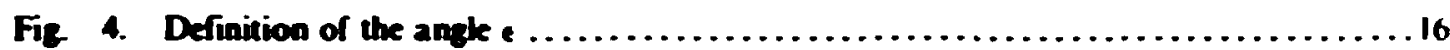

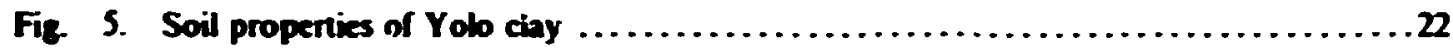

Fie 6. End-point Darcy velocity as a function of time for capilbry rise in Yolo chy .......23

Fig. 7. Water content and Darey vebcity as functions of time for capillary riae in Yolo clay. .24

Fig. 8. Water content and Darey velocity as functions of time for infiltration in Yolo clay ...25

Fig. 9. Water content and Darcy velocity as functions of time for horizontal flow in Yolo clay26

Fig. 10. Representative hydraulic conductivities for sand, clay, and loam soils ..........28

Fig. 11. Representative moisture characteristics for sand, clay, and bam soils ...........30

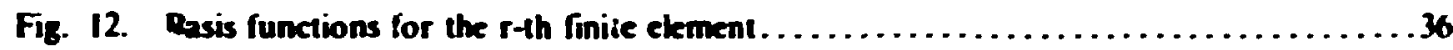

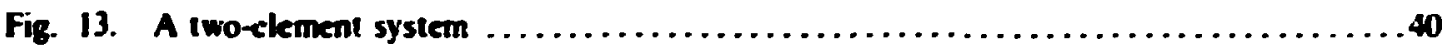

Fig. 14. Development of concentration profiks as a function of time for a variable advective

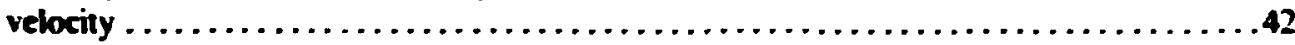

Fig. 15. Elfeet of the dispersivily parameters on profike development ................

Fig. 16. Effect of the distribution coefficient on profike development ..............44

Fig. 17. Examples of base-point exploration. pattern moves. and of successful pattem-point explorations ..............................................

Fig. 18. Flow chant connecting the functional units of the program ...............52

Fig. 19. Flow chant specifying the water-transport routines........................

Fig. 20. Flow chart specifying the mass-transport routines $\ldots \ldots \ldots \ldots \ldots \ldots \ldots \ldots \ldots$

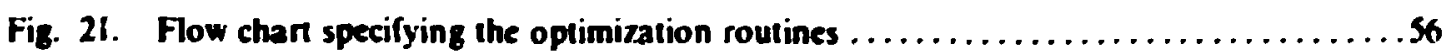

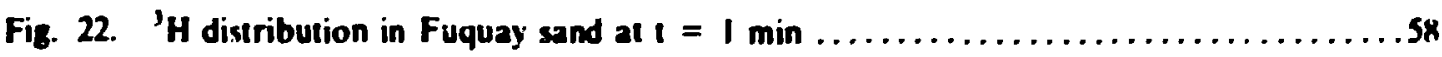

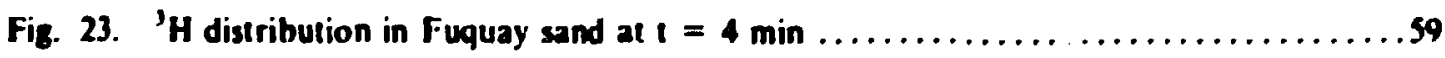

Fig. 24. "Sr distribution in Fuguay sand after one wetting with water $\ldots \ldots \ldots \ldots \ldots \ldots \ldots$ I 
Fy. 25. "Sr distribution in Fuquay sand after two wettings with water ................62

Fie 26. ${ }^{217}$ Pu distribution in Fuquay sand after one wetting with water................63

Fie 27. "3r Pu distribution in Fuquay sand after two wetting with water $\ldots \ldots \ldots \ldots \ldots \ldots$.

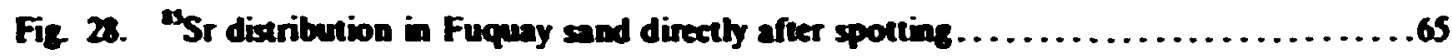

Fie 29. ${ }^{237}$ Pu distribution in Fuquay sand directly after spotting...................6

Fie. 30. "Sr distribution in Fuquay sand after one wetting with $0.01 \mathrm{~N} \mathrm{Ca}(\mathrm{NO})$, $\ldots \ldots \ldots .68$ 


\section{PHOTO CAPTIONS}

Photo. I. The columa-kyered chromatographic (CLC) phite after loading with soil ........6

Photo. 2. A picture of the soil columns, the TLC phe chapped to the CLC plate. and ine victs submersed in an eluting solution ...................................?

Photo. 3. Radionuclide mobilities as determined by medical $x$-ray film $\ldots \ldots \ldots \ldots \ldots \ldots . .$.

Photo. 4. The radiochromatographic scanner (top center) together with its associated recording apparatus: a multichannet aantyzer (keft) with its papertape punch altended by a technician and a strip-chart recorder (right) ............................ 


\section{FOREWORD}

In February 1976 the Energy Research and Development Administration (ERDA) anaounced a greally expanded waste manosment program for defense and commercial redicactive waste. In that announcement, ERDA indicated that the Oak Ridge Operations OThoc (ORO) of ERDA would have lead responsibility for overall coordination of ite expanded commercial geclogic disposal program and that an Office of Waste Isolation (OWI) would be created within Union Carbide Corporation-Nuckear Division (UCC-ND) with the responsibility for program mamagent of that activity.

The commercial seolopic dispoed program was astred the National Waste Terminal Storape (NWTS) program. The principal objective of the NWTS proprem is to provide facilities in various deep reologic formations at mulipk locations in the United States which will saffy dispose of comenercial radionctive waste.

In addition to the geologic studiex, the NWTS program includes a number of technizal suppen activities which are required to identily a waste repository site. demonstrate its iessibility. confirm its suitability. and thoroughty amalyze all aspects of the repository design proposed for the site. The material presented in this repon is rebted to the categery of activity identified as waste rock interaction proiscts. These projects are concerned with chemioal. physica. : nicai. geochemical. and radiochemical reactions and processes between emplaced radioactive waste and the surrounding rock which might affect the design. safe operation. and long-term containment of a ecologic repository. This document discusses soil chromatography and evaluates the potential for this analytial technique to provide useful cation exchange property data for soil and rock materials. 


\section{ACKNOWLEDGMENTS}

The authors gratefully ack nowied ge the Orfece of Waste Isobtion. Without the initial scientific interest of its representatives and the subseyuent financial support. this research would not have been possible. Credit is also due Ms. Janice W. Arwood for both her prompiness and her skill in computerized phototypesetting. and to Ms. Nancy C. Smith for tite artistic manner in which she set up the many equations of this document. Finally. the authors express their appreciation to Ms. linda B. Maddox. who was most helpful in editing and debugging the computer program. 


\title{
QUANTITATIVE ANALYSIS OF SOIL CHROMATOGR.APHY \\ I. WATER AND RADIONUCLIDE TRANSPORT
}

\author{
M. Reeves \\ C. W. Francis \\ J. O. Duguid
}

\begin{abstract}
Soil chromatography has been used successfully to evaluate rebtive mobilities of pesticides and nuclides in soils. Is major advantage over the commonly used suspension tecthicuve is that it mure accurately simulates field conditions. Under such conditions the rumber of potential exchange sites is limited both by the structure of the soil matrix and by the manner in which the carrier fluid moves through this structure. The major limitation of the chromatographic method. however. has been its qualitative nature. This document represents an effort to counter this objection. A theoretical basis is specified for the transport both of the carrier eluting fluid and of the dissolved constituent. A computer program based on this theory is developed which optimines the fit of theoretical data to experimental data by automatically adjusting the transport parameters. une of which is the distribution coefficient $k_{d}$. This analysis procedure thus constitutes an integral pan of the soil chromatographic method. by means of which mobilities of nuclides and other dissolved constituents in soils may be quantified.
\end{abstract}




\section{INTRODUCTION}

In erder to simulate the motement of a radiunuclade through geobogic lormations. it is necessang to describe the adsorption of the radioneclide. A parameier which is freyuently used for this purpose is the distribution coefficient $k_{2}$. This yuantity is delined simph as the ratio of the solid-phase concentration to the lixuid-phase conceatration. and in the dieute-solution limit it assumes a constant value. Conventionally. values of $k_{2}$ are obtained under eyuilibrium conditions using the suspension method. Determined in this manner. $k$ d values represent the maximum adsorption of a nuclide and may he greater than simibr values obtained under Treld conditions[Prolhorov. 1962] by more than an order of magnilude. The brex difference is. of course. altribulable to insufficient exchange between soiid and loyuid phases in the moist soil relative to that which takes place in licuuid suspension.

One inethod that appears to simuble environmental conditions helter than suspension $k$. measurements is soil chmmatography [Helling and Tumer. IFtix. and Rhodes. Bebscos. and Pease. 1970]. This method has been proposed by the AIBS-EPA environmental chemistn lask group as it: most suitable techniyue for evaluating the rebtive nobilities of pesticiries in soils. It consists basically in the preparation of a thill layier of soil. the transport of the dissolved constiturent through the soil by the carrier huid. and the observation of migration profikes. We have modified this metnod experimentally for the study of radionuclide movement pattems and have devekoped a computer model capable of extracting values of $k$, from these pattems.

Chapter II presents a brief overvicu of the experimental techniugeses. The purpense there. however. is not to present an exhaustive description of such techniugues but in introduce the remaining part of the document. which contains the principal thrust of this report. These chapters and appendices form a complete description of our computer muxicl. M/cisture-and mass-transpurt are the subjects of Chapeers III and IV. respectively. The optimination procedure uxid to adjust the transpon :arameters so as in theoretically -fit" the experimental data is hriefly discussed in (hapter V. The next chapter. Chapter VI. describex the organization of the computer program. and (hapter VII demonstrates its application. A test case. a listing of the computer program. and a completc description of the input may the fourd in the appendices. 


\section{EXPERIMENTAL SOIL CHROMATOGRAPHY}

Soil thin-byer chromatography $(T L C)$ has teen successfully used to evaluate the mobility cf pusticides in soils [Helling. 1971]. The major advantage of this technique is the ease in which the mobility of a number of pesticides can be assessed under nearly identical conditions. The technique is rapid and allows for the comparison of the :nobility of pesticides in a bres number of soils with a minimum of expense and equipment. Ascending chromelography, using water as a solvent. is the conventionally accepted eluting procedure. Operating in this manner, the water fux is determined by the soil propert:a. Unlike soil-coismn studies, excessive plugging and hydraulic short circuiting do not occur and are thus atiminated as potential sources of errur Because of these characteristics, the technique is also approprinte for evaluating the muvement of radionuclides in soils and porous media.

\section{CHROMATOGRAPHIC SOIL COLUMNS}

Instead of the conventional TLC plates, we use column-byered chromatczi aphic (CLC) plates. These platus are 20 by $20 \mathrm{~cm}$ with nine channels or colum is measuring $10 \mathrm{~mm}$ in width anc: $2 \mathrm{~mm}$ in depth. Srils are slurried with water until moderately fluid and then applied to the plates (Photc. 1) by us'ng a spreader. Strips of blotter paper. approxima:ely $0.7 \mathrm{~mm}$ wide and $5 \mathrm{~cm}$ bong. are used as wicks for transporting the eluting solution to the soil kyered in the channels. The wixks ar held in place by clamping a 20 by $20 \mathrm{~cm}$ conventional TLC plate on ton of the CLC plate (Photo. 2). By using these wicts, the soils in the CLC plates may be eluted again after drying. If wicks are not used. soil will usually slough off during immersion in the eluting. or feed. solution since the CLC plates are positioned at 68 degrees rebtive to the surface of the eluting solution

\section{GENERATION OF DISTRIBUTION PATTERNS}

The radionuclide to be considered may be introduced into the soil column either through the feed solution or by spotting the rarionuclide directly onto the soil. In the biter case a spot conteining $10^{4}-10^{4} \mathrm{dpm}$ is placed at $4 \mathrm{~cm}$ from the base of the chromatographic soil column. The wicks are then submerged in, the feed solution. We have used $\mathrm{H}_{2} \mathrm{O}, 0.01 \mathrm{~N} \mathrm{NaHCO}$, and solutions of $\mathrm{Ca}\left(\mathrm{CO}_{1}\right)_{2}$ having varying iunic strengths. Such an eluting solution is allowed to disperse the radionuclide for a measured period of time. The sntilc CLC plate is then removed from the eluting solution, and radionuclide patterns are determined.

\section{MEASUREMENT OF DISTR!BUTION PATTERNS}

In some of our earlier work autoradiography and a cissection method were used to determine distribution patterns. Medical X-ray film was used for the autoradiography. The film was enclosed in thin sheets of plastic to prevent its contamination. 1 was then clainped securely between the TLC plate and the CLC plate and exposed for periods ranging from 48 to 72 hours. Measuring the movement of radionuclides in this manner sufficed only in that it gave the general characteristics of the mobility of one radionuclide relative to another. For instance. Phoio. 3 shows that ${ }^{1 m}$ Ru. "II. "Co, and "Tc were quite mohile compared to "Sr, " $\mathrm{Cd}$, "Nb, and " ${ }^{\text {"N. }}$. There appeared to be a mobile and non-mobile specie of "'mu and "I. Alitoratiography. however, is not satisfactory for quantitatively measuring the movement of the radionuclides. Another method for ubtaining distribution patterns consisted of disserting each column itito $1.5 \mathrm{~cm}$ increments of soil. The radioactivity of each increment was then cn:inted separately with a $\mathrm{Nal}$ detcctor. Although this technigue was capable of quantitative measurement, it was extremely bborious and its resolution was limited to the lengths of the soil increments.

Currently, a radiushromatographic scanner (berthold Model LB 2760) equipped with a gas-flow detector is being used for measuring the movement of the various radionuclides (see Photo. 4). Because of the large selections of scanning speeds available $(6000,3000,1500,1200,600,300,120$. 
BLANK PAGE 
Pipto 5699-76

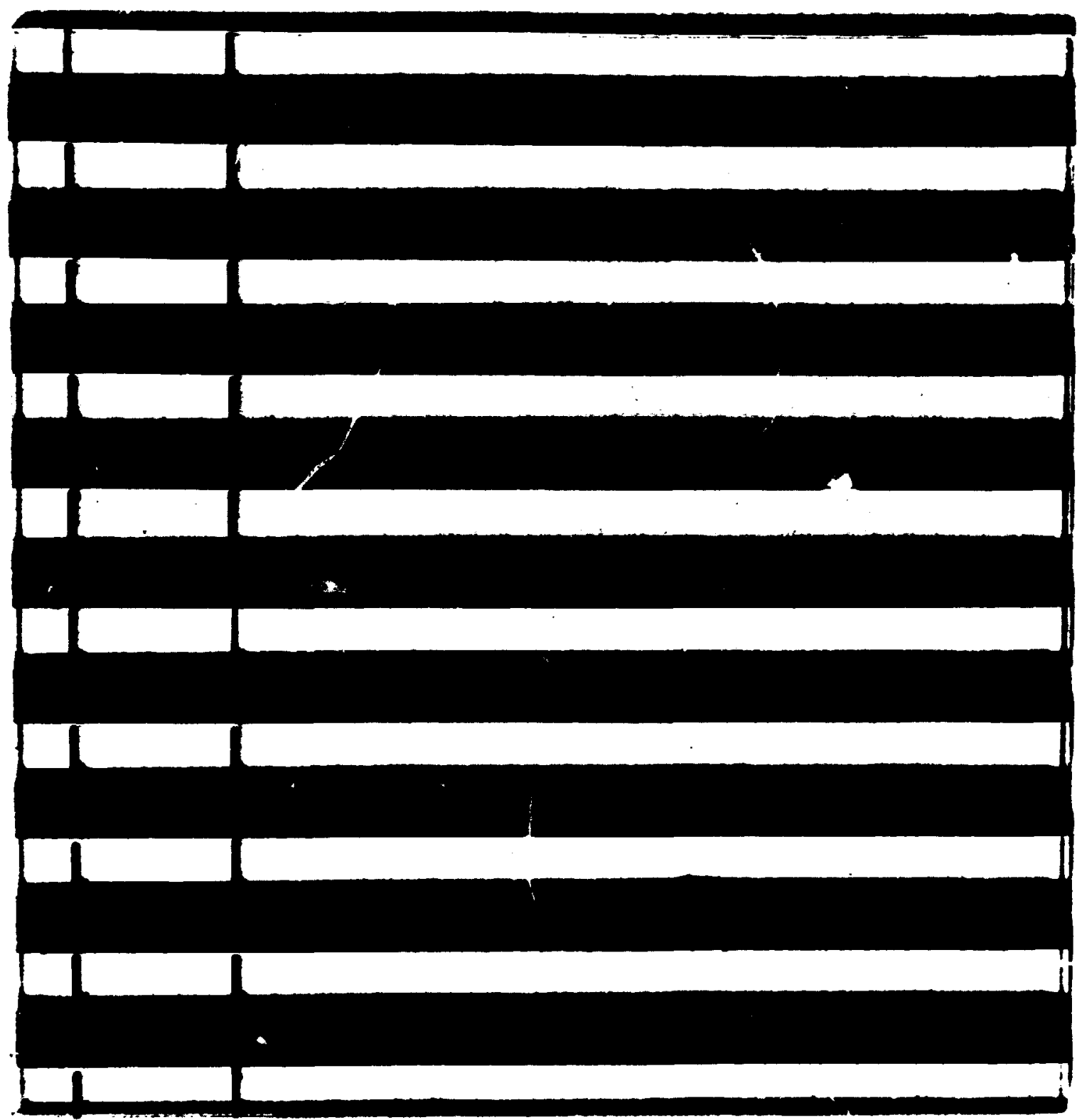

Photo. I. The column-layered chromatographic (CLC) plate after loading with soil 


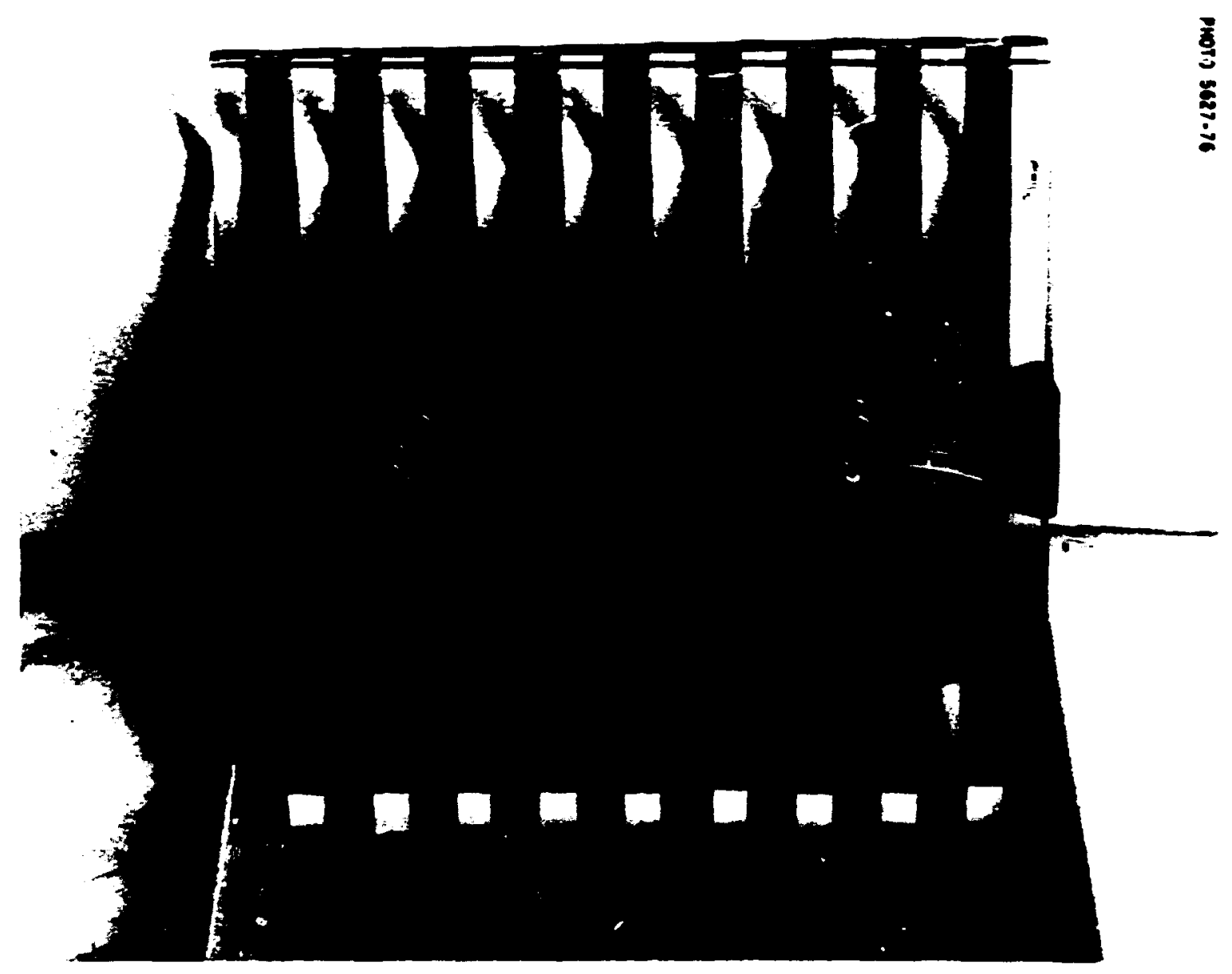

Photo. 2. A picture of the soil columns. the ïLC plate cbmped to the CL.C plate. and the wicks submerged in an eluting solution 

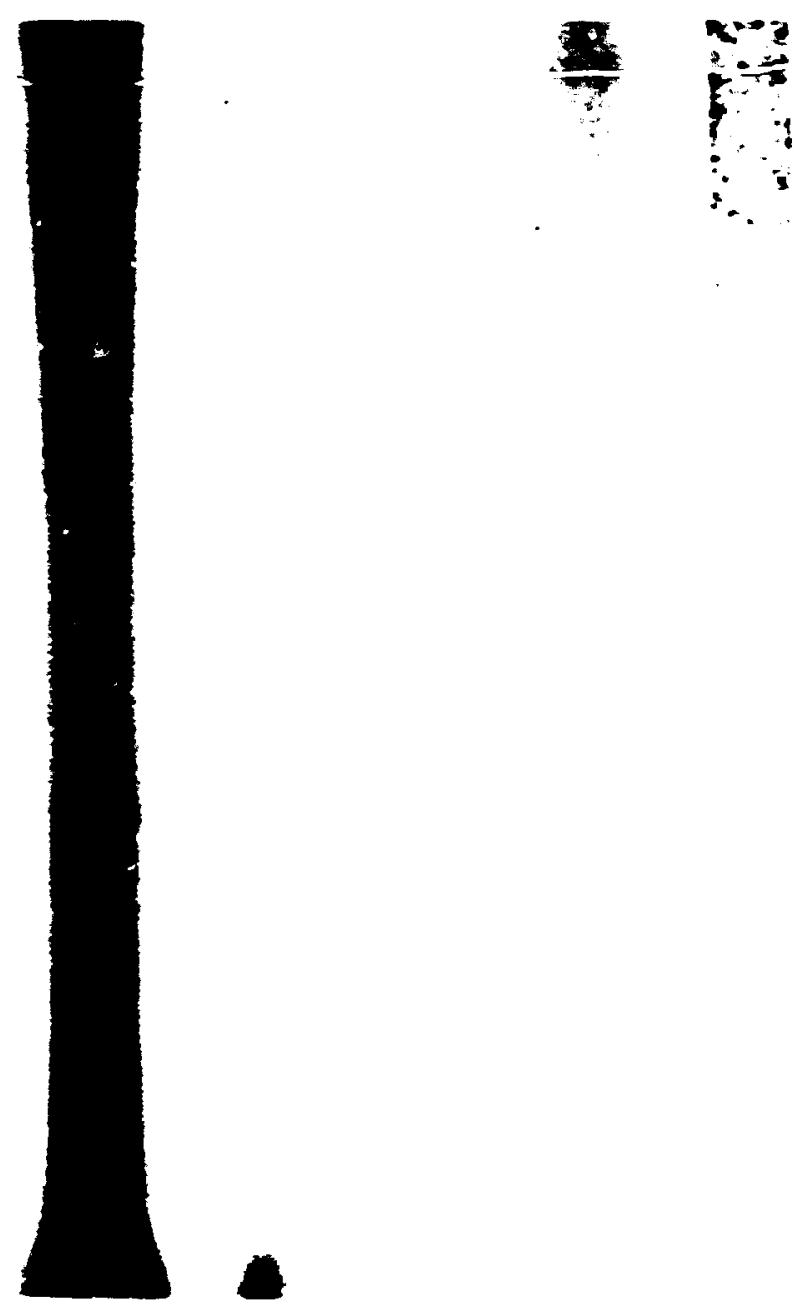

Photo. 3. Radinnuclide mobilities as determined by medical x-ray fi'm. 


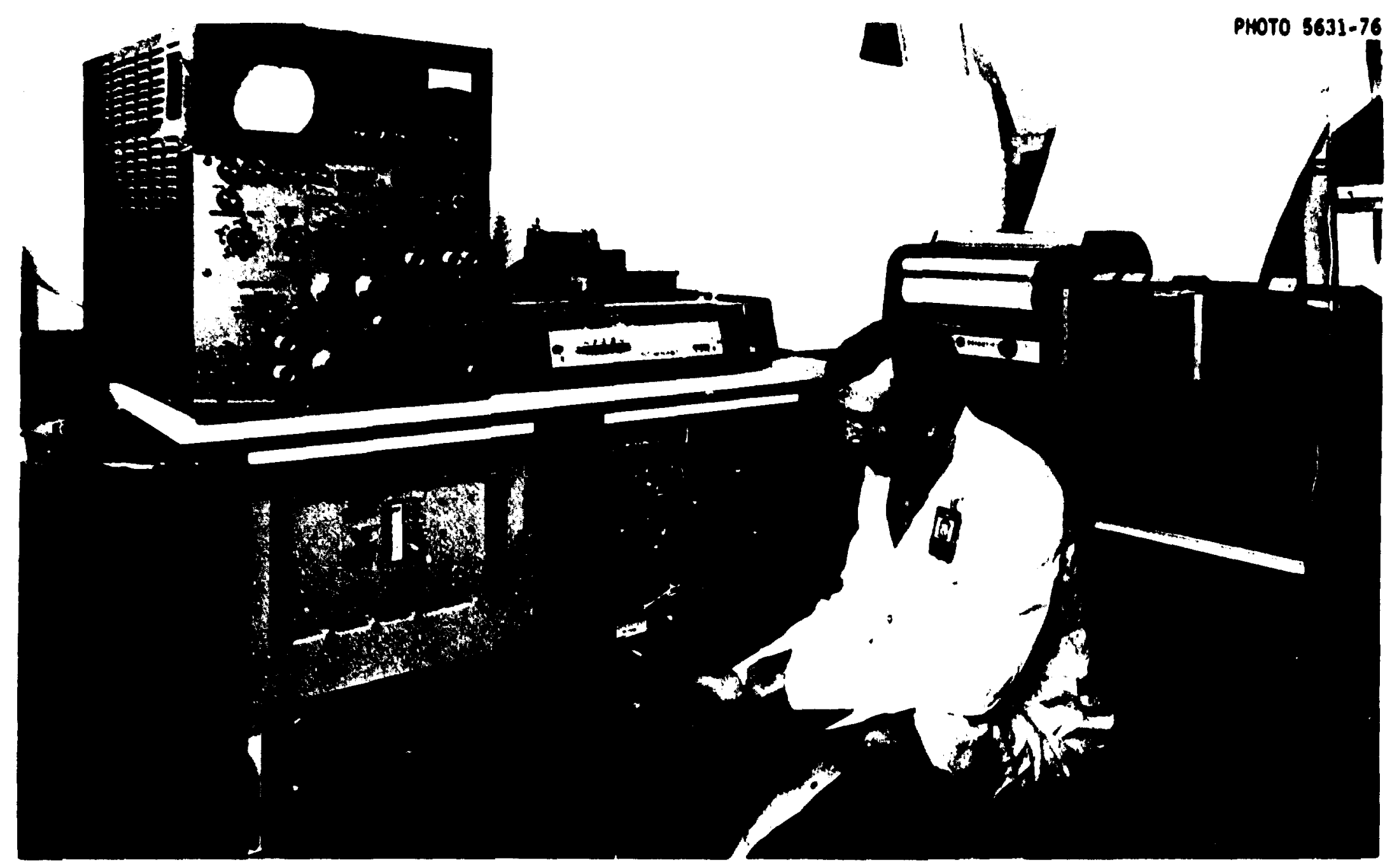

Photo. 4. The radiochromatographic scanner llop center) logether with its associaled recordiny apparalus: multichannel analyzer (left) with its paper-tape punch altended by is technician and il strip-chart recorder (right). 
60. 30 and (S mm hr) and the time selections avaibble for iniegrating the counts per chanacl in the muhichannet anaiyzer (12.5. 25. 50. 100. 200. 400 and 4000 sec). the resolution and sensitivity is

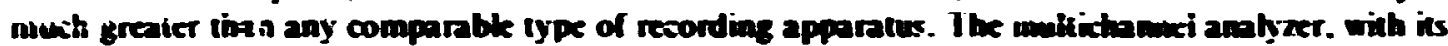
papertape purh. produces output suitable for compuner amabsis. For quick vesul inspection. however. the sananer may be coupled to a strip-chant recorder. The charts exhibied as figs. I and 2 are exaraples. They show a much more rapid movement of "Sr in Fupay sand than in Captina sih loam for ite same eluting solution.

\section{MOVEMENT OF THE ELUTING SOLUTION}

Profiles such as those shown in Fips. 1 and 2 are amemable to quantivative interpretation providing the movemcnt of the eluting solution an be uaderstood. Otserved novements of mater Ironis in two types of soils are shown in Fig. 3. As would be expected. a $t^{\prime}$ : dependence is observed initially doe to the domianance of capillary pressures over gravitatiomal pressures. An inafinant deficiency in Fig. 3 is that if yields the Darcy velocity $V$ oaly at the water from. where the reduced mointure content a $\approx 0.5$. However, this velocity can vary substantially as a function of a. ranging from a value which is sometimes in excess of the seturated conductivity $K$. al a $=$ I ic a value of rero at $a=0$. To obtain this additional information. we introduce a trecer. tritium. into the feed solution, and then generale and measure distribution pallerns as described above. These patterns are then analyzed theoretically to obtain complete velocity profiks. The formalism used for this purpose is examined in the next chapter. Chapter III, and it is applied to the fuquay soil in Chapter VII. 


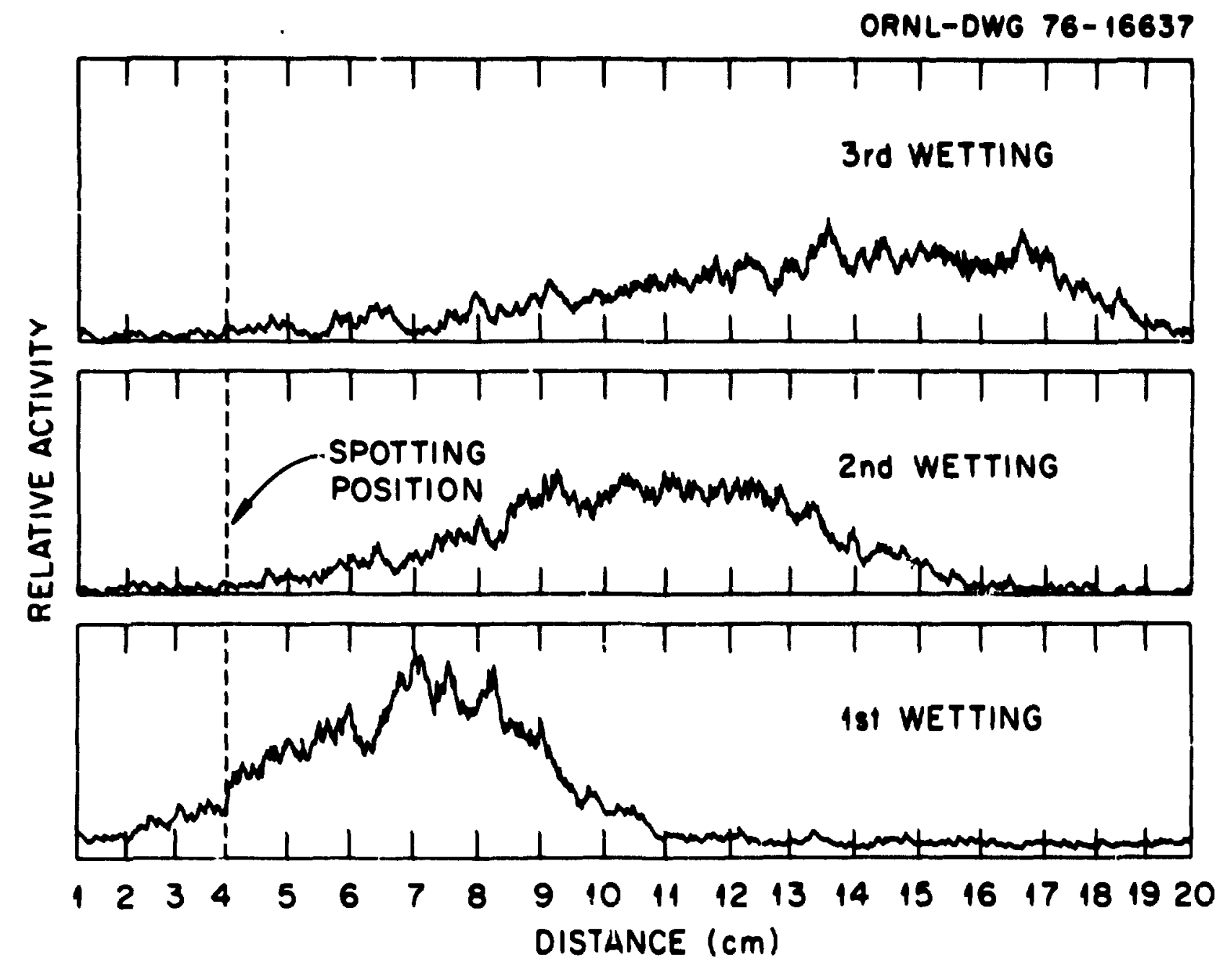

${ }^{25}$ Sr Movement in Fuquay Sond 200 ppm Co in Eluting Solution.

Fig. I. Mobility of "Sr in Fuyuuy wand lor an cluting wolutien cuneaining $200 \mathrm{ppm}$ C'n. 
OANL-DWG 76. 16638
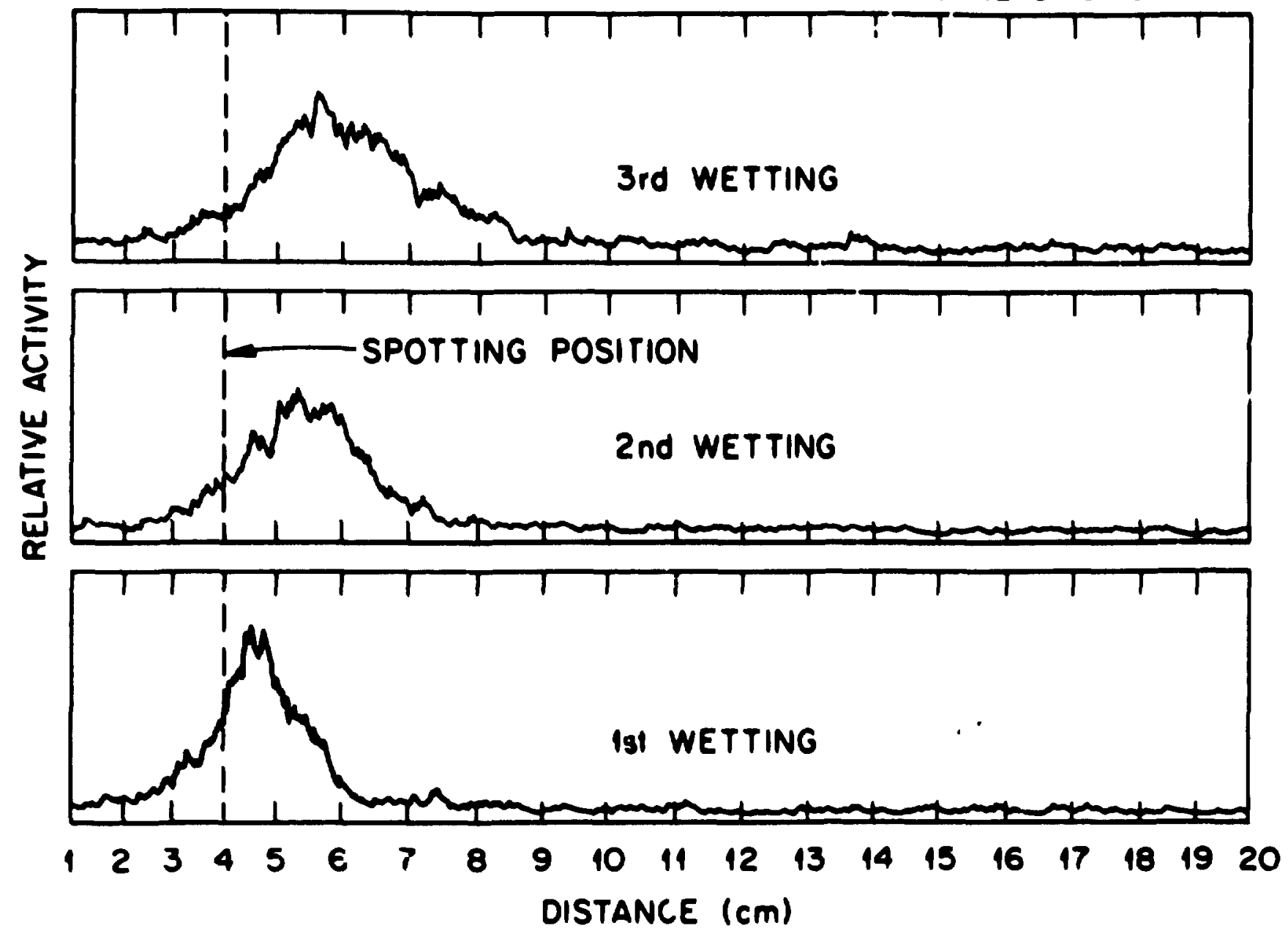

${ }^{85} \mathrm{Sr}$ Movement in Coptino Silt Loom 200-ppm Co in Eluting Solution.

Fis. 2. Mobility of "Sr in Captina silt loam for an eluting solution containing $200 \mathrm{ppm} \mathrm{Ca}$. 


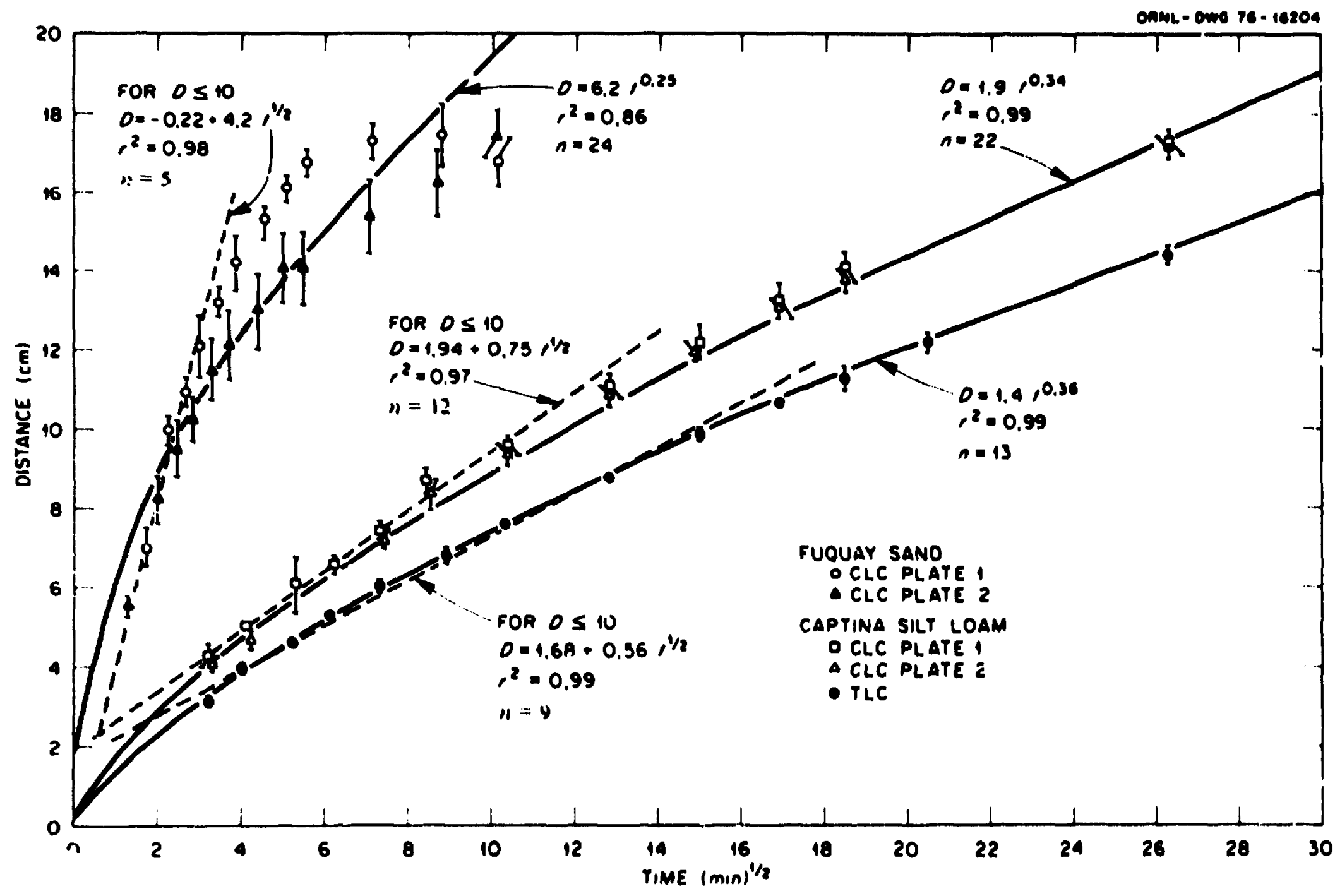

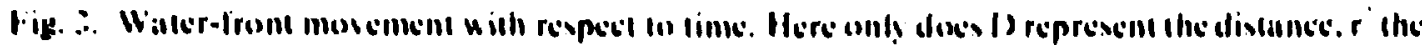
correlation cerellw: nt, and $n$ the number al puints. 


\section{WATER TRANSPORT}

\section{THEORY}

1. Trasport equations. Fortunately the mater-movemeat is sufficiently restricted that it may be treated analytically. The boundary-initial conditions may be prescribed simply as

$$
M(x=0,1)=0, \quad \text { and } \quad M(x>0,1=0)=0
$$

Where $\theta$ is the moisture content. Also. the transport equation

$$
\frac{\partial 2}{\partial 1}=\frac{\partial}{\partial x}\left(0 \frac{\partial x}{\partial x}\right)+\frac{\partial x}{\partial x} \sin c
$$

for a chromalographic column inctined at an angle e (see Fig. 4) is one dimensional. (Symbots which are not defined in the discussion to follow may be found in the notation. Thapter IX.)

In published work by Parbere [1971a, 19716, 1972] a singalar perturiation theory is used in obsain a sxcond-order solution to the above probkem subject to only one additional condition. namety that the column be semi-infinitc. i.e.

$$
0<x<\infty .
$$

Invoking such a condition will restrict applications to situations in which the wetting front is sufficiently well removed from the top end of the chrometographic cisfur:s .. However. this is a very mild restriction and is indeed a small price to pay lor the computational cilicinency of an amalytic or. more precisely. a partinlly analytic solution. Equation (2) is notorioushy difficult to solve for unsaturated moisture conditions duc to the highly nonlinear nature of the conductivity $K(0)$ and the Jiffusivity Q10). and, in general. one must resont to a strictly numerical and computer-time-consuming treatment such as that of Reeves and Duguid [1975).

Using the theory of implicit functions [Margenau and Murphy. 1956], as is frequently done in thermodynamic analyses. the water-eonient variable o may be employed as the independent variable in Eq. (2). i.e.

$$
\frac{\partial x}{\partial t}=\frac{\partial V}{\partial \theta}
$$

Here the Darcy velocity

$$
V=-\frac{Q}{\partial x / 20}-K \sin \epsilon
$$

has been se; arately identiined since it is the coupling variable hetween moisture iransport and mass Iranspon. 


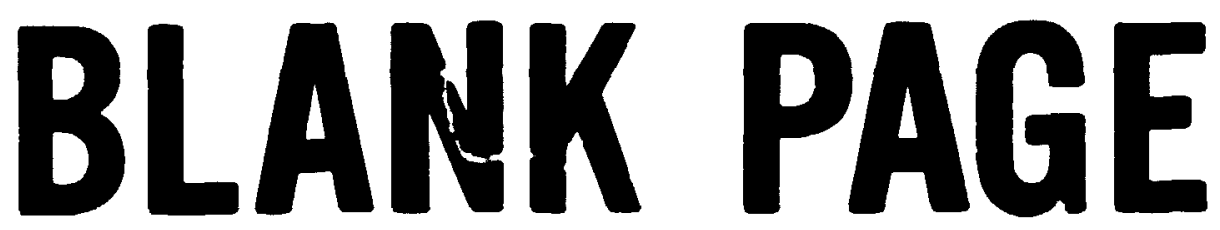


16

ORNL-DWG 76-19571

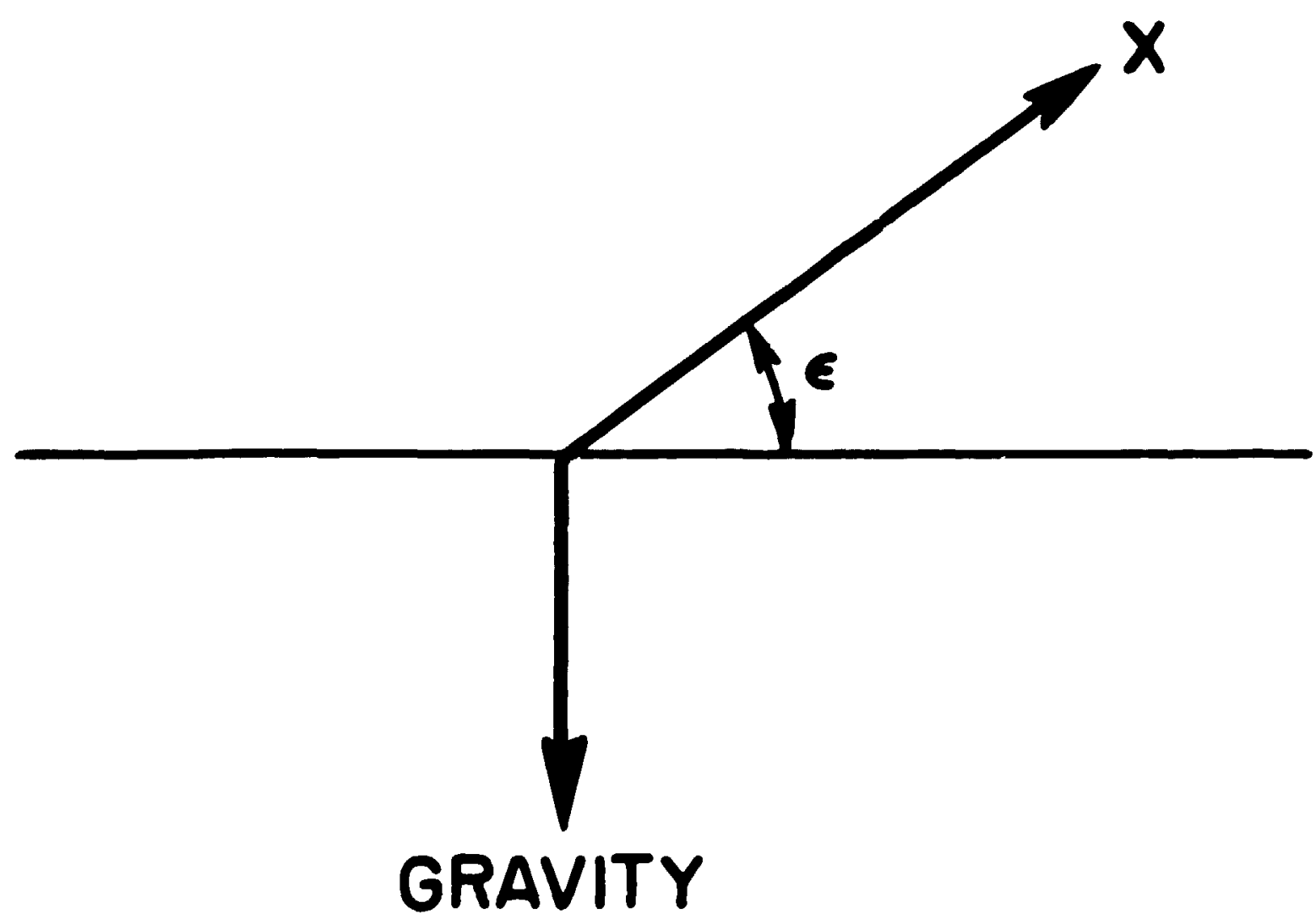

Fis. 4. Defmition of the angle. 
In terms of the reduced lariables

$$
a=\frac{0-0_{0}}{0,-0_{0}} \quad \text { and } \quad x=\frac{x(0)-x\left(0_{0}\right)}{0,-00} \text {. }
$$

Eys. (4) and (5) becoums

$$
\frac{\partial x}{\partial t}=\frac{\partial w}{2 x}
$$

and

$$
w=-\frac{Q}{2 x / 2 e}-r \sin e .
$$

The reduced vilocily $w$ is rebled in the Darey velocily by the cy alinen

$$
V=\left(0_{1}-\theta_{0}\right) V-K_{0} \sin e
$$

where $K_{.} .=K_{(0 .)}$. Expressed in terms of variabte n. the boundañ and initial conditions hecome

$$
x(a=1,1)=0 \quad \text { and } \quad x(a=0,1=0)>0 .
$$

since possition $x$ is a singke-tabued function of water content.

2. General application of the Parbase method. To apply the perturbation method. Parbnge [197/h] first inlegrales F.y. (7) as follows

$$
\int_{0}^{-1} d \frac{\partial x}{\partial t}=w_{1}-w
$$

where $W_{1}(t)=W(n=1.1)$. He then reasuns that since

$$
\left.\frac{\partial x}{\partial t}\right|_{0=1}=0
$$

[see Fy. (lQa)] the limederivalive Ierm will he small compared in nhther Ierms in Fy. (III provided a is sufficiensly close in unity. Thus this yulantity may he represenied $m$ a hower ordered approximation. Fxpressing the reduced velincity in expanded form of F.y. III). F.y. (x) yiclds. Ine the n-th approximation in $d x$ dn. the quantily

$$
\frac{\partial x^{(n)}}{\partial x}=\frac{0}{x \sin c+w_{1}-\int_{0}^{1} \frac{\partial x^{(n-1)}}{\partial t}}
$$


as a first integral. whict: Jefines the velanity [Ey. ( $(\mathbf{x})$ ]:

$$
w(n)=w_{1}-\int_{0}^{1} \Phi \frac{\partial x^{(n-1)}}{\partial 1} .
$$

The secund inicgral

$$
x^{(n)}=\int_{0}^{1}-\frac{Q d y}{x \sin \epsilon+W_{1}-\int_{0}^{1} \frac{\partial x^{(n-1)}}{\partial t}}
$$

is casily obtained by applying the boundary condition. E4. (10a). Evaluation of ithe :ime derivative in these two equations is considered in Sections 3 and 5. belou:

3. First-order solution. Although Eys. (14) and (15) are appropriate lor general $n$-th order approximations. Parlange [197/a. 197/ b. 1972] found that second order was quile adeyuatce for practical applications. To start the iterative scheme, it is assumed that t:y. (12) is also ialid for a $\neq$ I. i.e.

$$
\frac{\partial x^{(0)}}{\partial 1}=0
$$

The first-order solutions of Eys. (14) and (15) then become

$$
w(1)=w_{1}
$$

and

$$
x^{(1)}=\int_{0}^{1} d \gamma \frac{Q}{x \sin \epsilon+W_{1}} .
$$

Equation (17) simply savs that for each water-content value $a>0$. the velocity of advance of the werting i-ont is independent of $a$ and $i$. a function of time only $\left[\mathrm{V}^{\prime \prime \prime}=W^{\prime \prime \prime}(t)\right]$.

4. Temporal behavior of the er.d-pcint Darcy velocity. At this point a prohien associaled with $W_{1}$ is identified in Parlange's [197/h] analysis. This yuantity, the velocity at $a=1$ or $x=0$, is at this point an unknown function of time $W_{1}(t)$. However. a relation may be found for this yuantity by extending the range of integration in Eq. (II) to a $=0$ :

$$
\int_{0}^{1} d a \frac{\partial x}{\partial 1}=w_{1}-w_{0}
$$

where, from Fy. (8).

$$
W_{0}=-\left.\frac{Q}{\partial x / \partial \alpha}\right|_{a=0}-\left.x \sin \epsilon\right|_{a=0}
$$


Now. by definition [Ey. (6b) $] . x(0)=0$ since $a=0$ implies $\theta=\theta_{1}$ [Ey. (6a)]. In addition. it may be inferred from the initial condition [Ey. (10b)] that $\partial \mathrm{x}$. Da becomes indeterminantly large as a approaches zero. Hence Eq. (20) gives $W_{*}=0$. and Eq. (19) becomes

$$
w_{1}=\int_{0}^{\prime} \operatorname{le} \frac{\partial x}{\partial t}
$$

From the first-order result. Ey. (18), one obtains

$$
\frac{\partial x^{(1)}}{\partial t}=-\frac{\partial w_{1}}{\partial t} \int_{0}^{1} d z \frac{0}{\left(x \sin \epsilon+w_{1}\right)^{2}}
$$

Inserting this relation into Eq. (21) and integrating the resulting equation from 0 to I yields

$$
t=\int_{0}^{1} d x \int_{0}^{1} d Q(\gamma) 1(\gamma)
$$

where

$$
\begin{aligned}
I & =-\int_{W_{1}(0)}^{W_{1}} \overline{W_{1}\left(x \sin \epsilon+W_{1}\right)^{2}} \\
& =\frac{1}{x^{2} \sin ^{2} \epsilon}\left(\ln \left(\frac{x \sin \epsilon+W_{1}}{W_{1}}\right)-\frac{x \sin \epsilon}{x \sin \epsilon+W_{1}}\right)
\end{aligned}
$$

The last line of the above equation uses the fact that $W,(0)$ is infinite.

Interchanging the order of integration in ey. (2.3) yields

$$
1=\int_{0}^{1} d \gamma+Q(\gamma) !(\gamma)
$$

which. when combined with Eq. (24). gives

$$
1=\int_{0}^{1} d \frac{r \theta}{x^{2} \sin ^{2} \epsilon}\left(\ln \left(\frac{x \sin \epsilon+W_{1}}{W_{1}}\right)-\frac{x \sin \epsilon}{x \sin \epsilon+W_{1}}\right), \sin \epsilon \neq 0 .
$$

If $\sin e=0$, the indeterminate form may he evaluated to yicld

$$
1=\frac{1}{2 w_{1}^{2}} \int_{0}^{1} d \gamma Q(\gamma), \sin \epsilon=0 .
$$


Equations (26) may be inveried numerically to obtain the desired rebation $W_{1}(t)$. Actually. this function should be denoted by $w_{1}{ }^{\prime \prime}(t)$ since it is based on the firsi-order ywantity $x^{\prime \prime}$. However. we follow Partangr in not updating this function with an approximation of higher order. Thus there is no med to make such a notational distinction. As a consequence. the familiar $t^{\prime}$ " dependence is observed for both first and second onder in the horivontal-flow case. i.e. $x^{11+} \sim t^{\prime}$, and $x^{\prime \prime \prime} \sim t^{1}$.

5. Second-order solution. In proceeding to second order one should note that the time deritative of $x^{\prime \prime \prime}$ in Eqs. (14) and (15) will introduce the troublesome quantity $\partial W_{1} \partial t$. just as it did in Ey. (22). This quantity. however. may be eliminated algebraically. Using E4. (21) twice the following retation is obtained:

$$
\begin{aligned}
& w_{1}-\int_{0}^{1} \phi \frac{\partial x^{(1)}}{\partial t}=\int_{0}^{\infty} \phi \frac{\partial x^{(1)}}{\partial t} \\
& =w_{1} \int_{0}^{\infty} \phi \frac{\partial x^{(1)}}{\partial t} / \int_{0}^{1} \phi \frac{\partial x^{(1)}}{\partial t} .
\end{aligned}
$$

Differentiating Ey. (18) with respect to time yields

$$
\left.w_{1}-\int_{0}^{1} d \frac{\partial x^{(1)}}{\partial t}=w_{1}\right)(a) / 3(1)
$$

where

$$
J=\int_{0}^{a} d B \int_{0}^{1} d \frac{Q}{\left(x \sin \epsilon+w_{1}\right)^{2}}
$$

Parlange [1971b] used Eq. (29) directly. combining it with Eys. (28) and then with Eq. (15) to achieve the second-order result [Eq. (14) in the (197Ib) article]. Here Eq. (29) will be simplified before taking these final steps. By interchanging the order of integration. E4. (29) hecomes the sum of two single integrals:

$$
J(a)=\int_{0}^{0} d \gamma \frac{\gamma}{\left(x \sin e+W_{1}\right)^{2}}+a \int_{0}^{1} d \gamma \frac{Q}{\left(x \sin \epsilon+W_{1}\right)^{2}}
$$

The second integral. of course, vanishes when $\alpha=1$.

Cornbining Eq. (28) with Eqs. (14) ansi (15) yields the second-order approximations

$$
w(2)=w_{1} J(a) / J(1)
$$

and

$$
x^{(2)}=\int_{0}^{1} d y \frac{0}{\left.x \sin z+w_{1}\right)(a) / f(1)} .
$$


In contrast to $\mathrm{W}^{\prime \prime}(\mathrm{t})$ the second-order approximation to the reduced velocity is a function of both wier content and time. i.e. $w^{: 1}=w^{-1}(a . t)$. The unreduced Darey velocity

$$
V^{(2)}=\left(0_{1}-0_{0}\right)(2)-K_{0} \sin \epsilon
$$

oblained from Eq. (9). is the desired result.

\section{RESULTS FOR YOLO CLAY}

Parbnge's applications to onedimensional moisture flow ane of interest here. They pertain to capiltary rise [Partange and Aylor. 1972]. infikration [Partange. 197/6]. and horizonatal now [Parlange. 197 la]. Our purpose here is threefold: (1) to demonstrate the solution procedure. (2) to compare resules of our compuler program with those presented in the above-mentioned papers. and (3) to supplement the moisture profiks with their corresponding Darey-velocity profiks.

1. Soil properties. In each case the soil used is Yolo clay. Values of the conductivity and diffusivit: for this material are given in Phillip [1957) in tabubr form Here they are presented in graphical form as fig. S. The only other soil properties which are required ane the residual moisture content $\theta_{.}=0.2376 \mathrm{~cm}^{\prime} \mathrm{cm}^{\prime}$ and the end-point moisture content $\theta_{1}=0.4950 \mathrm{~cm}^{3} \mathrm{~cm}^{\prime}$, respectively.

2. Capilbry rise. The case of capiltary rise $\left(e=90^{\circ}\right)$ is used to demonstrace the solutior: procedure. (ieneration of the time curve (Fig. 6) is the initial step. In general this must the done in order to invert the transcendental equation. E4. (26a). Merween the time 1 and the end-point reduced Darcy velocity $W_{1}$. [Such a procedure is not reyuired. however. for the special case of horizontal flow. where the appropriate relation. E4. (26h). may he inverted analytically.] To produce the time curve. varion's values are chosen for $W_{1}$. [Actualh. values of the more physical yuantity $V_{1}$, in units of the saturated conductivity. are required for the computer program, which converts them to $W_{1}$ using Eq. (9).] Corresponding values of the elapsed time $t$ are then obtained via numericol integration of Eq. (26).

Determination of positions $x(a .1)$ and veloxities $W(a . t)$ [or equivakntly $V(a .1)$ ] is the second and final step in the splution procedure. For a specifed time t the corresponding end-point velocity $W_{1}(t)$ is obtained from Fig. 6 hy interpolation. Eyuations (30). (3) $)$ and (32). which depend on $W_{1}$. are then evaluated to obtain the second-order approximations $x^{\prime \prime \prime}(a .1)$ and $W^{\prime \prime 2}(a . t)$. Figure 7 exhibits $x^{\prime \prime \prime}(a .1)$ and $V^{\prime} \cdot(a . t)$. which is related to $W^{\prime \prime}(n .1)$ by Ey. (9). at four different values of the clapsed tirve for the case of capillary rise: the agreement with Parlange and Aykr [1972] is yuite satisfactory.

3. Infiltration and horizontal now. Comparisons with Parlanges work for $\neq 90$. huiwever. although acceptable. are mot of the same quality. This may he seen in Fig. 8 for the case of infiltration $\left(e=90^{\circ}\right)$ and in Fig. 9 for the case of horizontal fow $\left(e=0^{\circ}\right)$. One possible source of this discrepancy is the diffusion in the region near $a=1$. Since there are no experimental data there. extrapolation must he employed. Logarithmic extrapolation yields the value $Q_{1}=\left(T_{a}=1\right)=1.85 \times 10^{\circ} \mathrm{cm}^{\prime}$ sec. resulting in a position profile lying above Parlange's [197/a] results. as indicated in Fig. 9. If $Q$, is arbitrarily reduced by a factor of io. then the position profile balls beneath Parlange's colculation for a $>0.5$. Thus different extrapolations would appear to account for the discrepancy hetween our results and that of Parlange for a $>$ C.j.

As yet. however. we do not have a comparable explanation for the region n $<0.5$. As shown in Fig. 9. our first-order profiles for $x^{\prime \prime \prime}(a, 1)$ agree rather well with those of Parlange. Such a circumstance would appear in indicate that our Ingarithmic interpolation for $Q_{(a)}$ ) and $K(a)$ (see Eqs. (6) and (18)] and our adaptive Causs quadrature [see Ey. (18) only] are consistent with the 


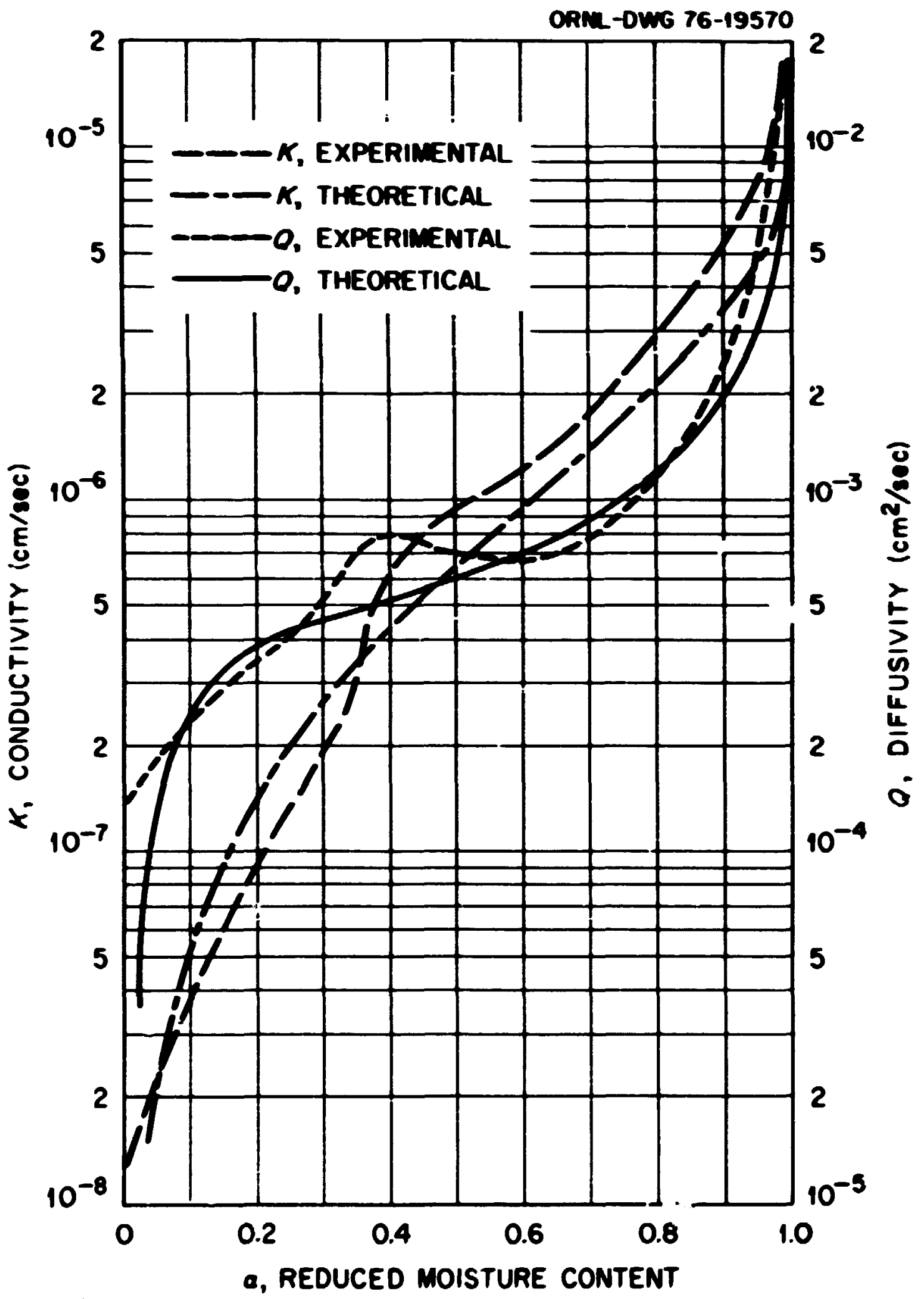

Fig. 5. Soil properties of Yolo clay. 


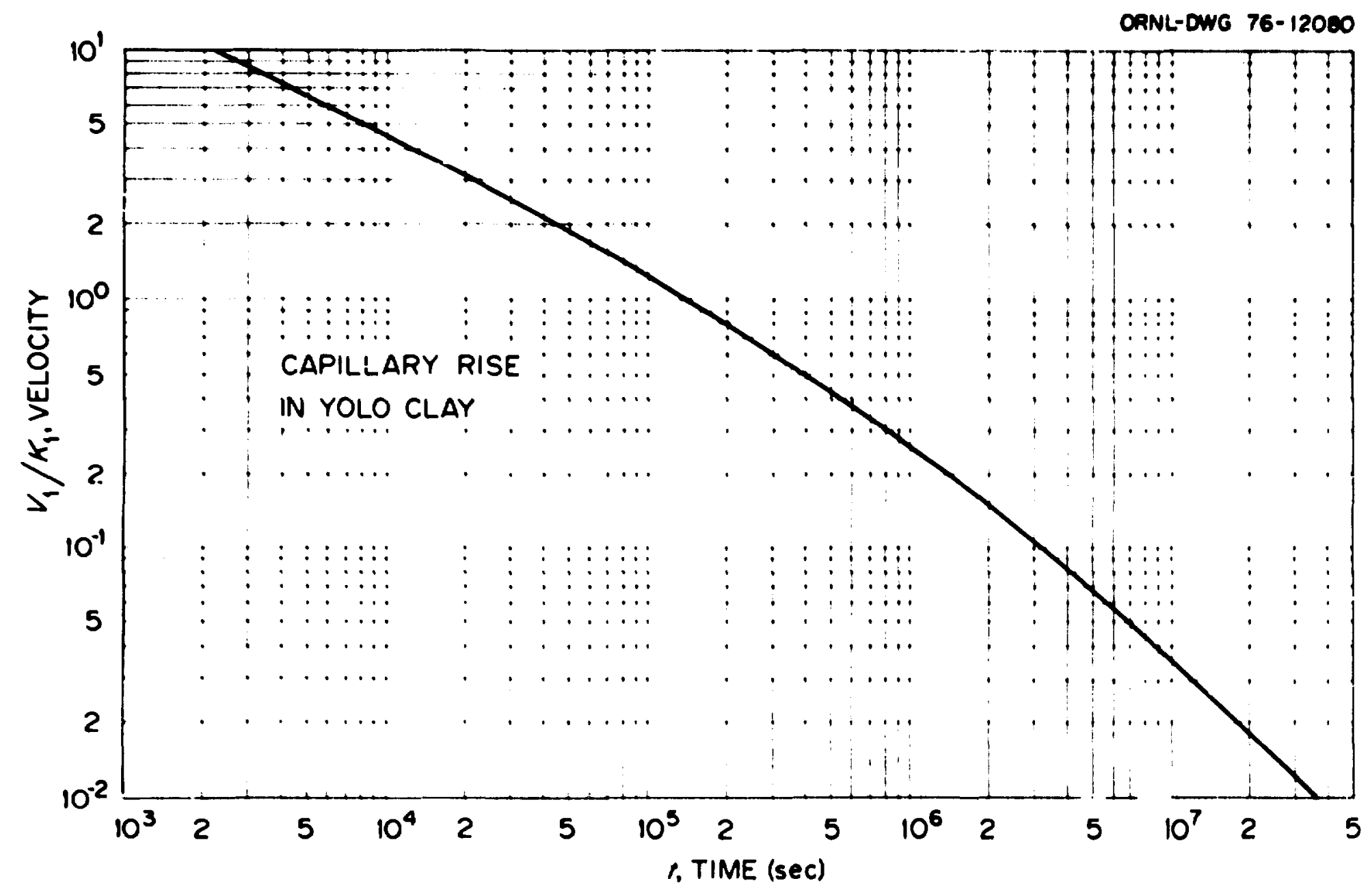

Fig. 6. Fend-point Dancy velocity as a function of time for capillary rise in Yolo clay. 


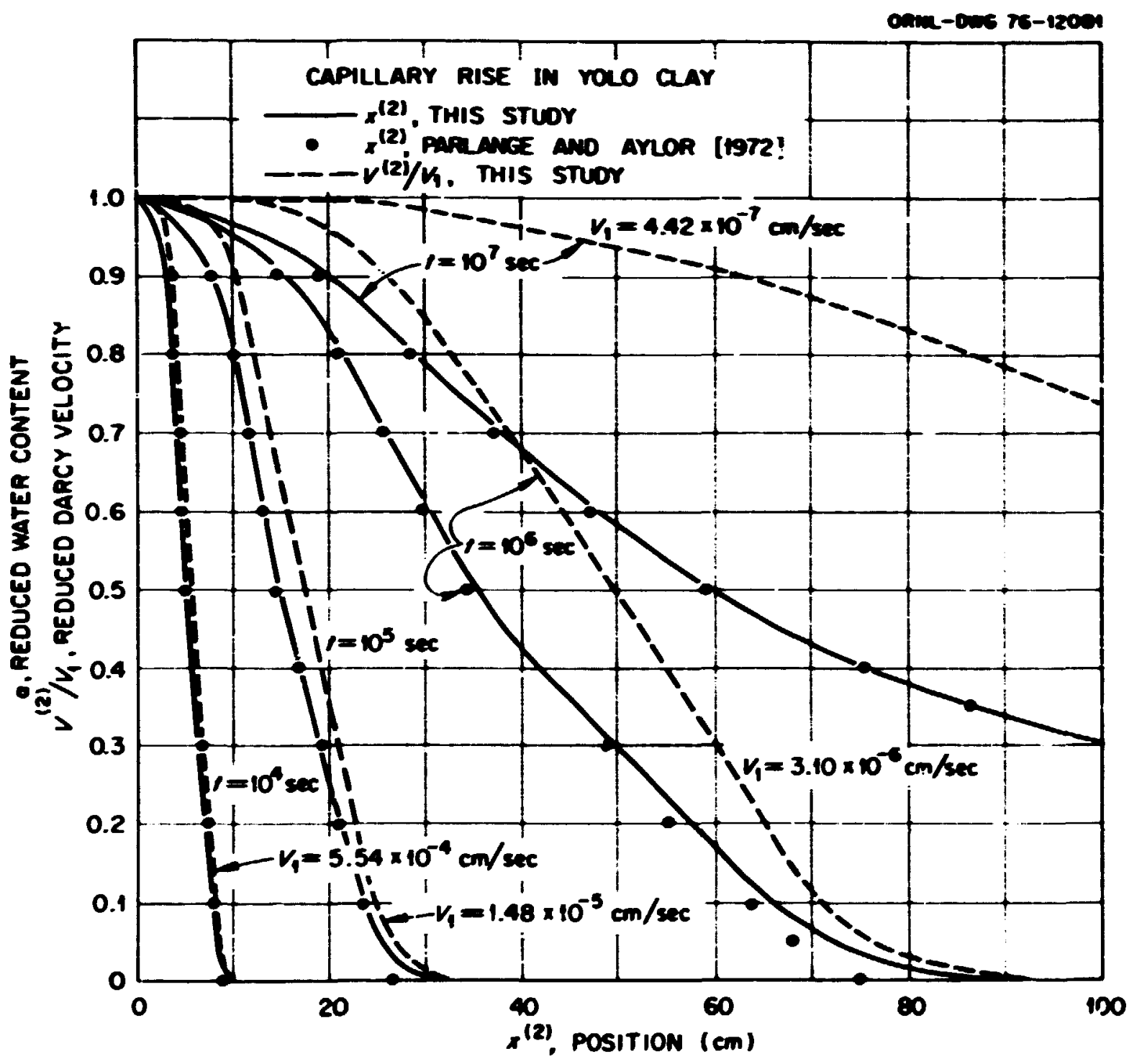

Fig. 7. Water content and Darcy velocity as functions of time for apilbry rise in Yolo chy. 


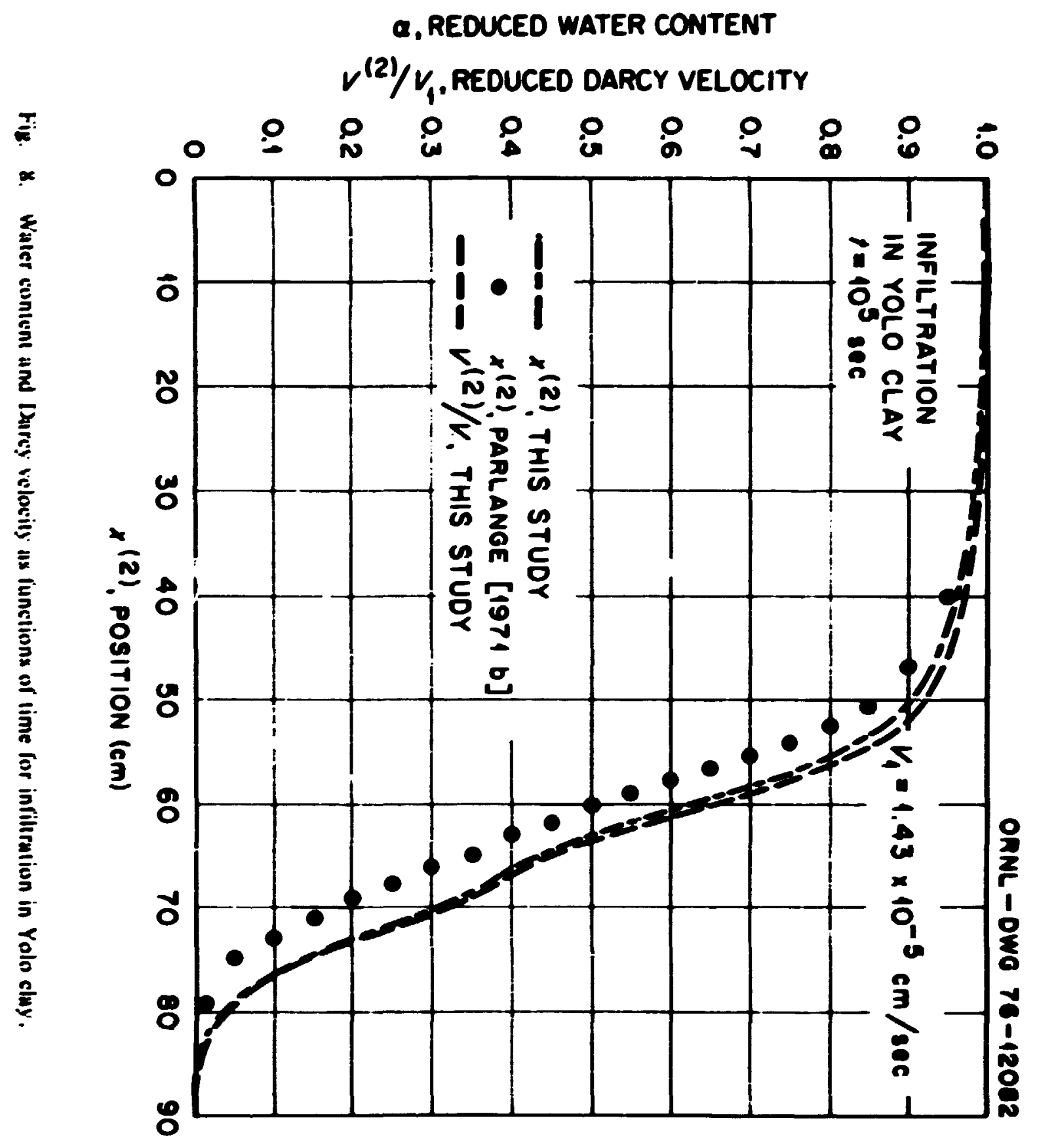




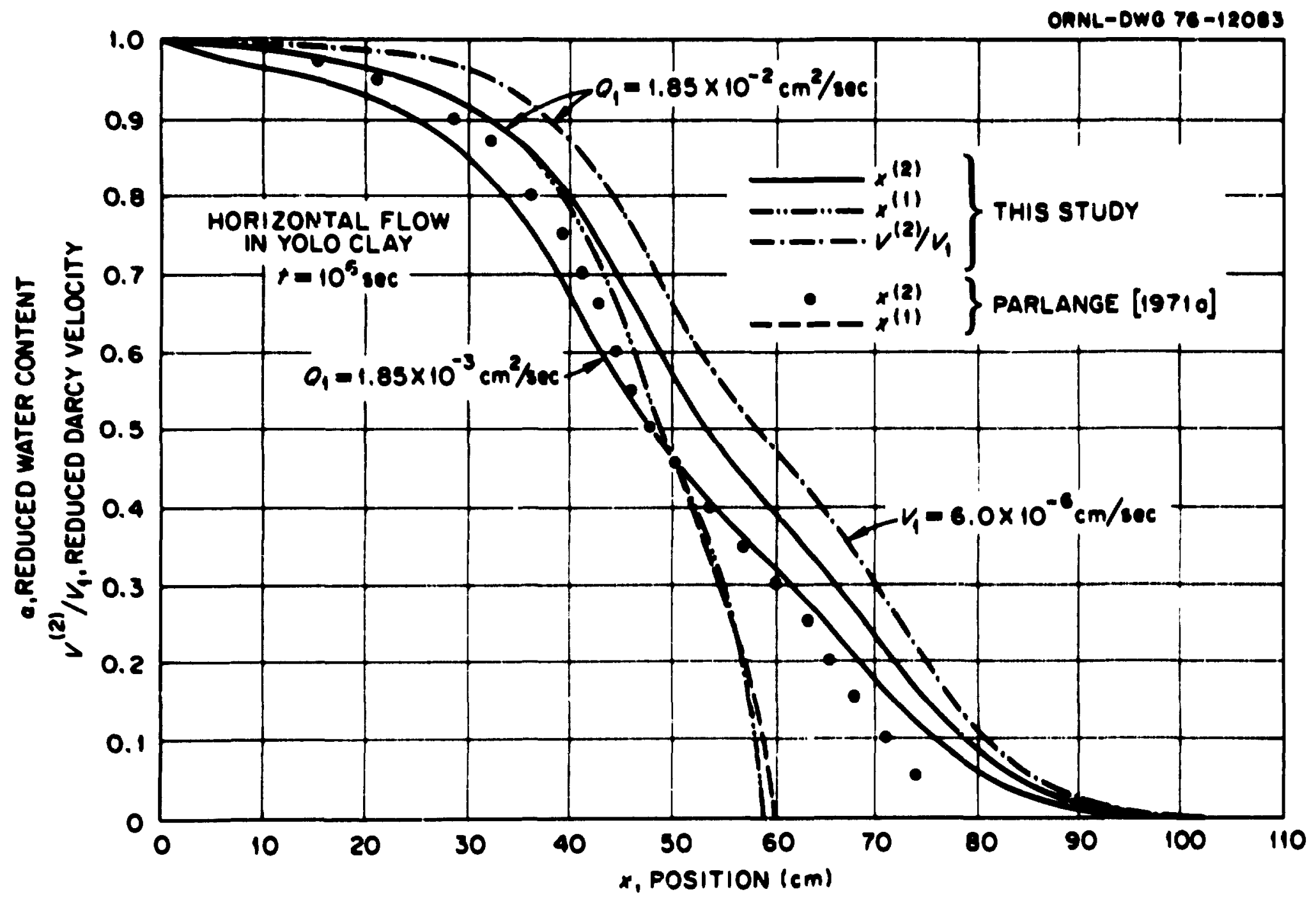

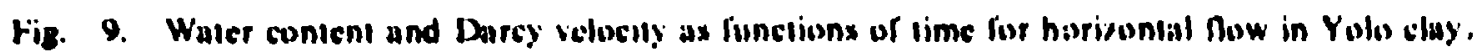


numerial techniugues uxed by Parbagx. Since E.y. (32) for $x$ "diflers from Ey. (1x) for $x$ " only in the appearance of H(a) H(1). the discrepancy nould appear to lix in this juantiky. Honcuer. increases in the order of the Gauss yeadrature procedure used to evaluale $J(a)$ al nodal poiats a. [E4 (30)] and in the order of the lagrangian interpotation used to craluate this quanting between nodal poins bive lailed to produce significant changes in our resulus for $x:$.

To place this discrepancy in perspective. One must consider the iunction of the water-transpon formalism in the anahsis of chromatographic results. Basically this is to prov ide a physiesthased

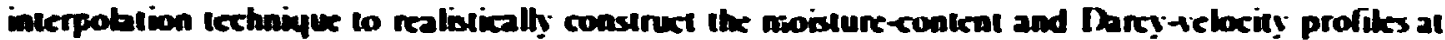
arbiarary times using a minimal number of phisical observations. I ixe tecthiyues of this chapier. we ket. ane quite salisfoxtory for this purpose. By using the automatio-seanch methods described in a bler chapter. measured moisture-content profiks may be stmikesined to approximateh six parameters. These parameters may then be used to whtain hoth moisture contents and larcy ielocitics at the times and positions required by the mass-traspoun description. The water-transport parameters themseltes are the subject of the fullowing section.

\section{PARAMETERIZATION OF SOIL PROPERTIES}

For some specialived applications of the chromatographic vechniuux. soil moisture-flow properties will be obtainahk from the literature just as they wer: Ioi the Yoho chy. However. the authors suspect that in the most common stluation such properties will need to the measured jointly with ite mass-transport characteristics. Is i in section a methox' for dekermining the moisture-Ilow properive is sugessed.

1. Hydraulic conductivity. In contrast in the mass-transport caxe where the transport characteristics ane expressed as simple comslants such as the distribution cocfficient and the bngitudinal dispersivity. functional rebtionships with the independent variahk are involved here (sce. for exampte. Fig. 5). A treyuintly used formula for the hydraulic conductin ity is that presented my. (iardner [ 195:]:

$$
K(h)=\frac{k_{3}}{\left(h / h_{0}\right)^{d}+1}
$$

where $h<0$ is the pressure head. Parameters $K$.. h... and d characterife the wil lype. From simple mathematical manipubtions the rignificance of these paramelers may he determil.ed. Values of conduclis ify apprias:h that of the saturaled conductivity $K$. as $h \rightarrow 0$. Alst. it may he seen that at the critical pressure $K(h)=$.$K . 2$. In addition. the skope of the conductivit! cune at $h=h$. is directly proportinnal in the pore-sice distribution parameler d. Figure 10 presents curses which. according in Bouwer [1944], are typical of sand. Inam. and cley wils.

2. Moisture characteristic. King [1\%5] has shown that a wide range of water content-pressurc data (the moisture characteristic) ma! he filted with an cyuation of the form:

$$
\theta(h)=\theta_{1}\left(\frac{\cosh \left(h^{\prime} h_{0}^{j}\right)^{d} \delta \cosh x}{\cosh \left(h^{\prime} h_{0}^{\prime}\right)^{d}+\delta \cosh x}\right)
$$

where $s$ is defined in terms of the residual water content $\theta$, and the saturated water content (porosity) $\theta_{1}$ :

$$
s=\frac{\theta_{1} \theta_{1}}{\theta_{1}+\theta_{1}} .
$$




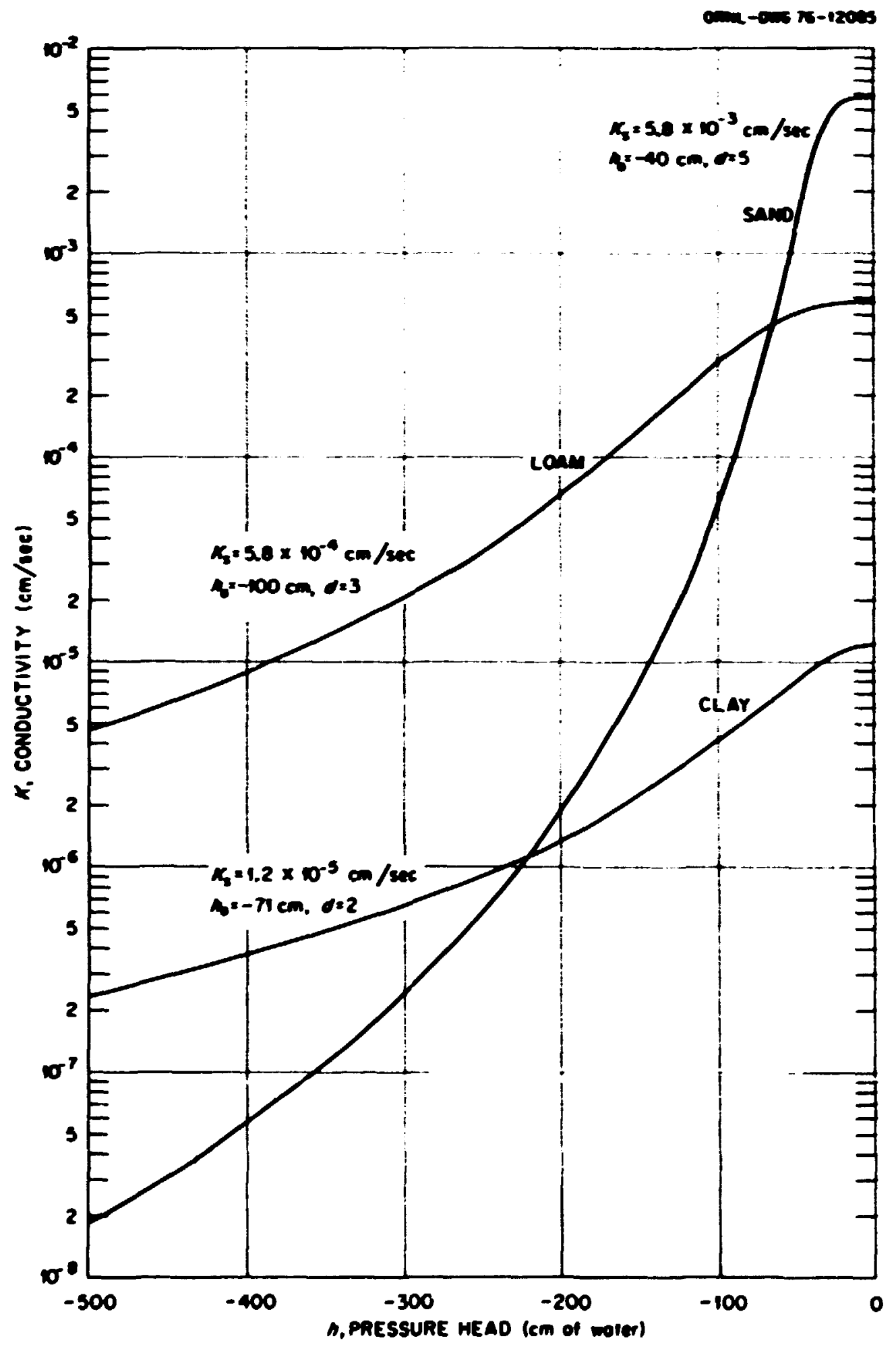

Fig. 10. Representative hydraulic conductivities for sand, chy, and loam soils. 
Coilham. et al. [1976] found that paremetse 1 could be bken as nero without seriuush =flecting fes to their data. i.e.

$$
M(h)=O_{1}\left(\frac{\cosh \left(h / h i t^{2}-8\right.}{\cosh \left(h / h j p^{2}+8\right.}\right)
$$

This cymation mey be differentiated

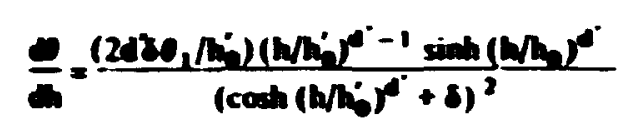

and inverted

$$
M(0)=\ln \left(\ln \left(5 / 8^{\circ}\right)+\left(15.8^{\circ}\right)^{2}-1 !^{12}\right)^{1 / 4}
$$

Quantily $\delta$ is defined anahogoushy to that of $\delta$ [F:4. (36)]:

$$
r_{1}=\frac{0_{1}-0}{0_{1}+0}
$$

Parameters $\theta_{1}, h^{2}$. and $d^{\prime}$ have meanings simibr in that of their civunterparts $K$.. h.. and $d$ in the conductivity parameterization. The water content approaches its salurated value whenever $h-0$ since $d^{\prime}<0$. In addition. it may be seen that at the critical pressure $\left(h^{\circ}\right.$ ) $=0,5$ provided $0 .<\theta_{1}$ S. At this same pressure the slope is directly proportioral in the pore-sive distritution parameter d: i.e. do dh(h.) $\sim\left|d^{\prime}\right|$. Figure || presents three moisulure-charackeriatic curves which mizht te appropriale for sand. ham. or cby soik. In truth. the curves of fïg. II were generaled as raiber crude fiss in the moisture characteristics shown by Hillel and ian Bavel [1976]. The inten! is merely to show the adaptahility of F.4. (37) in different soil textures.

3. Moisture storage and diffusivity. The eneralied moisture-sinrage functionn [Reeves and Inuguid. 1975] heromes

$$
F(h)=\frac{(n)}{d h}+\theta(h)
$$

Strictly speaking. $B$ is the modified coefficient of compressibility of waier. Here. howeter. this parameter will also the used empirically in characterize the compressibility of the soil medium. The effer' of including this quantity in the formulation is to give a non/cro value io the sinrage function at saluration. i.e. $f(0)=\theta_{1} \beta$. Thus the Jiffusivity

$$
Q(h)=\frac{K(h)}{F(h)}
$$




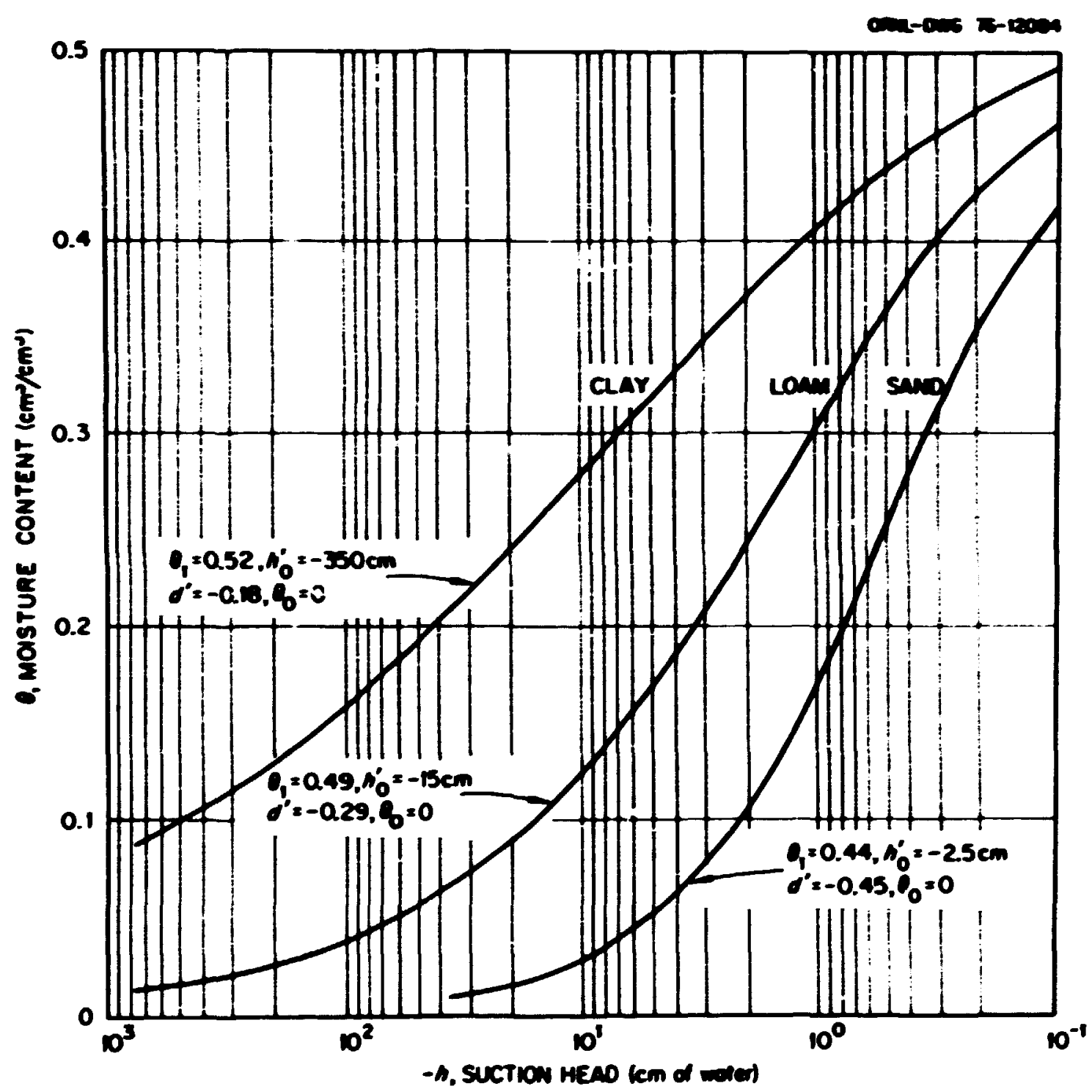

Fiz. II. Representative moisture characteristics for sand. chy. and bam soils. 


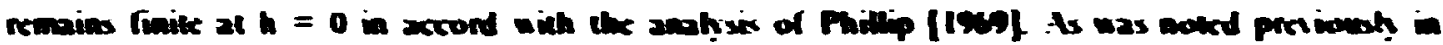

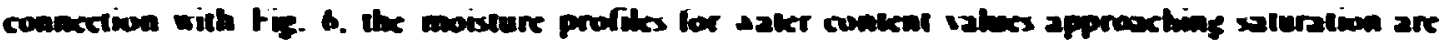

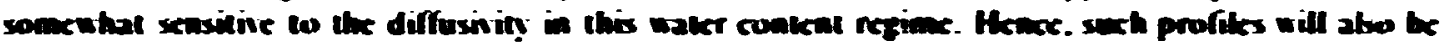
scusitive to ith valex cthosen bor p.

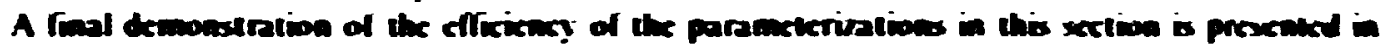

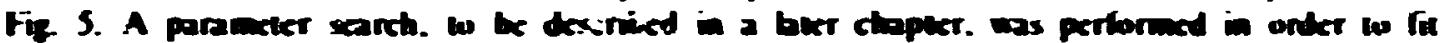

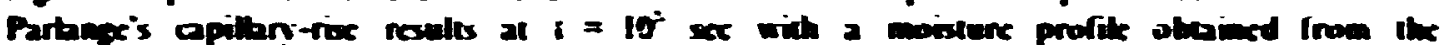

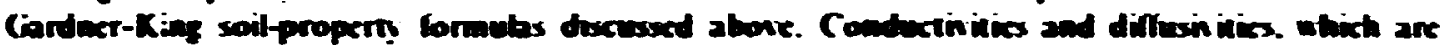

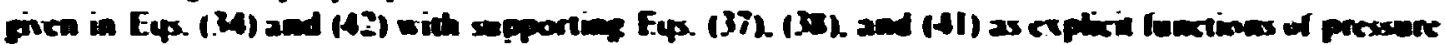

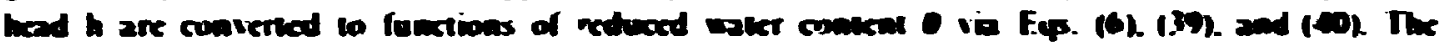

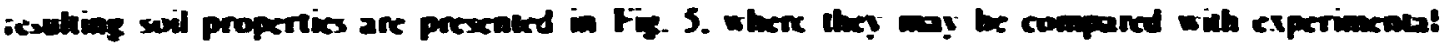
don. 


\section{MASS TRANSPORT}

\section{THEORY}

In contrast to the water transport, where an approximate ana:vtic solution was : ppropriate. a fully numerical approach is used here. Such an approach is necessany since the advec' ve flux. Darey velocity $V(x, t)$, is not, in general, separable in the space-time variables $x$ and $t$. A so. the variety of initial conditions which are contemplated preclude a penurbative treatment like that used for the nater transjort. Thus a one-diunensional Gakerkin-finite-sement impkementation similar to the two-dimensinnal formubtion used by Duguid and Reeves [1976] is employed.

1. Transport equation. The mass-transport equation may be written as

$$
\frac{\partial i_{i}}{\partial t}-\frac{\partial}{\partial x}\left(\partial D \frac{\partial i}{\partial x}\right)+\frac{\partial}{\partial x}\left(V_{i}\right)+\lambda_{i_{b}}=0 .
$$

(Symbois which are not delined it: the discussion to follow may be found in the notation. Chapter IX.) Variable $c_{m}$, the physically measurable quantity, is the bulk concentr.tion and inciudes both a liquid-phase component $c$ and a solid-phase component s':

$$
i_{0}=0 c+p s^{\circ}
$$

where $\theta$ is the waler content and $\rho$ is the bulk density of the solid. If one assumes local cyuilibrium. i.e. the rate of the adsutptive reaction is fast relative to the rate of transport. then s' will be a timeand space-independent function of $c$. If. furthermore, a livear adsorption isotherm is assumed. then

$$
s^{\prime}=\frac{\theta}{n} k_{d} c
$$

[Reeves and Duguid, 1976] where $n$ is the porosity. Quantity $k_{d}$ is the distribution coefficient, whose determinatiun is a primary object of this work. With these assumptions, the bulk concentration becomes

$$
i_{b}=R_{d} \theta_{c}
$$

where

$$
R_{d}=1+\frac{p k_{d}}{n}
$$

is the retardation factor, and the transport equation. Eq. (1), may be rewritten in terms of one dependent variable:

$$
R_{d} \frac{\partial(\theta c)}{\partial i}-\frac{\partial}{\partial x}\left(U D \frac{2 c}{\partial x}\right)+\frac{\partial}{\partial x}\left(V_{c}\right)+\lambda R_{d} \theta c=0 .
$$


BLANK PAGE 
Adsorption is included above in 'be first and fourth terms (from the keft) of Eq- (6), and the mechanism of dispersion is depicted mathematically by the second term of Ey. (6). Here the equation of Schcidcgear [Bear. 1972]

$$
O D=a_{\mathbf{L}} \mid \mathbf{V} \mathbf{V}
$$

relates dispersion to the magnitude of the Darcy velocity viu the bongitudinal dispersivity $a_{1}$. Advection by the carrier nux $V$ appears in the third term. Radioactive decay (iceay constant $\lambda$ ) is included in the fourth term of E4. (6) for compketeness even though it is expected to play a very minor role in most chromatographic measurements. A derivation of E4. (6) may be found it the document by Duzuid and Recies [1976].)

2. Spatial integration by the Gakertin method. The hasic idea here is quite straightforward and may he seen most transparently if Ey. (6) is rewriten in opesator form:

$$
\boldsymbol{l}(\mathrm{c})=\mathbf{0}
$$

Consider a trial function of the form

$$
\therefore=\sum_{i=1}^{m} N_{i}(x) c_{i}
$$

where the $X$ are basis functions spanning the region of interest $0 \leqslant x \leqslant 1$.. and the $m$ yuantities $c$ are expansion coefficients. In general. Ey. (X) will not be salisfied hy $c^{\prime}$ and there will be a residual. i.e.

$$
\mathscr{l}\left(c^{\prime}\right) \neq 0
$$

The (ialerkin method. however. requires that the weighted averages of this yuantity vanish:

$$
\int_{0}^{L} d x N_{i}(x)\left(t c^{\prime}\right)=0
$$

(Taking the weighting functions $N$, to be identical to the basis functions is the characteristic of the Galerkin method which distinguishes it from amnng a hroad catcgory cilled weighted-residual techniques [Finlayson. 1972].) The working equatiors here are found by combining Eys. (9) and (II). The result

$$
\int_{0}^{L} d x N_{i}(x) \mathscr{L}\left(\sum_{i} N_{j}(x) c_{i}\right)=0
$$

is a matrix equation. which may be solved for the $c_{1 .}$ These coefficients may then he uxed in Fy. (9) to yield the approximate solution $c^{\prime}$ at any position $x$. 


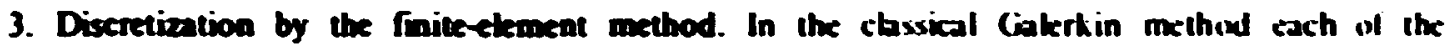
functions $\mathbf{X}$, extends over the entire domain of integration. Since there is considerable otertapping of the $X_{\text {. }}$ each integral. Ey. (12). must he carried over its complete extent $0 \leqslant x \leqslant 1$. and a full matrix is necessang to depict the coupling of the expansion cronstants $c$. Such a situation may the alketialed by the use of finite elements. In threedimensional space these freures wiould he polsthedra. and in two dimensions they would be polyzons. However. For the one-dimenswonal space considered here they simply constitute segments of a straight line. Each ekement is spanned hy basis functions which are nonnero onty in the interiur and on the boundaries of the etement. Thus each intezral of the form of E4. (12) need be carried only ons: the region of an individual etemest. and a sparce matrix results.

To formulise the Gakertin preblem for E4. (6) in terms of finite-element hasis functions. it is convenient to introduce the matrix function $|\mathrm{V}(\mathrm{X})|$. This ywantity is a column vector containing twit linear functions $N_{1}(x)$ and $X_{1}(x)$. These quantities. which are shown in Fig. 12. permit continuit! only in the function itself across ekment boundaries. Hence. first derivatives. are. in entreral discontinuous. and there will he unatoidably some nonconseniation of mass at the nodes. Ay

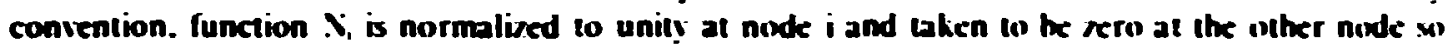
that the expansion constant $c_{1}$ is identical to the concentration at node i. as anticipated in f.4. (9) by the choice of symbols. In matrix notation this eyuatiun hecumes. for the r-th finite ekement

$$
, c(x, t)=\{N(x)\}^{T}\{, d(\cdots
$$

where the superseript T denotes the transposed matrix. (The nrime has heen dropped from the notation since only the approximate solution will he consideral in the remainder of this work.) Using this notation. both (iakerkin integrals [F.y. (12)] for the r-th ekement hecome one malrix cyuation. namely

$$
\int_{0}^{L} d x\{N\} \mathscr{Q}\left(\{N\}^{\top}(, c\}\right) d x=0
$$

4. Numerical implementation of the finite-element Gakerkin method. To dcvelop work ing eyuations from Ey. (14) reyuires hasically the same sIcps as in document OR.VI.492x [1 Huguid and Rectes. 1976]. The result is

$$
[, A]\{\dot{c}\}+[, B)(C\}+\left\{, R^{\prime}\right\}=0
$$

where

$$
\begin{aligned}
& {[r A]={ }_{n} J \int_{-1}^{1} d(N)\left(R_{d} \theta\right)(N)^{T}} \\
& {[, B]=, J \int_{-1}^{1} d\left(\frac{\partial}{\partial x}(N) O D \frac{\partial}{\partial x}(N)^{\top}\right.} \\
& \left.-\frac{\partial}{\partial x}\{N\} \vee\{N\}^{\top}+\{N\} R_{d}\left(\frac{\partial \theta}{\partial t}+\lambda \theta\right)(N\}^{\top}\right)
\end{aligned}
$$


ORNL-DWG 77-6269

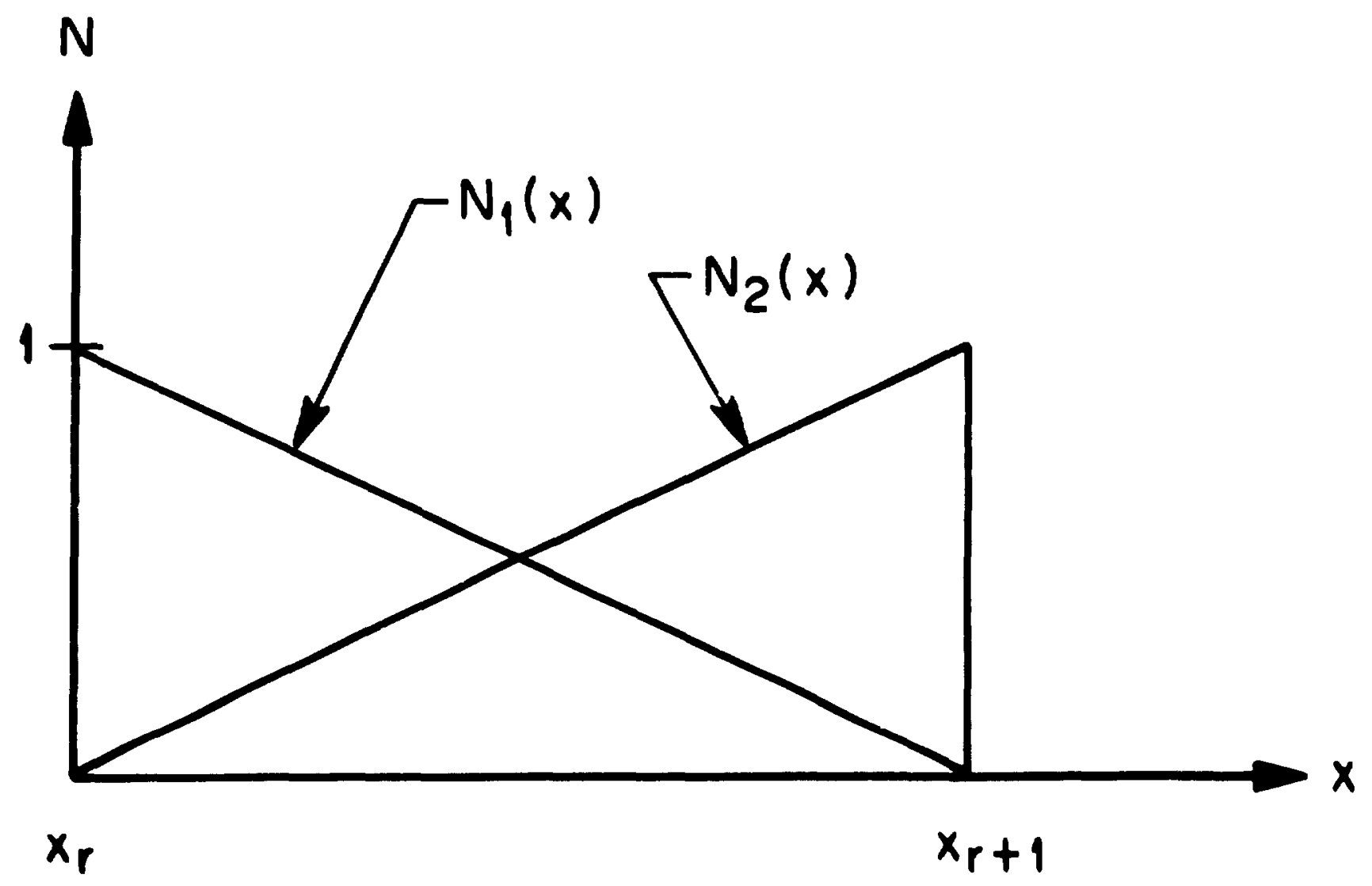

Fig. 12. Basis lunctions for the r-th finite element. 
and

$$
\left\{R^{2}\right\}=(N) \times\left.\right|_{=-1} ^{s=1}
$$

Quantivies [,A] and $(, B)$ are $2 \times 2$ matrices whereas $\{, R \mid$ is a $2 \times l$ column vector. The first term on the lett-hand side of Eq. (6) contributes both 10 [:A] through the,term $R$ s and to [,B] through the term Rua 2t). The second and thind terms on the kft thand side of Ey. (6) contribute. after an untegration by parts. both to $(, B)$ through the term $O D$ and to $\mid, R \cdot$. Quantity $X$ in the batter is the mass nux

$$
X=-O D \frac{\partial}{\partial x}+c V
$$

Finally the fourth term in Eo. (6). the radioactive decay. gives rise onhy to the term in $(, B)$ containing $\lambda \theta$.

For convenience of implementation a new local variable of integration s has been chosen in Eqs. (I6) - (IB):

$$
s=-1+2 \frac{x-x_{1}}{x_{2}-x_{1}}
$$

Thus the Jacobian is a simple constant:

$$
J=\frac{\partial x}{\partial s}=\left(x_{2}-x_{1}, y / 2\right.
$$

and the vector of basis functions may be written:

$$
\{N\}=y,[1+s ; s\}, s_{j}=x\left(x_{j}\right) \text {. }
$$

5. Time integntion by the funite-difference technique. In order to obtain the solution of Ey. (15) at time $t+J i$ from that at time $t$. Eq. (IS) is written for some intermeriate time $t+a j:$

$$
[, A]\{r c\}_{1+w \Delta t}+\{, B]\{c\}_{t+w \Delta t}+\left\{R^{\prime}\right\}=0
$$

where $0 \leqslant \omega \leqslant 1$. In the Crank-Nicholson centered-in-time approach $\omega=1 ; 2$, ain in the backward-difference approximation $\omega=1$. The Crank-Nicholson algorithm has a truncation error of $\mathrm{O}\left(\mathrm{Ji}^{*}\right)$, but its propagation-or-error characteristics frequently lead to oscillatory instabilities. The backward-difference scheme. on the other hand. has a truncation error of $O(1)$ ) but is quite resistant to oscillatory instabilities. An arbitrary $w$ allows an investigation to find the appropriate balance for the problem being considered. 
The time derivative of the cuncentration is expressed as

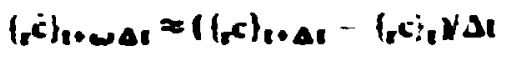

and the value of this ywentity at the arbitrany point in time is obsained by linear inverpolation:

$$
\{r\}_{1 \cdot \omega \Delta t}=\omega(\alpha\}_{1+\Delta t}+(1-\omega)\{c\}_{t}
$$

Substitution of F.ys. (24) and (25) into F.y. (15) yiclds the folkowing rebtionships:

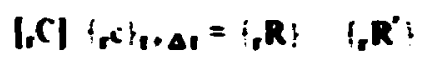

where

$$
\left.\left.I_{r} C\right]=|, A||\Delta I+\omega|_{r} B\right]
$$

and

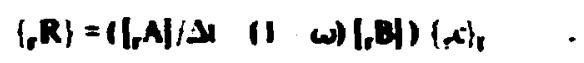

It should be understond that matrices $[, A]$. $[, B]$. and $\{R\}$. and. hence. $[, C]$ and $\{, R\}$. are craluated at time $1+\infty$ t. These matrices must therefore be ohtained by the interpotation procedure of F.y. (25).

6. Assembly of elements. Ip to this point the (aakrkin-finite-ekment formulation has heen presented only for a typical ekment $r$ among the colketion of finite ekments which comprise the region of interest. The result of this analisis is Fog (26). which is expressed in terms of the $2 x$ : matrix $\{C]$ and the two $2 x \mid$ vectors $\{, R\}$ and $\{, R\}$. It is now necessary in sum noer all $m$ finite elements in order to ohtain the corresponding cyuation for the complete system. namely

$$
|C|\left\{C ! \cdot \Delta t=\{R\}-\left\{R^{\prime}\right\}=\{Y\}\right.
$$

where

$$
\begin{aligned}
& |C|=\sum_{e}|r| r \mid \\
& \{R\}=\sum_{e}\{, R\} \\
& \left\{R^{\prime}\right\}=\sum_{f}\left\{R^{\prime}\right\}
\end{aligned}
$$


If there are $p$ nodal poinis in the sysem. then matrix $[C]$ is $p$ x $p$ and collumn vectors $\{R\} .\{R\}$.

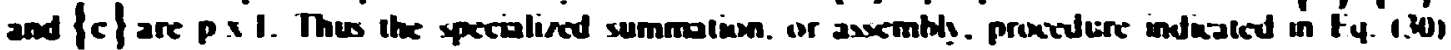
converts matrices and vectors of order iso into simibr yuntitios of order p. In illus rate this this

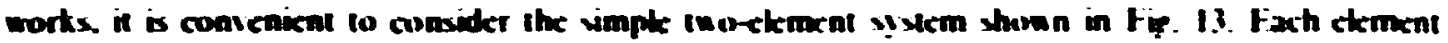
contains two nodes. which are numbered locally as indicaled. By means of the husis functiuns of tig.

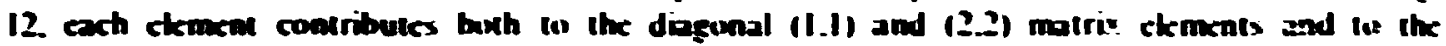
off-diagonal (1.2) and (2.1) matrix ekements of all two-dimensingal matrixes and to the (1) and (2)

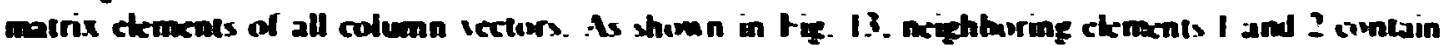

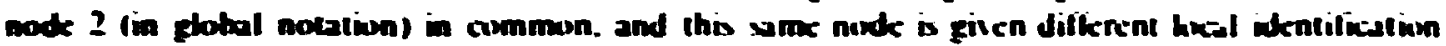
numbers within these ekments. Such a circumstancr is acciunnted fior in the asxembly pruxess. which yields

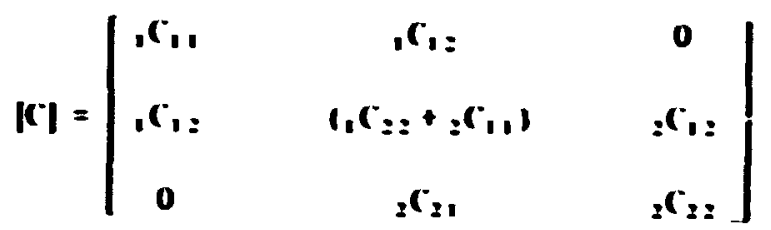

and

$$
R \cdot=\left\{\begin{array}{c}
1 R_{1} \\
, R_{2}+2 R_{1} \\
z R_{z}
\end{array}\right\}
$$

nith similar cxpressions "or $\{c\}$ and $\{R \cdot$. Malrix $[C \mid$ is tridiagonal due in the seyuential igliohal) numbering of the nodes. Fyuatiouns 131 , and 1.32) demonstrate hoth the index-shilting and summation properties of the assembly process.

7. Application of boundary conditions. Two types of moundan condilions are considered there. namely Seumann constant-lhux and itrichict constant-concentration specifications. Ithe tormer

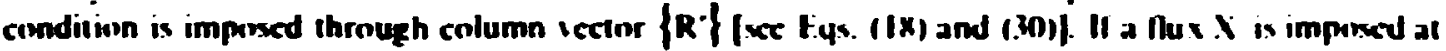
nonde $i$. then $R^{\prime}=X$ is prescribed. libe appropriate hasis lunction $X$ of 144 . 11 .3 has a value of unity at nodk i.) Contersele it there is no extermally appliced nux at node i. then it lollous that $\mathbf{R}^{\circ}:=\mathbf{n}$

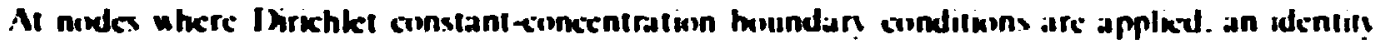
cyuation is generaled for each such node and included in the matrices of Fy. 124). Is an cxampi-. lake the two-etement system of Fiz. II with the corrcentration al node I constrained to the balue of h at all limes. i.c.

$$
\therefore=h \quad \text { and } h \neq m(1) \text {. }
$$

Fyuation (29) then lakes the form

$$
\left[\begin{array}{lll}
1 & 0 & 0 \\
0 & c_{22} & c_{23} \\
0 & c_{32} & c_{33}
\end{array}\right]\left\{\begin{array}{c}
c_{1} \\
c_{2} \\
c_{3}
\end{array}\right\}=\left\{\begin{array}{cc}
b \\
y_{2} & c_{21} b \\
y_{3}
\end{array}\right\}
$$



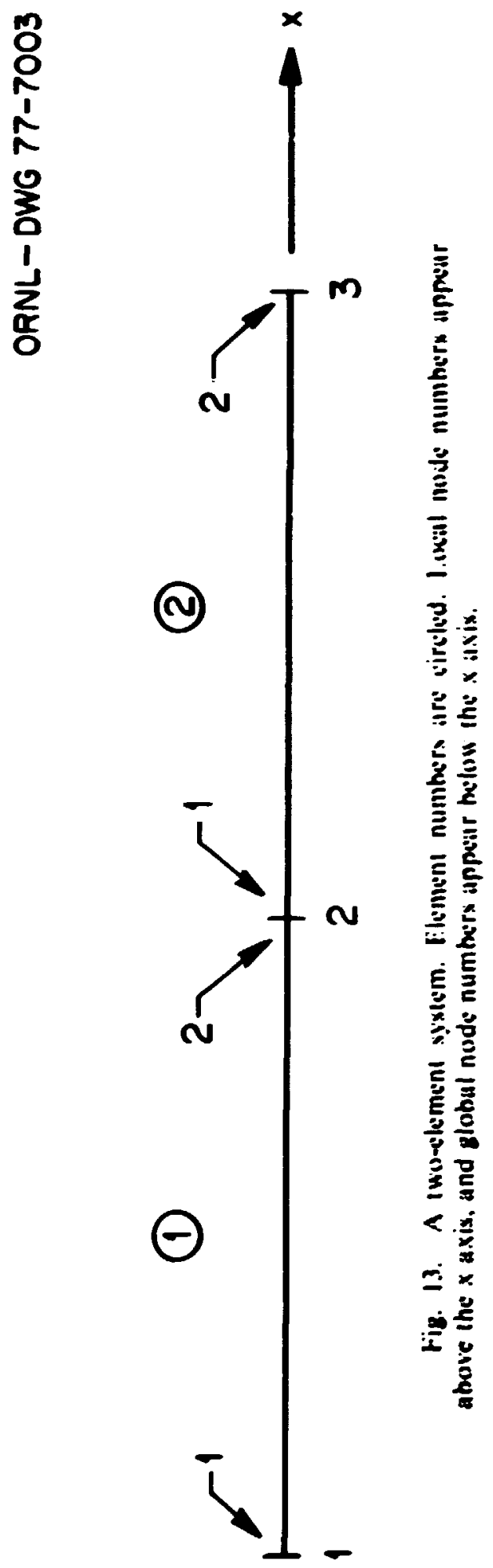
in which the iridiagonal structure of matrix [C] [Ey (31)] has been blien into account. Ihis result

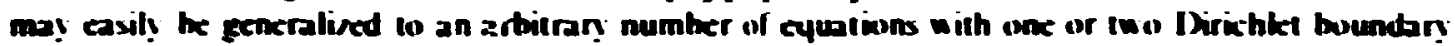
andes.

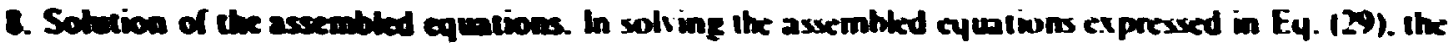
matrix [C] is decomposed into the product of upper and iswer triangubr matrices using the (jauss ecthaiyue. The bover triangular matrix is used to modify the righthand side of $\{Y$ for back-substituion indo the upper Iriangular matrix to ohtain a solutiun. If the matrix [C] and the

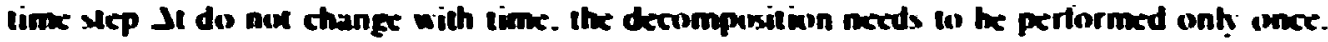

\section{SAMPLE CALCULATIONS}

In this section the results of three sample calcubtions are presented. Each of these hypothetical cases are hased on a chromatographic column of kngth $1=40 \mathrm{~cm}$ with boundary-initial conditions

$$
\begin{aligned}
& d x=0.1)=1 \\
& d x=(, 1)=0 \\
& (0<x<L, 1=0)=0 .
\end{aligned}
$$

Whenever a temporally and spatially variable Ibercy veluxity $V(x .1)$ is uxed. it is taken to be that for horionatal the in Yoks chy as described in the previnus chapler.

I. Numerical results. The objective here is threcfold. Firsly. we would like to typify the time detelopment of a concentratoon profike for the variable advective velucity. This is dome in rig. 14. lising the cune efx.l = 1 dayl ax experimental data." a parameter scarch (xee next chapter) is

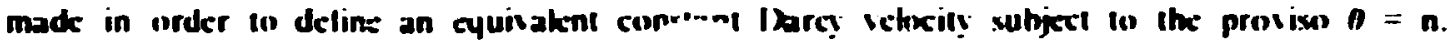
Concentrations for this vekcity are alsu shown in lig. 14 for compariuon.

Sccondly. we wiould lake to demonstrate the effects ol both the distribution cuxetficient k.: and the dispersivity $a_{1}$ and in dixtinguish one Irom the other. Figure 15 stows concentrat oon profikes

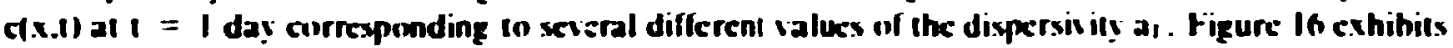
similar curves for seteral different values of the distributon cuefficicnt $k$.. (Wi inusly the elfects on nuid concentration $c$ of changing values of a, are quitc similar io those attributable to changing values of $k_{\text {.: }}$ If only Auid concenirations nere meaured in a chromalograph. there would the littke tope lor dixlinguishing the two. Fortunately. howeter. the chromilographic methoul measures the hulk concentration

$$
i_{n}=R_{d} O_{i}
$$

where

$$
R_{d}=1+\frac{p k_{d}}{n}
$$

The water-conient lactor $\theta(x . I)$ serses In modify the shape of the fluid concentratunn profike, as shown hy the plots of $c_{n} R_{t}, n$ in Fig. It. Nevertheless. it prosides no distinction hetucen al and $k$, The normalization $R_{4}$ docs provide such a distinctoon since it depends only on $k_{\text {.: }}$ [ F.4.(5)]. A.

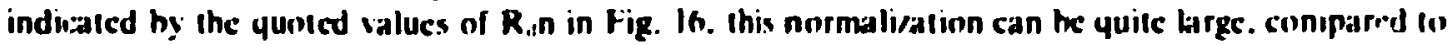
the maximum nuid concentration ol unity. and quite variahle. changing hy orer three orders of magnilude as $k$, changes $I \mathrm{rom} / \mathrm{cro}$ lo $11 \mathrm{~km} \mathrm{~cm}$ : $\mathrm{gm}$. 


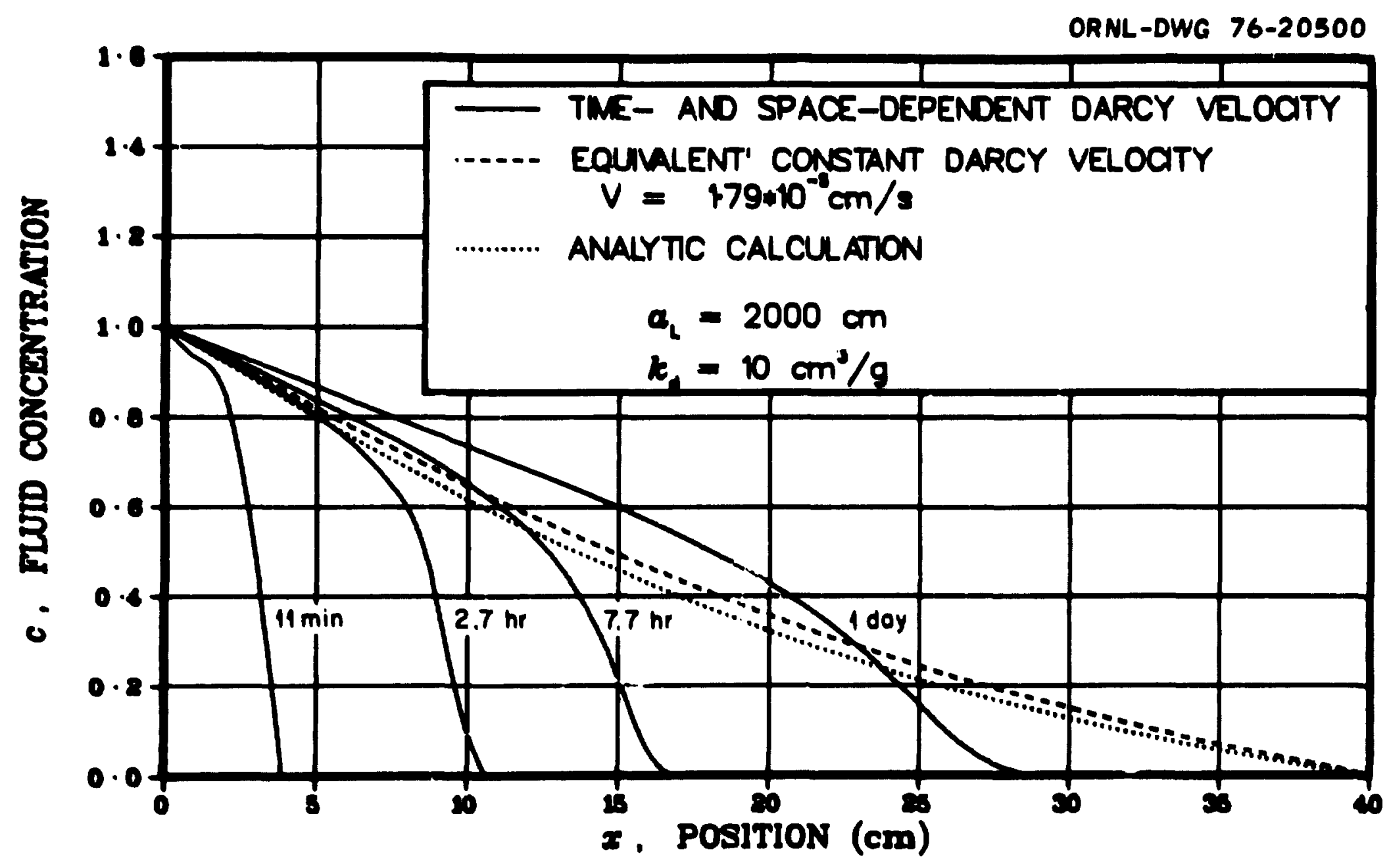

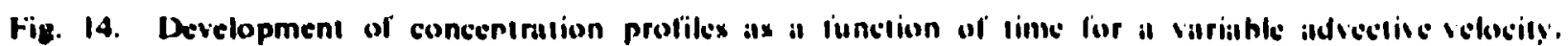




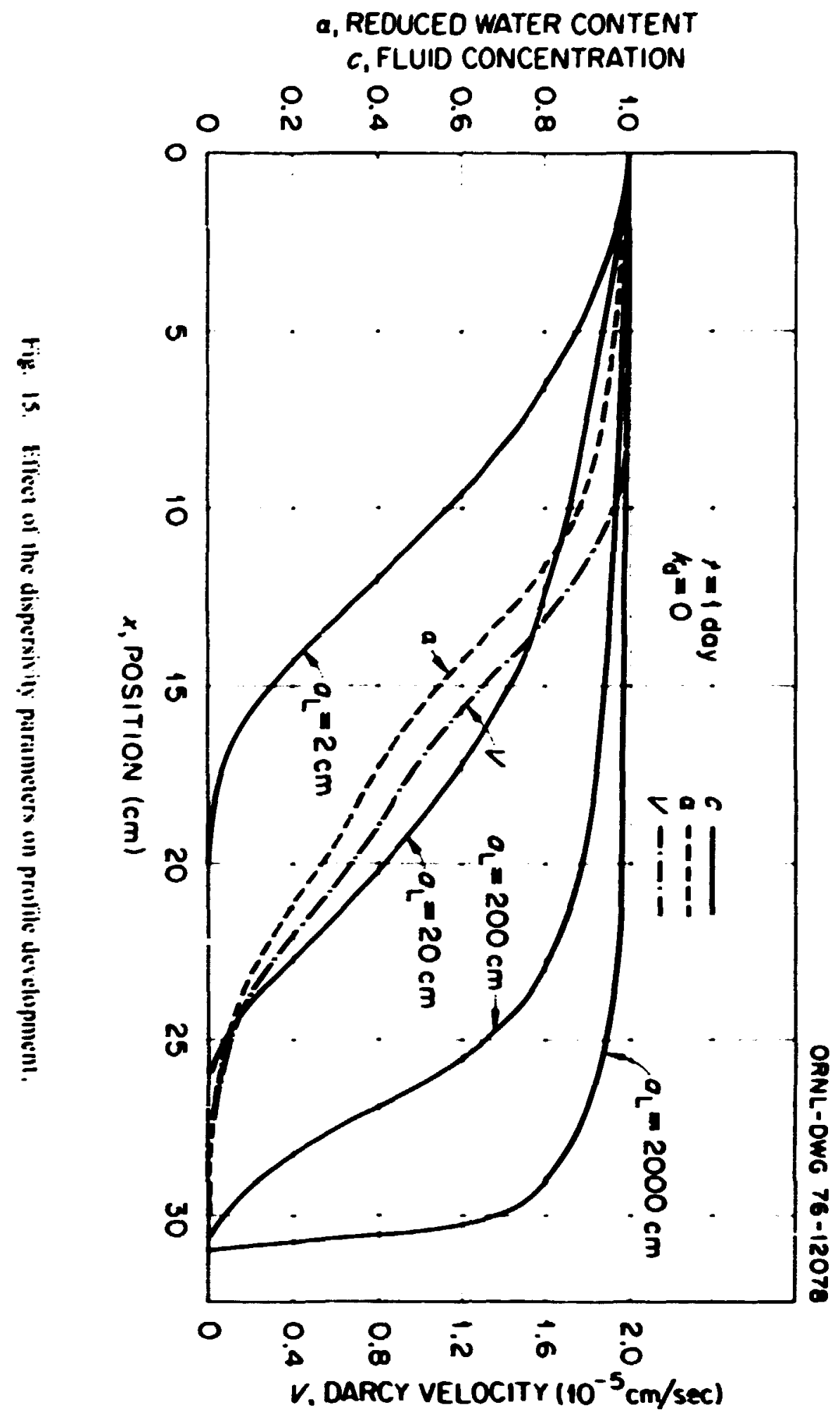


ORNL-OWG 76-12079

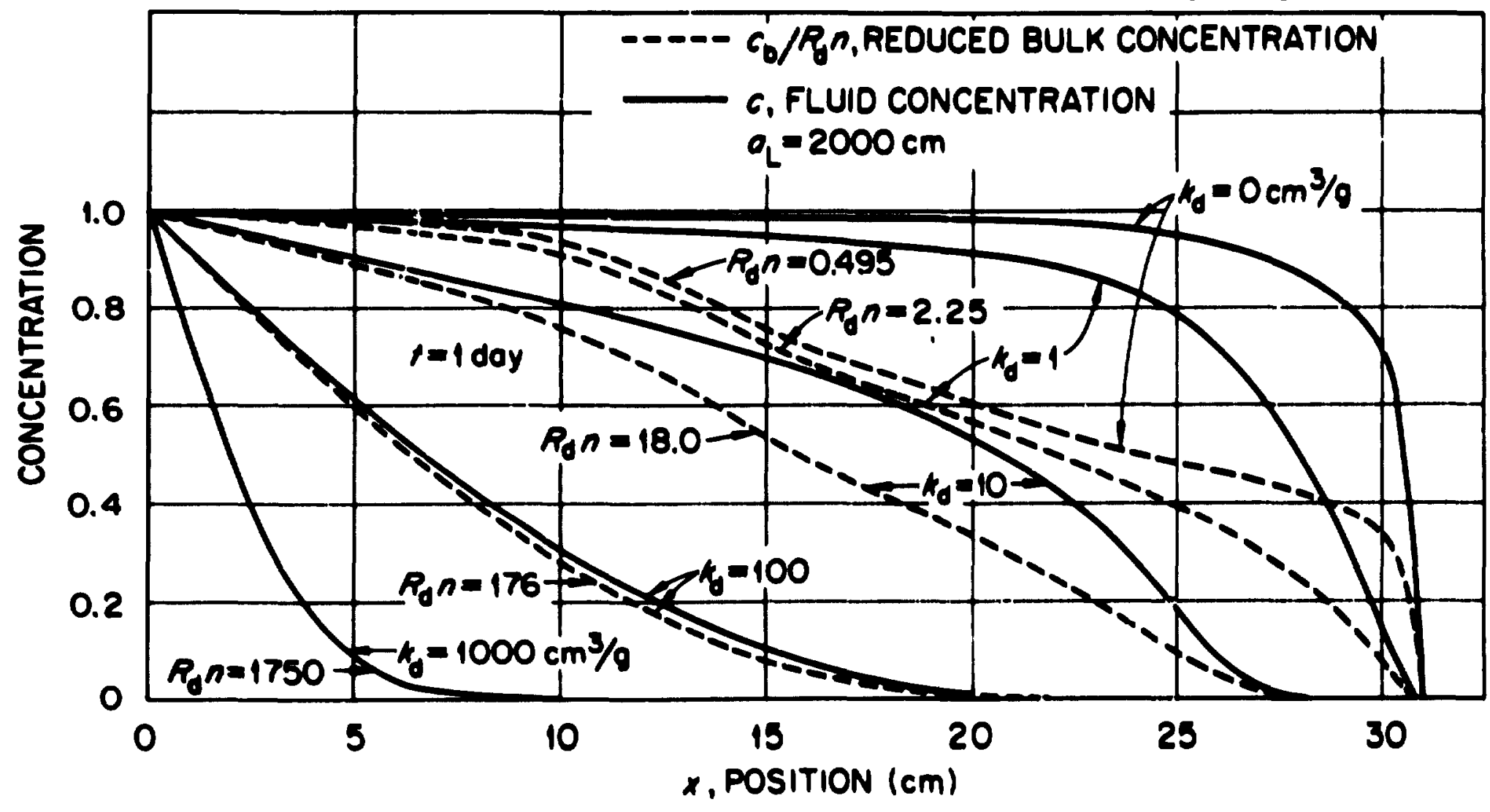

Fig. 16. Effect of the distribution coesficient on profite development. 


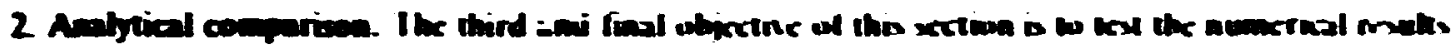

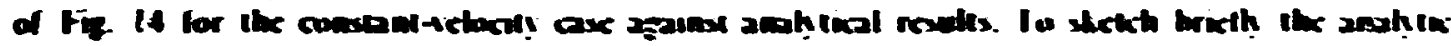
solution procoss we ast Ey. (6) indu the lorm

$$
\frac{\partial x}{2 x}=q^{2} \frac{\partial^{2} x}{\partial x^{2}}-\frac{2 x}{2 x} .
$$

13,

Hene

$$
q^{2}=n_{2} \text { Vien, }
$$

and

$$
\nabla=\text { v!or. }
$$

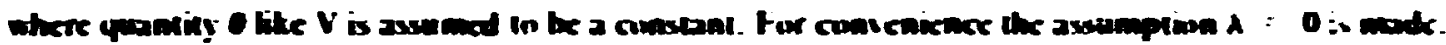

The trandormation

$$
c=s \pi n=8 / 3 q^{2}
$$

remolies the first derivative kerm in Ey. 136) (o yield the horm

$$
\frac{\partial z}{\partial x}=q^{2}\left(\frac{\partial^{2} z}{\partial x^{2}} a^{2} t\right) .
$$

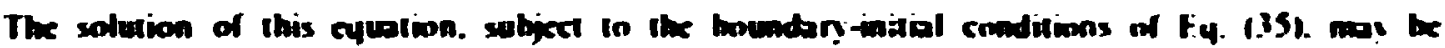

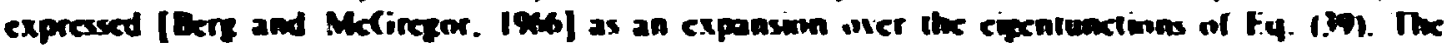
result is

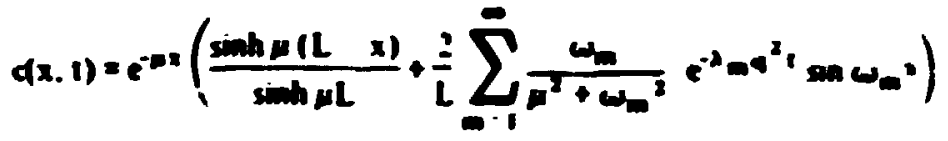

where

$$
\begin{gathered}
\omega_{m}=\frac{m}{L} \\
\lambda_{m}=\left(\frac{m \pi}{L}\right)^{2}+\omega^{2} .
\end{gathered}
$$

Results obtained from E.q. (40) are photled akongaide the corresponding numerical results in Fig. If. The veriation. about gri on the average. is acceptable for the spaci mesh used here for which $\delta x=0.5 \mathrm{~cm}$. 


\section{OPTIMIZATION}

\section{INTRODUCTION}

In contrast to the water-transpon ard inass-t, ansport developments of previous sections. no improvements or modifications have been added in this chapter tu existing numerical procedures. Thus the objective here is to present these basic comi-pts which permit use of the computer program li:ted in Appendix B. Additional technisal information may be obtained from the references to be ci'ed.

The optimization problem for chromatographic analysis is twofold. Firstly. given the experimentally determined water contents $J^{\prime \prime}(x . t)$, it is required to find soil purameters for the best-fitting theoretical function G(x,t,K,.h.,d.,...h.,d) so that the corresponding Darcy velocities may be determined. Secondly. given these velocities and the experimentally determined conentrations cil $(x, 1)$. it is required to find mass-transport parameters for the best fitting theoretical function $c_{M}\left(x .1 . k_{2} a_{1} . \rho . n\right)$. It is. of course. desirable independently to measure parameters $a_{1}$. $p$. and $n$ whenever possible in order to reduce numerical error in the determination of $k_{d}$.

The hest fit of a theoretical function f(x.t.p) is defined as that set of parameter talues $p$ (in vector notation) which minimizes th : quantity

$$
x^{2}(\bar{p})=\sum_{i=1}^{N_{1}} \sum_{j=1}^{N_{2}(j)}\left(\left(f\left(x_{j}, t_{i}, \bar{p}\right) r^{x}\left(x_{1}, t_{i}\right) j / \sigma^{x}\left(x_{j}, t_{i}\right)\right)^{2} .\right.
$$

Symbol f may be idemsified with either $\theta$ or $c_{n}$, and $\sigma^{\prime}$ is the experimentai error. The number of position variables $N$, will, in gencral. be a function of the time $t$, at which the measurements were taken. as indicated by the argument. Integer $N$, represents the total number of such time steps.

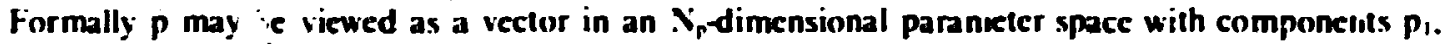
$P_{\text {.. .... }} p_{\text {ip. }}$ and $X^{\prime}(p)$ is a hypersurface in an $\left(N_{r}+1\right.$-dimensional space. The problem is to lecate the point $p$ a: which $X^{2}$ is minimized.

\section{OPTIMAL SEARCH}

One of the simplest methods for minimizing $\mathrm{X}^{-}$is the direct search. This technique involves seyuential cvaluation of this dependent variable and subseyuent comparison with the hest previousiy drtermined value together with a strategy for determining where the next trial will be made. One particular strategy characterizes the paitern-search meshod [Hocke and Jeeves. 1961]. When this technique is generalized to the case of constrained parameters. it is called the optimal-search metherl [Weissman and Wood. 1966]. The latter is chosen here since it permits the user to impose physical restrictions hy specifying an allowable range for any parameter. The computer implementation used here is that of Westley [Westley and Watts. 1970].

The eptimal-suarch strategy may be explained as follows. I "ially a hase point p., is chosen arbitrarily. Then expluration hegins about this point. First the exploratory irial poin: $\left.p=p_{1}+e_{1}\right\lrcorner p_{1}$ is chosen where $e_{1}$ is a unit vector parallel to the $p_{1}$ axis. If a success is obtained. i.e. $X^{\prime}\left(p_{1}\right)<\left(I-T_{1}\right) X^{\prime}\left(p_{1}\right)$. then an explorotory move is made to $p^{\prime}=p$.. where $T$, is an acceptance factor for function improvement and $p^{\prime}$ is the current estimate for the next hase point $p_{1}$. If a failure is obtained, i.e. $X^{\prime}(p)>\left(I-T_{1}\right) X\left(p_{1}\right)$. then a new trial point $p_{-}=p_{.} . \quad c_{1} \Delta p_{1}$ is chosen. If success is achieved at $p_{-}$then an exploratory move is made to $p^{\prime}=p_{-}$. Here and in the case of incrementation. whenever therc is a success. the step is accelerated in preparation for the next

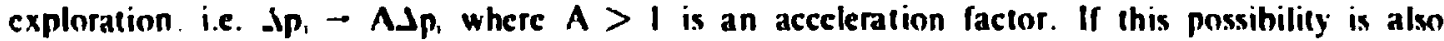
exhausted. 'ien there is no exploralory move. i.e. $p^{\prime}=p$. . The lep size in then reduced in preparation for the w:xt exploration. i.e. $\Delta p_{1} \rightarrow B J p$, wherc $B<I$ is a reduclion factor. Th: next step is to in-rement. decrement. or leave unchanged parameter $p$ : in the same manner as for 


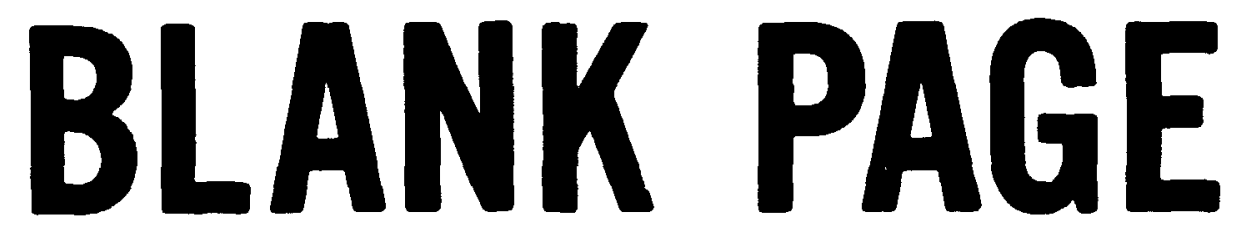


parameter p.. After taking each parameter, in turn. a new bese point pi will most likely be obtained. Figure 17 presents an example for a two-dimensional parameter space.

The next step is to take a pattern trial move to $\mathrm{p}^{\prime}=2 \mathrm{p}_{1} \quad$ p. followed by exphuratory trial moves. (Trial moves are indicated as dashed lines in Fig. 17.) If this series of mones is successful. i.e. $x^{*}\left(p^{\prime}\right)<\left(1-T_{1}\right) X^{*}\left(p_{1}\right)$. then a patirm mos, is made $10 \mathrm{p}:=p^{*}$. It should be noted here that the sequence of trial moves ou:iined asove continues even if $X^{\prime}\left(2 p_{1} \quad p_{.}\right)>\left(I \quad T_{2}\right) X^{\prime}\left(p_{1}\right)$. In addition. there is no accek.ration or reduction of the step sines in such a trial-point exploration. Similar pattern moves are taken until there is a failure. Then a return is effected to the bas: point. say p. from which the trial moves emanated. A hasepuint exploretion then follows. in wiicht: step-sixe reductions an permitted.

At this point all the distinctions between a bese-point exploration and a patrem expherarium should be chrified. Basically there are three differences. Firsty. for the former a bascepoint move. in effect, is made ach time there is a successful exphratory move. For a pattem exploration. on the other hand. a bese-point move is made only after the inclusion of exploratory moves of atl parameters have been made. and there has been a successful comparison with the previnus hase point. rather than the origin of the exploration. Such was the case in the example of Fig. 17. where a base-point exploration was employed about the initial guess p.. Secondly. as noted carlier. step-sire modification is allowed only during a hase-point explusation. Finally. normal termination of the search may only follow a base-point exploration. ?his happens when there are failures in all

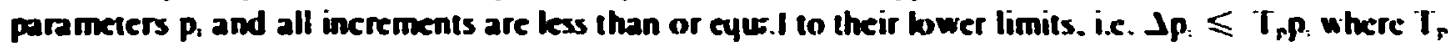
is a step-size tokeance factor. Pattem exploration. since it uccurs about a trial point rather than an established base pivint. is not deemed to be suffici-ntly reliable to justify either step-sive modification or normai terminatin. (Nonnormal terminatir a occurs whenever the prescribed maximum number of function evaluations of ( $\mathbf{x . t . p )}$ has heen :xceeded.)

The above strategy is ilentical to tha: of the pattem-search method. The only additional feature reyuired by the optimal-searc. strategy is to test after each iscrementation (or decrementation) (t) see whether the paramiter is hi:un the prescribed range of allowable values. If not. then the parameter value is simply set eyual to the nearest bound. 


$$
\text { ORNL-DWG 76- } 19569
$$

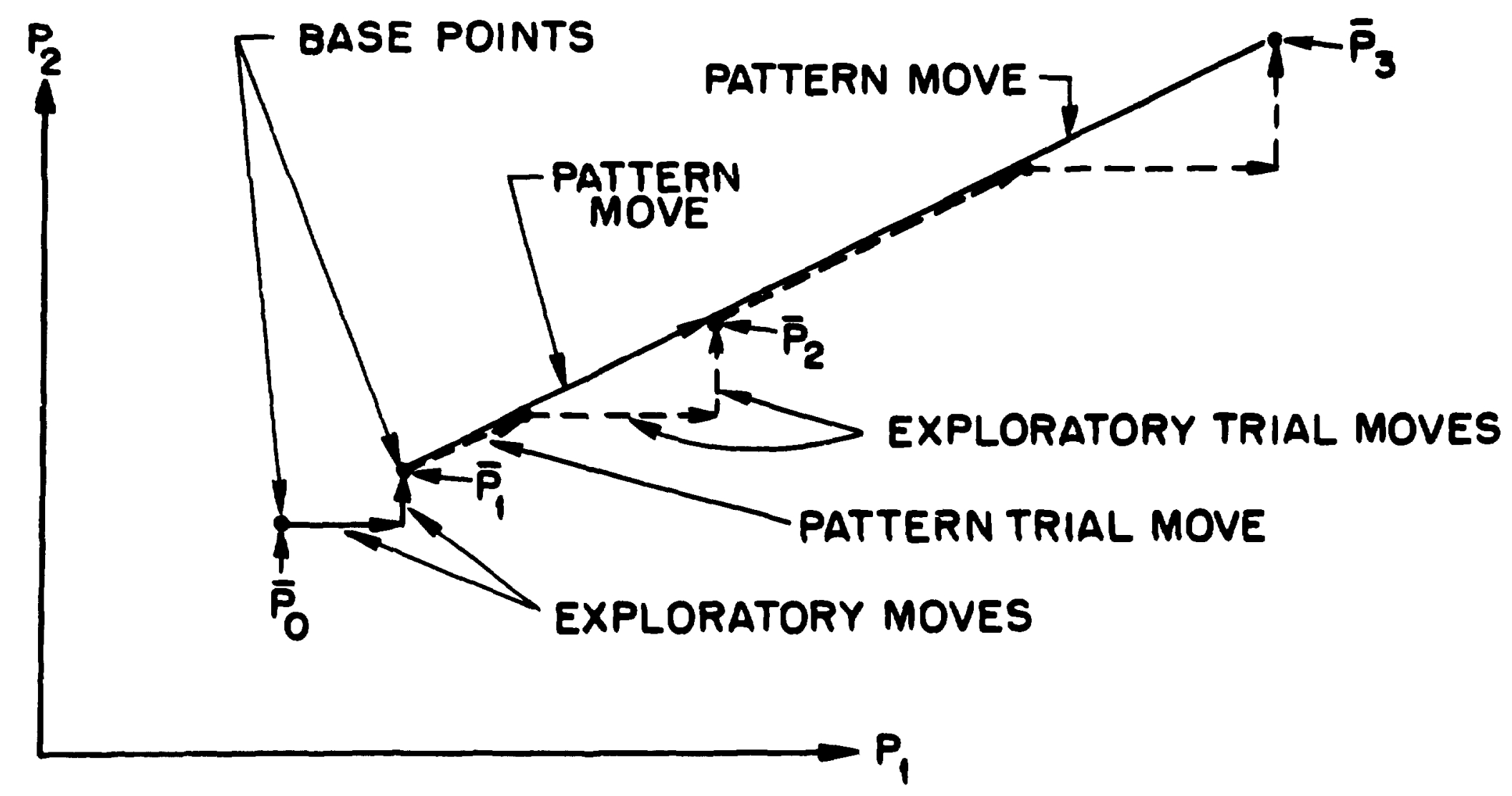




\section{COMPUTER IMPLEMENTATION}

The computer program is divided into three functional units pertaining in (I) the water Iranspor: (2) the mass Iranspor. and (3) the automatic search procedures. all of which were decribed formally in precuding chapters. Routine MAIX controb the operation of these units as prescribed by the user (sec Fig. 18). The individual urits are suructured as shown in figs. 19. 20. and 2I. In all. there are 34 separate subprograms. lislings of which may be found in Appendix $B$.

\section{WATER TRANSPORT}

Foc the wetertianspon proe rures the control function is performed by WTR (sec Fiz. |9). Using input data obtained by DATAW. routine WTR directs its supporting routines wi as (o (ubtain both position $x(0.1)$ and Darcy velocity V(E.t) as functions of buth lime 1 and the water content variable, which may be cither or its reduced counterpan a. If desired. these results may be printed (PRISTW) or stored (STRW) on an auxiliany storage device.

The quantities which detemine the moistureflow characteristics of the suil are the wil properties Q(O) and $\mathrm{K}(0)$. These functions may either he read in as babubr functions or he exenerated from the Garaner and King form factors. as described in the last section of Chapter II. In the former case semi-togarithmic lagrangian interpobtion by routine YI.AC; [Wesley and Watls. 1970] is uxed in order to ohain soil propertics appropriale for subsequent (iauss integration. In the latter caxe the diffusivitios and conductivities are cakubted directh by SPROP on such a grid. Since a given set of soil properties is independent of both position and time. and since these values are reyuired only for the Caus-yuadrature grid of water-content values. they are cakcubted onk once.

Initially the soil properties are aced to determine the time function $\left(\mathrm{W}_{\mathrm{i}}\right)$ for selected alues of t'ke reduced end-point Darcy velocity $W_{1}$. This is done by applying the Causs youdrature algrithm (subroutine (iAUSS) to evaluate the integral in F.y. (III.26). By sorting (routine ISSORT) (he results into ascending order in the time variable. the labular function is pbeed in a form suitahk for interpolation. This is necessary since cakulation of $x(a, 1)$ and $W(a .1)$ reyuine the end-print veloxity W(11). as indicated by Eqs. (III.31) and (III.32). Double borithmic I agrangian interpolation (YI.A(i) is used for this purpose.

Dependent variables $x(a, 1)$ and $W(x .1)$ are evaluated by cither the first-onter formulas. F.ys. (III. 17) and (III. I8). or the second-order formules. Fys. (III.3I) and (III.32). as specified m- the usce. Integrals in the above-mentioned eyuations are evaluated by subroutine CAliss with the various integrands supplied by the function routine FUNS. The unreduced velocity $V$ is obtained from the reduced velocity $W$ through application of Eq. (III.9). In addition. when coupling with the mass transport is required. functions $x(\theta .1)$ and $V(\theta .1)$ are transiomed in the functions $\theta(x, 1)$ and $V(x, 1)$ hy WTR. and then Iagrangian interpolation is performed to yicld the moisture transport variables $\theta$ and $V$ on the spatial grid specified by the mass-franspon cakulation.

Obviously. the I agrange-interpolation and Causs-quadrature techniques play important roles in the water-: ranspon determination. For this reason the order parameters. which govsm the accuracy of each method. are separately identified as input quantities. (Appendices C and D give a compliste description of the input.)

\section{MASS TRANSPORT}

When the moisture-transport variables $\theta$ and $V$ are obtained. either as results of the above-mentioned calculation or as input quantitics. the mass-transport equation. Eq. (IV.h). is solved numerically as depicted by Fig. 20. As indicated by its central location. subroutine MTR performs the control function here. Using input data obained by DAT AM. routine MTR directs its supporting routines so as to obtain huid concentmition $c(x, t)$ and its hulk counterpart $c,(x, t)$ as functions of both position $x$ and time t. Restils may be printed (PRINTM) or stored (STRM). 


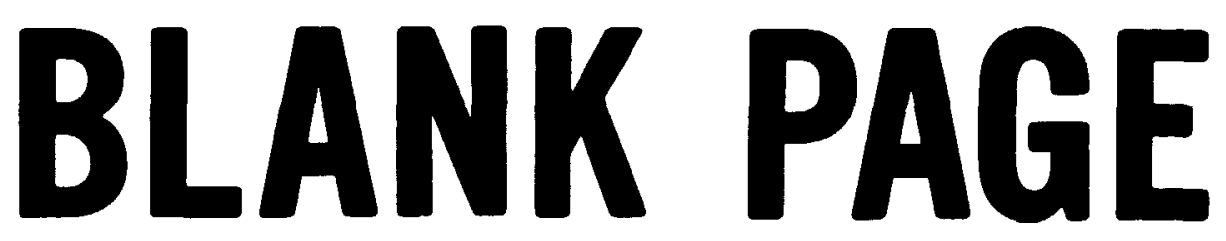


ORNL- OWG 76-12073

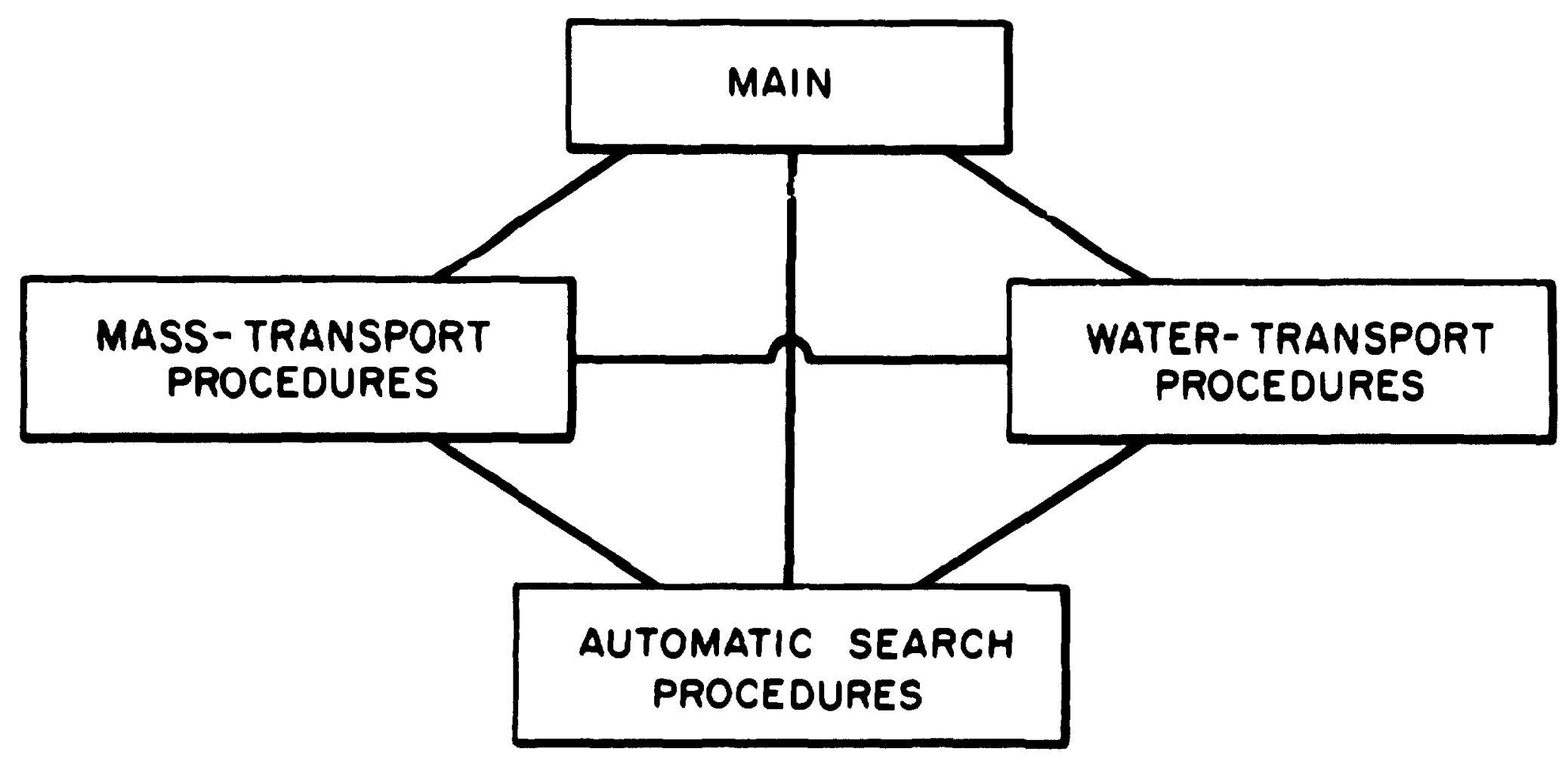

Fig. 18. Flow chart connecting the functional unies of the program. 
OPNL-DWG 76-12074

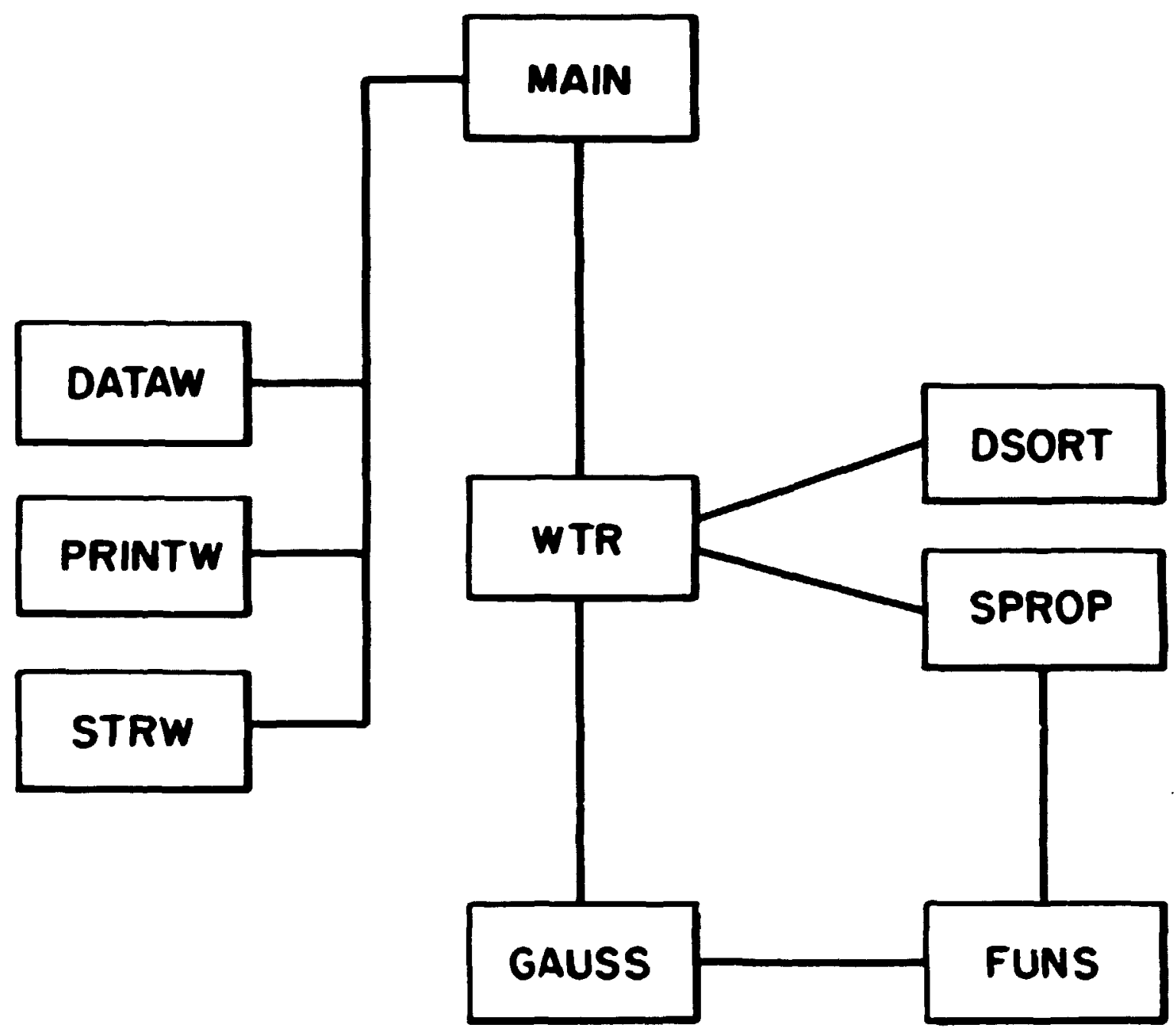

Fig. 19. Flow chan specilying the water-transport routines. 
ORNL-OWG 76-12075

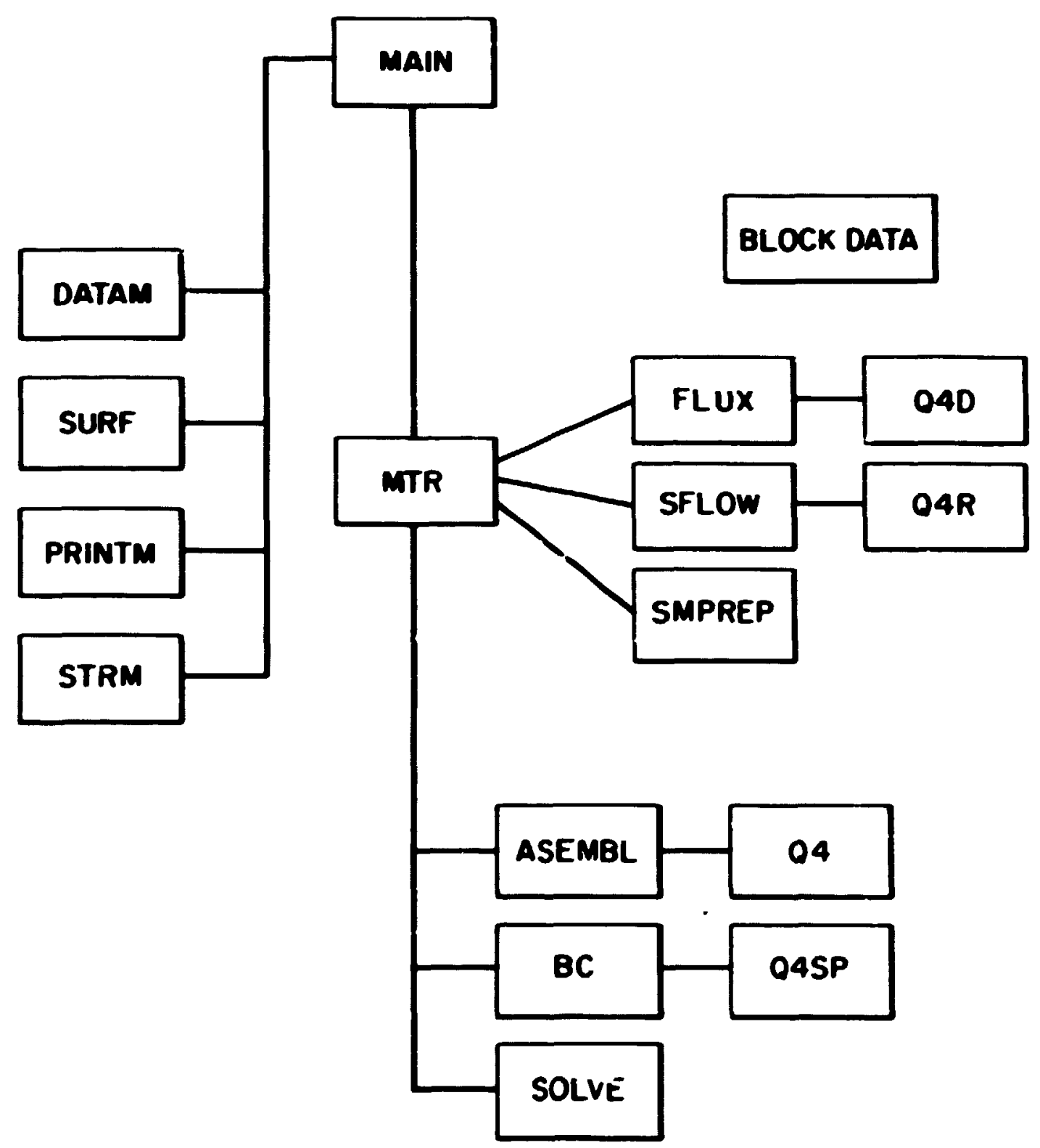

Fig. 20. Flow chant specifying the mass-transport routines. 
The primary computations tor the mass transpon are carriced out in rosutines (4. MSFMIHI.

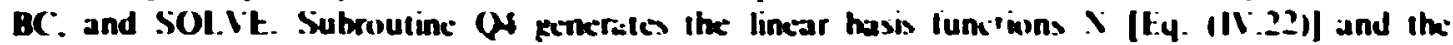
Jacobian .J and. using kmoun (or assumed) soil-wolution propertis. perfiorms the integrations necessary to obtain ekment matrices [.A] and [.B]. The (kauss ywadrature algeorithm of order tuon is employed here. Subroutine ASEMBI. has two lunctwisa. Firs it appliks the finitediflerence

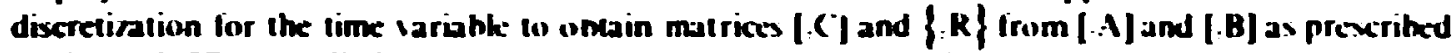

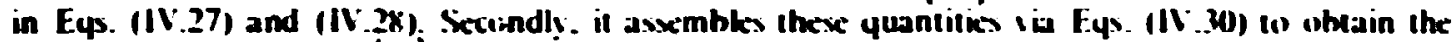
global matrices $[C]$ and $\{R\}$. Routine $B C$ applics the huondary conditions as discussed in Chapter IV. Theory Secticen 7, and SOI.VE solses the resulting asymmetric handed matrix system hy. Caussian climination.

Supporting calculations are carried out in St RF. FI.1X. (AI). SHI.OW. and QAR. Subroutine SURF identifies boundary :odes and ekements. Routine FI.t $X$ and QUI) deitermine the mass flux at each node from the predetermined concentration distribution. Io determine the mass hatance. end-point mass fluxes are integrat"' over time hy SFI.OW. and concentration distributions are integrated over space by Q4R.

\section{OPTIMIZATI' s}

The uptimat-earch techniulue. which was dexcribed brielly in Chapter $V$. is impkemented as shown in Fig. 21. Esing xearch parameters and experimental data input through DATAS. routine SEARCH procuces a set of physical parameters $p$ which minimize $X$ (p). Fy. (V.l). This set of parameters and the corresponding hest fits to the experimental datia are then printed by PRISTS.

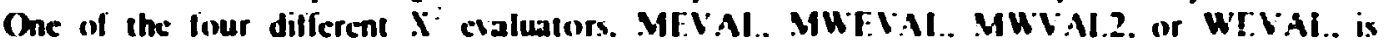
chosen depending on user specifications. For example. WI: WII is used uhemeter the experimental water contents o'(x.l) are to he fitted. whereas MUI:YAl. is uxed wheneier experimental concentrations eid $x .1$ are to be optimally approximated. In the batler caxe it is understood that the water transport is to the calculated simultamerosly from known soil parametcis.

The material-transport and water-trinsport pricedures here assume the roke of providing theoretical functions for the $\boldsymbol{x}$ evaluators. There are necessarily. howeter. sume linkage routines. Parameter linkage is accomplished hy BIFFM and BLFFW. Subroutine BI:FFM establishes the correspondence hetween various elements of the parameter array $p$ and the malerial-iransport

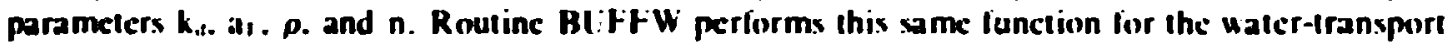
parameters. Nidal-point linkage is accomp.lished by YI.ACi. SWPRFP. and ISSORT. Calcalational space grids must. in general. differ from experimental space grids. The lormer is chosen from considerations to achieve computation efficiency. Whereas the bitfer is dictated hy the experimental lechniques. This disparity is rectified hy simply interpolating with YI.Af; to obtion the theoretical functions at the experimental positions. 


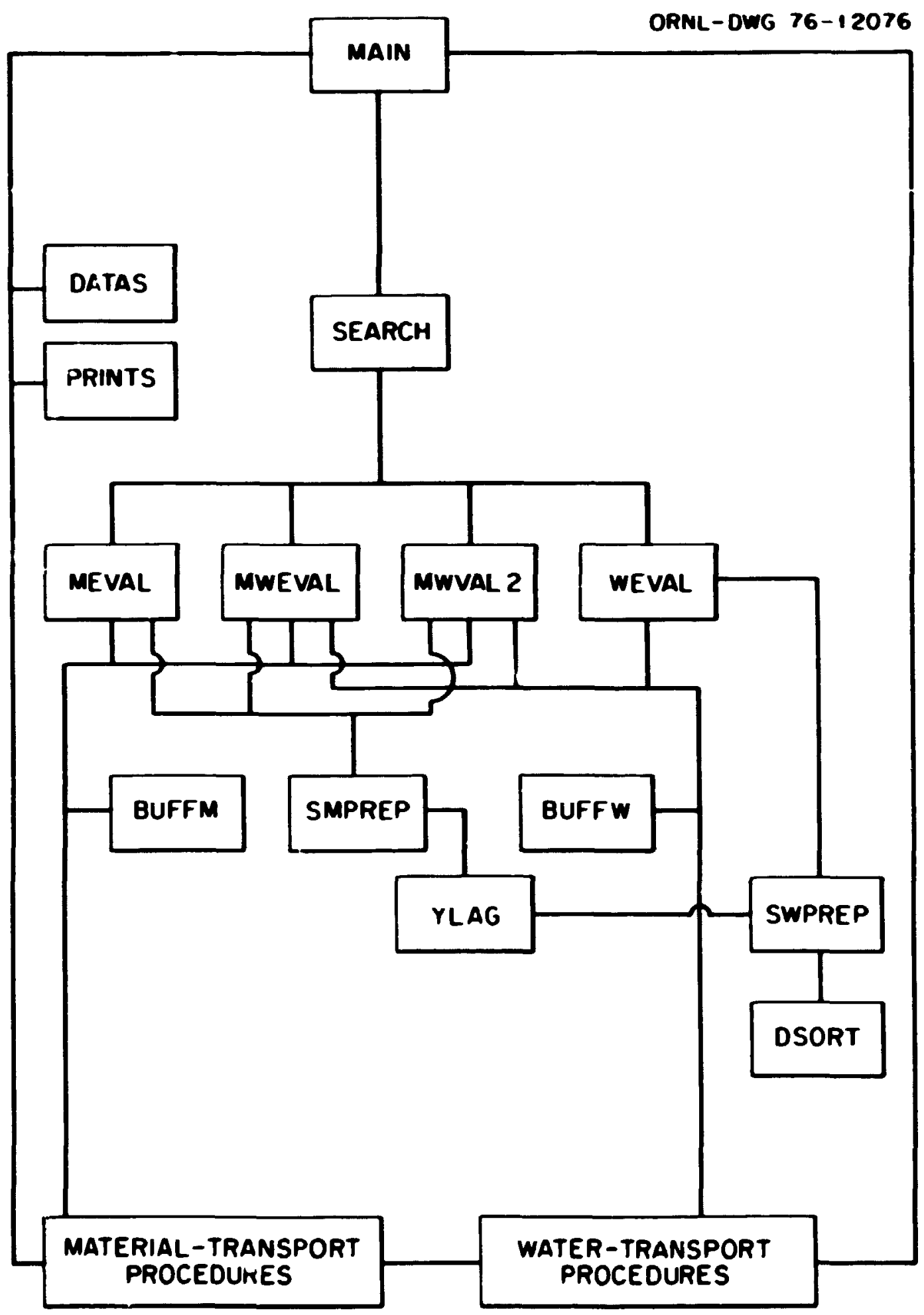

Fig. 21. Flow chart specifying the optimization routines. 


\section{ANALYSIS OF FXPERIMENTAL DATA}

Correspondence of theory and experiment is the subject of this chapter. Mitre precisels. the optimization procedure of Chapter $V$ is used to automatically adjust parame: $n$ of buth the watertiansport theory '(hapter III) and the mass-trasspon theory (Chapter IVI w) as to thest lit' the experimental data (Chapter II). One of the mass-transport parameters. namely the disuribution coefficient h. is of special interest.

Belore proceding. howceter. certain exneral remarks shoukd be mack rezaruing the work presented in this chapter. In the first place. it is somewhat fragmentan sime it reproxents our lirst allempe to analyre experimental data. Even wo. feasibility is demunstrated by the Sr and Pu anali xes presented. Finality the need for further refinement of iwo different aspects of our anal! sis. namel! the water-transpurt and the migration of multiple ypecies. can me seen.

\section{WATER TRANSPORT}

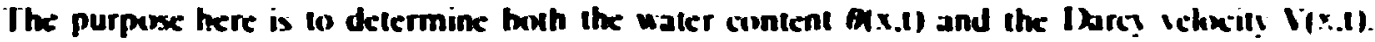
These yuantitios are mecessan since they characterice the carrice lluid and therehy comtrol ithe mass transport. Io calculate the blter. a space-time grid must he superposed on the region of integralion (x.t). The spacings within this grid are governed by consergence and stability criteris of the numerical algorithms. and. in gemeral. are much fimer than the correspending experimental grid. Thus the need for an interpolating provedure arises. The stratezy adopted there is to til the experimental dala at the selected points at which it is measured. (the therchy determines parametrically an interpolation function which maly be uxed at spacie-lime prints isther than thone for which measurements are taken.

Another consideration concerns the experimental obuervable. which is simply the relative radioactivily. In the case of tritium. which is not adsurbed. this radiosetivily is laken lo be proportional to the waler content. Thus the fitting function must be more than a simple interpobation function. It must have suflicient theoretical loundation that Itarey celixitica maly he extracted from it. The formal deciclopment of such a function is the subjecl of (hapter III.

Figures 22 and 23 present two different radioaclivity profiks lor the motement of tritiated waler in Fuyuay and corresponding to iwo different values of the eluting tirme. I the radienuclide here is placed in the feed solution ralher than heing spotted direcily onfo the soil.) barameler s:alues for the theoretical fits are given in Table $I$. These fits are not extremely gend. There is a plateatu in the experimental data for the lower vaiues of the position $x$ which is nol present in the theory. Secondly. the experimental wetting front is steeper than that of the theorctical fit. The problem heis

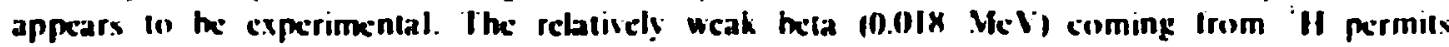
observation of only the topmost layer of soil, where evaporation. inhomogencily. and tho-dimensional effects are the greatest. A different experimental technique appears to the citlled lorr. Perhaps diswection followed by weighing the increments helore and afler drying uould be more satisfactiors.

\section{MASS TRANSPORT}

The best fits oblained to date are shown in Figs. 24-26. Figures 24 and 25 pertain in "Sr transport in fuyuay sand and figs. 26 and 27 pertain to" Pu transport in the same sill. In each ease the radionuclide is spotted directly onto the soil. (Figures $2 X$ and 29 shou the corresponding initial conditions.)

The soil is then wetled for approximately 17 hours using water as the cluting solution and counted to obtain the radinnuclide profiles. Figures 24 and 26 exhibit the resulting profiles. After drying. the soil is uelled for a second time and counled. Figures 25 and 27 pertain to this welling. again for Sr and Pu. respectively. 


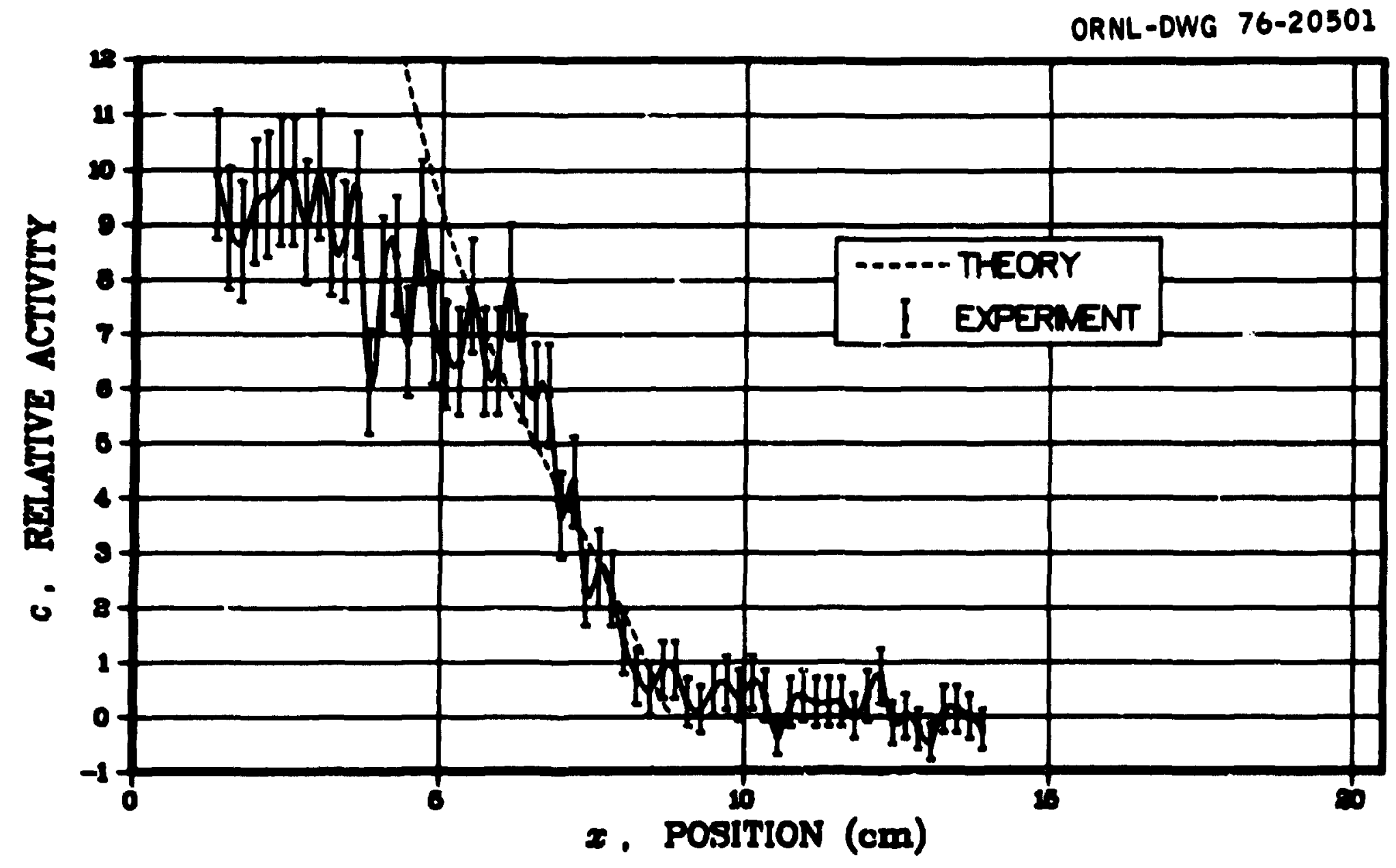

Fig. 22. 'H distribution in Fuywily wand al $1=1 \mathrm{~min}$. 


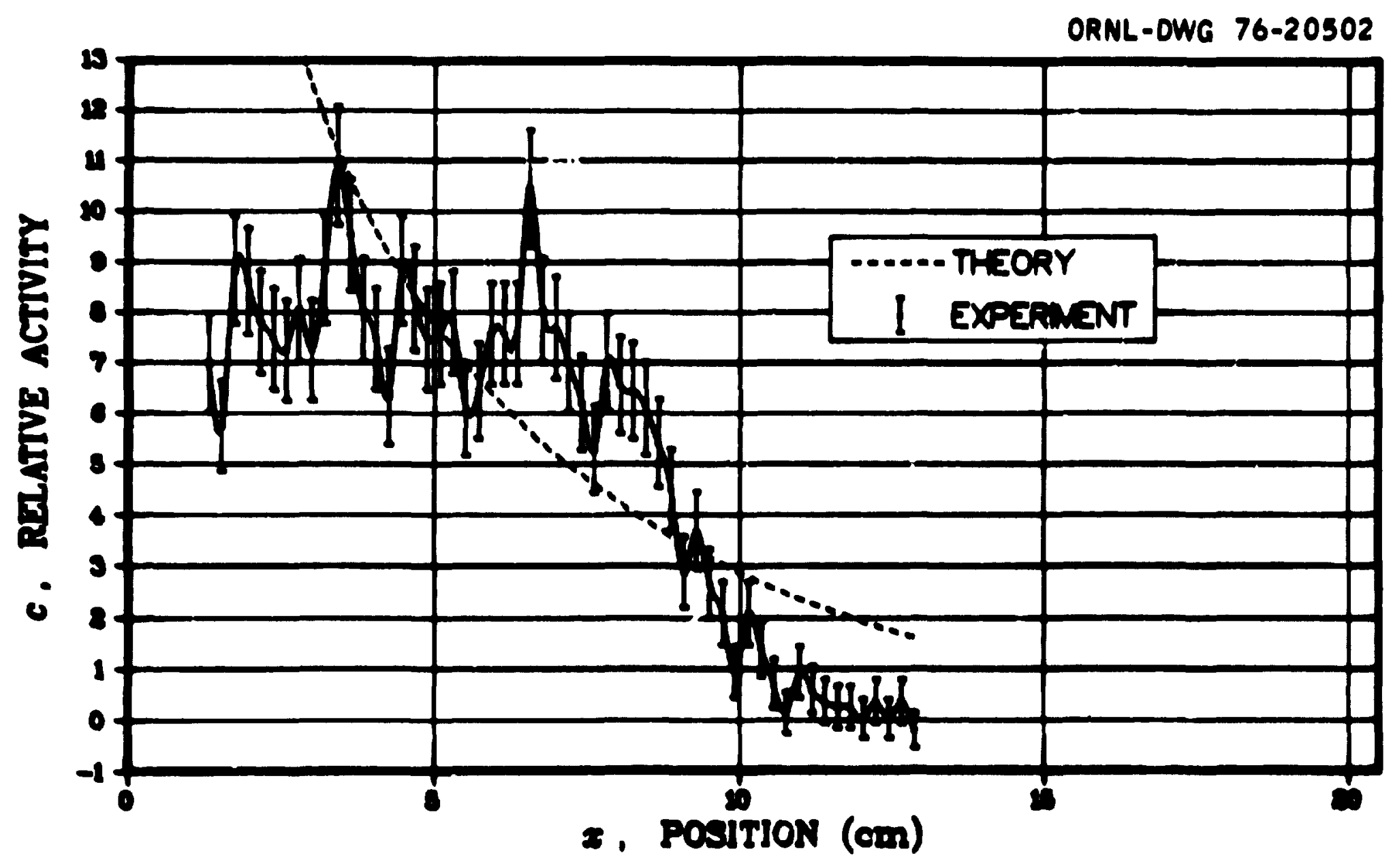

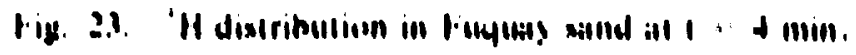


Table 1. MoistureTransport Parameters for Fuquay Sand

\begin{tabular}{|c|c|c|}
\hline \multirow{3}{*}{$\begin{array}{l}\text { Conductivity } \\
\text { Parmeters }\end{array}$} & $\mathbf{k}$ & $7.57 \times 10^{-5} \mathrm{~cm} ; \mathrm{sec}$ \\
\hline & h. & $-49.9 \mathrm{~cm}$ \\
\hline & d & 1.78 \\
\hline \multirow[t]{4}{*}{$\begin{array}{l}\text { Moisture-Content } \\
\text { Parameters }\end{array}$} & $\begin{array}{l}\boldsymbol{\beta} \\
\mathbf{h}^{\prime}\end{array}$ & $\begin{array}{l}3.97 \times 10^{-4} \\
-23.2 \mathrm{~cm}\end{array}$ \\
\hline & $d^{\prime}$ & -0.419 \\
\hline & $\theta_{r}, \theta$ & 0.00625 \\
\hline & $\theta_{1}, n$ & 0.625 \\
\hline
\end{tabular}

Table 2. Mase-Transpert Parameters for Fuquay Sand

Parameter

$k .\left(\mathrm{cm}^{\prime} / \mathrm{s}\right)$

$\rho\left(8 / \mathrm{cm}^{3}\right)$

a. $(\mathrm{cm})$

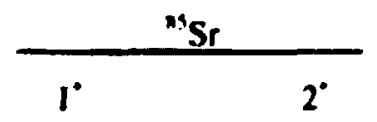

$25.9^{\circ}$

1.75

$0.150^{\circ}$
36.3

1.75

$0^{3333^{\circ}}$

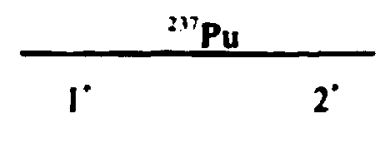

44.0

$42.3^{\circ}$

1.75

1.75

$0.446^{\circ}$

$0.20^{\circ}$

'These numbers refer either to the first or second wetting. 


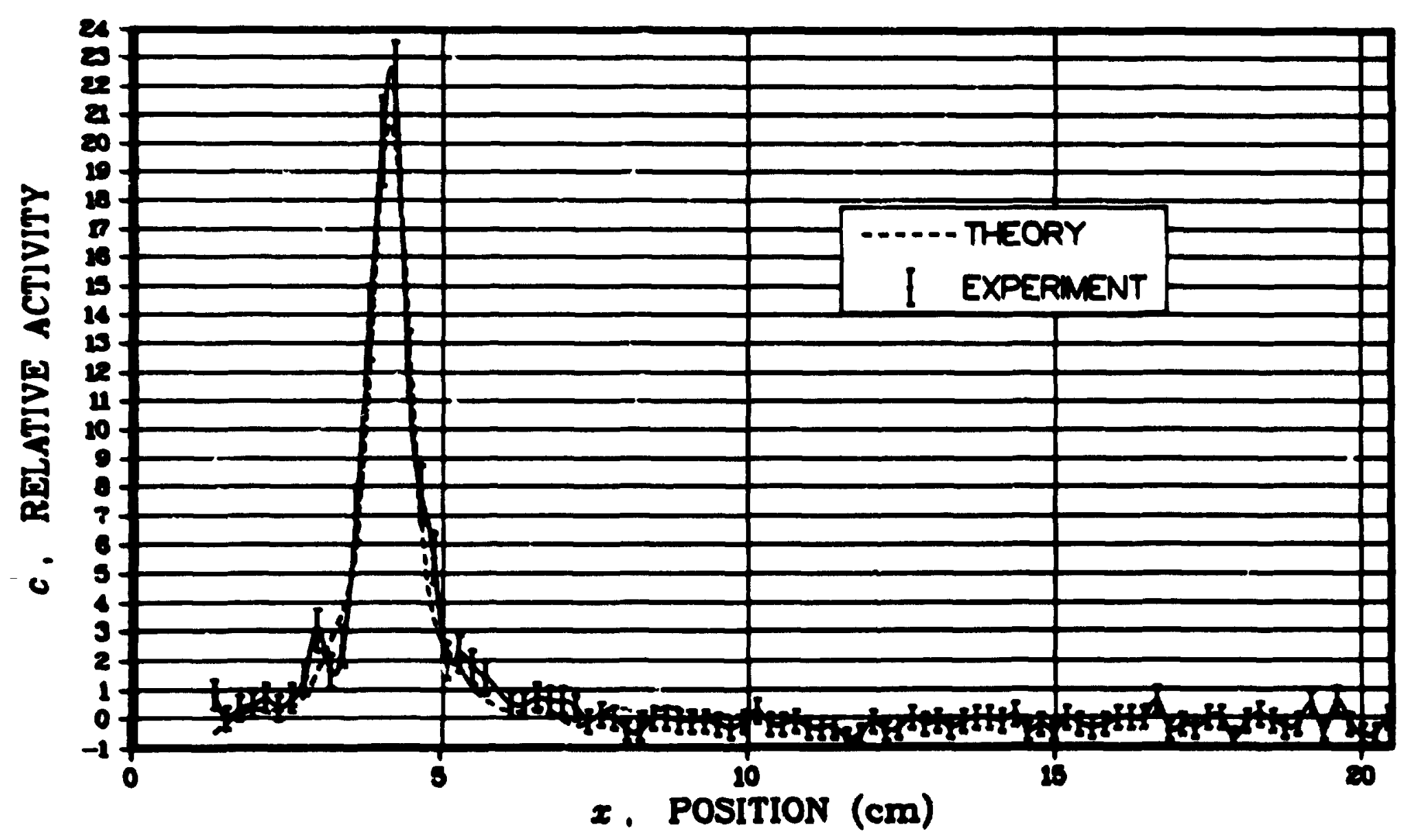

Fig. 24. "Si distrithution in Fllyway sund aller une welling with watler. 
$n$
0
0
0
0
0
3
2
0
0

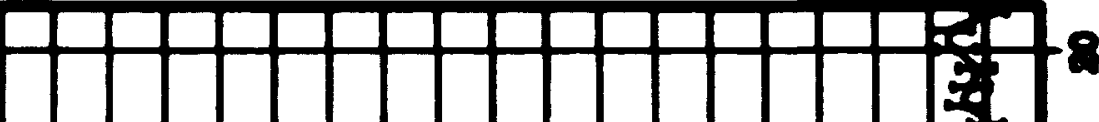

$\frac{3}{2}$
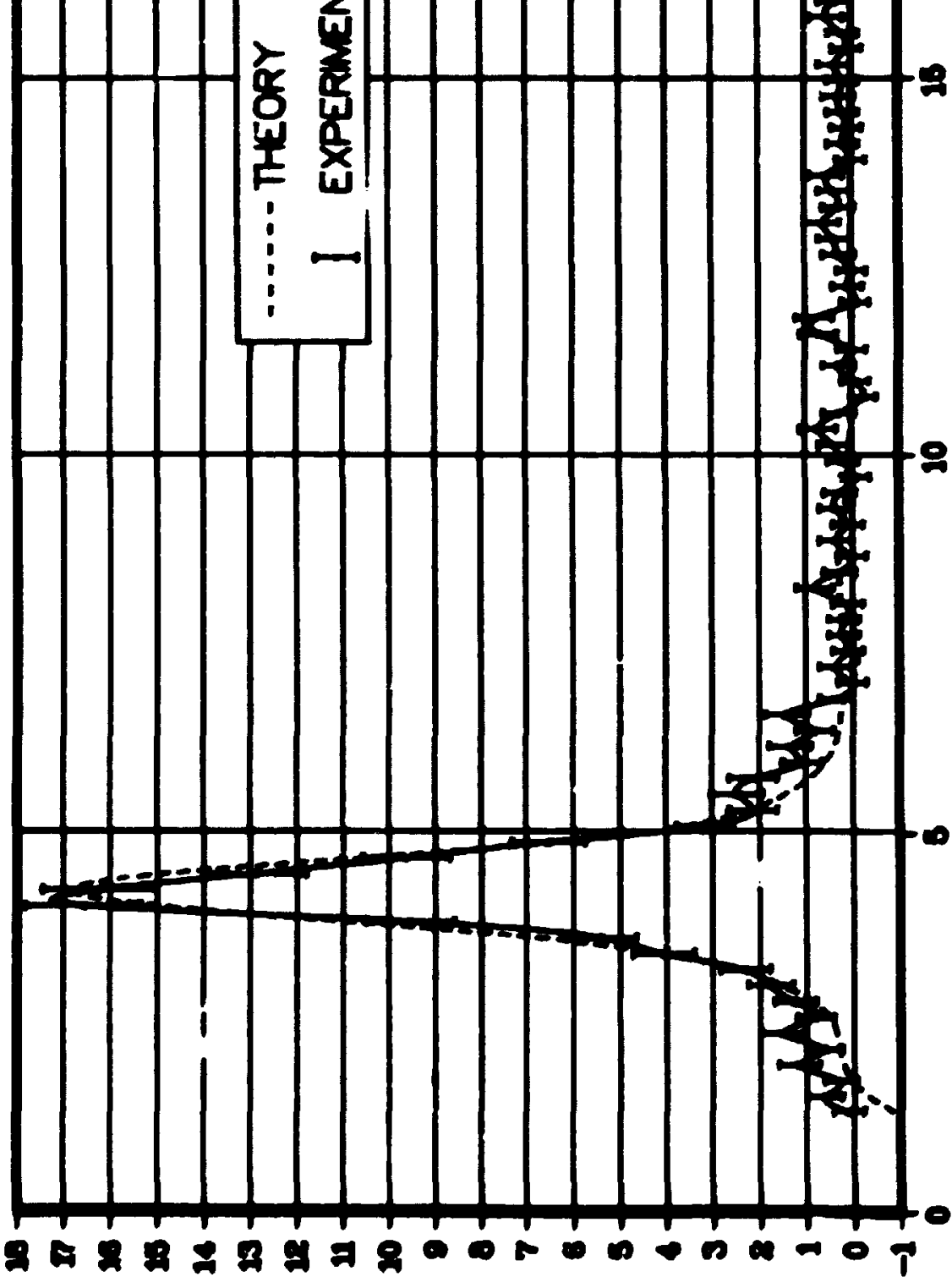

$\check{r i j}_{i}$

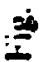

\section{RLIAILOV TAILVTE\& '}




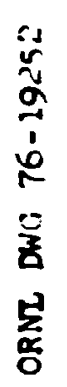

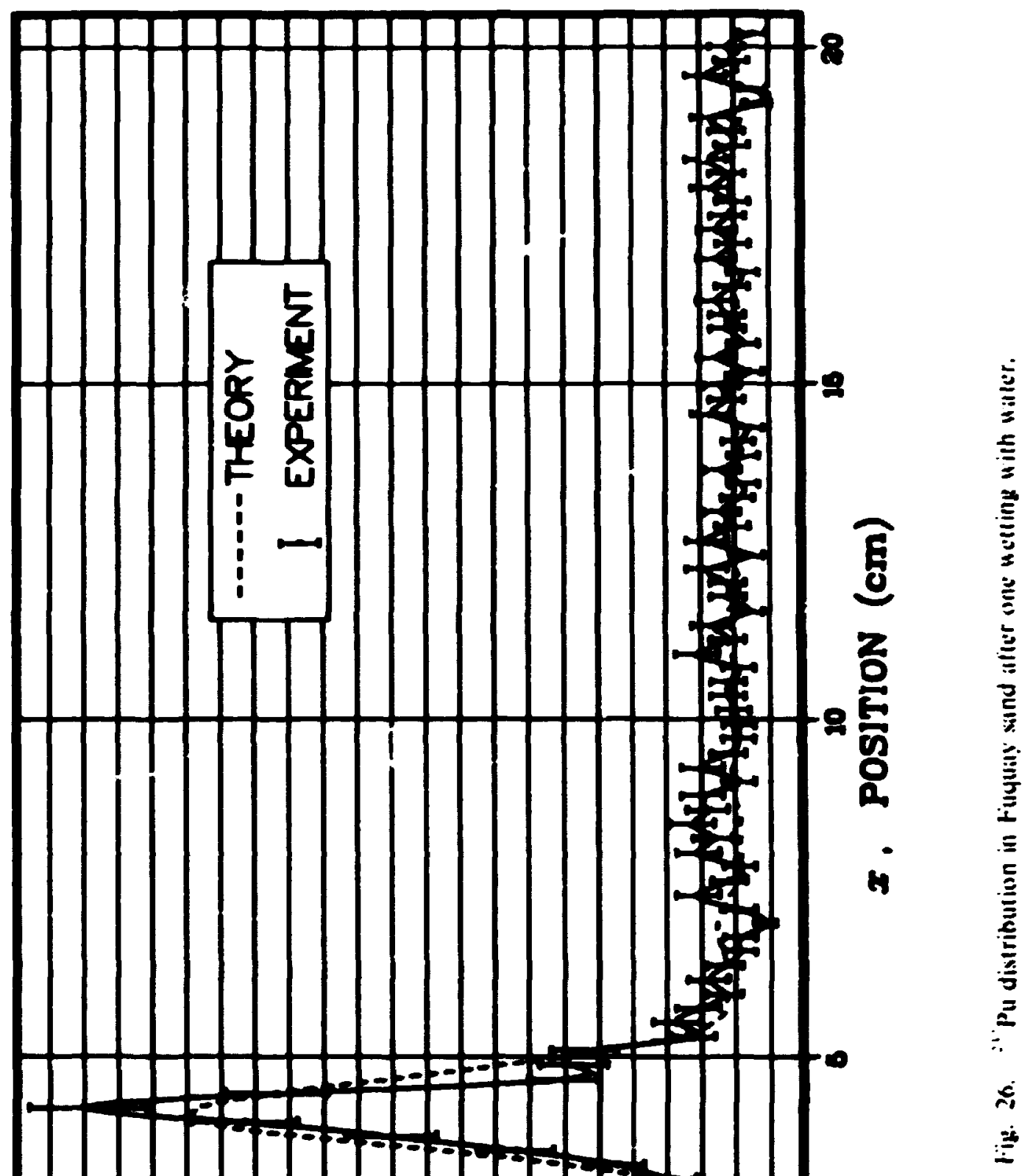

T89

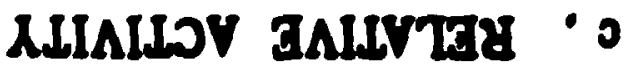


0
0
0
0
$\vdots$
0
0
$\vdots$
0
1
$\frac{1}{2}$
0
0
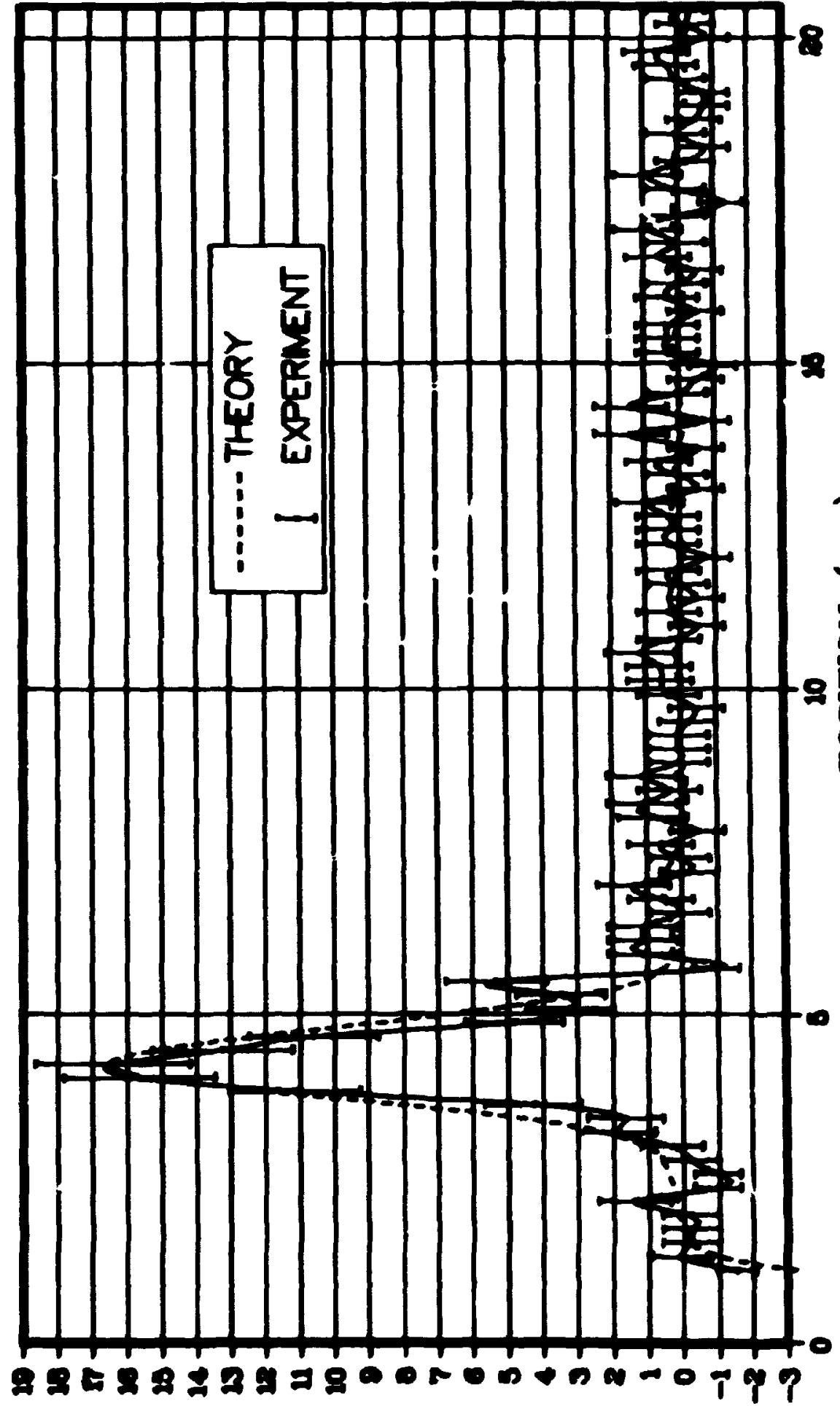

ALIALIOV EAILVTE\& ' 


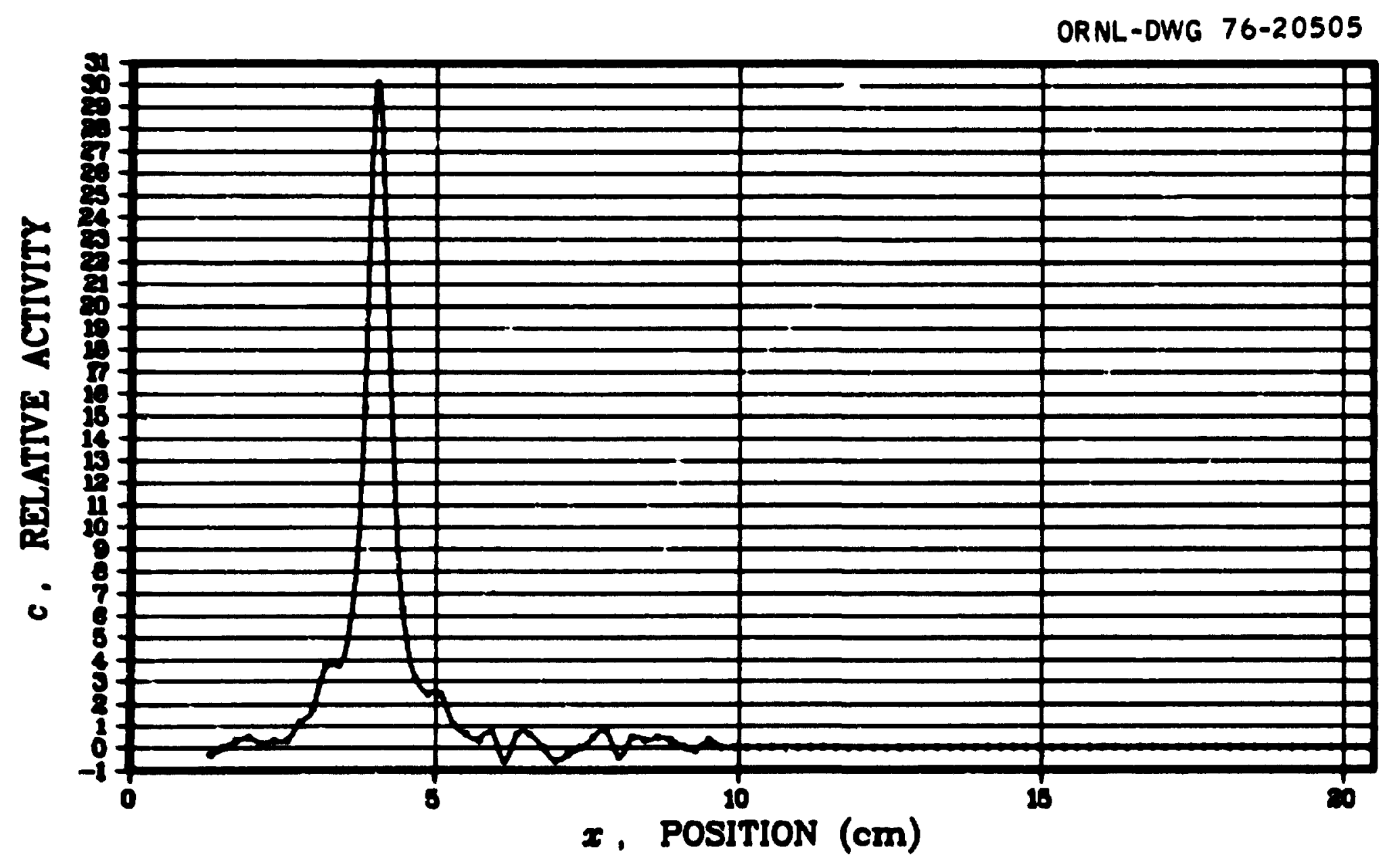

Fig. 28. "Sr distribution in Fuyualy simd directly aller sponting. 


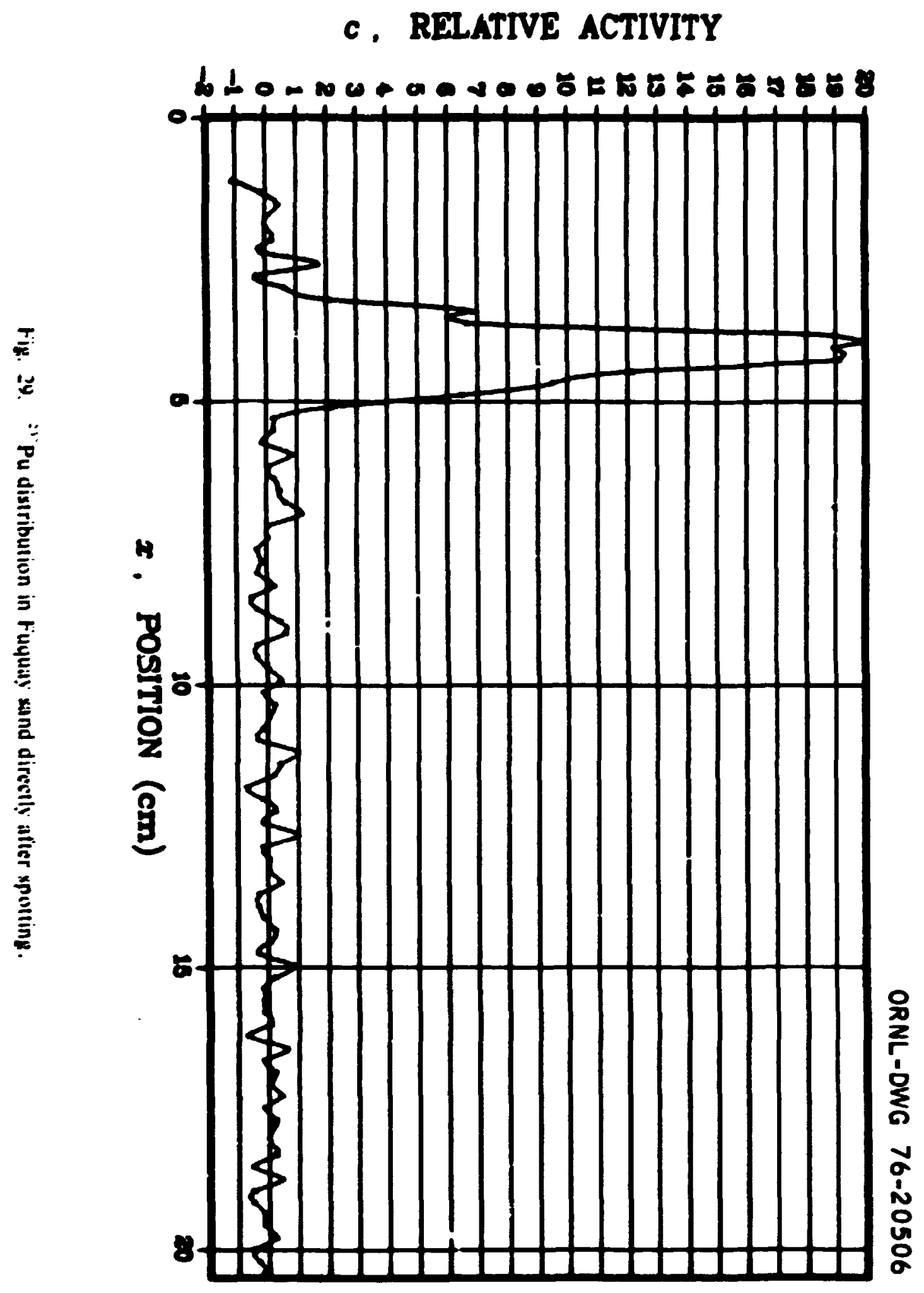




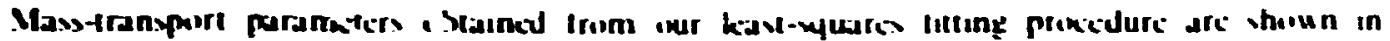

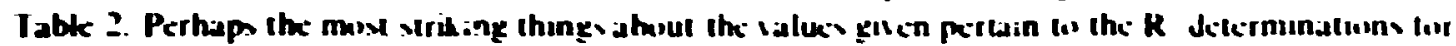

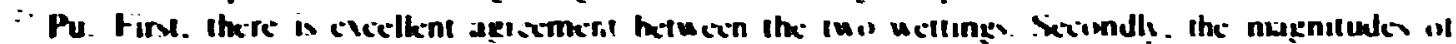

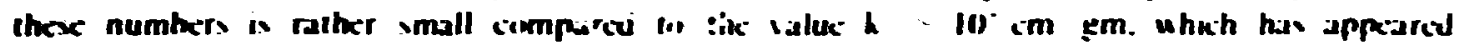

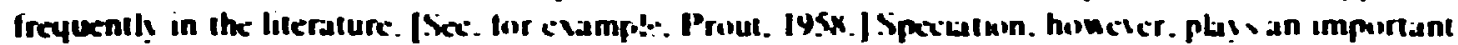

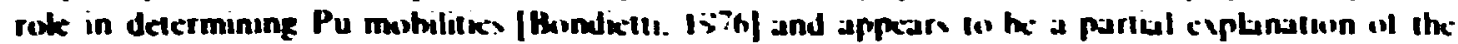

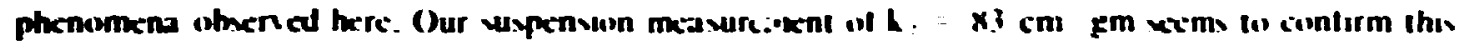

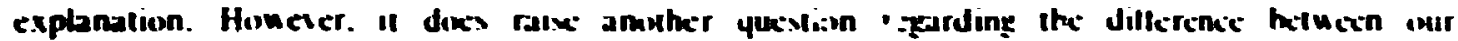

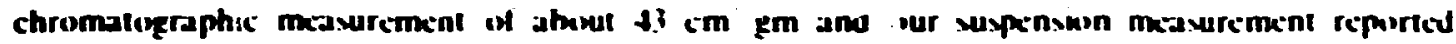

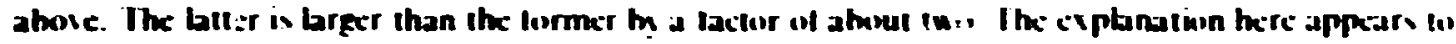

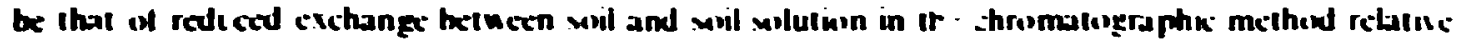
io the suspension method.

A similar point may he made regarding the chromalugeraje:ac measurements lur "Sir repurted in

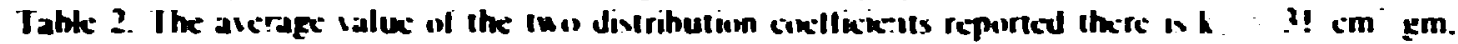

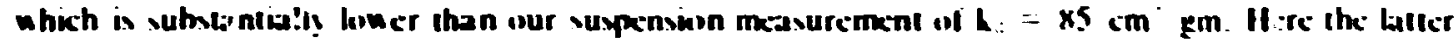

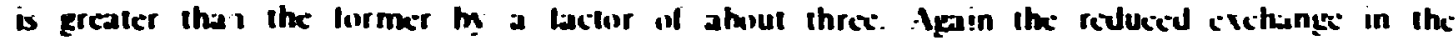

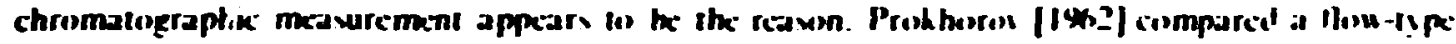

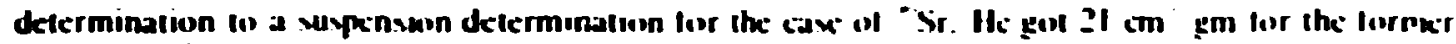

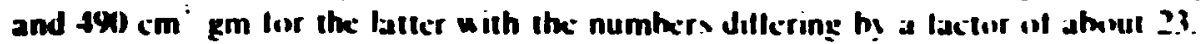

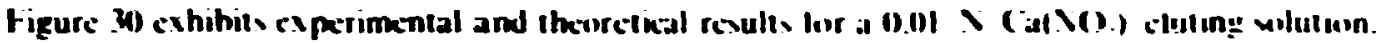
Experimentally the patk moves rather than heing distorfed. as was the cax when waller was the cluting agent. The theors. however. is unable to account for this mol ing prak. as nus be wen hy

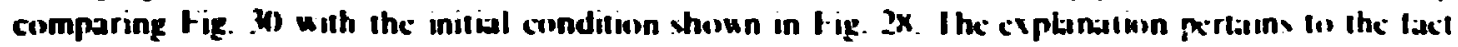

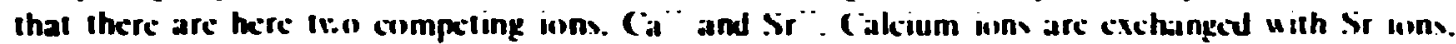

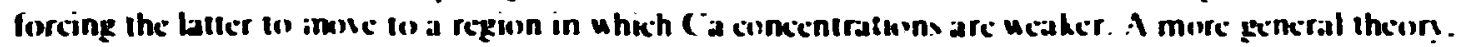
like that of Ruhir and Jame, [197.3]. is called ler here. 


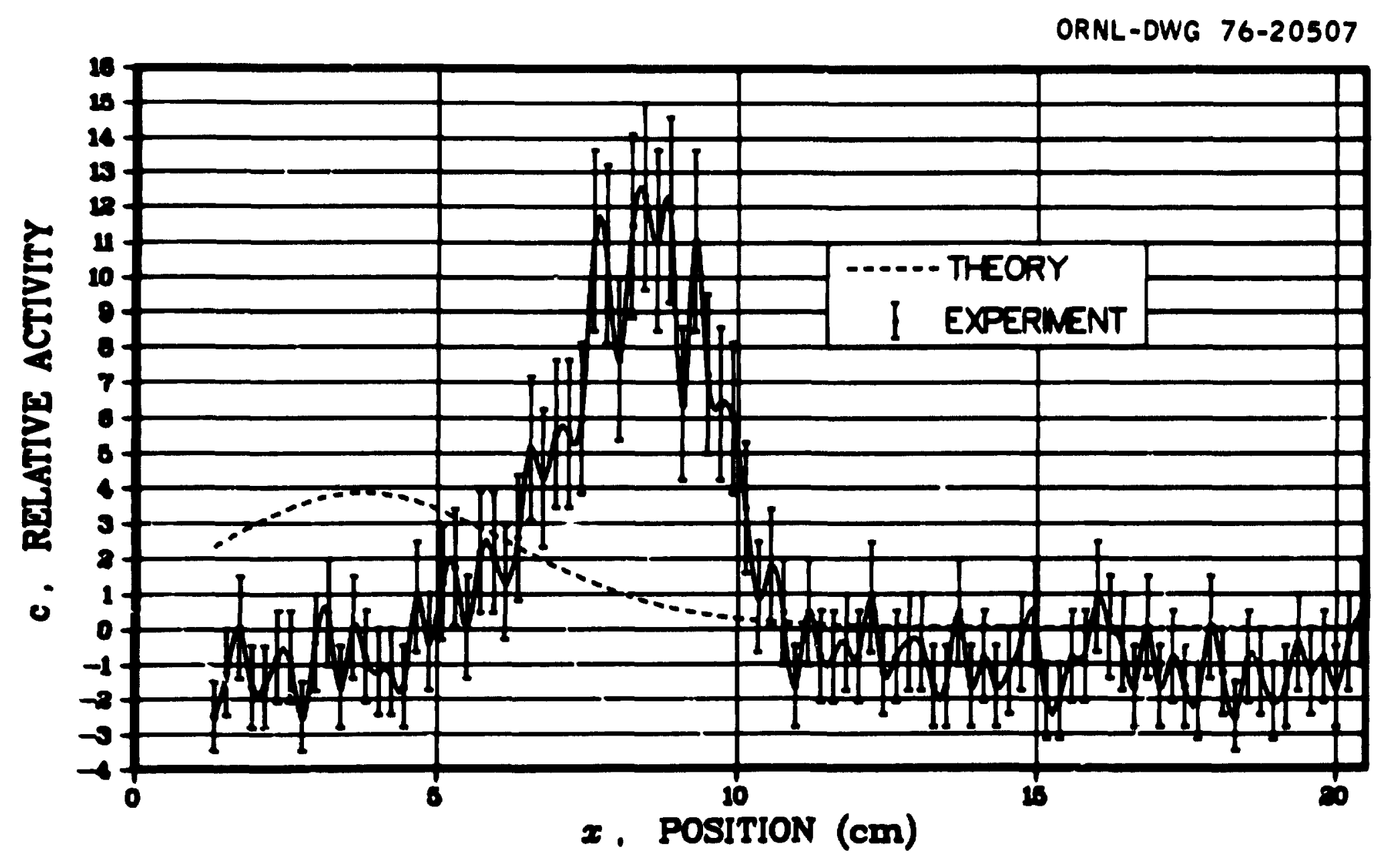

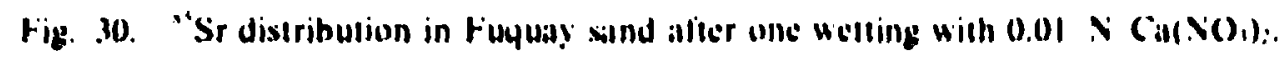




\section{CONCLUSIONS}

This report decuments our initial effort to yetantity soii chromatography. Fxperiementally. a radiochromatographic seanner coupled to a multichannel analy ret is employsed. I heese instruments provide the ress.jution. the setositivity. and the numeric output neciessan for computer analysis of the chromalogeraphic profiks.

Theorat:cally. the chromalographic eluting process is perceil ed as a couphed tlow of uater and at dissolsed constituent through a wil matrix. Siolution procedures for wolsing the appropriate transport eyuations are deteloped and implemented. The end product hete is a computer cinde copabte of automatically ana!yring the experimental data. This analysis consists in tilling the chromatographic profiles to determine seteral water-and mass-transport paramelers. ome of which is the distribution coefficient $k$ :-

The merit of the chromalographic method is that it simulates feid conditions more accurately than do other techniques. This is ven important for the determinition of the distribution coefficient. (hur results for "Sr and" Pu shou that the reduced exchange inherent in a thow-type situation leads (1) $k$ : values which are kower than consentional suspension measurements by factors of three and Iwii). respectively.

Finally the need for tuo refinements is noted. (me pertains to experimentai determination ot the water transport. From a preliminan investization it appears that a dissection method is the answer here. The other pertains is theoretical ascessment of competing cation:. In audition. a uider sariety of woils. including stabs of porous rocks. is desired. Future rewearch will fexcus on the'se areas. 


\section{NOTATION}

$d^{\circ}$

h.

h:.

Accekeration parameter (dimensionkess).

(2x2) matrix of integrals for th finite ekment (1.).

I.ongitudinal dispersis ity (1.).

Reductiun parameler (dimensionkss).

(2x2) matrix of integrals for r-th finite ekement (I. I).

Iirichket boundary condition for the concentration I.M I. ',

(2x2) matrix of integrals for $\mathrm{r}$-th linite ekment (I. I).

Assembly of all [.C] (I. I).

Concentration of the diswolied constituent (M I.').

Numeriral approximation to e (M I. ).

Bulk concentration including both dissolved and adworhed constituents (M I.').

Concentration at noxde i IM I. ).

(2x/) vector of concentration values at nodes of r-th ek'n!ent (.M I. ').

Vector of concentrations value at all nodes of the system (M I. ').

Hỵdrodỵnamic dispersion (1: 'T).

Pore-sire distribution index of the (jardner conductivity retation (dimensionless).

Pore-size distribution index of the King moisture-characteristic function (dimensiknkess).

Moisture-storage function (I. ').

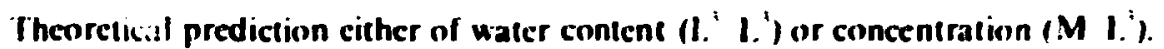

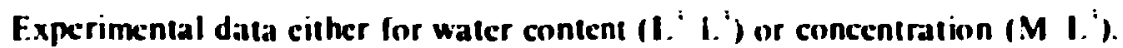

Transformed concentration (M I.').

Pressure head (I.).

Critical-pressure parameter of the Gardner conductivity relation (I.).

Critical-pressure parameter of the King moisture-characteristic function (1.).

Integral encountered in the relation $\left(\left(W_{1}\right)\left(T^{-} I^{-}\right)\right.$.

Integra' -neountered in the second-order solution of the water-transport equation (7).

Jacobian for transformation to local condinates (I.).

Hydraulic conductivity (I. T).

Saturated conductivity parameter of the (jardner conducitvity relation (1. T). $K(\theta=\theta).(1 . T)$. 


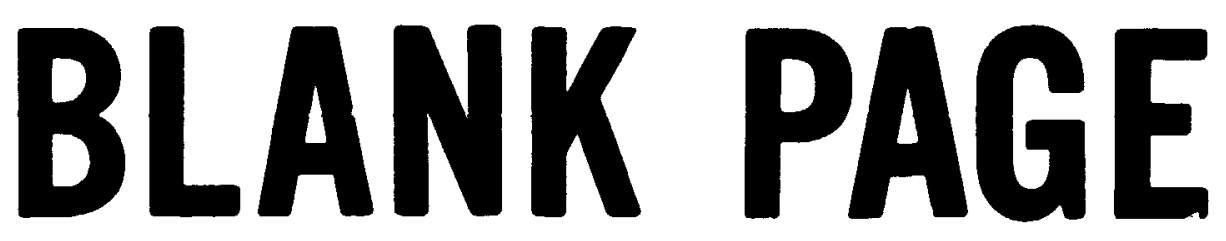




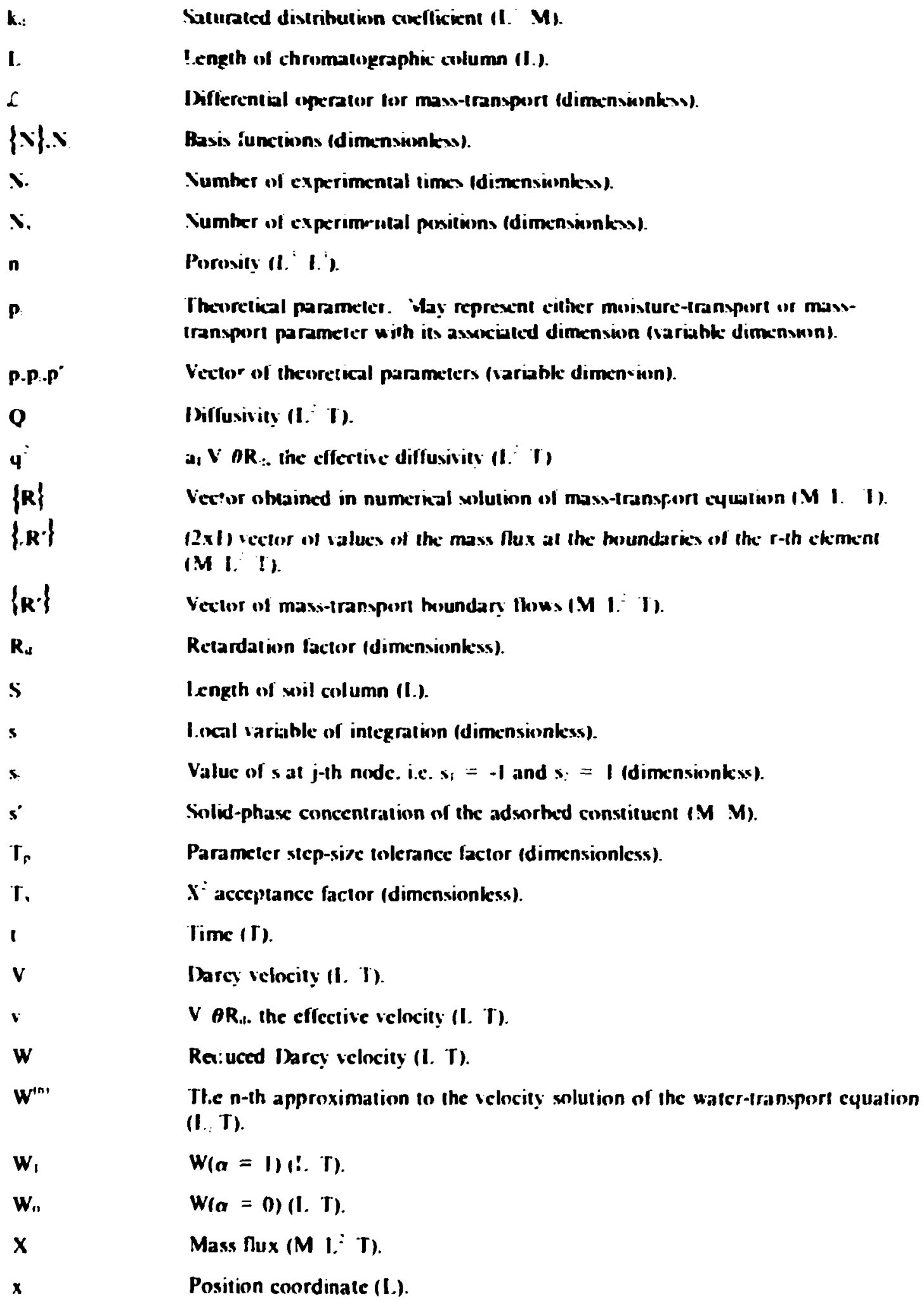


I

|vi

a $\beta$

$\boldsymbol{p}$

Ip

II

$\delta$

-

i

a.

a.

ต:

i)

$n$

A

A.

$\mu$

$\delta^{\circ}$

ค

$\sigma^{\circ}$

$x$

$\gamma$

$\infty$

a-
The $n$-th approsimalion to the positum shlutum of the aler-iranspon cyuation (1).

|R| $|R|$. vectore obtained in the numerical solutimn of the mass-transpert cyeation (M I: T).

Reduced water ctmient (dimensinnless).

Modified confficient of compressibility (1. ')

Parameter increment (variable dimensinon).

Time increment (T).

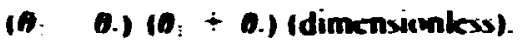

Angle of incination of the chromatograghic columa ( ).

Moisture content (1.' I. ').

Revidual mossture-content parameter 11.' I. ').

Initial muisture content (I.' I. ').

Boundan moisure content. cyual to the mortsity $n$ in this dexument (I.' I.').

Exprimental watet content (I." I.')

Reduced hydraulic conductivity (I. T).

Weca! constant it';

Figensalues of translormed mass-transport cyuation (I. ").

Transformation parameter (1 :).

(B). D) (0: + A) (dimensionless).

Bulk density of the medium (.M I. ').

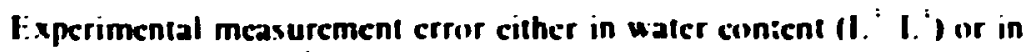
concentration (:M I. ').

Sum of weighted squarex of residuals hetucen cxperimenial and theoretical points (dime: ionless).

Parameter of the King moisture-characteristic function. taken (o) be rero in this documeni (dimensionless).

Time-integration parameter (dimerisiuniess).

Spatial freyuency for cigenfunctions of concentrations (I. "). 


\section{REFERENCES}

Bear. J.. Dinumies of Ficuids in Pesrous .Mediu. Amerian Elsevier Pubuishing Co., Inc.. 1972.

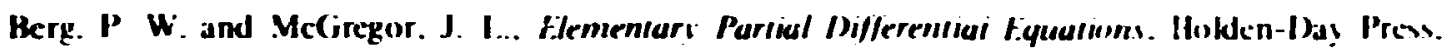
1966.

Bendictti. E. A. "Environmental Chemisery of Neptunium: Valence Stobulity and Sivil Reactions."

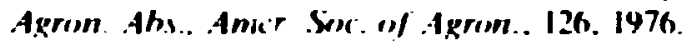

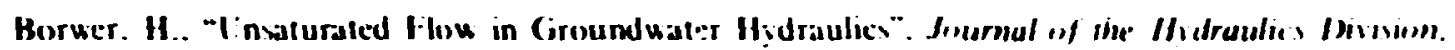
A.SC.. 90. HYS. 121-144, 194.

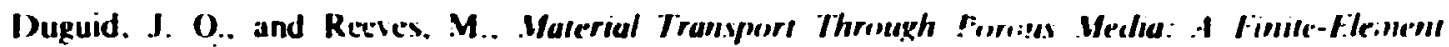

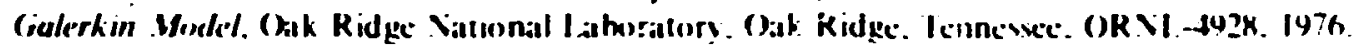

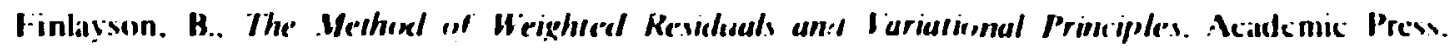
1972.

Gardner, W. R.. "Some Steady-State Solutions of the I nsilurated Movisture Flou Fyuatioti with

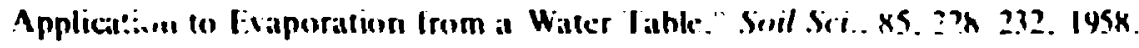

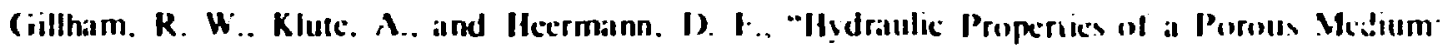

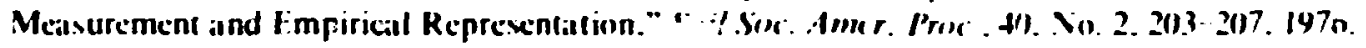

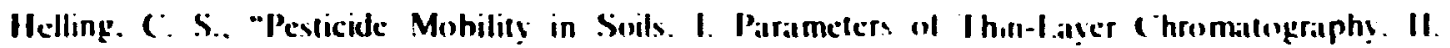

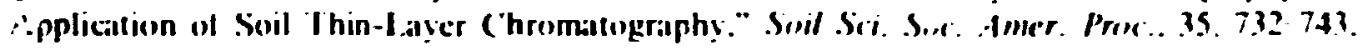
1971

Helling. (. S., and Tumer, B. C.. "P'sticid: Mohility: Ikelermination hy Siril !hin-latyer Chromalography." Sricence. 162. 562 56.3. 1968.

Hillel. D.. and van Bavs:. C. Hi. Ri. "Simulation of Profike Walter Storage as Relatted to Soil

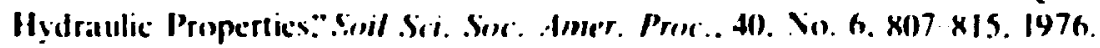

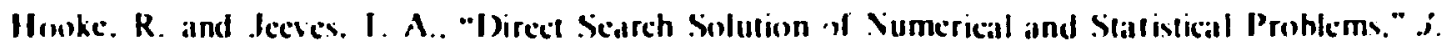
Assoc. (inmpl. Morh., X, 212-224. 1961.

King. I (;.. "I)escription of Soil Characteristics for Partially Saturated Flou. "Soil Si i. Sinc. Amer. Prow.. 24. 354 362. 1965.

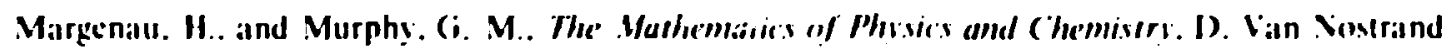
Company. Inc., 6-7. 19ah.

Vorsett. S. P.. "One-Step Metheds i Hermite Tỵpe for Numerical Integration of Stiff Sỵstems." BrI. 14. 6.1.77. 1979.

Parlange. J.-Y.. "Tneory of Water Motement in Soils: I. One-I Simensional Absorption," Soril Sici.. III. .1o. 2. 134 - 1.37. 1971 a.

Parlang:. I.-Y.. "Theors of Waller Mowe:nent in Sorils: 2. One-IDimen.ional Infileralion." Soril Sir.. !! I. . No. 3, 170-174. 197if. 


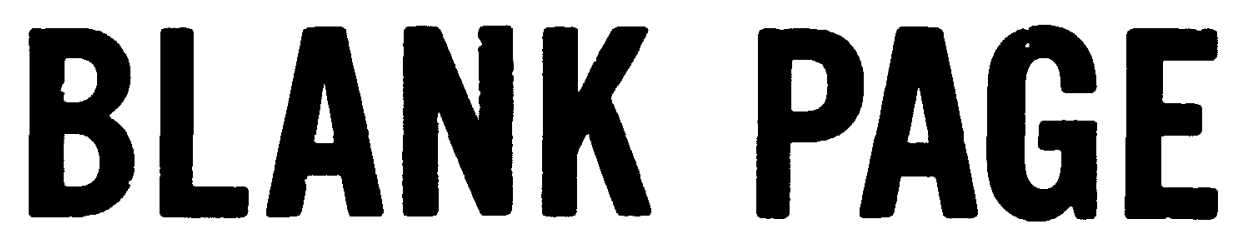


Parbunge. J.-Y.. and Aylor. D.. -Theory of Water Mosement in Soils: 9. The Dỵnamics of Capillary Rixc." Sevil Sici. 114. .o. 4. 70-xI. 1972.

Phillip. J. R., Theory of Infilt:ation." Ach: in H!drosei.. 5. 215-305. 1969.

Phillip. J. R., -The Theory of Infiltration: I." Sisil Sci., 83, 345-351. 1957.

Prokhorov. V. M.. -Diffusion of "Sr in Soil and Sand," Sivivet Radiuchemistr!. 4. 183-188. I962.

Prout. W. E., -Adsorption of Radioactive Wastes bỵ Savannah River Plant Soil." Sivil Sci.. \$6. 13-17, 1958.

Reeves. M., and Duguid. J. O., Water M.nement through Saturated-Cinsalurated Porrous Media: A finire Ekement Galerkin Miockel. Oak Ridge lational Laboratory. Oak Ridge. Tennessec. ORNL-4927, 1975.

Rhodes. R. C.. Belasco. I. J.. and Pease. H. I... "Letermination of Mobility and Adsorption of Agrichemicals on Soiks." J. Agr. Fined Chem.. IX. 524-52K. 1970.

Rubin. J. and James, R. V.. -Dispersion-Affected Transport of Reacting Solutes in Saturated Porous Media: Gakerkin Method Applied to Eyuilibrium-Controikd Exchange in Unidirectional Steady Water Flow." Woter Resour. Res., 9. No. 5. 1332-1356.

Weisman. J., and Wood. C. F., "The Use of Optimal Search for Engineering Design." in Recent Advanres in Oprimizarion Terhniques. A. I.evi and T. P. Vogel (edilors). 219-228. I966.

Westley. G. W., and Watts, J. A., The Compuling Technology Cenier Numerical Analysis Lihrarr. Union Carbide Corporation, Nuclear Division, Oak Ridge. Tennessee, CTC-39, 1970. 
APPENDIX A

EXAMPLE CALCULATION: ${ }^{37}$ Pu IN FUQUAY SAND 
INPUT 


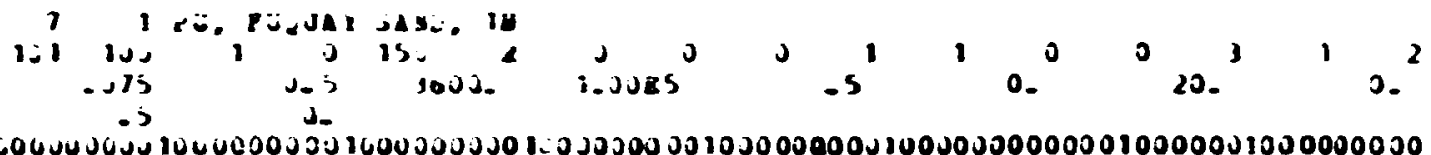

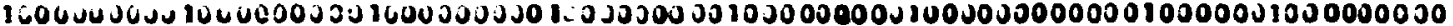

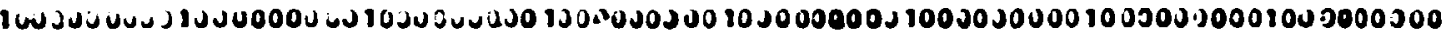

1.525
1.525
1.205
4.415
6.565
0.245
9.125
11.005
11.145
14.965
10.645
12.125
20.005
21.695
2.190
11.190
11.190
1.190
1.190
2.190
1.190
0.190
1.190
-0.810
1.190
-2.810
-5.810
0.

1.735
3.615
5.395
6.775

1.947

5.303

6.983

a.663

10.135

11.015

11.695

15. 175

16 .es5

18.535

20.215

21.095

0.190

16. 190

11. 190

3.190

$-2.810$

$-0.010$

$-3.410$

2. 19

1.19

1.151

$-2.810$

$-1.010$

$-5.810$

2.663
10.343

12.023

13.703

15. 34,

12.000

10.705

20.423

0.190

35 190

1.190

6.190

$-1.010$

1.850

$-0.010$

$-1.010$

-0.esa

0.190

2.180

$-0.010$

0.

2. 155

1.035

5.515

7. 195

d. 075

10.555

12235

13.915

15. 595

17.275

18. 955

20.635

1. 190

100. 190

1. 190

0.190

2. 190

0. 190

1.190

$-1.010$

$-0.810$

2. 190

$-2.010$

$-3.010$
$2-305$
-005

5.725

7.005

1.005

10.765

12.045

14.125

15.805

11.

17.165

20.845

$-0.810$

190.190

$-0.810$

0.180

3.190

$-0.810$

$-0.010$

$-0.810$

$-0.810$

$-0.810$

$-2.810$

$-3.810$
2. 575

0.255

5.935

J.615

9.295

10.975

12.055

14. 335

16.015

17.695

19.375

21.055

9.190

101.190

4.190

$-1.810$

$-1.810$

$-1.810$

S. 190

1. 190

0.190

1.190

$-9.810$

$-5.810$

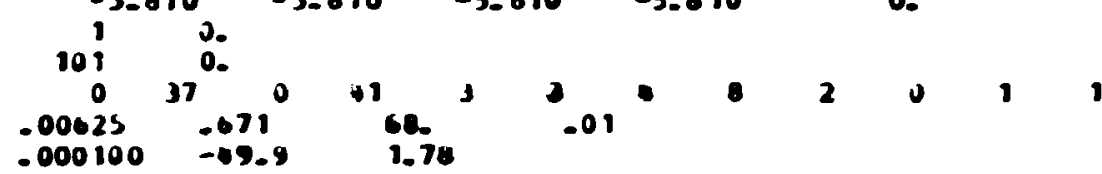

$\begin{array}{lll}.000100 & -09.9 & 1.74 \\ .000347 & -23.2 & -.419\end{array}$

$$
10 .
$$

90.

i.

20.

-1
.9

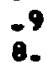

600.

1.5 1700.

30

20.

2.

9.

200. 900 .

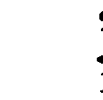

so.

3.

200.

1000.

0.000397

$0.04191^{1.5-10} 0.0625-100.11$

60.
.5
9.

300.

70.

5.6

80.

.7

400. 500 .

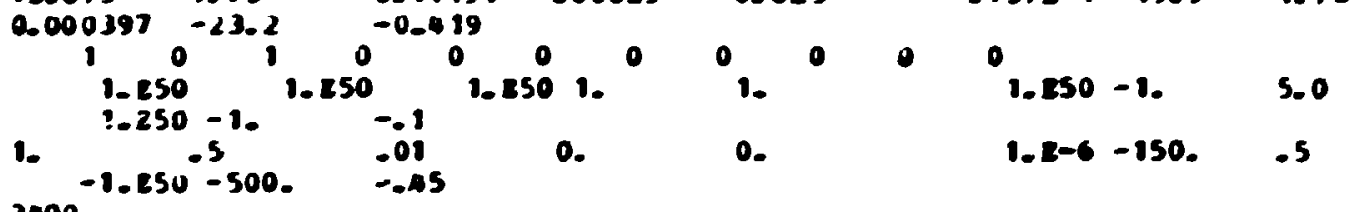

2400.

92

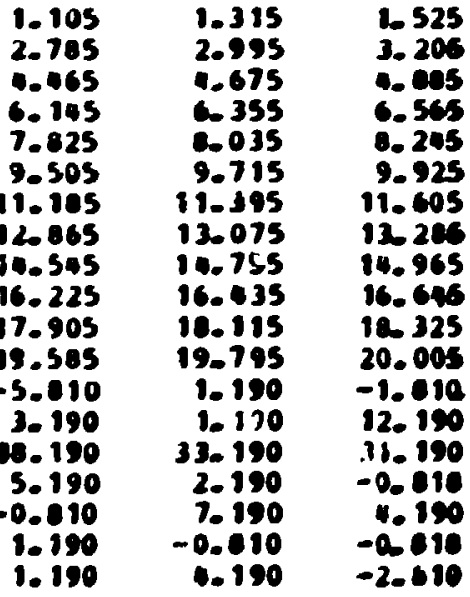

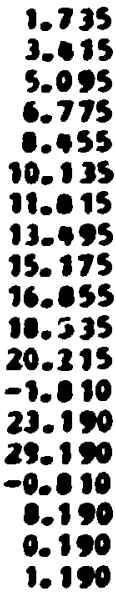

6.995
3.625
5.305
6.905
6.605
10.395
12.025
13.705
15.305
17.055
12.795
1.190
12.180
0.190
-5.010
5.190
1.190
1.190

2. 155

2.365

2.575

$3.035 \quad 0.005$

5.515

7.195

co7s

10.555

12.235

13.915

15. 595

17.275

10.955

5.725

7. 605

9.005

10.765

12.445

14. 125

15.005

17. 65

19.165

5.935

7.615

9.295

10.975

12.655

14.335

16.015

17.695

19.375

-1.110
6.190
11.190
-0.6180
6.190
1.190
5.190

2. 190

$-0.810$

94.180

7.190

124.190

7. 180

2. 190

$-0.010$

1.190

$-0.010$

6.190

$-2.010$

5.190 


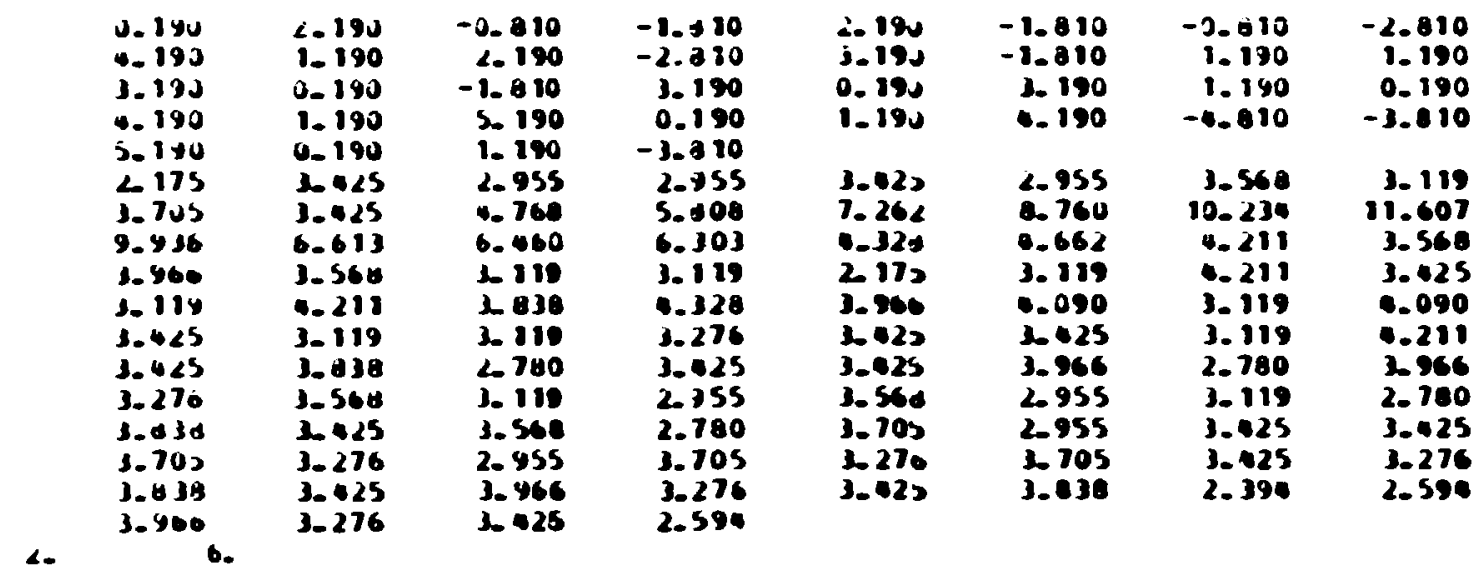


$\because:$

OUTPUT 


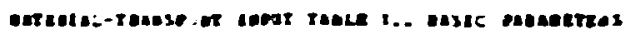

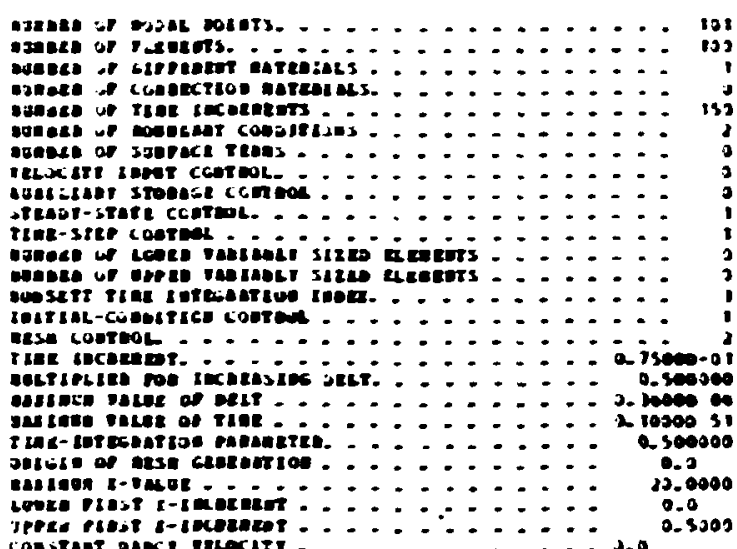

$00 t e 05 \cos 20 L$

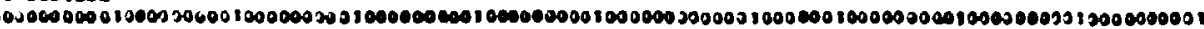

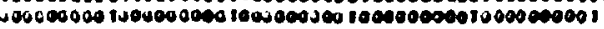

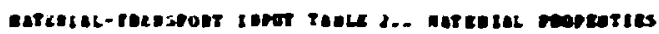

ant. w.

I0

0.0

0.04

rectan

$0.0^{\infty 02}$

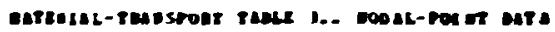

\begin{tabular}{|c|c|}
\hline wot & $\mathbf{I}$ \\
\hline 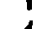 & Q-inese ol \\
\hline 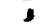 & 0.01940 ol \\
\hline & $\begin{array}{l}0.73150 \\
01 \\
0-37350\end{array}$ \\
\hline 1 & $\begin{array}{lll}0-19450 & 01 \\
0-21558 & 01\end{array}$ \\
\hline 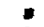 & u.disso ol \\
\hline 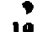 & 0.25750 ol \\
\hline 11 & D.cesso a \\
\hline 18 & 0.jusose ar \\
\hline (1) & 0.1013001 \\
\hline 16 & 4 - 20250 : \\
\hline 10. & 0.0005001 \\
\hline 30 & 0.0135001 \\
\hline
\end{tabular}




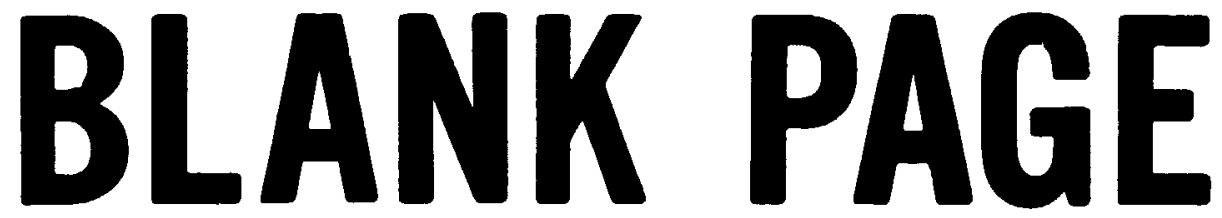




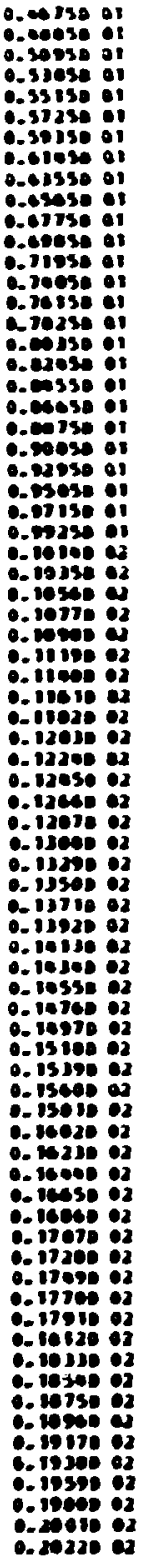



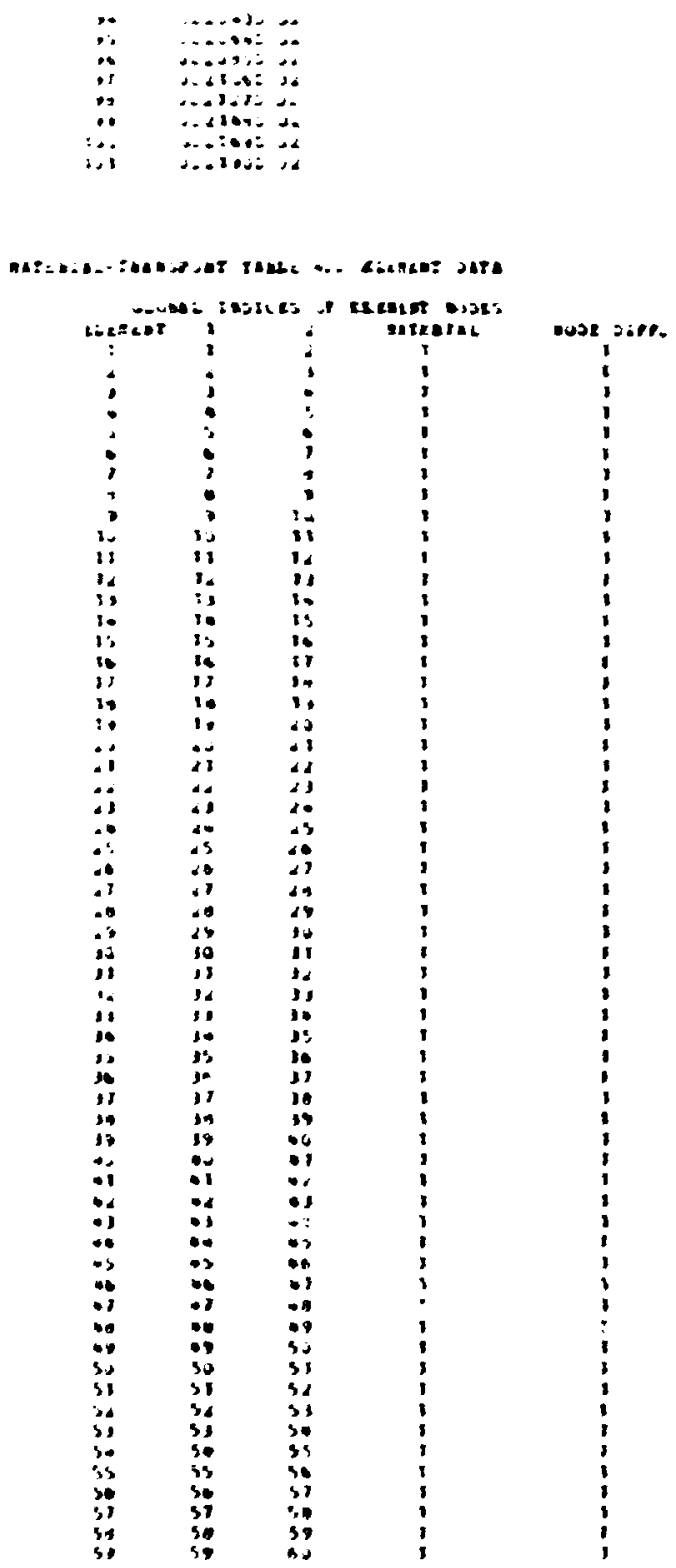


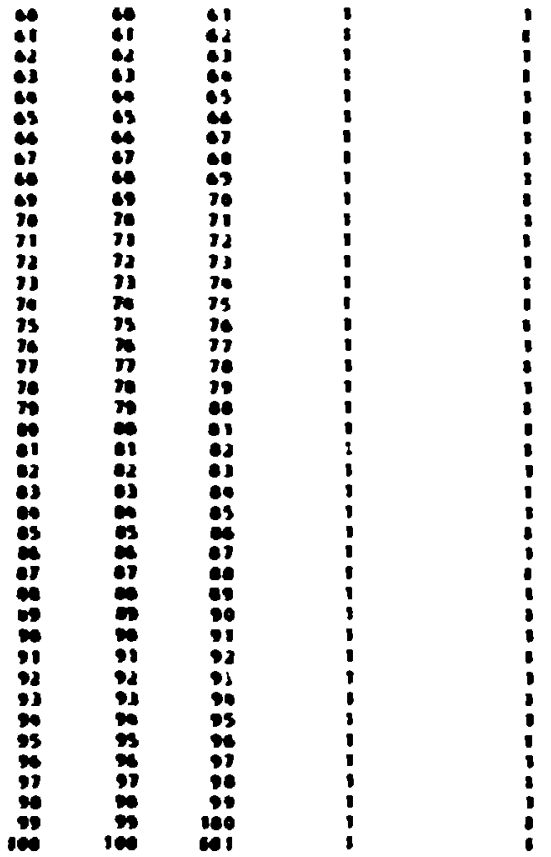

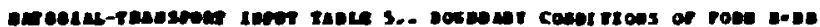

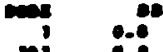

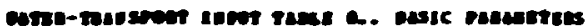

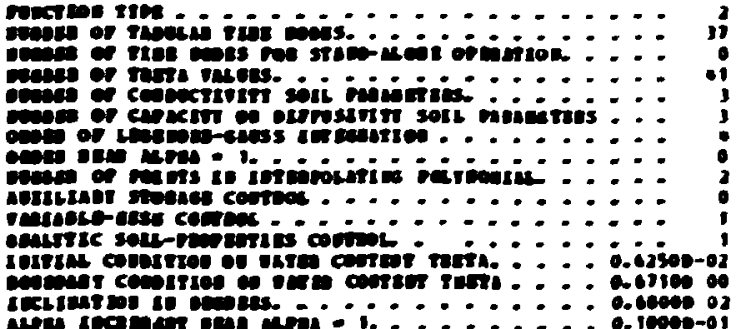

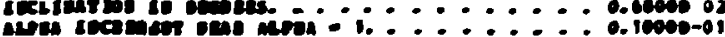

104:

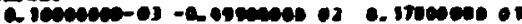




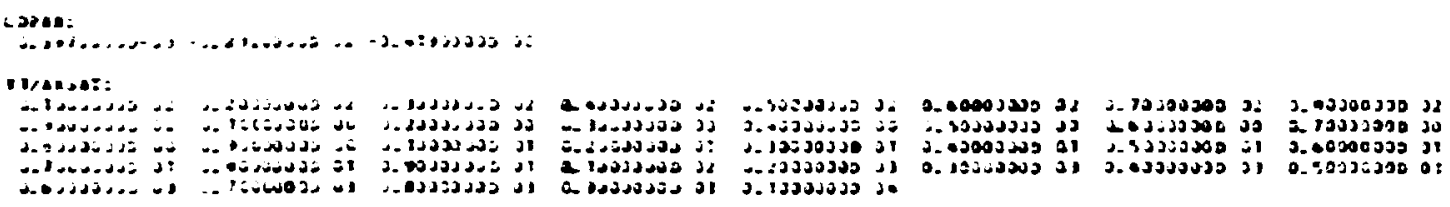

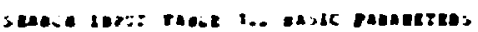

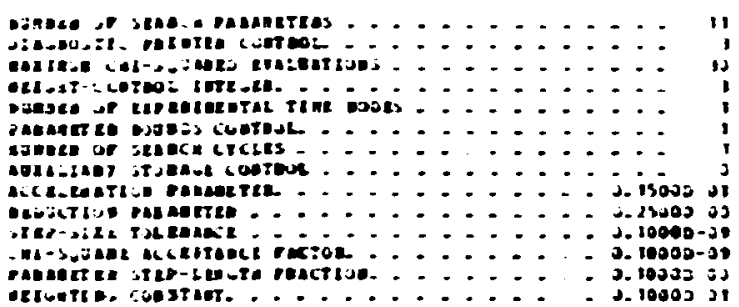

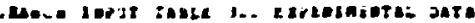

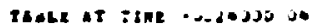

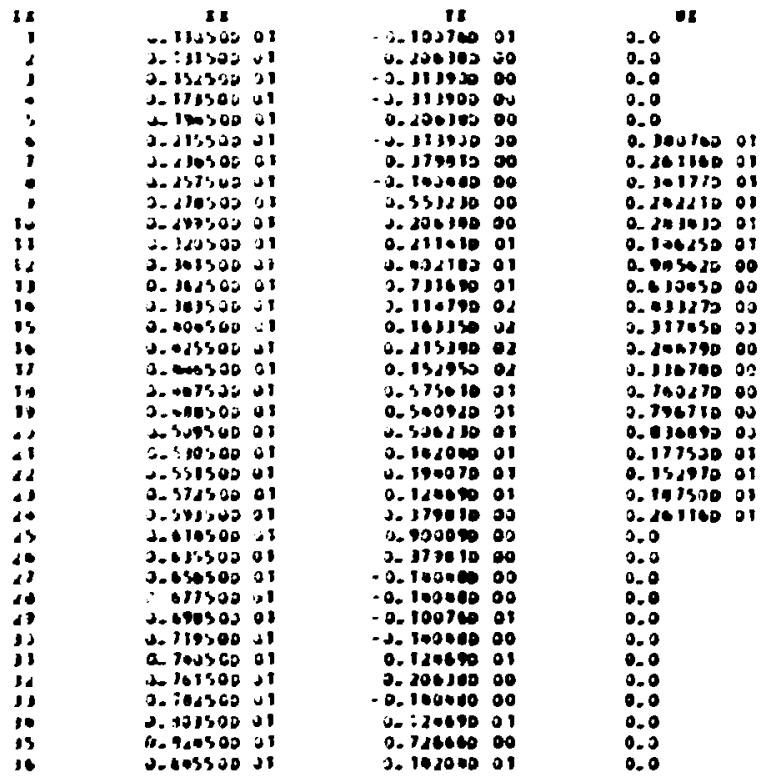




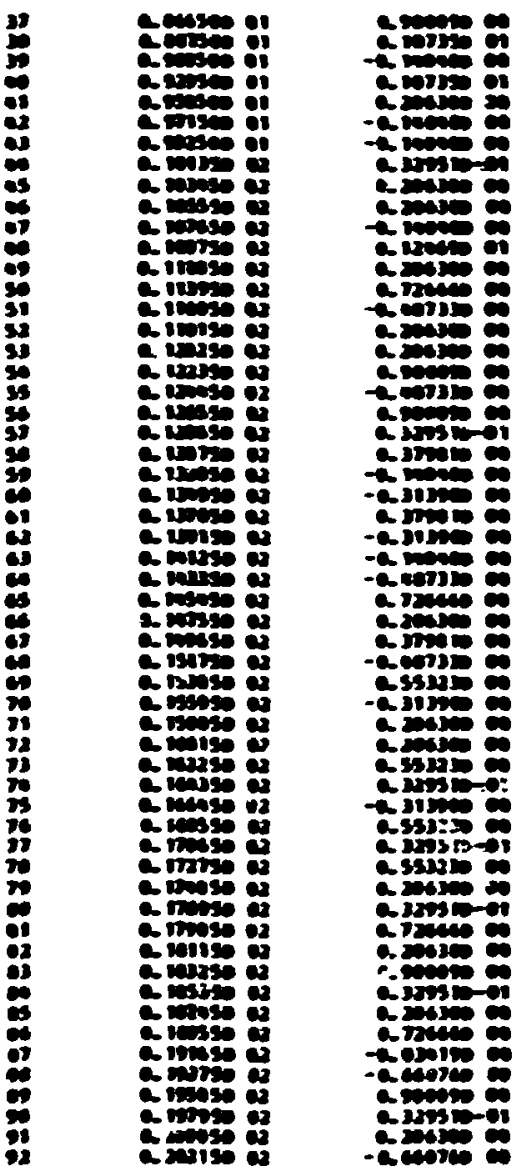

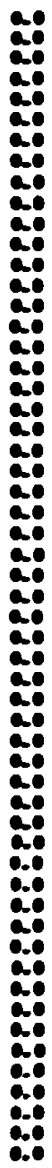

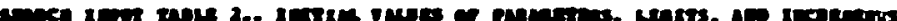
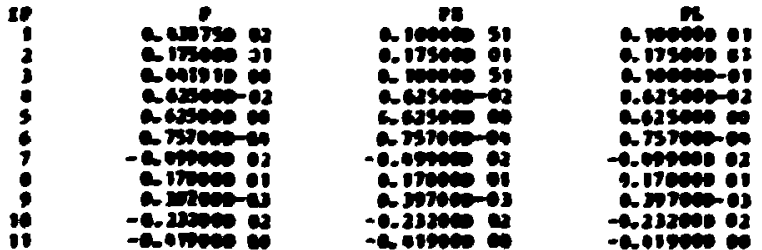

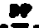

ise of arsese atsentas

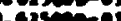
ascos

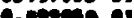

a.

0.

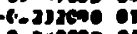
$-001960$ 


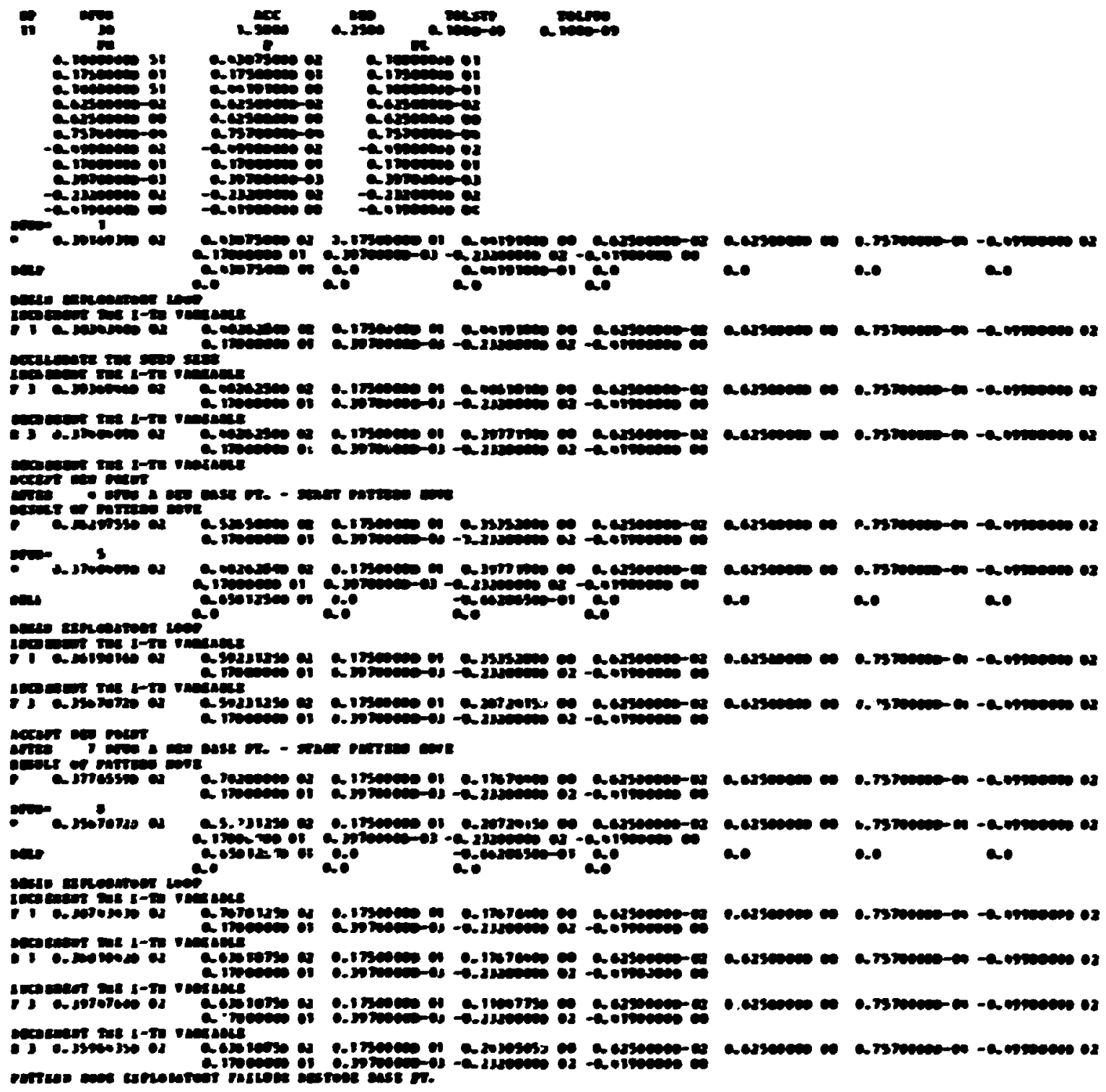




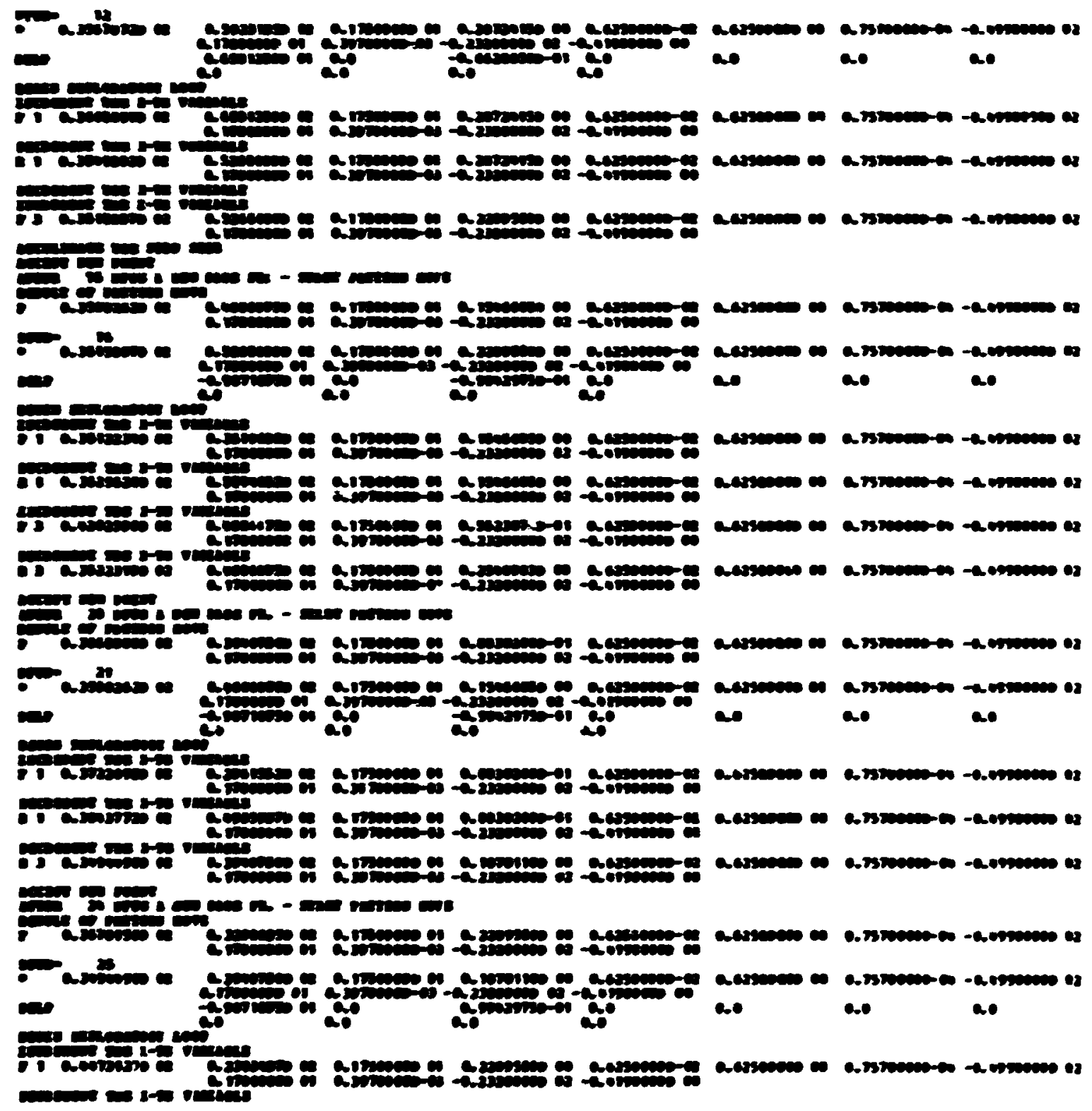




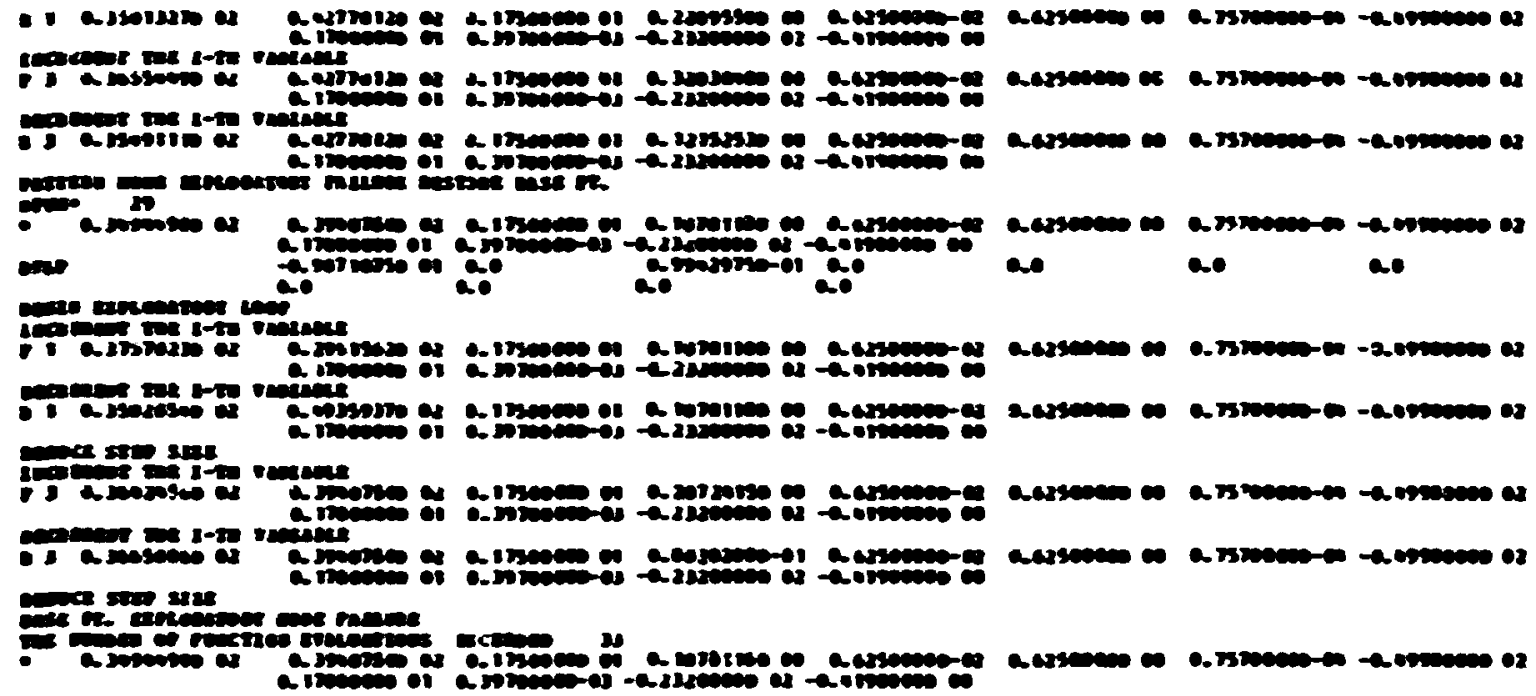

25

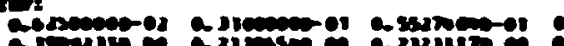

-

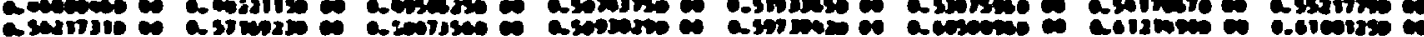

arinos 1

as:

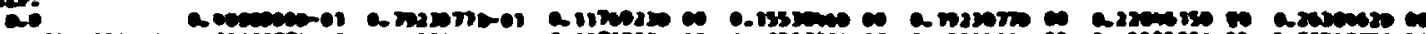

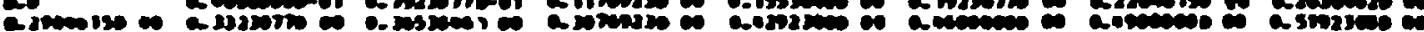

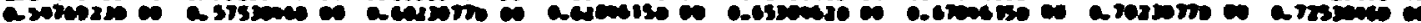

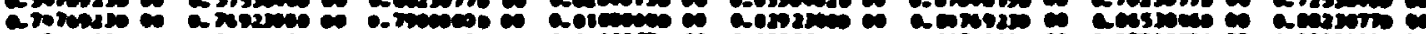

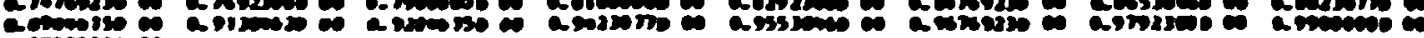
-

"

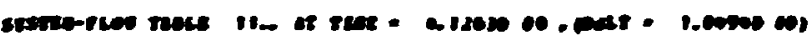

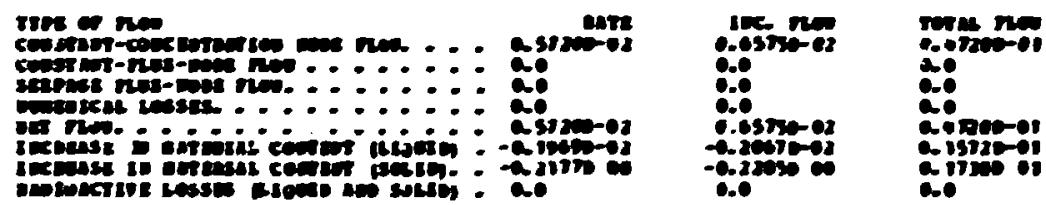




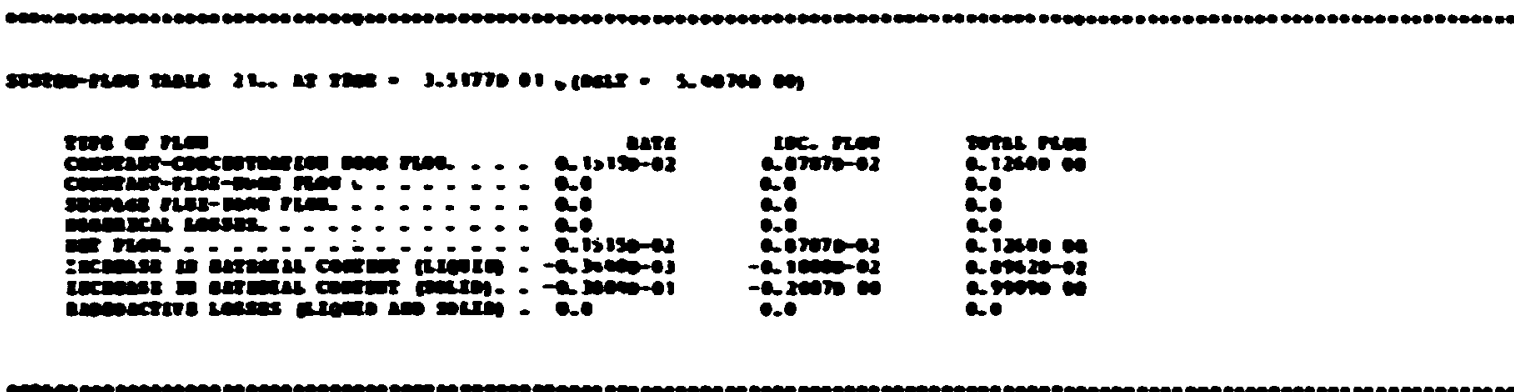

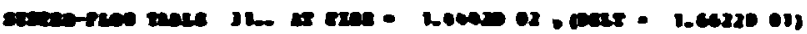

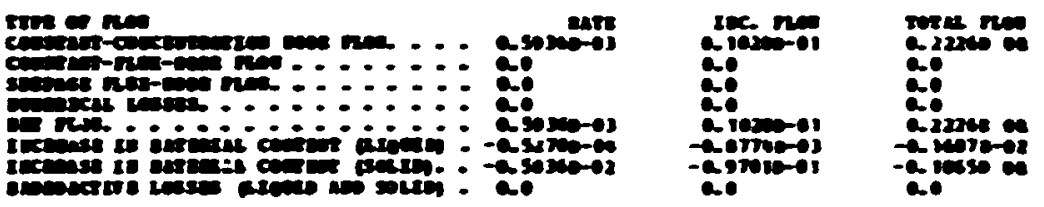

C60.1

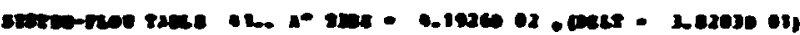

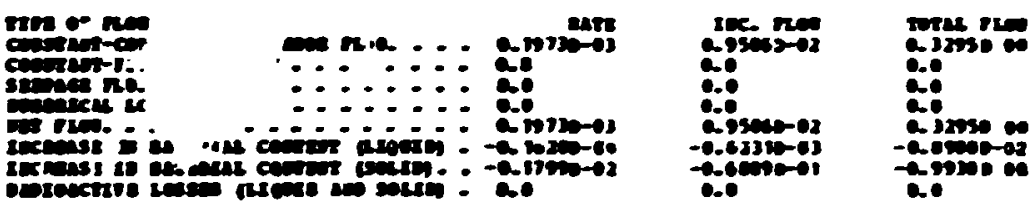

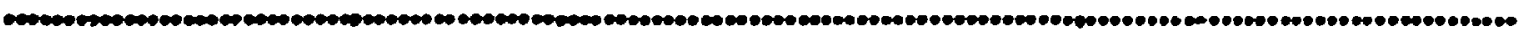

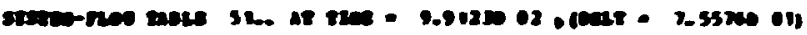

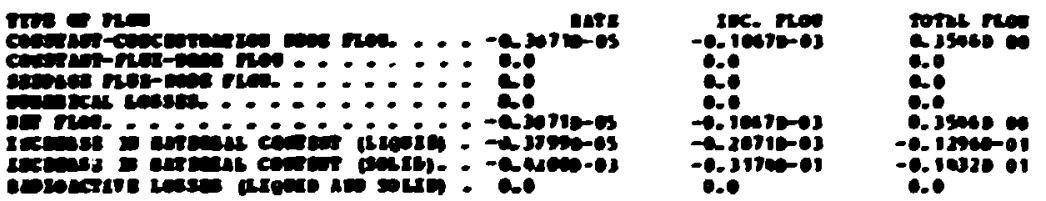




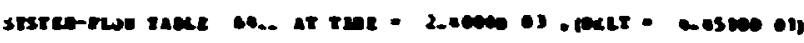

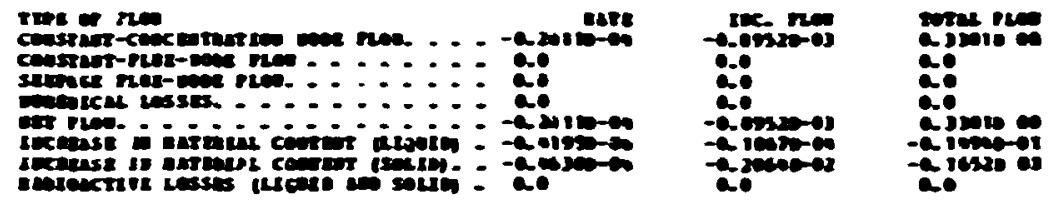

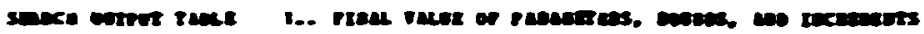

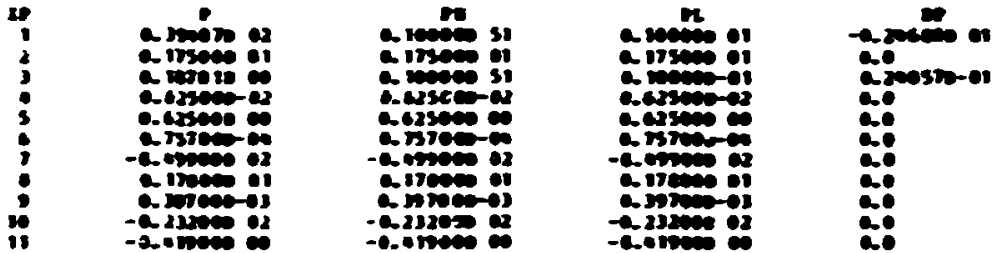

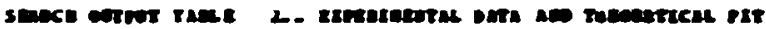

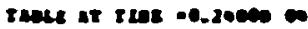

II

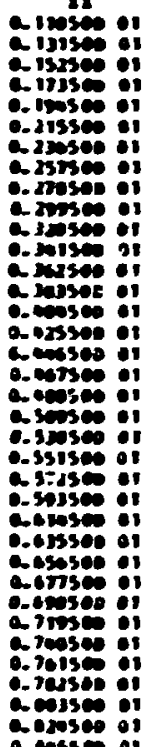

82

- 6007 es

-1esice

-

arsecte

- 61336

c invere 0

- 10eve

C5sB220

- zesies o

c 2110

a.9210 os

a Miser

a inres

- 16j3se a

- issies a

a isnso

e smeszo or

asscass

- 10xans

- 19607.

- izeste

a bis

a 17ve

a. Brever

- Livenes

- iostes

- el iodes

- 1206s of

a iesses

- iebes

- 1zeses

o. riveses es

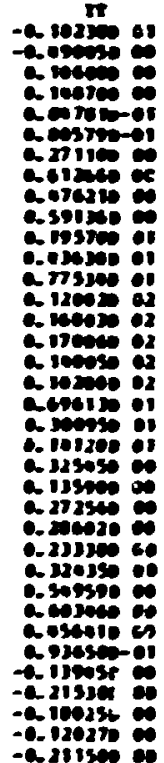

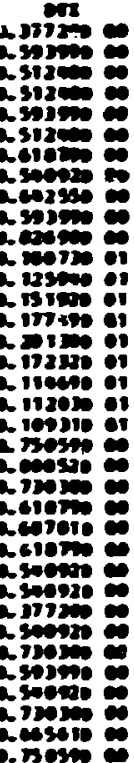



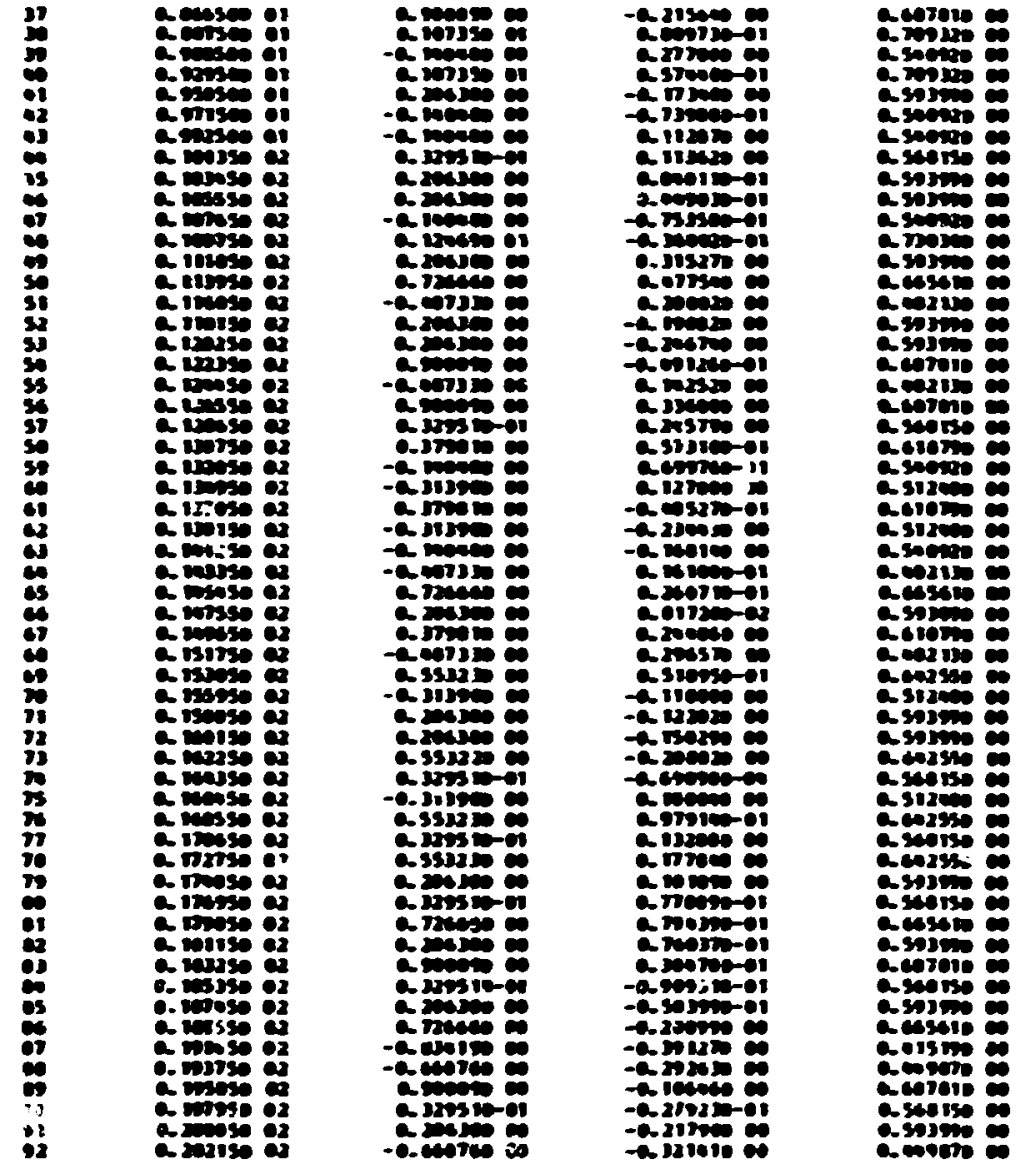

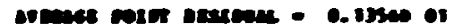




\section{APPENDIX B}

\section{LISTING OF THE COMPUTER PROGRAM}


BLOCK DATA

AII

aAII

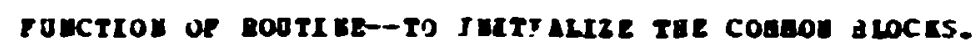

ari 10

IAPLICIT REAL+8 (A-B,0-2)

REALEQ PALT

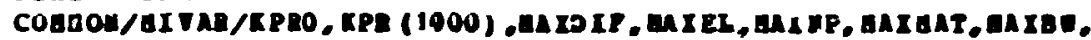

GAID 15

DAII 20

I GAIm I. IAPPE

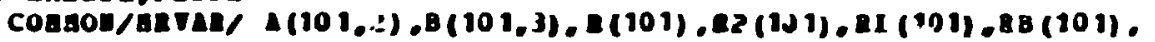

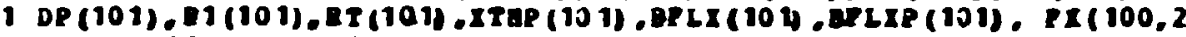

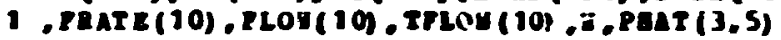

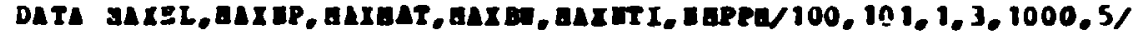

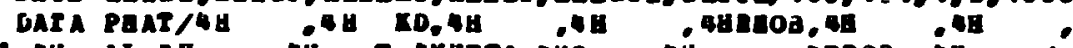

IED

AAIU 25

aAI 30

GAII 35

anI 40

Mais 4

anE 50

BAII 55

aId 60

gare 65

aId 70

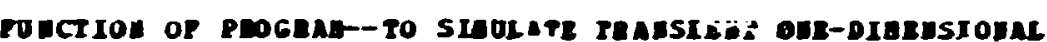

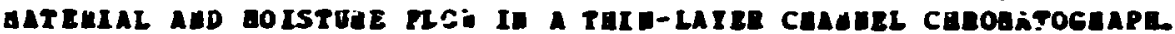

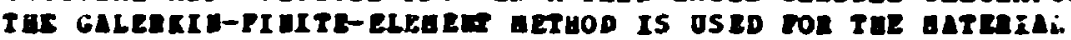

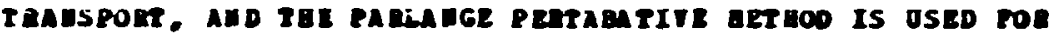
tae dorstóe raAusport.

\section{DIAEMSIOUI UG PORALT-}

\section{COARCD/PEOBI D/TITLE(B), APAOB}

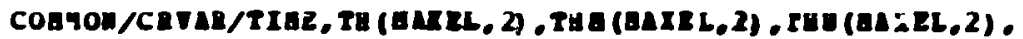

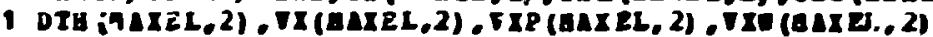

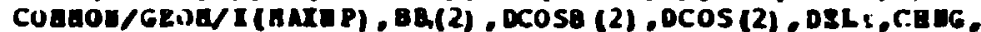

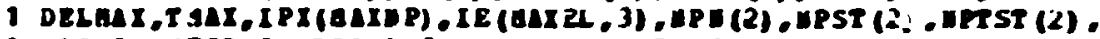

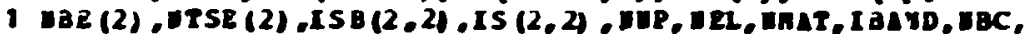

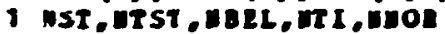

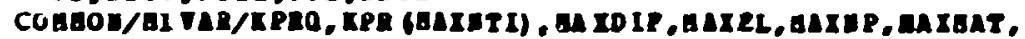

1 IAXBE, AL IITI I BAPP G

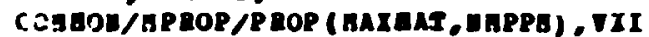

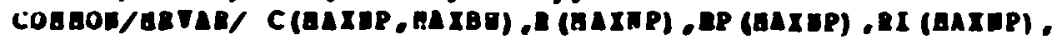

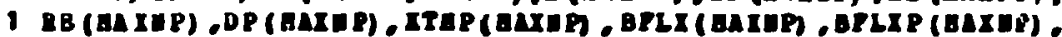

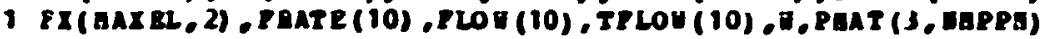

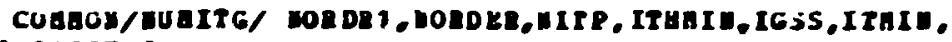

1 IGSST (3)

COBAON/TR LX/TTAB(AXTTAB, , TIIAXTTAB, , TTAB(AXTTAB) .

1 UTAB (AXTTAB) , OTAB (AXTTAB) , TTABL (GITTAB) ,UITABL(GXTTAB) .

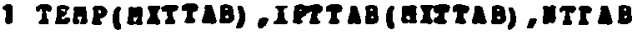

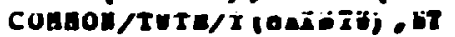

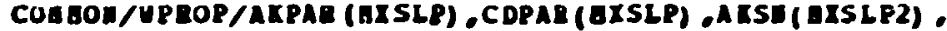

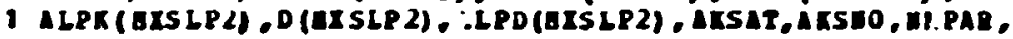

1 URSP, ECDPAR, DDSP

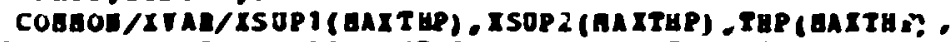

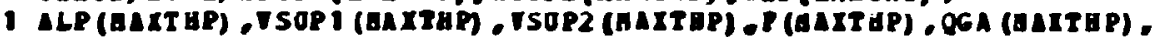

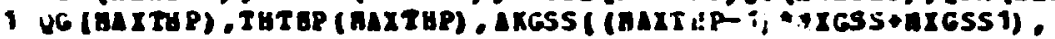

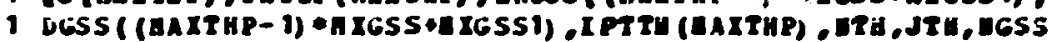

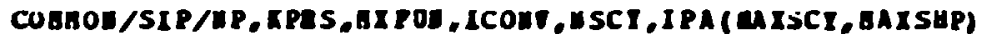

CUEHOK/SEP/ DELTO, CAISO,ACC,RED, TOLSTP, TOLPUN,PO (AAXSAP).

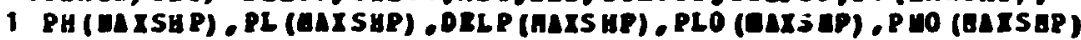

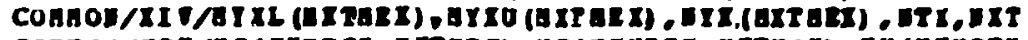

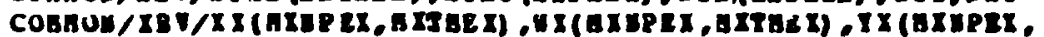

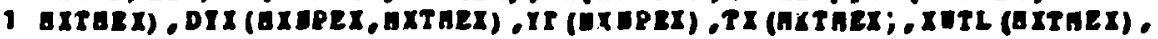

1 xuto (nxtari)

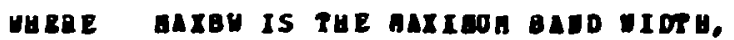

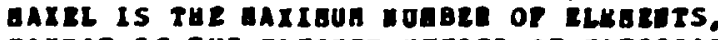

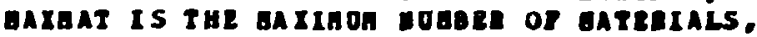

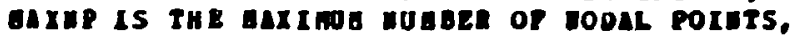

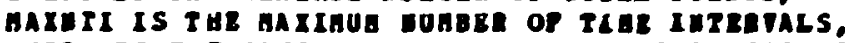

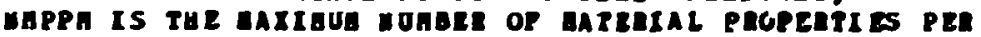
ant zaL LL.

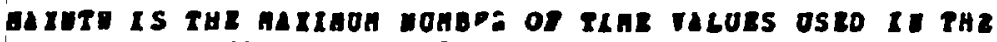
OHCOOPLED UATER TALISPOA CALCULATIOA,

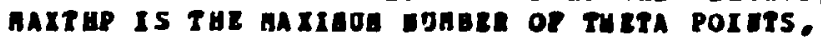




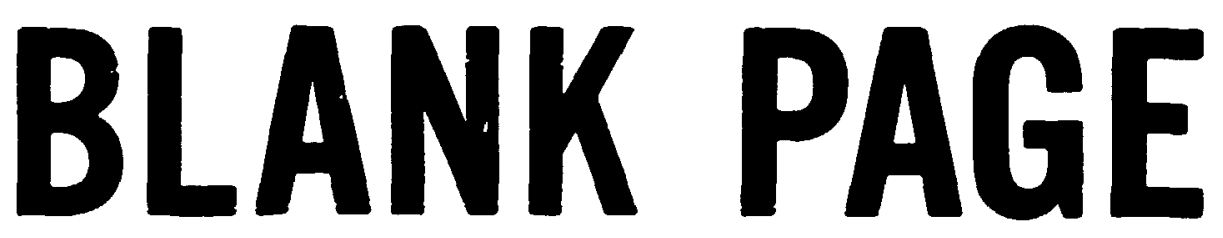



IUTERALS ELCEPT THE OTE IEALEST ALPAA = 1 .

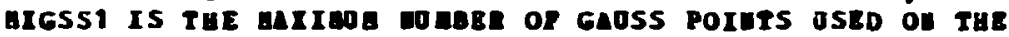
IUTERTLL URARS ALHA $=1$.

aSLP IS Ta a

C

C

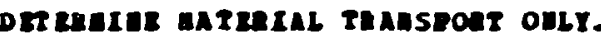

20 CaLl DARA.

30 CabL IIUL

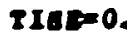

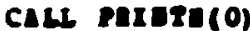

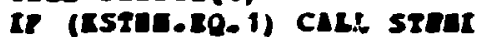

TIDE-DLS

DO 40 IRE= 1. IRI

CALL IRE

CALl Rezere (280)

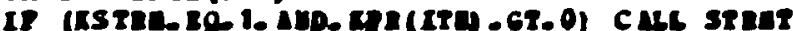

II (ISS. 20.0$) 602010$

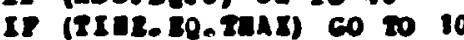

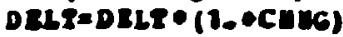

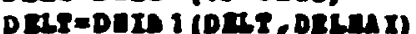

RTERLE*DER

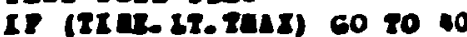

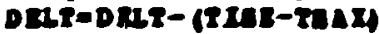

TLD $=20 \mathrm{CL}$

40

conervor

n 2010

c

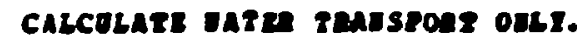

50 CALL DLE

50 cris reas

cars 0202 


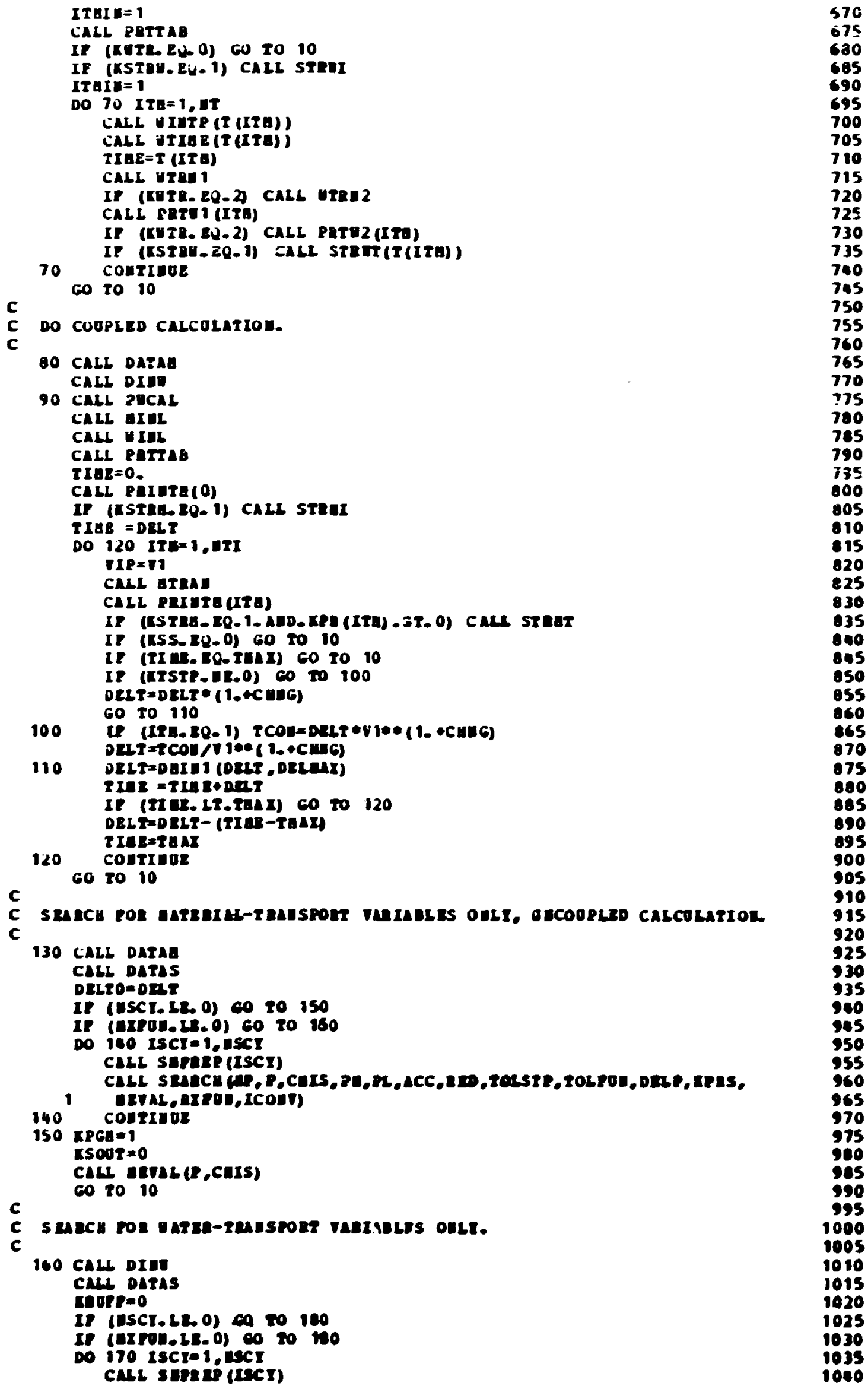




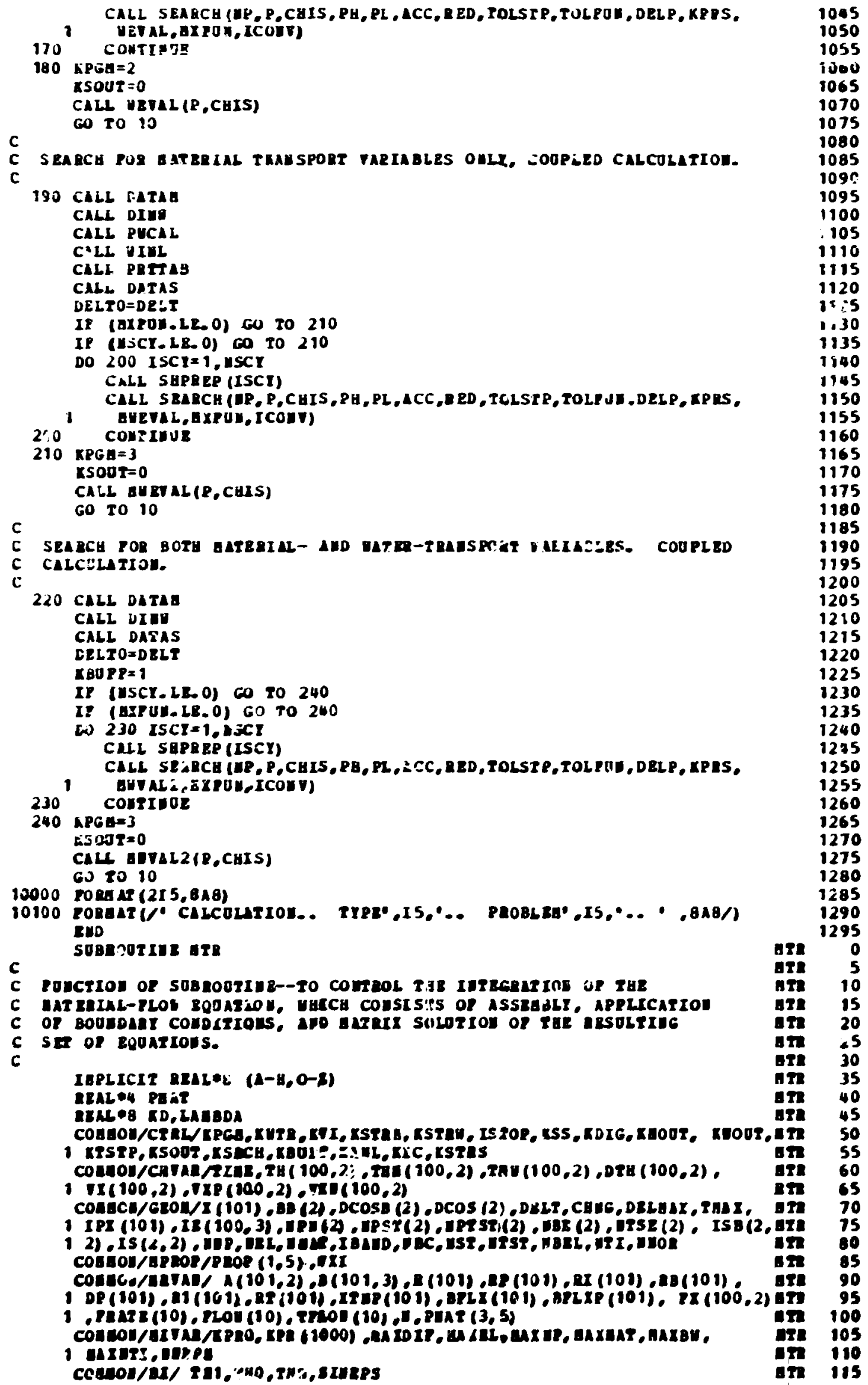




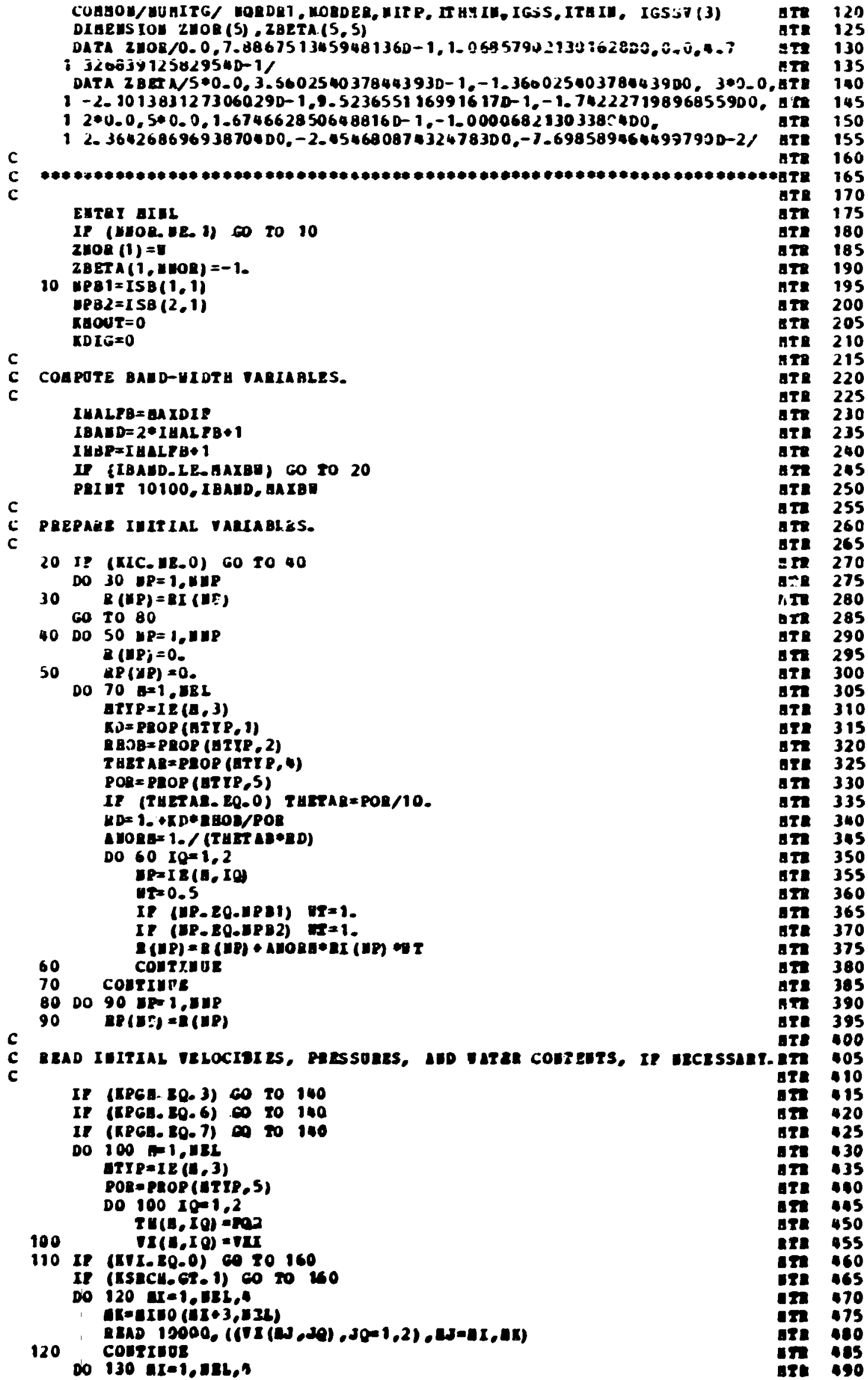




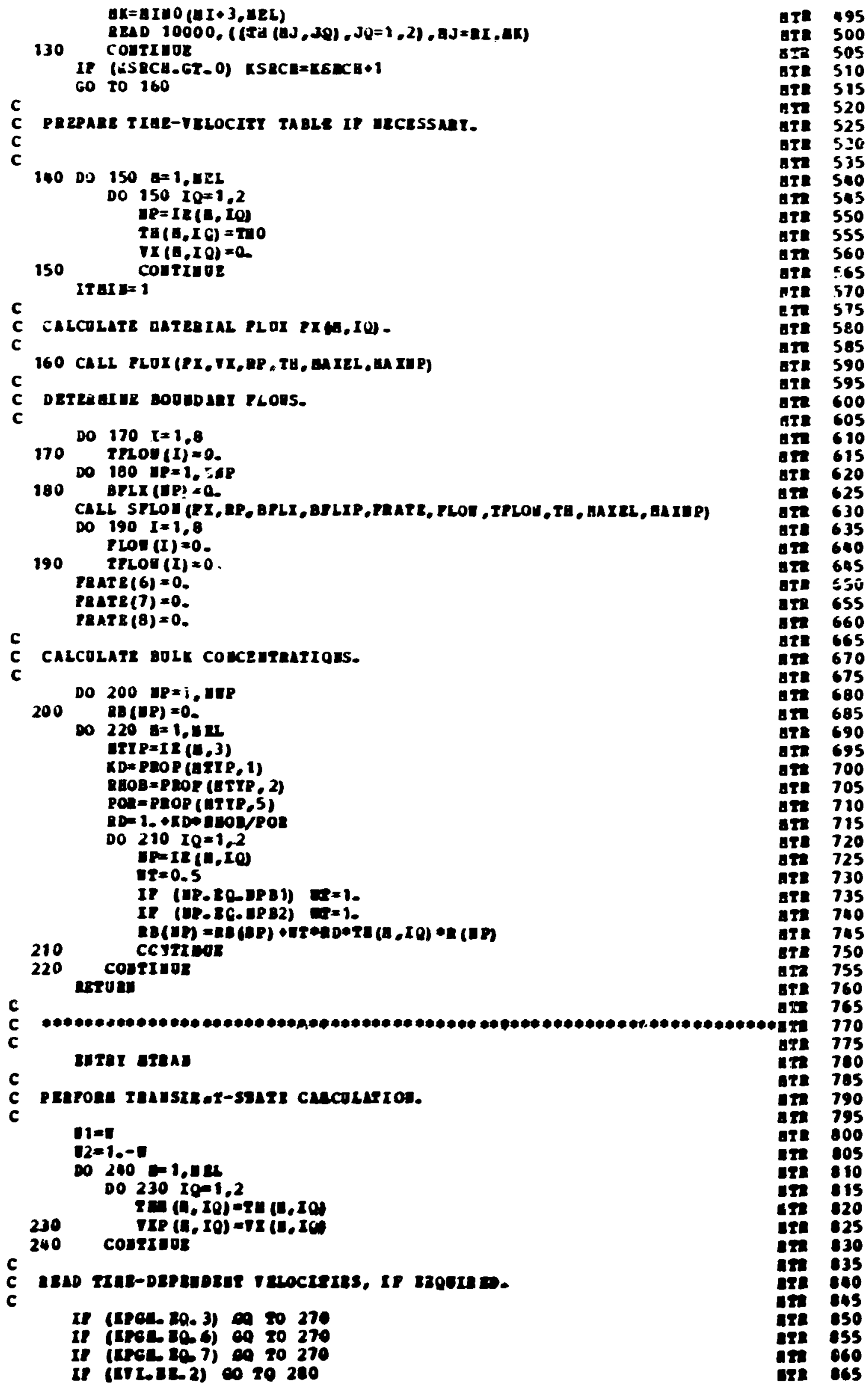




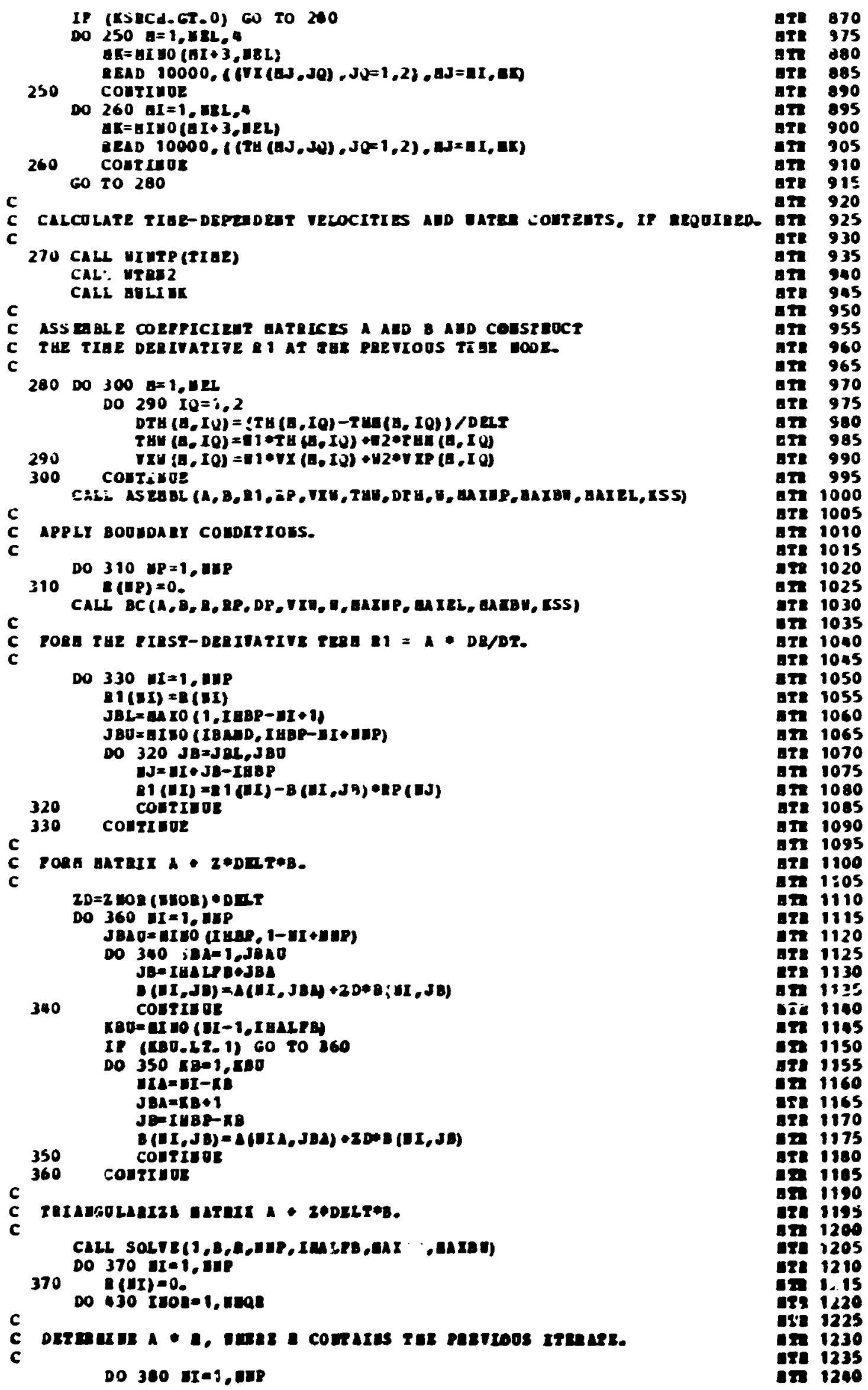




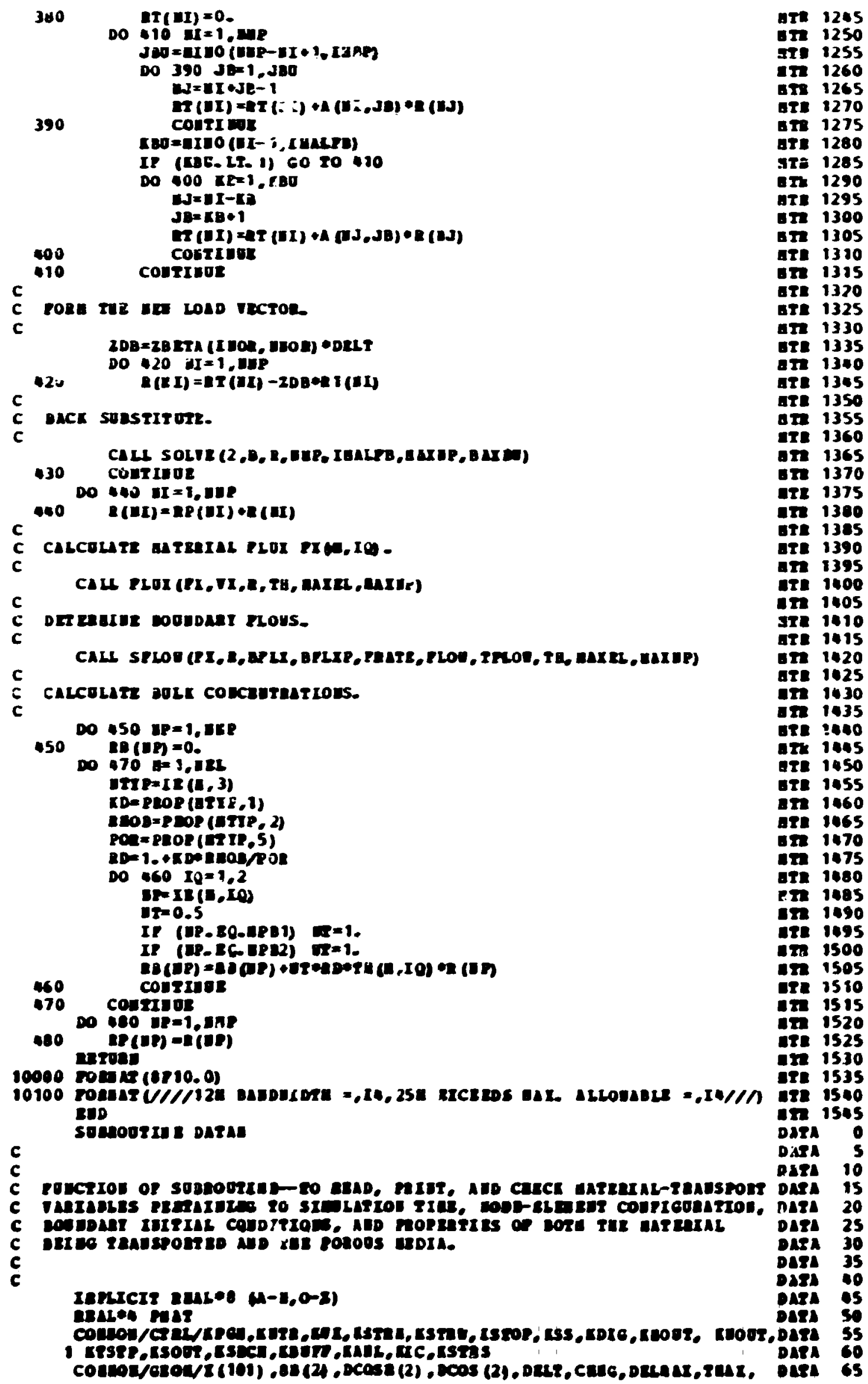

aTt 1245

are 1250

IT 1255

121260

are 1265

CTE 1270

aT 1275

are 1280

are 1285

CT. 1290

aT 1295

CII 1300

an 1305

are 1330

are 1335

are 1370

are 1325

are 1330

er2 1335

ax 1340

ara 1365

are 1350

aII 1355

ara 1360

oI 1365

DT 1370

are 1375

aTe 1380

are 1385

ar2 1390

aT1 1395

ara 1400

aI 1405

ITE 1410

are 1415

बII 1420

are 1025

aT 1630

oII 1435

ere 1940

art 1845

ara 1450

are 1855

1060

arn 1465

a.8 1470

aTe 1475

are 1480

T2 1485

III 1090

are 1495

ati 1500

are ises

ER 3580

ax 1515

12. 1520

ar2 1525

ax 1530

arR 1535

4201540

in isas

dasa o

Dara 5

Das1 10

dara is

20

Dasa 30

Das1 35

Dasa 40

DATI 45

5

dara 60

dea 65 


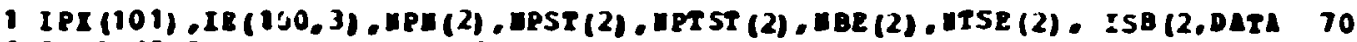

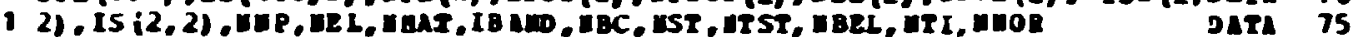

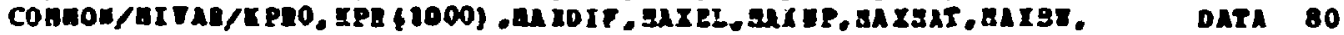

1 axtrI, InPPB

COQDOU/APLOP/P RQP (1.5), EII

DATA BS

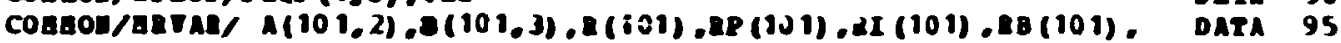

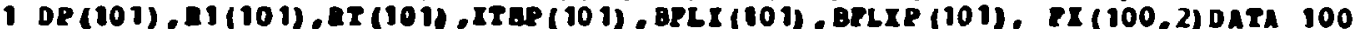

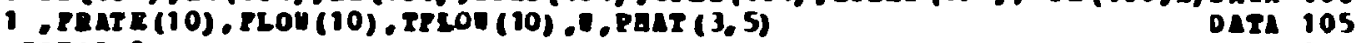
ISTOP $=0$

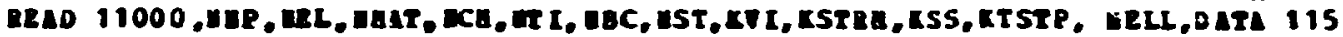

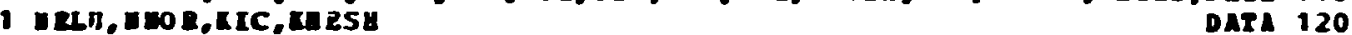

IST $=0$

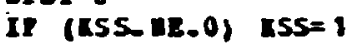

IP (KSTan. BE. O) KSTEA=1

IP (UHOL LT. I) MHOZ=1

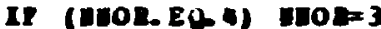

IP (HOL GT. S) WHOE=5

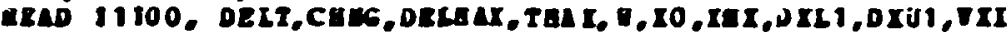

Ir (RSS. UR. 0) 60 TO 10

DUOB $=1$

$\|=1$.

10 It (xgesh. Bt. 1$) 60$ Tu 20

MELXIELL+URO

WIP $=\mathrm{HBL}+1$

IF (EELO. EO O) IO=XEX

IP (UELL 80 o) $x 0=0$.

20 If (ORLALX.LE. 0.DO) DLLNI $=1.250$

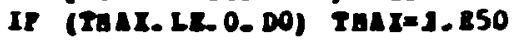

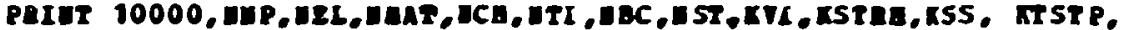

DATA 125

DATA 130

DATA $\cdot 35$

Dara 100

DATA 195

Dara 150

DATA 155

DATL 160

DATA 165

Data 170

DATI 175

Dara 180

DATA 185

DLTA 190

DATA 195

DATA 200

Data 205

DATa 210

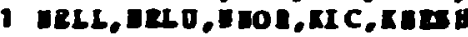

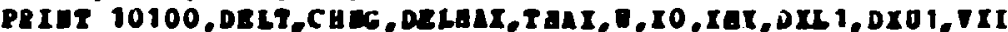

ARAD 11200, KPRO, (KPR (IRU) , ITA=1, ETI)

PRIET 10200

PRIUT 11300, RPAO, (KRE (ITA), ITE= 1, DTI)

c

c

CAECK TO BE SORE IUPUT DATA DOES DOT RICEEO STURLG CAPACITT.

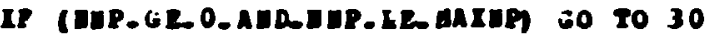

ISTOP I STOP+ 1

PAIET 12400, DAXEP

30 IR (URL.GLO. ADD.URL.LLGAIEL 60 TO 40 ISTOP=ISTOP +1 parue 12500, Gaxa

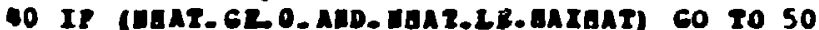
ISTOP=I ISTOP 1 PRIIT 12900, GAXnht

50 IP IECE.GR.O.AUD-UCA.LLEAXEH GO TO 60 ISTOP=ISTOR 1 PRIET 12600, nAIA

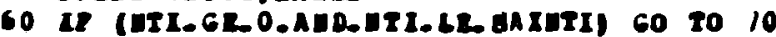
ISTOP $=I S T O P * 1$ paint 12700, gaxuti

70 IP (UBC GL O.AUAGEC.bL WIUP) 602080 ISTOP=ISTOP+I PaIU2 13000, 14708

80 IF (UST.GR_O.AMD.UST.LELUAIUR) 50 TO 90 ISTOR=ISTOP 1 PAIUT 13100, GAXIAP

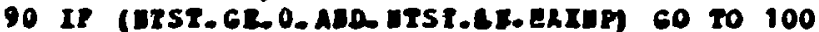
isTOR=ISTOP:1 PLIE2 13200, EAxus

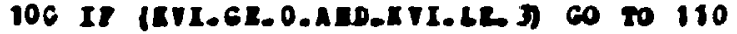
ISTOP=ISTOP 1 PaIer 12800

11012 (Isrop-20.0) co To :20 DII 13300 . Istor stop

C

c

120 IT (ILPPA.L.0.0) 0020180

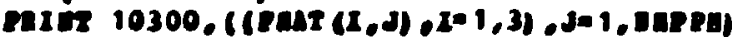

Do 130 In 1,010

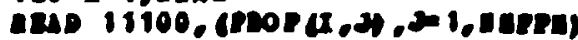

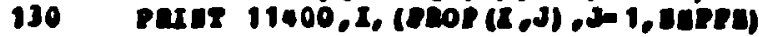

Data 215

DATA 220

DATA 225

DATA 230

DATA 235

Dara 280

Data 245

DATA 250

DATA 255

DATL 260

DAR1 265

dara 270

DATI 275

DATL 280

DATA 285

Daza 290

DLTA 295

DATa 300

Data 305

dara 310

DATA 315

DIT 320

DATL 325

DATA 330

DAER 335

DATA 340

DATA 345

DATA 350

dara 355

Dara 360

DAP: 365

D._ 370

DArA 375

Daga 390

DAgI 305

DAFA 390

DAFA 395

Dasa 400

DATa 405

dara 410

Dasa 415

gara 420

dara 425

onsa $\$ 30$

daza 435

dara 400 
c

$c$

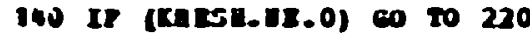

$t P=1$

$X(D P)=x 0$

II (18b-50.0) on 20 160

UVEILLL

$\mathrm{VI}=\mathrm{ET}-1$

DIAV=10/DFLOAT (DV)

SD $I=2$. (DIAT-DEC I: AOLLOTE (DA)

DIIx DI!1

Do $150 \quad J \nabla=1,57$

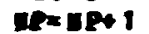

$I(E R)=I(D P-])-D I I$

$D I=D I I+S D E$

150 courres

$x(10)=0$.

160 It (IELd.20.0) c0 20 190

$\nabla P=\square R+1$

$x(D)=\mathbf{I 0}+0 \leq \mathbb{1}$

DT=IIL

TVE $=87-1$

DIAT $=(x a x-20) / 020 A T(D T)$

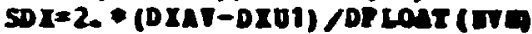

$D I=0 \pi 01+5 D X$

DO $170 \mathrm{JV}=2, \mathrm{~T}$

ari $1 P \rightarrow 1$

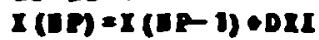

170 conzü os

$I I \bullet S D I$

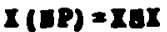

C

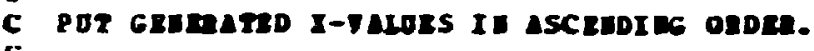

$c$

c

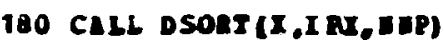

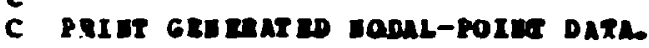

C

cerer 10400

Do $190 \quad \square P=1, \pi 18$

$$
\text { c }
$$

Dara 495

DATa 450

inea ess

DaTa 460

dara 465

Dara 970

DATa 475

DATI 480

Dare uas

para 980

Data ess

Data 500

Dara 505

dara 510

DATa 515

Dara 520

Dara 525

Daza 530

dara 535

Data 540

Dara 535

Dara 550

Dara 555

Dasa 560

Daza 565

DeTa 570

DARA 575

Data 580

Dara 505

Data 590

Data 595

DaTa 600

Data 605

Daza 610

Daza 615

Dara 620

Dara 625

DARA 630

Daza 635

Desa 640

pata ges

Data 650

DAR 655

Data 060

Deza 665

Dara 670

Data 675

Dara 580

Daza 685

Dara 690

Daza 695

DSR 700

Data 705

Dasa 710

Daza 715

DNTA 720

dara 725

Dara 730

DA2 735

oner 740

Dara 745

olsa 750

Dese 755

daA 760

Dara 765

Dasa 770

onea 775

Dara 780

D28 705

Dnia 790

Dara 795

Dasa 000

drea 0 os

Dasa 810

Dese 015 


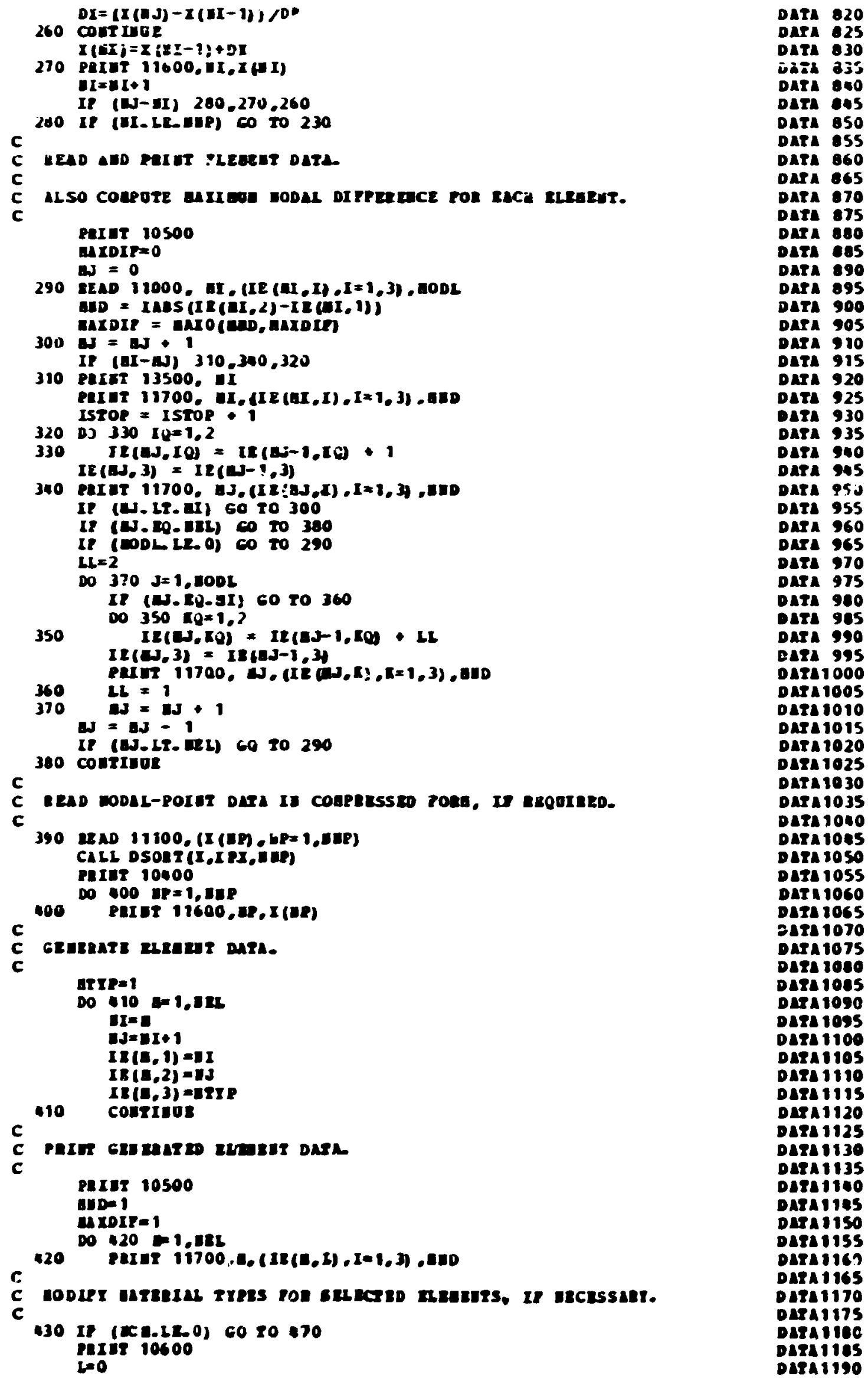




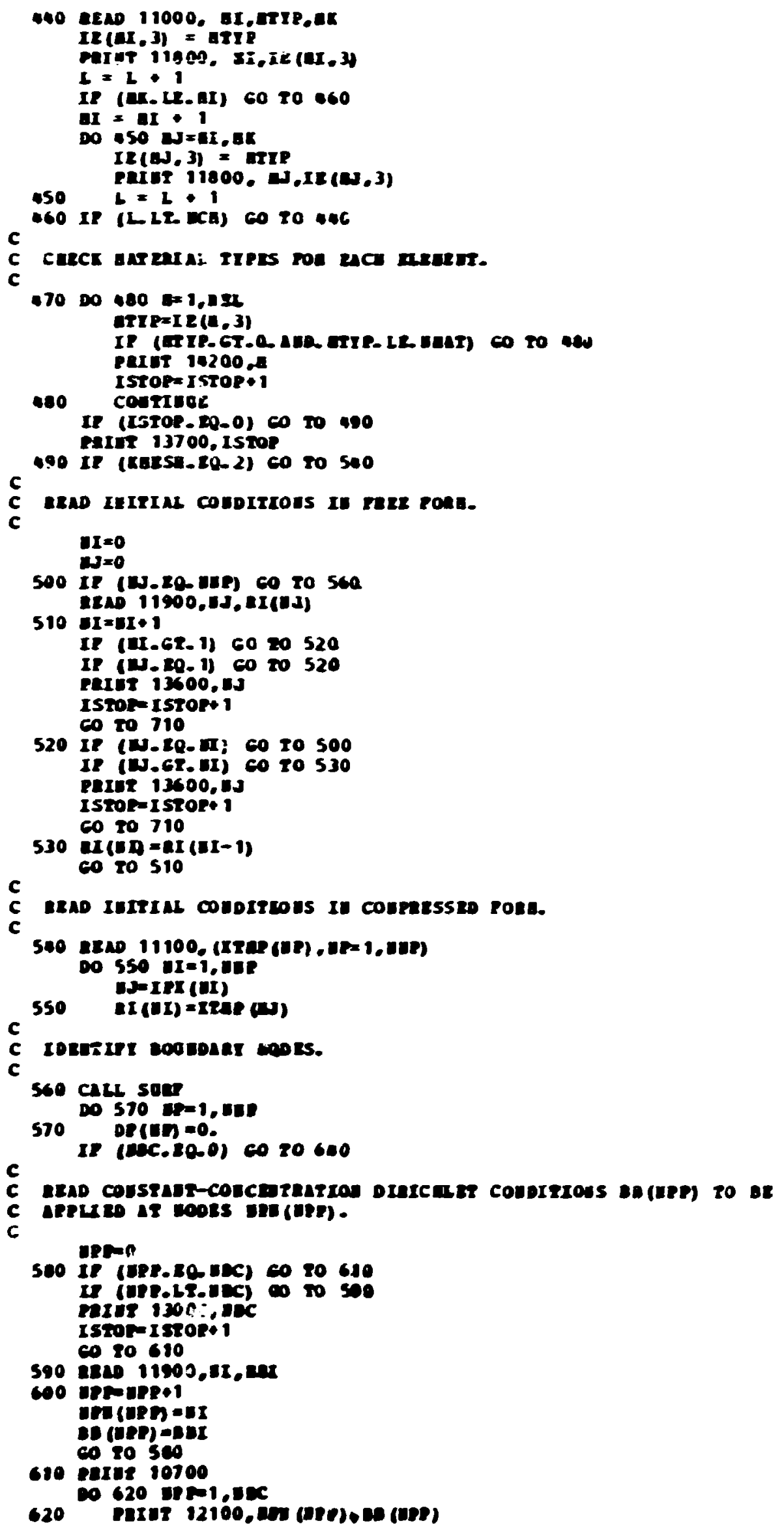

Darailes

dataizú

Data 1205

Dara1210

Dara 1215

Dara 220

Daraiz25

Dara 1230

DLra 1235

Dara1240

Daraizes

paras250

daraizss

dara 1260

Dara 1265

DATA1270

Dara 1275

DATa 1280

Dara 1285

Dara 1290

Dara 1295

Daraijoo

Dara 8305

oata 7310

Daraizis

DLraj320

Dara1325

Dara1330

Dar11335

Dara 1350

Dara 1345

Dara1350

DArA1355

Dara 1350

Daraj36s

Dara 3370

Dara 1375

Dara ijao

Dara lues

Dara 1390

Darajugs

DAra 1400

DAra 1005

Dara 1410

Daraieis

Dara 1420

Dara 1425

Dataiajo

cara 1035

Data 1440

paraigas

Dara 1 eso

Dara 1 ass

Dara 1060

Dara 1465

Darajazo

DATI 1975

DAta 1980

Daraises

Dara 1490

daraias

para 1500

Daraisos

- ara 1510

Darais 15

DL21 1520

dara1525

Daraig30

DLRI 1535

Dara 8300

oara ises

Daraisso

paraisss

dara isso

daraises 


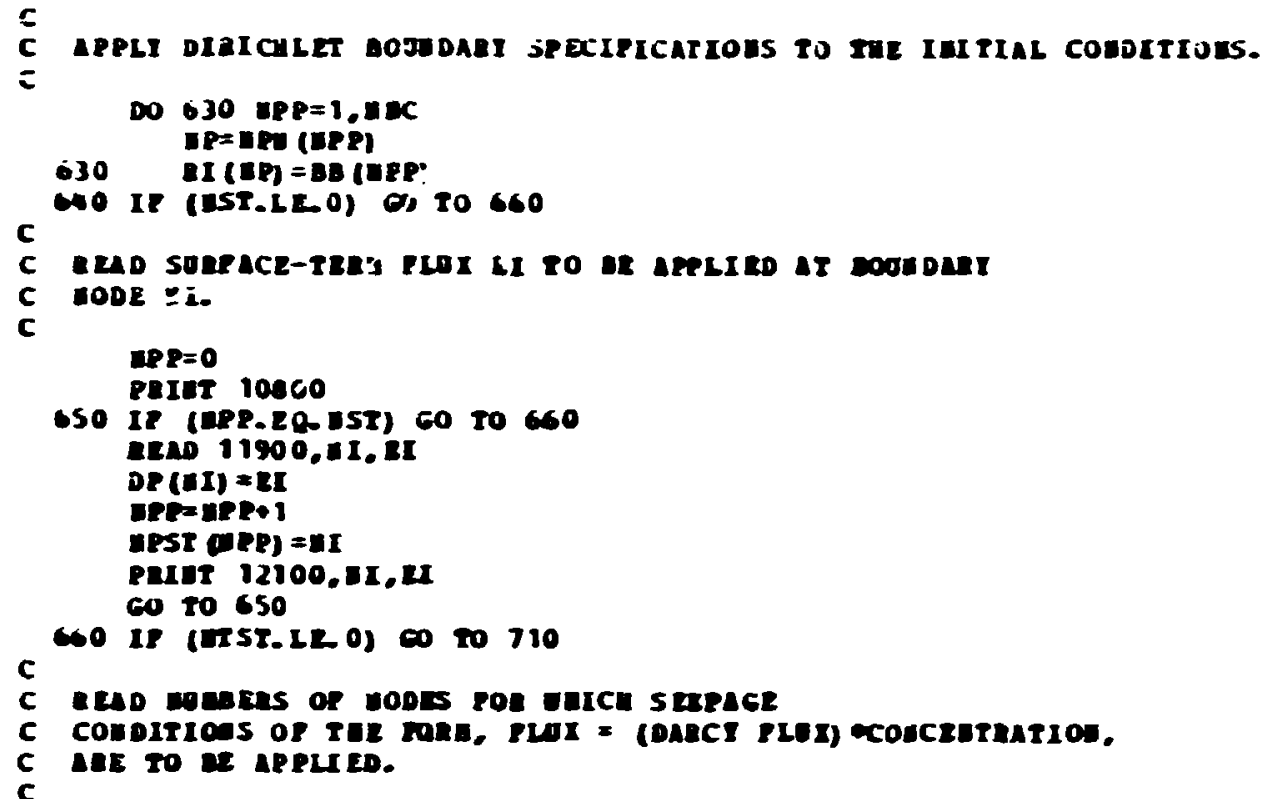

DLTa1570

datais75

data 150 o

dataisas

oaraisso

ontaises

Darais0o

darajés

DATA 1610

Daraist5

data 1620

Dataiszs

DATA1630

DATA 1635

data 1690

daraises

data 1650

data ic5s

daraicso

data icos

darais7o

daraists

-arascoo

Daraices

Daraicso

Daraices

Dasa1700

$D P I=0$

APR $=0$

PEIET 10900

670 IP (UPR.EQ-ATSI) 60 TO 710

IEAO 12000,01

DPI $=\mathrm{API}+\mathrm{I}$

IPF $=$ IPP* 1

DrTST (NRP) $= \pm 1$

DO 690 aPJ=,.$D 024$

$n=D E R$ (DPJ)

$M J=I S B(A P J, 1)$

If (II. IE- (J) 60 TO 690

UTSE (IRI) $=$ a

$\operatorname{Dcos}(A P I)=\operatorname{DCOSA}(\pi P J)$

$00600 \mathrm{j}=1.2$

680

IS (DPI, J) ISB ISRJ, J)

6070700

690

conzruos

ISTOP =ISTOP+1

PEInT 13900, DI

co to 710

700 PAxur 11700,01

co 20670

710 IR (ISTOP-20.0) CO TO 720

parar 13700, ISTOP

Daraizos

CATA1710

S2841735

DATA1720

Daraiz25

DLTa 1730

osza1735

Darag740

Dataizas

Daraizso

dara1755

oaraizgo

Daraitos

Daraiz70

Daraiz75

Dara1780

ontaizes

Darai7so

Daraites

odira 1800

Da:ates

Daraiero

oaea 10 is

Daraigzo

Daratez5

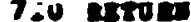

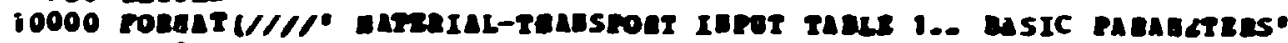
$1 / 15 x$.

Dara 1830

1. woure or elecers.

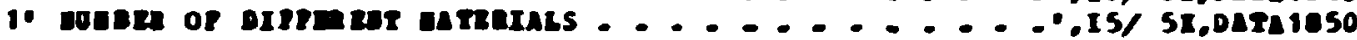

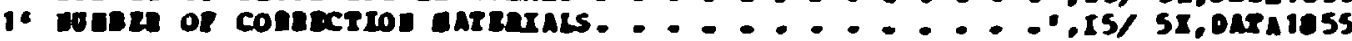

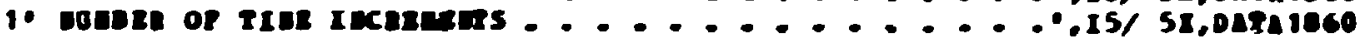

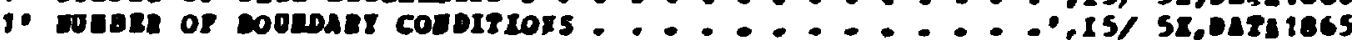

1. doeres of sonrace rens

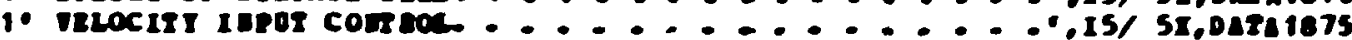

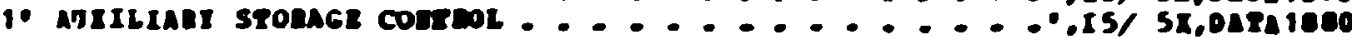

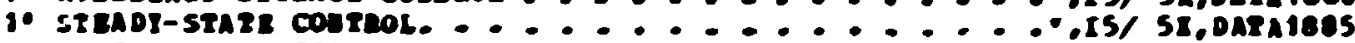

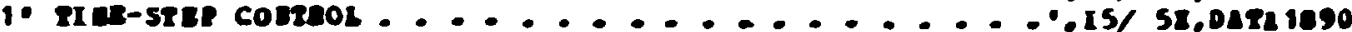

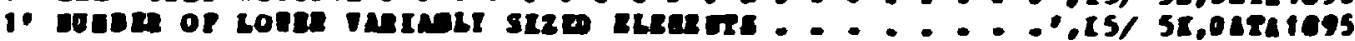

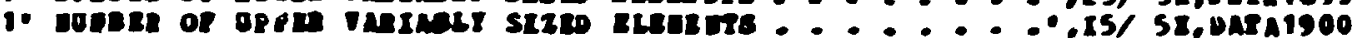

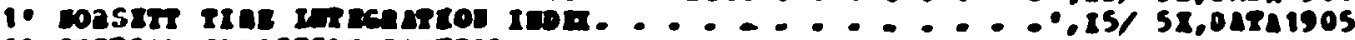

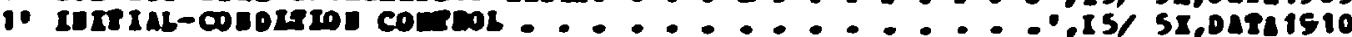

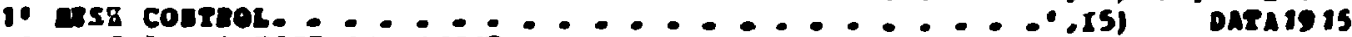

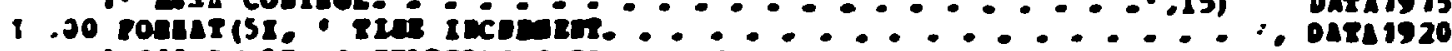

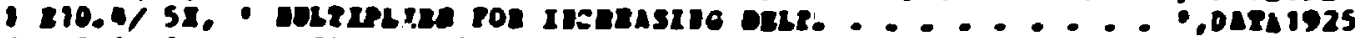

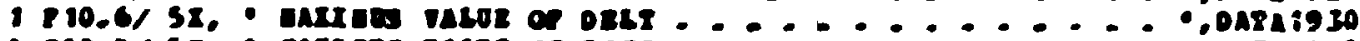

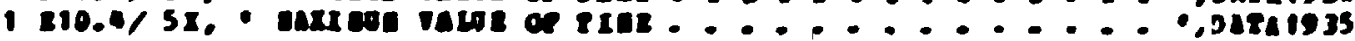

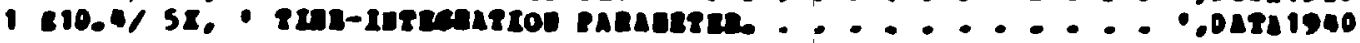




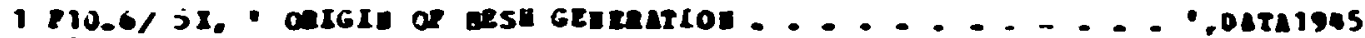

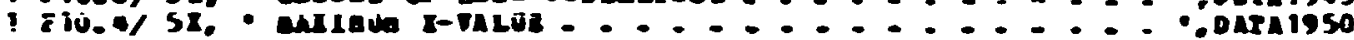

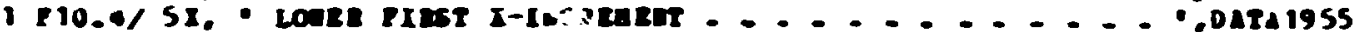

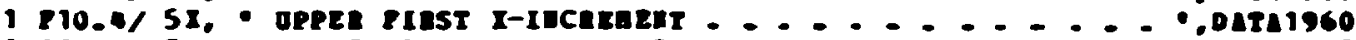

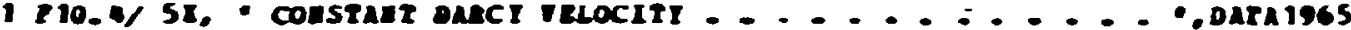

I E10-0)

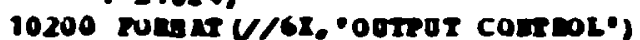

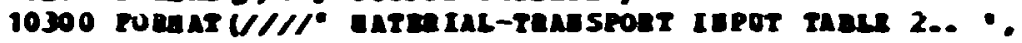

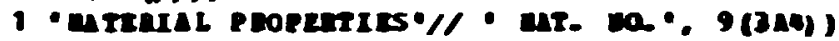

DAra1975

DAra1980

Dara isas

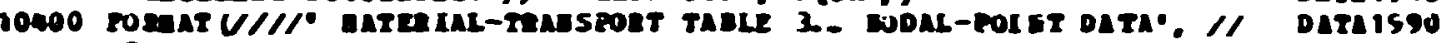

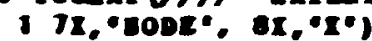

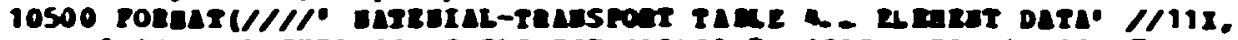

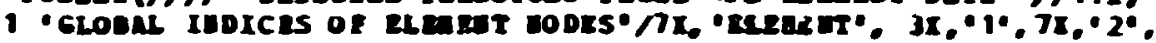

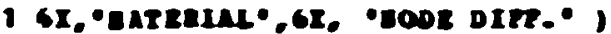

DAra1995

DArऽ2000

Dara2005

Data 2010

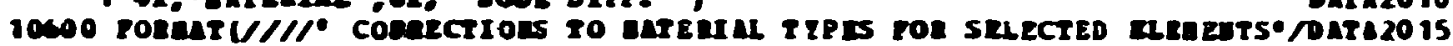
11

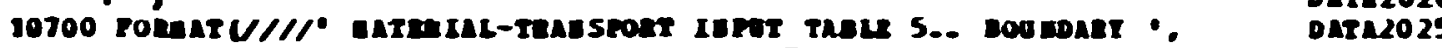

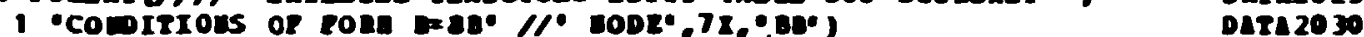

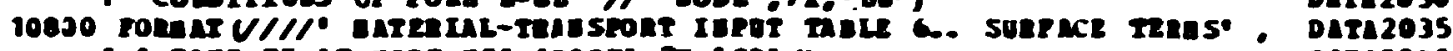

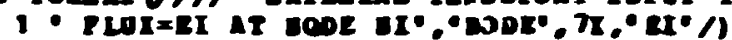

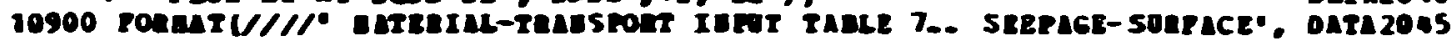

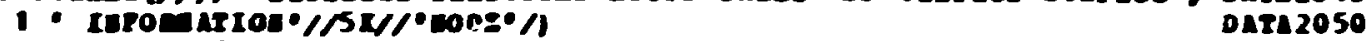

10000 ronat (16IS)

18100 conast (8r10_0)

11200 rotax (e0I1)

11300 Folatat (10x, iviciu

11900 Fonsat (I0.9012.4)

13500 porder (IS, 2210.3$)$

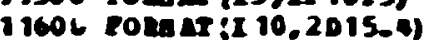

11700 pongat (x10,218,110,xis)

1000 poen ax $(110,32 x, 110)$

11900 romar $(15,5 ; ., 710.0)$

12000 pora

12100 ruka 20 (I5, 615.4)

12200 romen $(32 \div, 5 x, 2210.0)$

12300 coneat ieIs.2 (iepis-4)

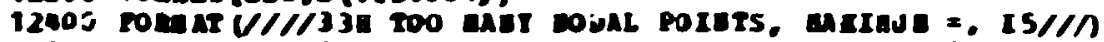

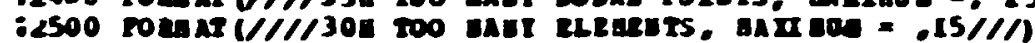

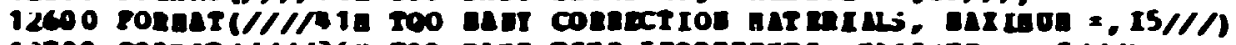

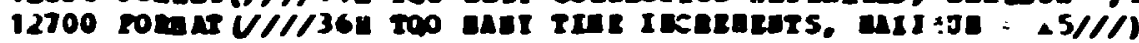

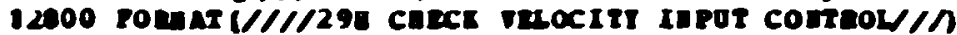

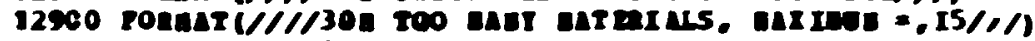

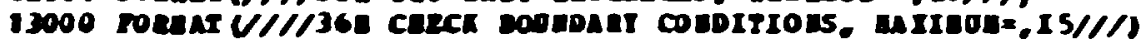

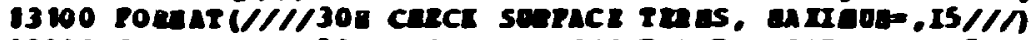

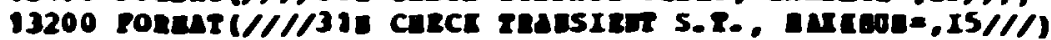

DATA2055

Datr 2060

0.TA2065

Darazo70

Dara 2075

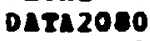

DATA2085

DAT 2090

Dara20s5

Data2100

DLra 2105

DArL2110

DATA2115

DBTA 2120

$0 \Delta T \triangle 2125$

Daraz130

DArL2135

DATA2140

Darazias

Dara 2150

Daraziss

DAta2160

DARI2165

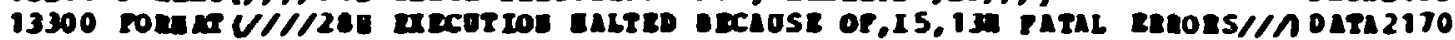

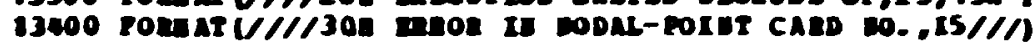

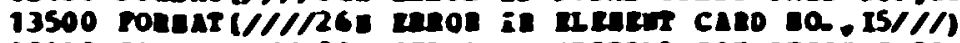

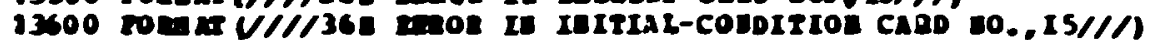

DATA2175

Dara 2180

Darnzies

13700 POTN

DATA2190 i 19a paral cano earons//l)

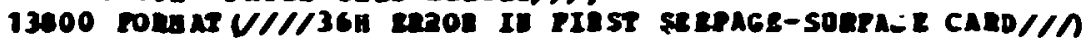

DAra2195

Data 2200

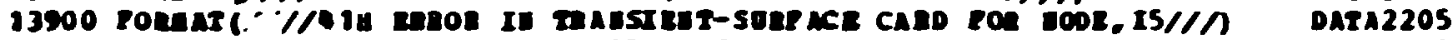

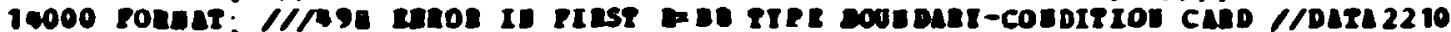
11

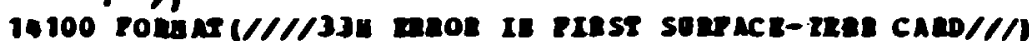

DArA 2215

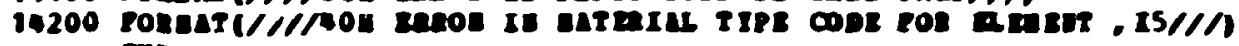

DAR12220

DLTム2225 LOD

c

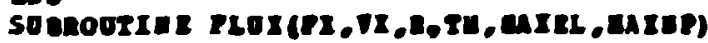

c

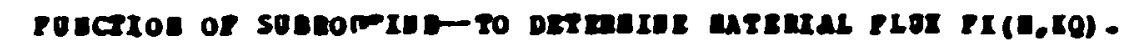

$\operatorname{ligx} 0$

TLOI 10

PLI 65

$120 \times 20$

PLOX 25

F⿻上丨 30

IARICIR IBhLe $(A-0,0-2)$

2408

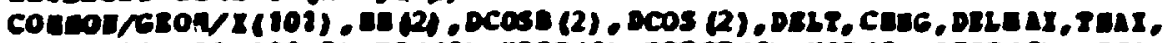

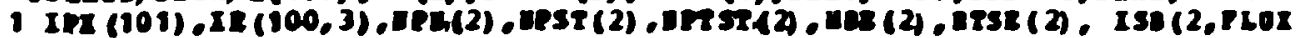

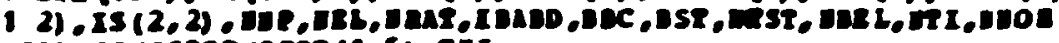

coneos I I

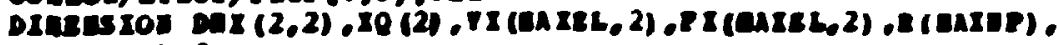

$1 \sin (2 \times 18,2)$

Istoreo

DO 50 de1,0Rs

c

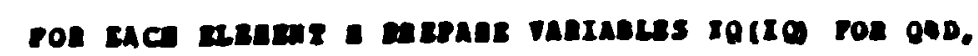

201 45

T201 50

pwer 55

PLUI 60

puros 65

pur 70

Pevi 75

1208 00 


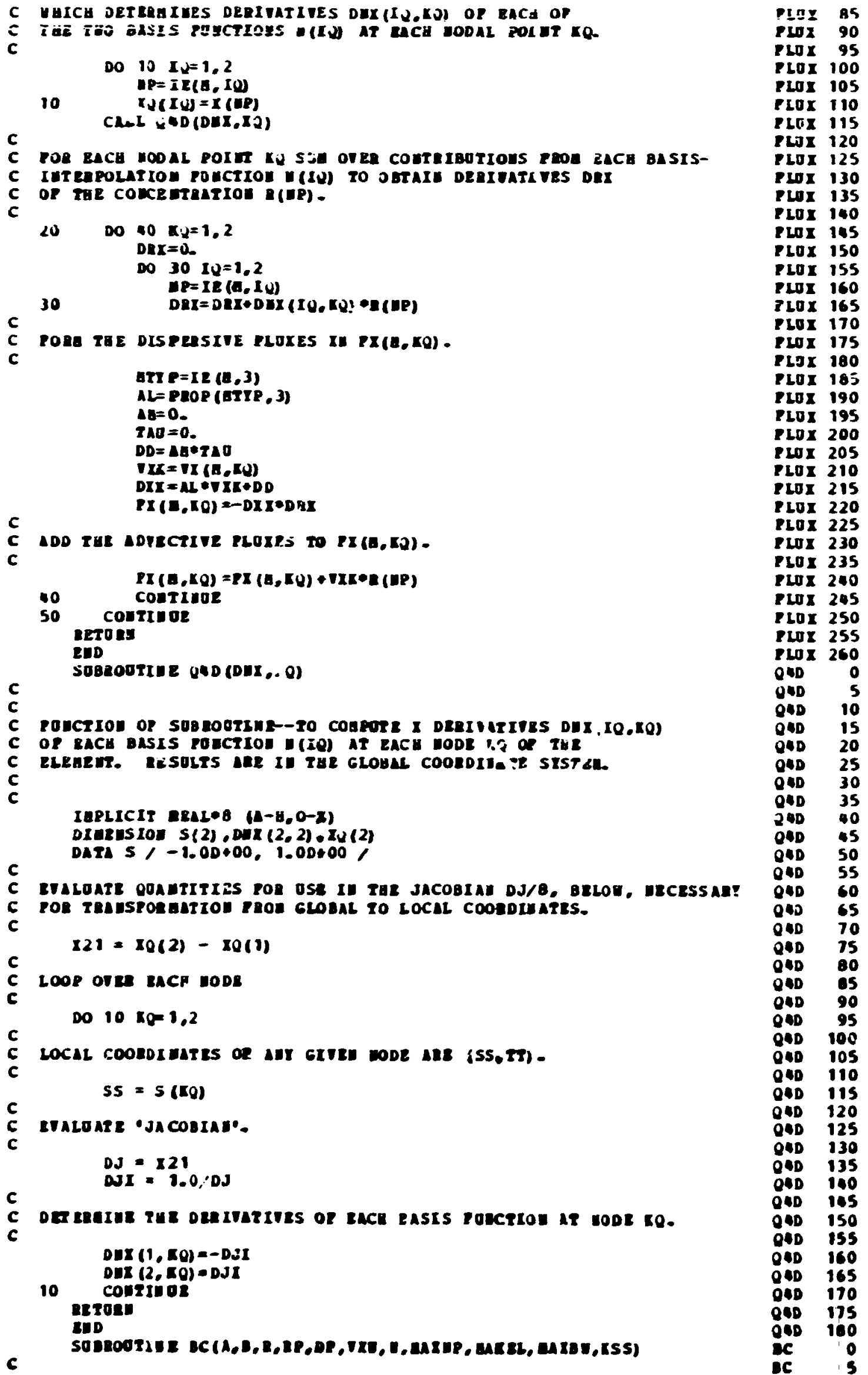




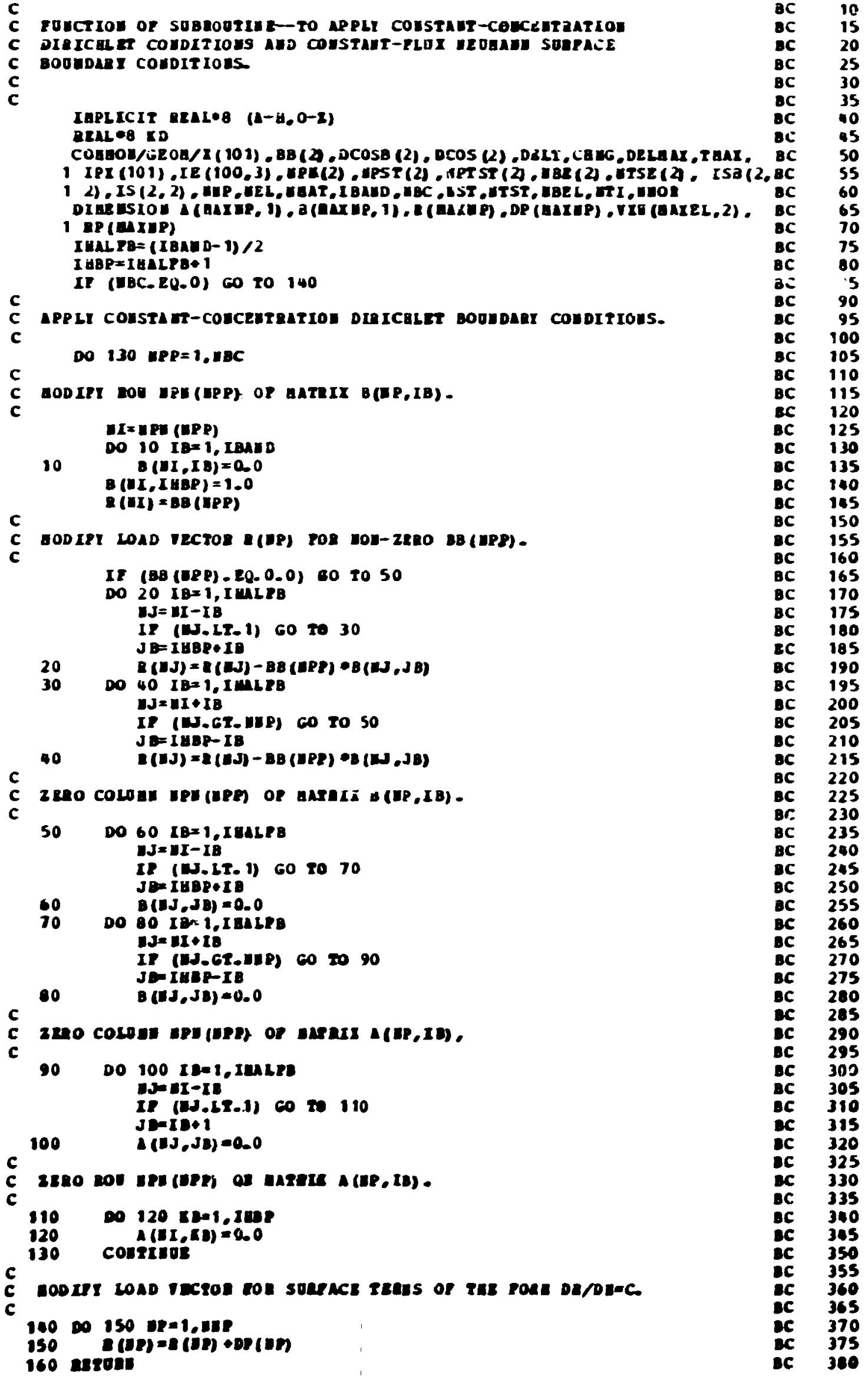




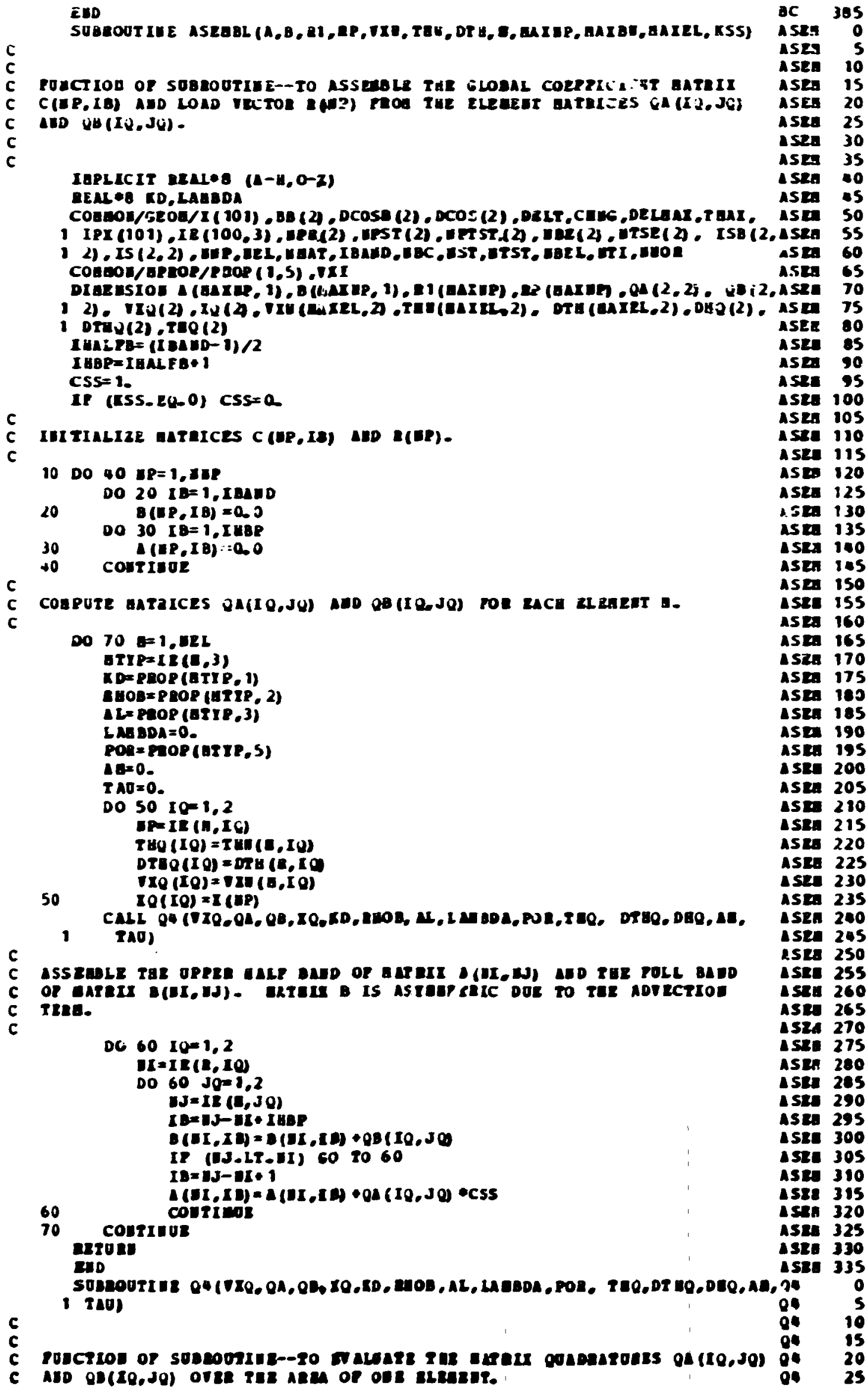




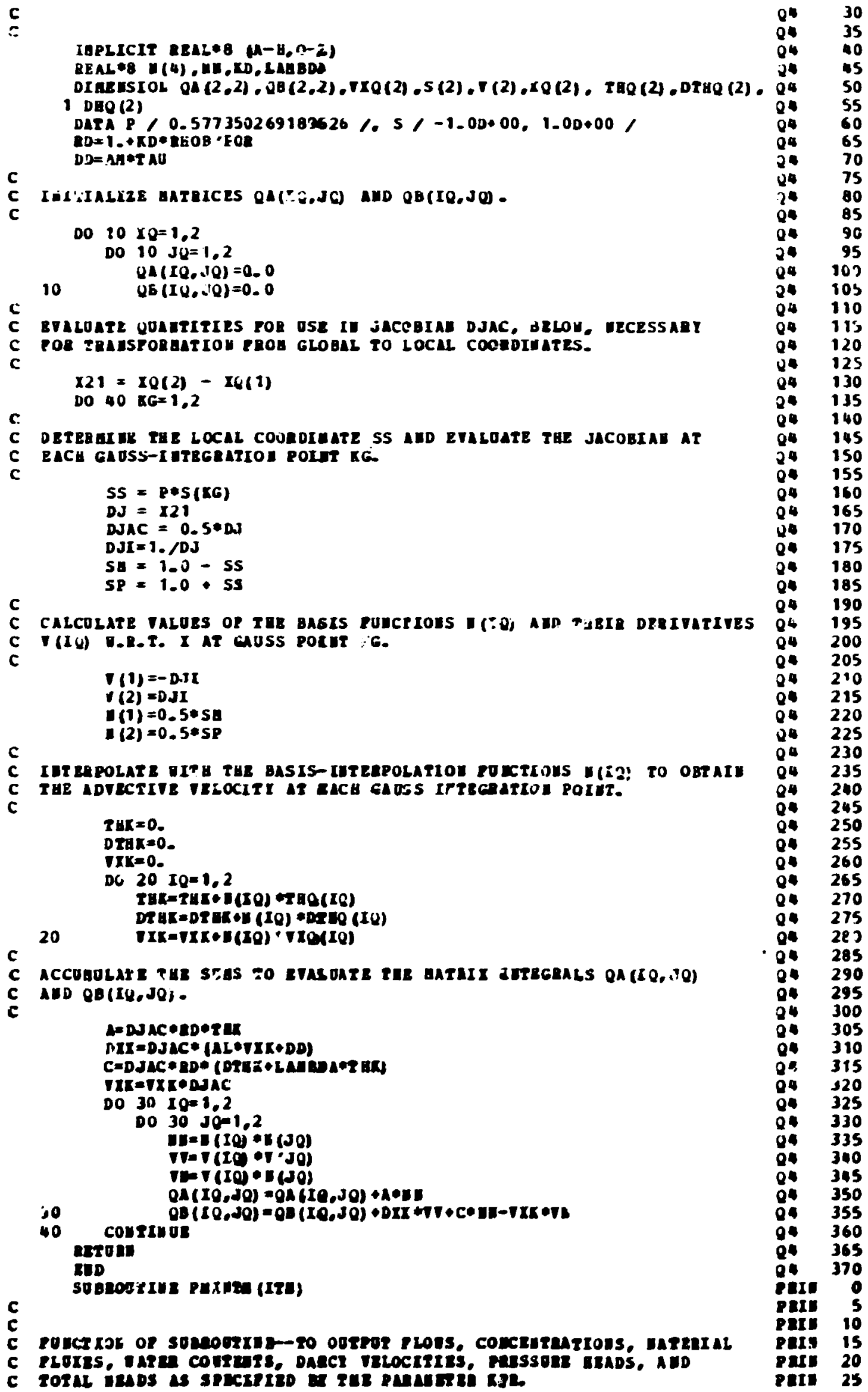


PRI: 35

COABOW/CTRL/KPGA, KUTE,KJI, ESTEA, KSTE, ISTOP, KSS,KDIG, KHOOT, KBOUT,PEIU 50

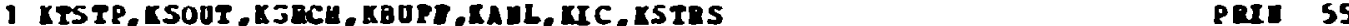

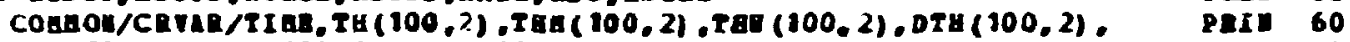

$1 \mathrm{VI}(100,2), V X P(100,2), V E(100,2) \quad 65$

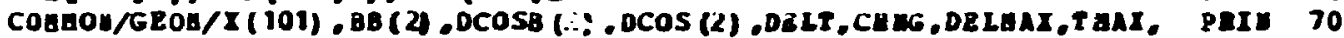

1 IPI (101) ,IB ! 100,3), DPE (2), UPST (2), DPTST (2), IAE (2), UTSE (2), ISB (2,PEIX TS

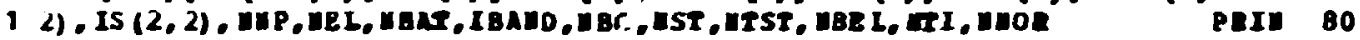

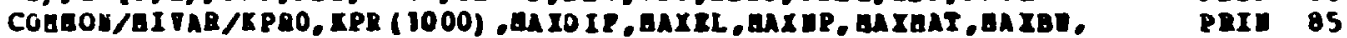

1 axmI G OPPE

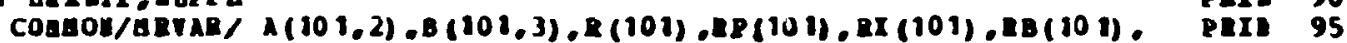

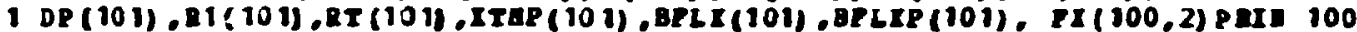

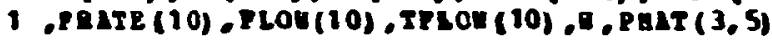

$K G I G=X D I G+1$

II (KHOUT_EQ.0) KEOUT=1

IP (KPR (ITE) - EG-a) PETOEU

c

IP (ITA.EQ.0) GO TO 10

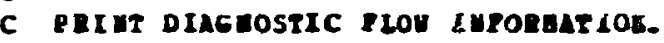

C

PRIET 10700, KDLE,TIAE,DDLT

PREUT $1060 \%$, (TRAEE (I), FLOU (I), ITLOU(I) ,I=1,d)

$K$ MOOT=KDOUT 1

c

10 IP (KPI (ITI) - EQ I) RETUEU

C Parut conceurgations.

PEIUT 10000, KEOOT, TIAE,DILT

DO $20 \Sigma I=1,1 \pm P, 8$

MJUI $=$ hI

MJaX $=\square I M 0(U I * 7, M U P)$

20

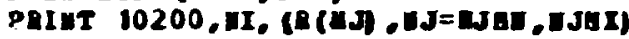

KEOU T=KBOUT 1

PEIMT 10100, KHOUT, TIAE,DELT

DO $30 \quad I=1,14 P_{0} 8$

$M J a=\mathbf{I I}$

Hax $=8 I m 0(1+1 * 7$, WHP $)$

30 PRIUT 10200,UL, (AB (WW), EJ=HJaJ, DJEX)

IP (KPE (ITA) - EQ 2) BTTOBU

c

C PEIUt aAREIAL RLOL.

c

$x 800 T=x B 00 T+1$

PEI BT 10300, IUOW, IIER,DLLT

DO $40 \mathrm{II}=1, \mathrm{EL}, 4$

ar= $200(4 I+3, \mathrm{EL})$

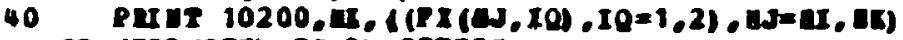

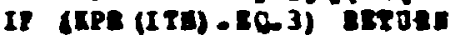

c
c

peIn: uarea courings.

KEOOT=KMOOT*I

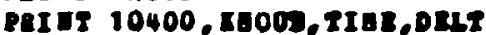

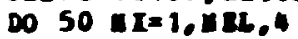

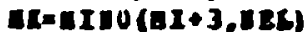

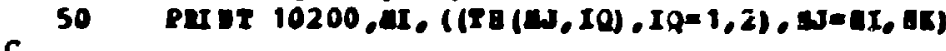

PaI 280

PEID 105

PaIn 110

PRI 115

Par: 120

PEIn 125

उ2x 110

PRII 135

PQIA 140

PRIE 145

PaII 150

PRII 155

Par. 160

PAI 165

PEII 970

PEII 175

PEIY 180

PAI 185

PEI 190

PEII 195

PaIn 200

PEII 205

PEII 280

perr 215

PEII 220

ParI 225

PIII 230

PEII 235

PAII 240

peId 245

PAII 250

PnI 255

PEII 260

PaId 265

PrII 270

PEII 275

PeII 205

PEII 290

PEI 295

PuI 300

PeI 305

PEII 310

Pary 315

perr 320

PEII 325

Bard 330

pary 335

Par: 340

pary 345

rnourarsour $* 1$

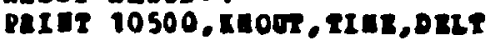

PEII 350

DO $60 \mathrm{II=1,ULL,4}$

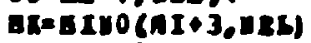

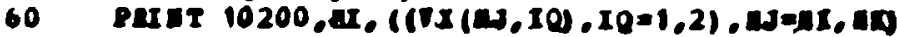

Pari jss

Pax 360 DBTOAY

Par 365

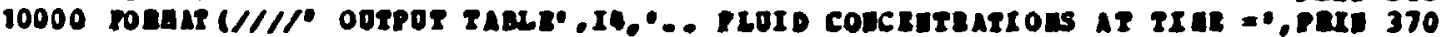

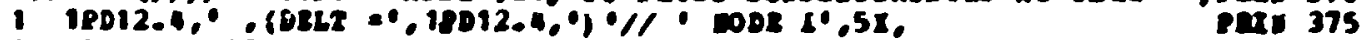

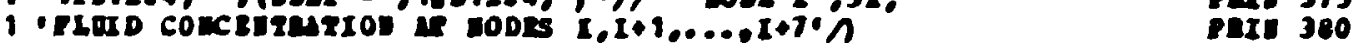

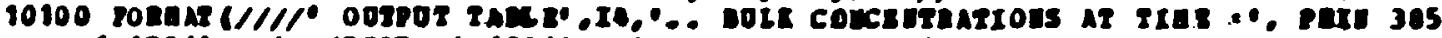

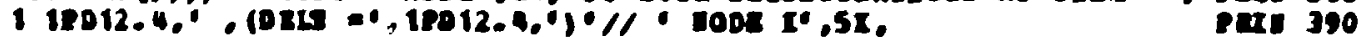

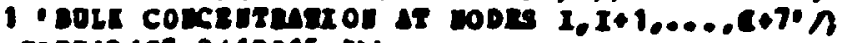

Dex 395

10200 rotnat $\{17,8(18015,4)\}$ 


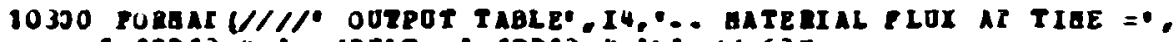

1 IPD 12-4." - (DELT $=0$, IPDI2-4,, $1 / 63 x_{0}$

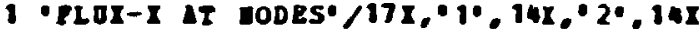

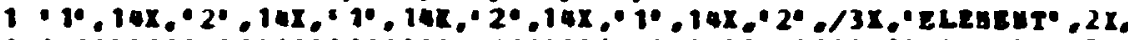

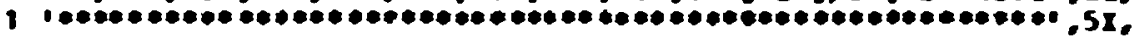

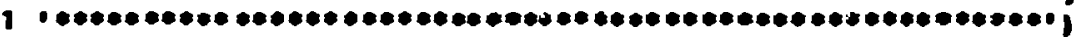

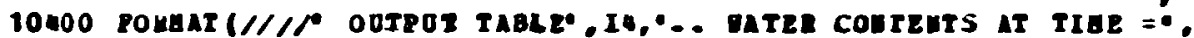

1 IPD 12-4, . (DELI = $, 18 D 12,4, \cdot 1, . / 163 x_{0}$

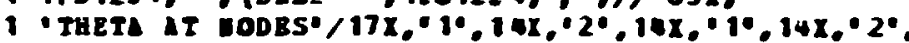

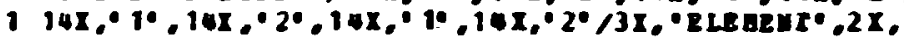

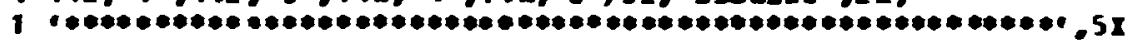

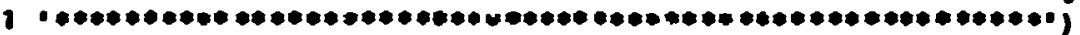

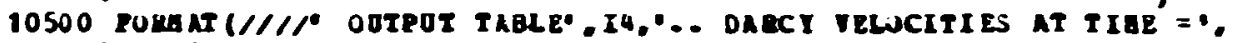

1 JPD 12.4, . (DELT $=., 18012,4,0^{\circ}, . / 163 x_{0}$

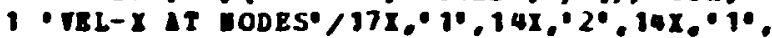

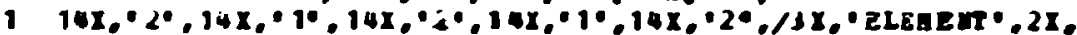

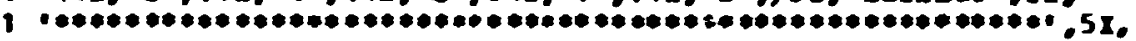

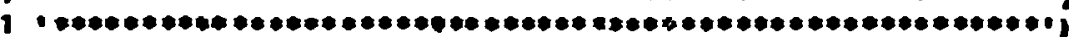

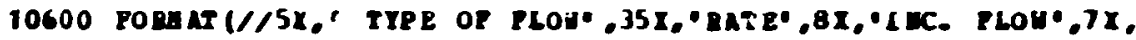

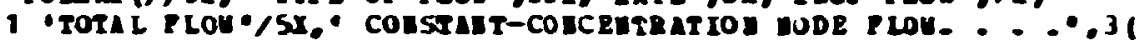

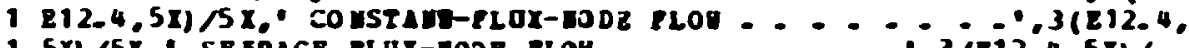

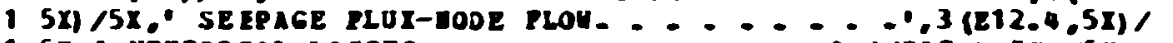

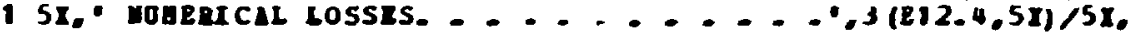

1 VeT PLON. . . . . . . . . . . - $3(2124.5 x) / 5 x$.

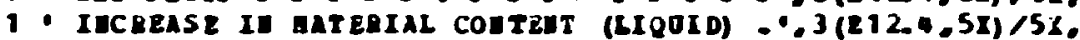

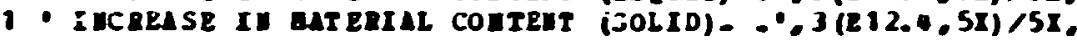

1 IADIOACTI VE LOSSES (LIQOID IND SOLID - - 3(E12.4.5I))

PRI 405

PRID 10

PRI 15

PIII $0: 0$

PEID 25

PRI 430

PRIV 435

PAI $\$ 40$

PEII 405

PEI 450

PRI $\$ 55$

PRI 460

PEIM 465

PRI $\quad 70$

PEI 475

PRI $\$ 80$

PEI 485

PRID 490

PAII 95

PEI 500

PRIE 505

para 510

PRIU 515

PRIE 520

PNII 525

par 530

PRII 535

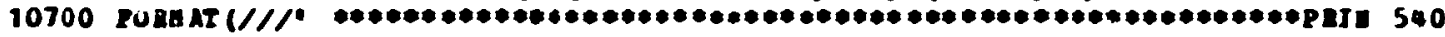

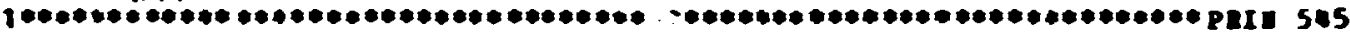

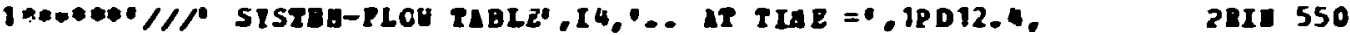
$1 \cdot,(D E L T=\bullet, 1 P D 12-4, \cdot) \cdot)$

EUD

SUBROOTIME STRE

PEII 555

PRI 560

$$
\text { C }
$$

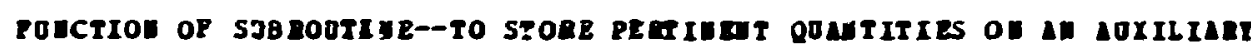
DET ICE TOR PUTORE USE, E.G POR PLOTTIG. GBAT DEVICE IS TO 82 SE

OSED GOST BE SPECIRIED BI APPEOPRITE JOB-COITIOL CIRDS.

c

IAPLICIX REALOB $(4-H, 0-3)$

REAL 4 PHAT

COABOIPLOBID/TITLE (8), UPLOB

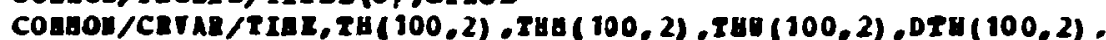

$1 \mathrm{~V}(100,2), \mathrm{VXP}(100,2), V \mathrm{~V}(100,2)$

COABOI/GEOA/I (101),BB (2),DCOSB (2),DCOS (2),DELT, CBWG, DELAAX, THX,

1 IPX (10u, IR (190, 3), UPH, (2), UPST (2), IPI ST, (2), UB2 (2), UTSE (2), ISB (2,

1 2) IS $(2,2)$.

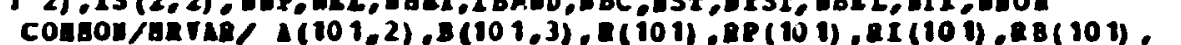

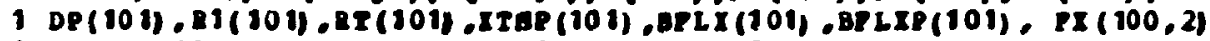

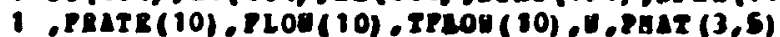

srat

5

STan 10

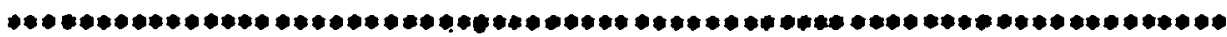

IETEX STRaI

PONCA 10000, (TIRLE(I), I=1,8)

Poice 10100 , wne

POECH 10200, (X (DP) , IP= 1, UUP)

c

Catoh:

C

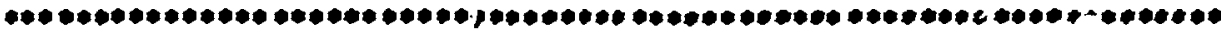

EUTET START

pouca 10200, 2Ias

Ponch 10200, (R (UP) , IPE 1, UMP)

aroes

10000 Pongar (an 8)

10100 PoLeat (1675)

10200 roen $18(8210.4)$

IUD

somoorIy sone

c

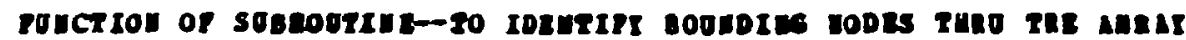
ISD $(n e, 2)$.

Sma 30

siat 35

STER 0

Srad 45

STR日 50

ST20 55

SIR日 60

sina 65

70

STRE 75

SII: 60

STRE 85

ST2 90

Sme 95

Srad 100

srar 105

Sma 110

S2R日 115

SIIA 120

sint 125

STR: 130

sme 135

sme 140

ST20 105

527n 150

srat 155

sma 160

sma 165

s2a 170

Sm0 175

S2I1 100

SF2: 105

$\sin 0$

sote 5

sour 10

swe 15

son 20 


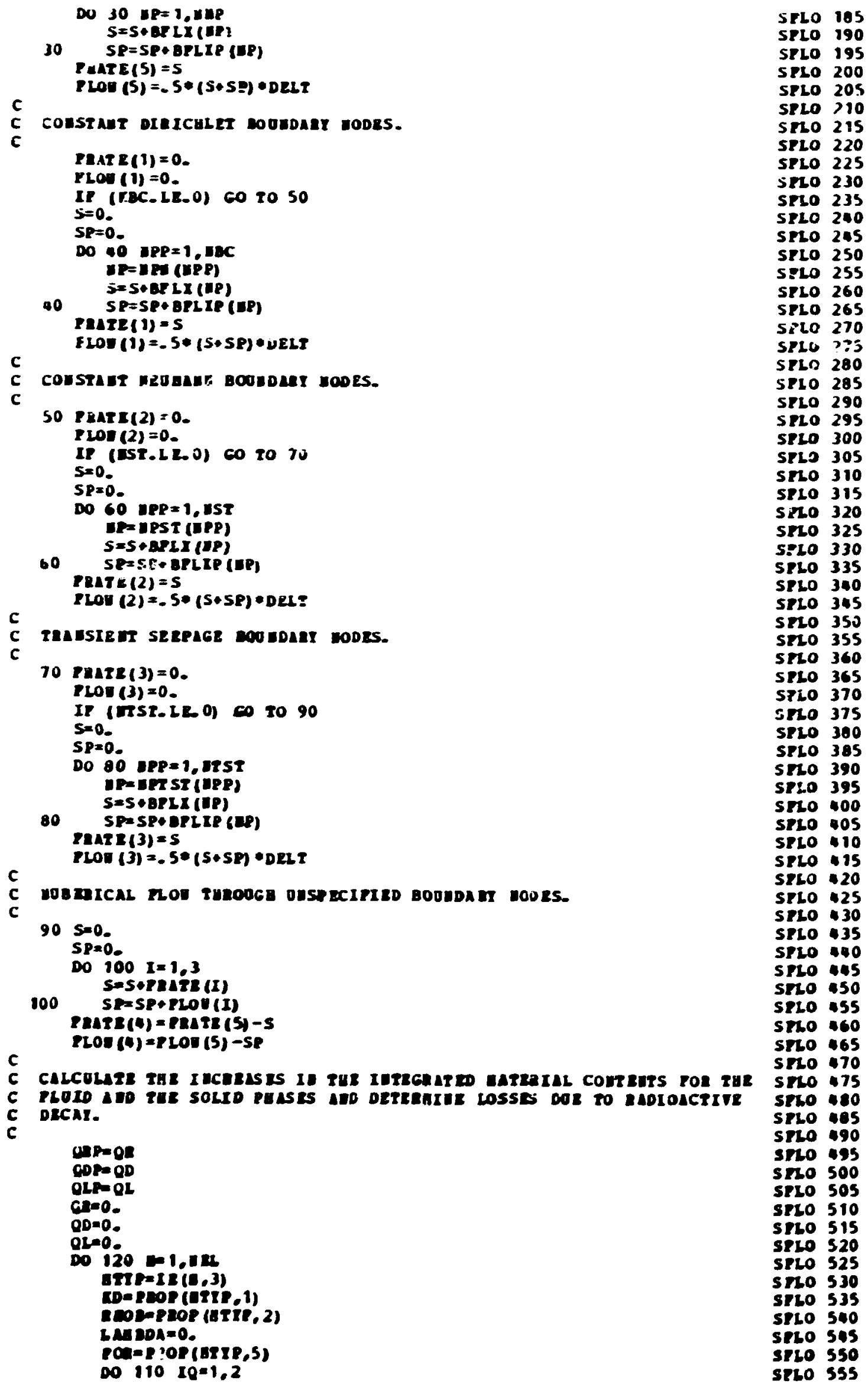

SFLO 105

SRLO 190

STLO 195

5 PLO 200

SPLO 20 S

SPLO $>10$

STLO 215

SFLO 220

SRLO 225

SRLO 230

SPLO 235

SPLO 240

SPLO 245

STLO 250

SFLO 25S

STLO 260

SPLO 265

SELO 270

SFLO $7 ? 3$

STLO 280

5710285

SPLO 290

SPLO 295

SPLO 300

STLO 305

SRO 310

SP10 315

SiLO 320

SRLO 325

SELO 330

SPLO 335

SPLO 310

$5 P 20345$

SELO 350

SELO 355

SRLO 360

SRLO 365

5710370

sRo 375

SPLO 300

SFLO 385

SRO 390

SFLo 395

SRO 400

SRLO MOS

SPLO 10

SPLO 15

SRLO 420

SPLO $\$ 25$

SRLO $\$ 30$

SPLO 35

SPLO 440

SPLO 45

sno 450

SRLO 455

SRO $\$ 60$

sTho 465

SRL 470

s.ro 45

SFLo 480

spro ies

SRLO 490

sno iss

$5 \% 0500$

SPLO 505

SRLO 510

SPLO 515

SPLO 520

SPLO 525

$5 \pi 0530$

STLO 535

SRLO 540

seto 545

STLO 550

STRO S5S 


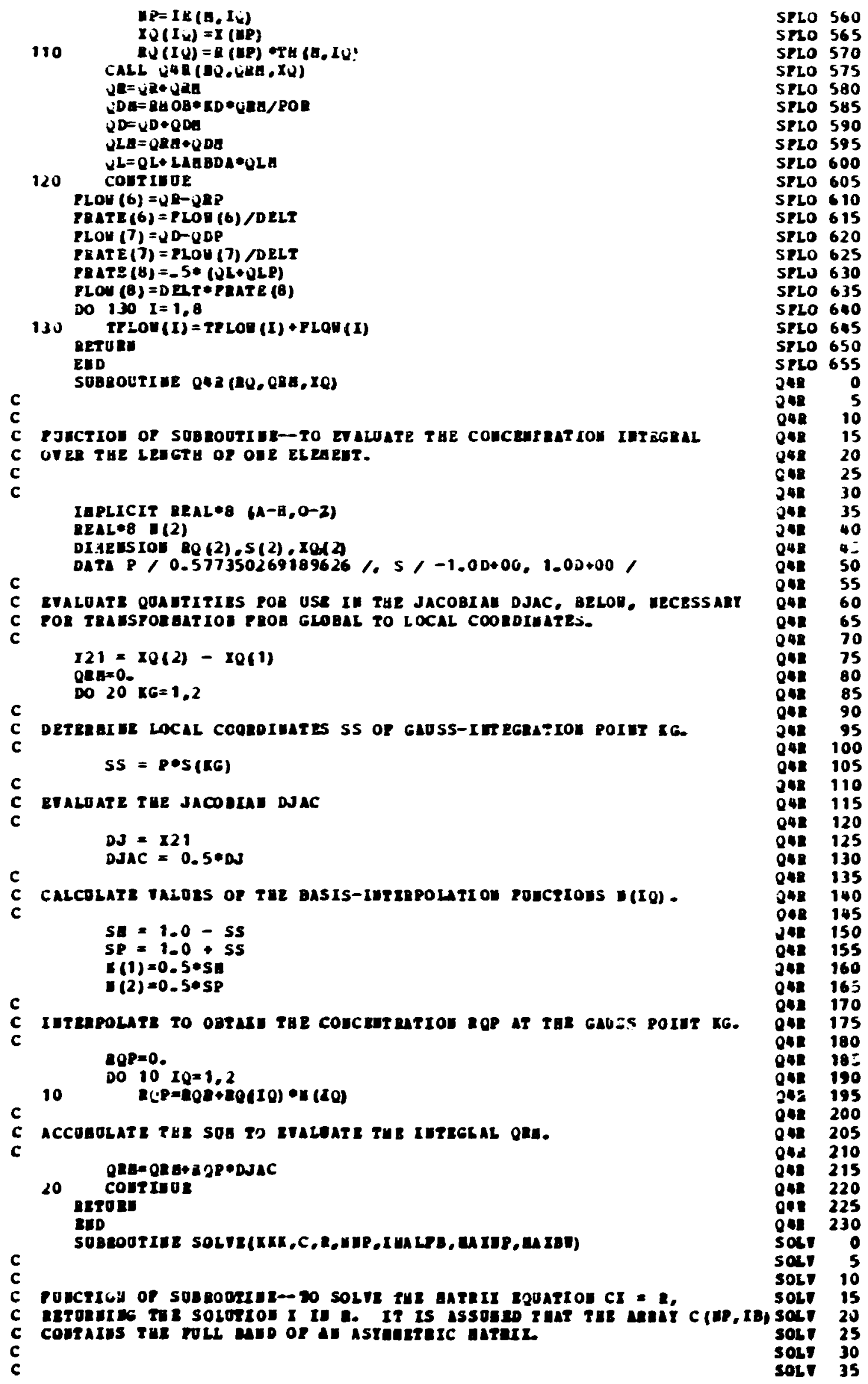




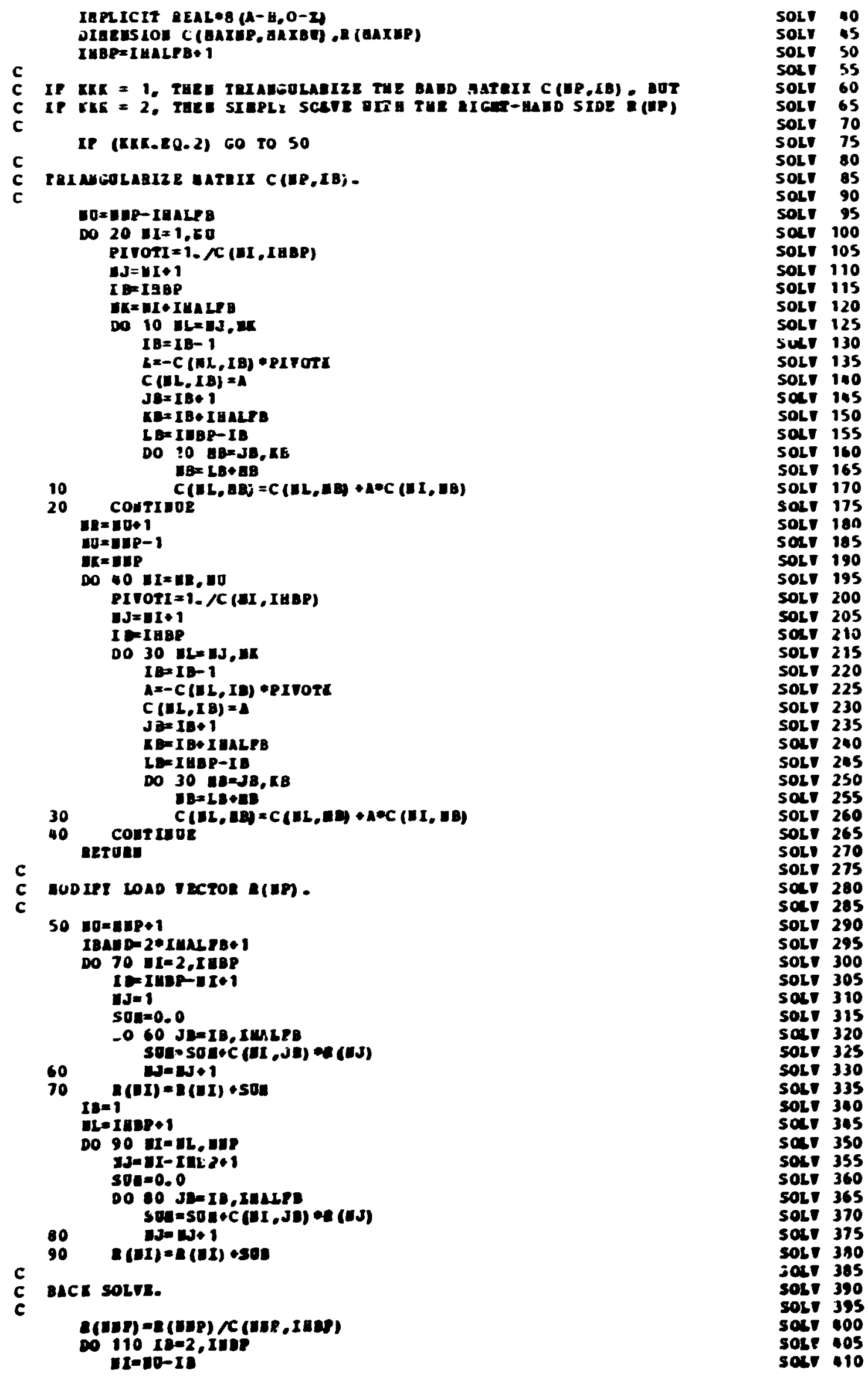




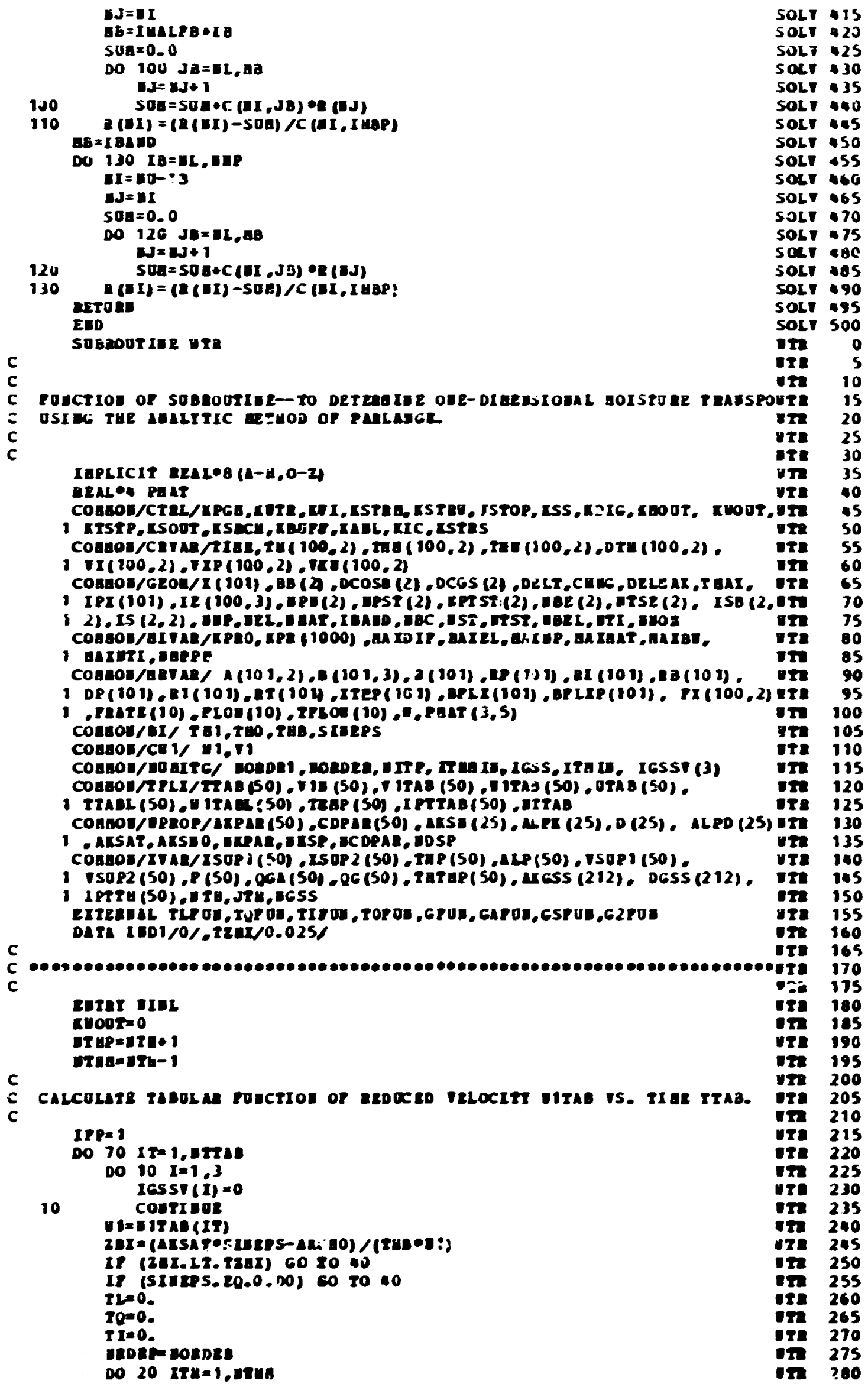




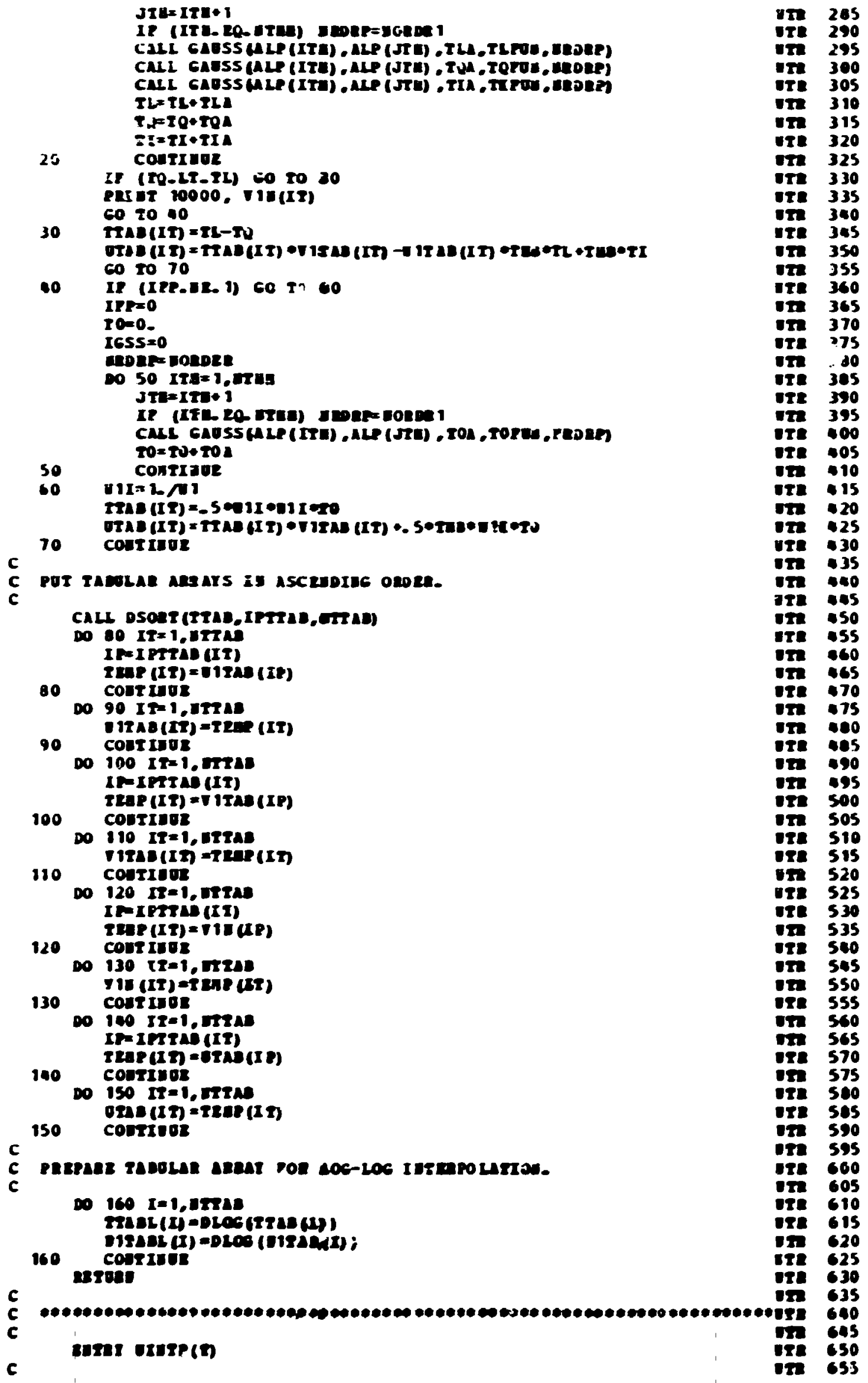




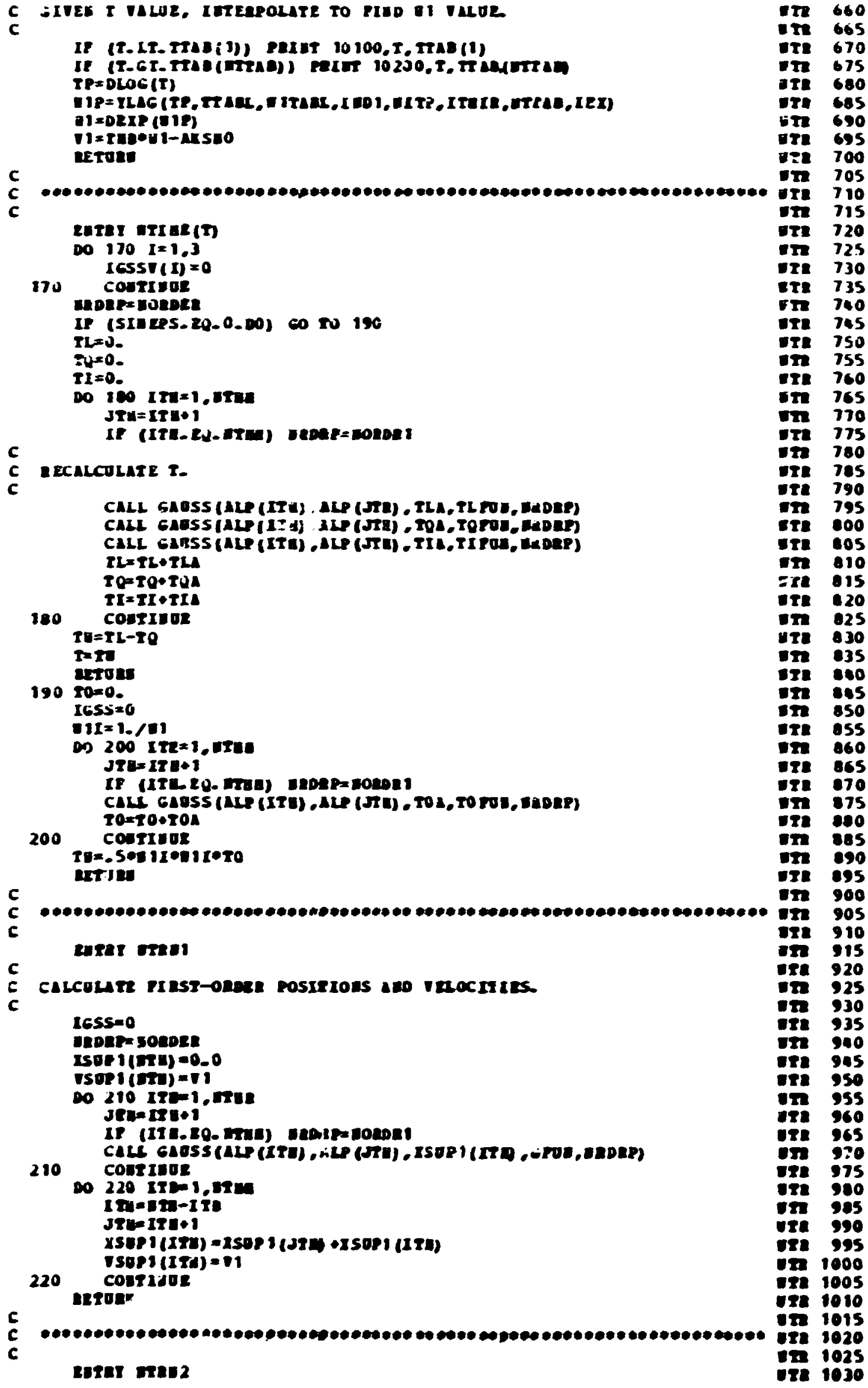


C

$\cos (1)=0$

I $655=0$

maparanonda

00230 ITI $=1, \pi T 2 a$

$\mathrm{JII}=\mathrm{IIT} \cdot 1$

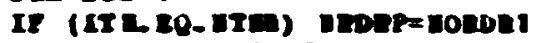

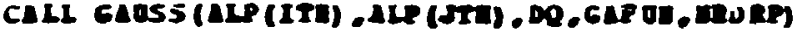

230

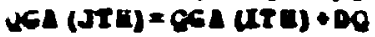

IESS=0 courIIUE

ERDER DORDER

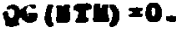

DO 200 ITH=1, DTE

$\mathrm{JTE}=\mathrm{Ix} \mathrm{I} * 1$

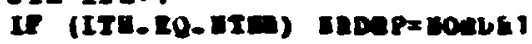

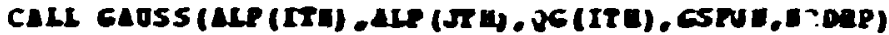

240 Cortune

DO 250 IRE=1, $62 \mathrm{II}$

ITI* DIII-ITB

JTR= IT $1+1$

250

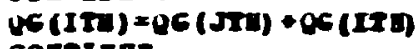

$$
\text { courimos }
$$

DUI:1-NOCA (III)

$F(1)=0$.

00260 ITI $=2$, nTI

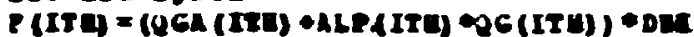

$c$

260 consimor

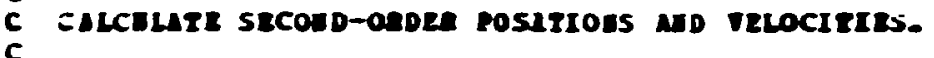

$$
I C 55=0
$$

Iruar $=1$

InDer $=$ mondere

ISUP 2 (UTA) $=0.0$

TSUP $2(2 \mathrm{ET})=1 \mathrm{~T}$

DO 270 IrE=1, .7TE

JTE= ITI+

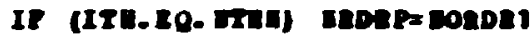

270 coligiss

DO 280 ITE=1, שren

IT:-7x-IT

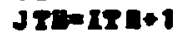

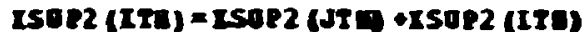

280

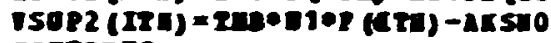

$c$ erroat corrives

C

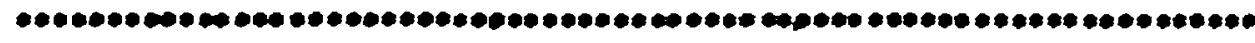

ERex DLID

C

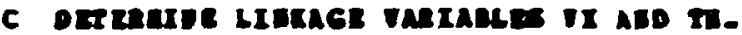

c

call osost (150R2, IRern, IU)

Do $290 \quad 1 \mathrm{~m}=1, \pi 24$

Vreisen (UP)

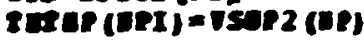

290 contros

$15=2 \operatorname{sen}($ (rin)

vorerues (usa)

Ixarye

Do $310 \quad n=1,00 \%$

IP (IfDn-Lx-InI) 0020300

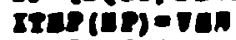

0020310

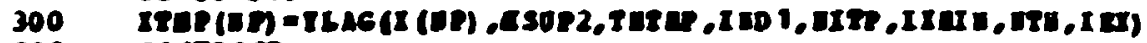

310 copint

Do $320=8,0 \pi$

$1032010-1,2$

UTrese.ron

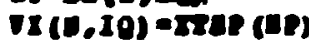

12. $10 \% 0$

1045

aTa 1050

I. 1055

DTR 1060

uTe 1005

T2. 1070

v21 1275

טT2 1080

vil 1085

DTR 1090

ETe 1095

-2 1100

aT) 1105

I. 8110

021115

घ21 1120

UI 1125

บ21 130

ตรe 1135

ㄷ․ 1180

บ2E 1145

vT2 1150

บ1เ 1155

DT2 1160

DI 1165

DIt 1170

02 1175

II 1180

DII 1185

טT2 1190

D21 1195

वTE 1200

ט2E 1205

บT 1210

vIR 1215

Dre 1220

ס21 1225

บT2 1230

व2E 1235

121280

T20 1245

y28 1250

DII 1255

DIE 1260

D2. 1265

ㄷ 1270

g20 1275

D21 1280

⒉ 1285

I2 1290

III 1295

vTE 1300

ㄷ 1305

021310

ㄹ 1315

721320

$02 \mathrm{1} 1325$

다 1336

ㄷ 1335

OIR 1340

อ21 1345

028 1350

02R 1355

느 1360

DIR 1365

C2R 1370

․ 1375

D2. 1300

021305

111390

02R 1395

Den 1400

다 1405 


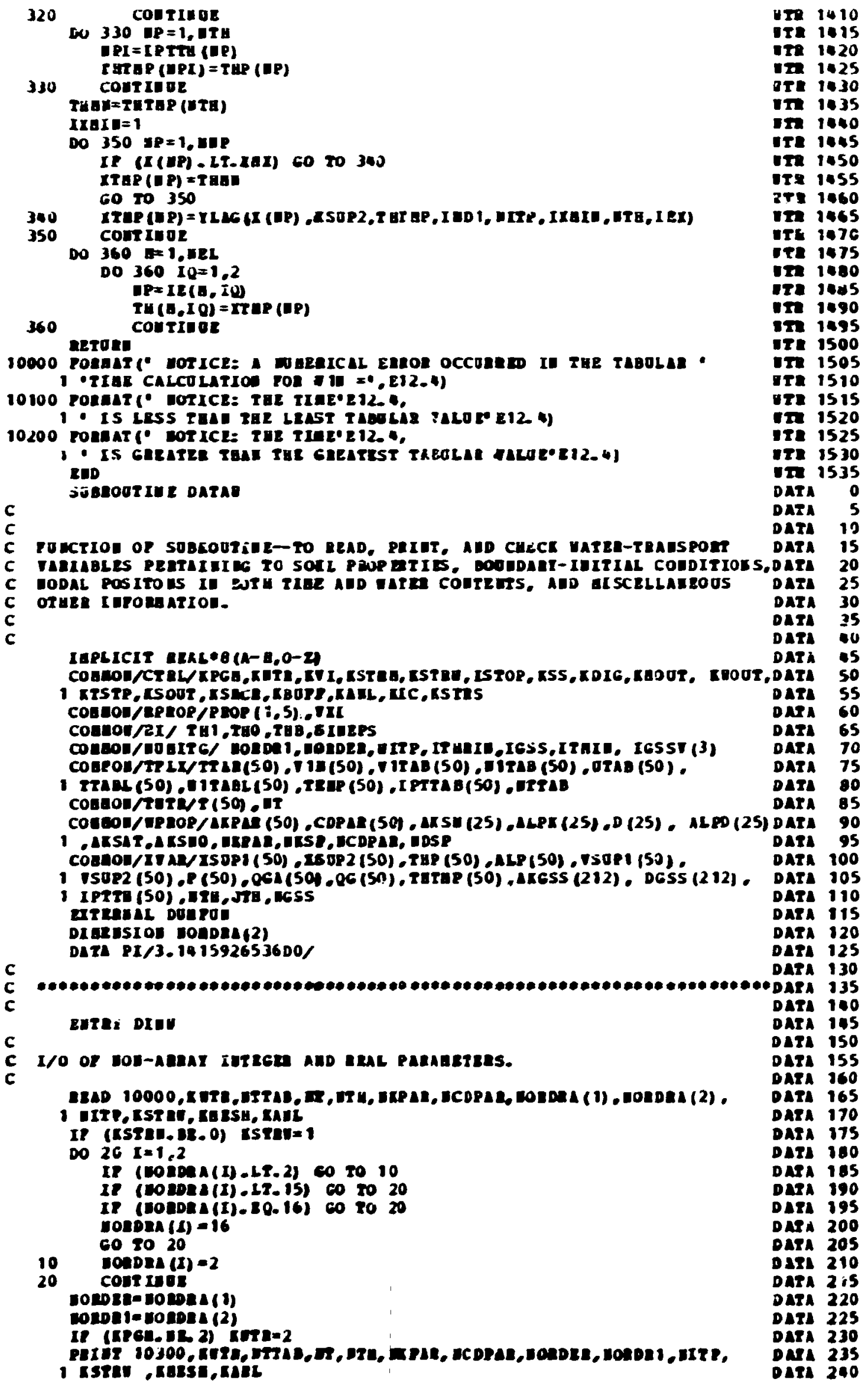




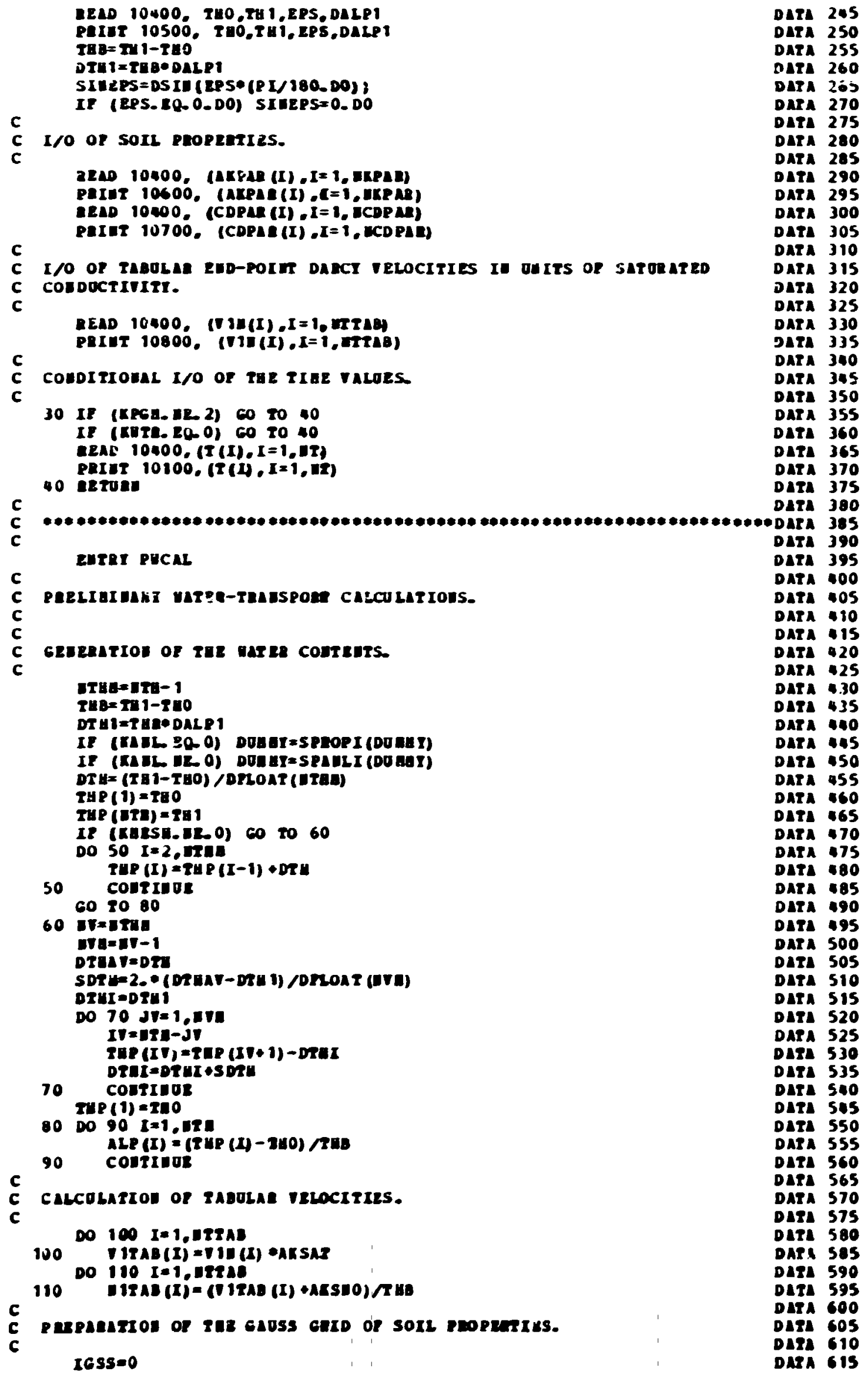

DATA 205

Dara 250

Data 255

oara 260

Data 2ós

Dara 270

Dara 275

Dara 280

Data 285

Data 290

Dara 295

Dara 300

DATA 305

Dara 310

Data 315

Data 320

Dara 325

Dara 330

DATA 335

Dara 340

Dara 345

Dara 350

Dara 355

Dara 360

Data 365

Dara 370

Dara 375

Dara 380

Data 390

data 395

Dara 400

Data 405

Dara 480

Dara 15

Dara 420

Dara 425

Dara 4.30

DAra 435

Dara 400

Dara 445

Data 450

Dara 455

Dara 460

Dara 465

Dara 470

Dara 45

Data 480

Dara 685

DAra 490

Dara 495

dara 500

Data 505

Dara 510

Dara 515

dara 520

Dara 525

dase 530

Dara 535

Dara 540

dara 505

data 550

Dara 555

Data 560

Dara 565

Dara 570

Daza 575

data 580

DAra 5 as

DArL 590

Data 595

data 600

Darl cos

dasa 610

Dara 6 is 


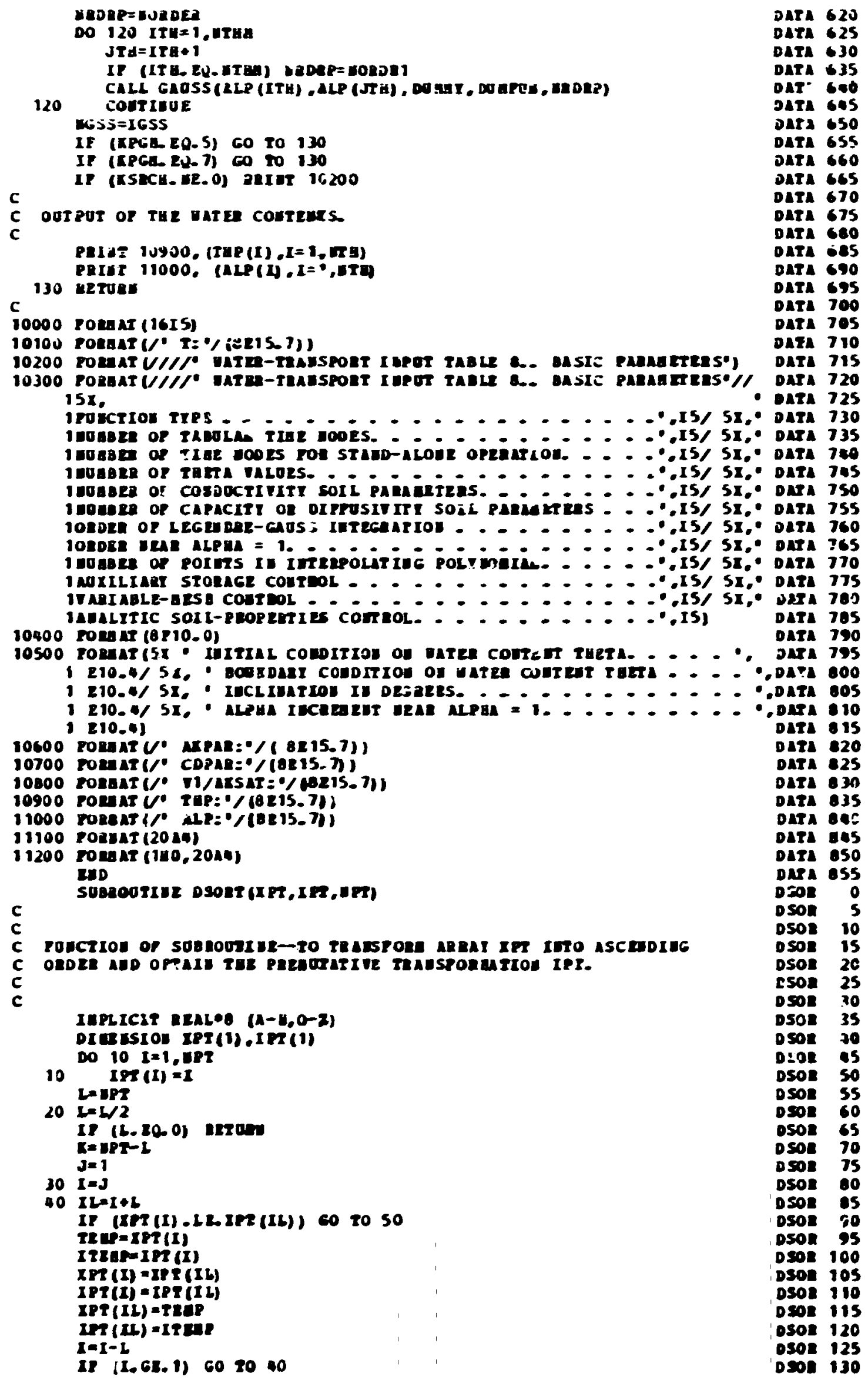




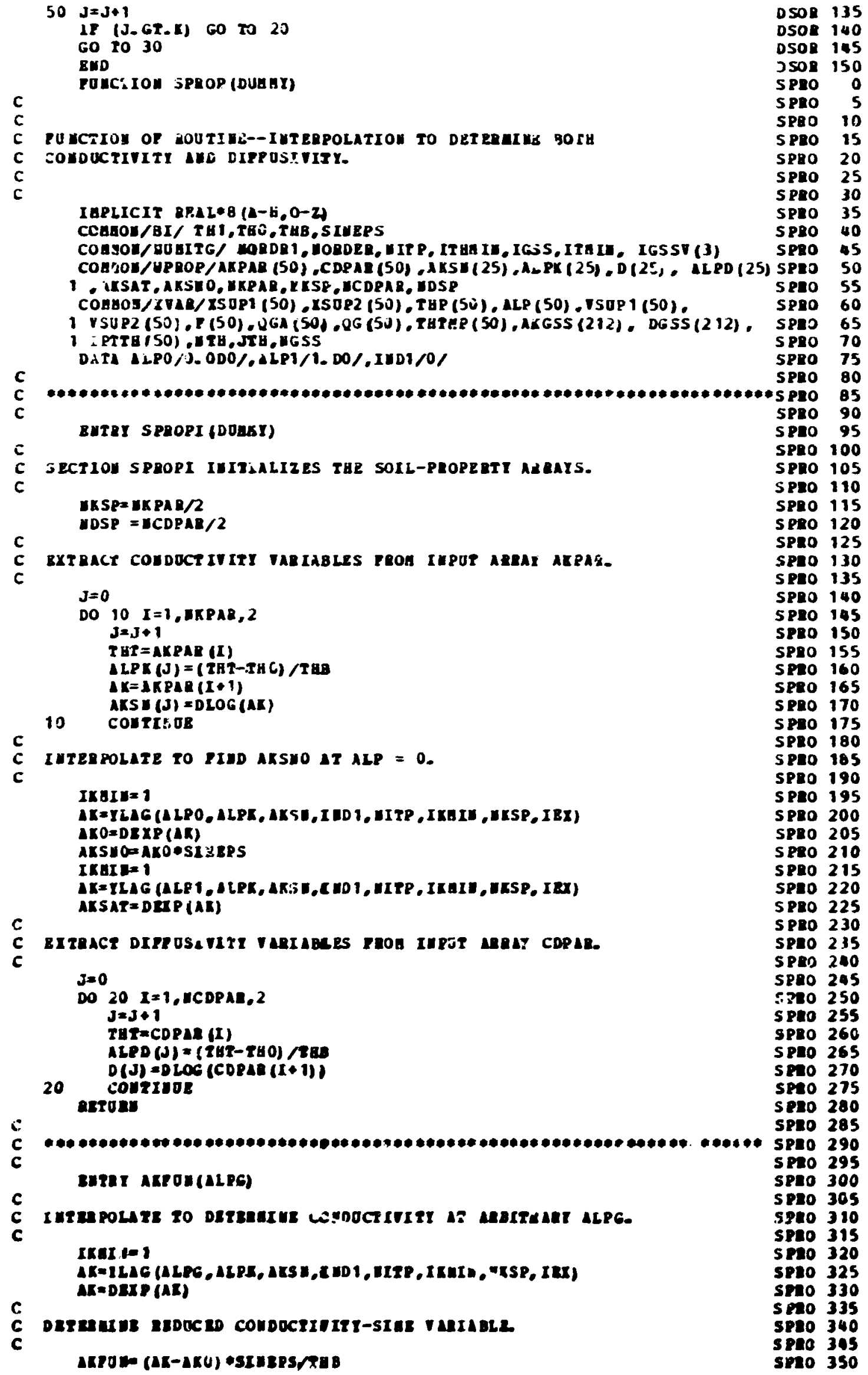




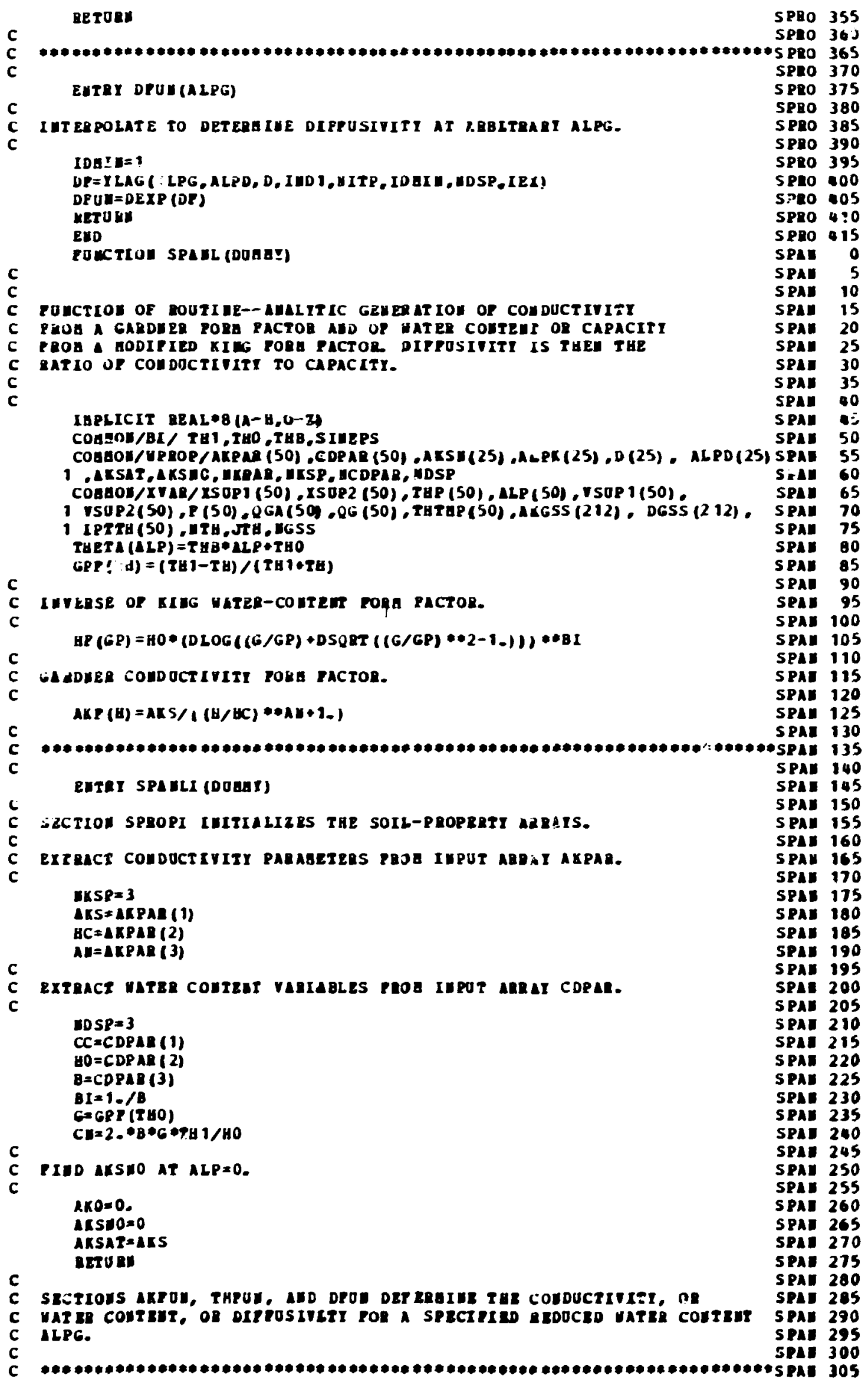


C

c

c

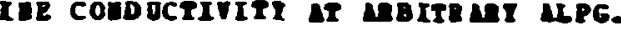

IR (ALPS. nE. 1.) 60 To 10

$\triangle R=\triangle K S$

GO 2020

10 TH=TARTA (ALEG)

$G P=G P R$ (TH)

$H=H P$ (GP)

$\Delta R=A R P(B)$

C

c

20 AKAUL $=(A K-A K 0) \cdot$ SIU EPS $/$ TUB aetuan

c

C

c

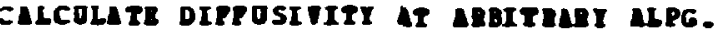

IF (ILPG. DE. 2,) 60 T0 30

TH= rat

AK=AIS

C=ccer:

601040

30 TH=T ATR (NLPG)

$G P=G R T$ (TE)

$B=A R(G P)$

$A x=\operatorname{lar}(\mathrm{B})$

$X=\dot{d} / \mathbf{H O}$

$x B=x * B$

$I B]=I B / X$

$C=C D * X B T * D S I N H(x B) /(D C O S B(X B) * G) * 2 * C C * T$ t

$40 \mathrm{DAIL}=\mathrm{AK} / \mathrm{C}$

RETUR:

C

c

c

C

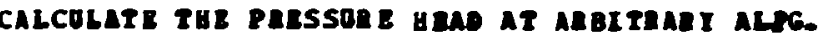

IF (ALPG. IR 1.) 60 TO 50

$\mathrm{B}=0$.

60 To 60

50 THETHETA (ALPG)

GP=GPT (TH)

$H=\mathbb{R}(G P)$

60 BADLER

ERTon

c

Calcolare tue ware capacter at aeserent alpo.

EUTAT CANL(ALEG)

IT (ALPG. UE. I.) 60 To 70

TH=2E1

coccer:

601080

$70 \mathrm{TD}=\mathrm{TITSL}$ (ILPG)

cPecp2 (Tii)

ien (OP)

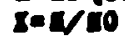

$x=x+4$

I01020/8

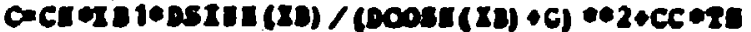

00 CalLac

ansond

I0
SPAI 310

SPLI 375

SPAE 320

SPAE 325

SPAI 330

SPAE 335

SPLE 390

SPAV 345

SPAE 350

SPAE 355

SPAD 360

SPAE 365

SPAI 370

SPAU 375

SPAI 380

SPAD 385

SPAL 390

SPAI 395

espal 400

SPAI 05

SPLU 110

SPAV A15

SPAU 420

SPAD 125

SPAE 130

SPAI 35

SPAI 440

SPAV 445

SPAU 450

SPA. 55

SPAI 460

SPAI 465

SPAI $\$ 70$

SPAY 45

SPAL $\$ 80$

SPAU 485

SPAI 490

SPAU 495

SPAI 500

SPAI 505

SPAI 510

SPLU 515

SPAI 520

SPAU 525

SPAI 530

SPAI 535

SPAI 540

SPAV 545

SPAU 550

SPAE 555

SPAE 560

SPA? 565

SPAE 570

SPAD 575

SPAI 580

spal 585

SPAI 590

SPAI 595

SPAI 600

SPA 605

STAI 610

SPAI 685

SPAD 620

SRAL 625

SRAI 630

SPAD 635

SRAL 640

S2AD 605

sed 650

spal 655

SPDE 600

sDnd 665

SDAD 670

SPLI 675

sRal 600 
Fons 10

rous 15

Pous 20

Pons 25

Fons 30

IAPLICIT AEALA (A-B,0-Z)

rous 35

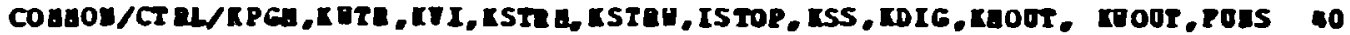

1 KTSTR,KSOUT,ISECH,KeOR, KAUE, KIC,ISTAS Fons es

conaor/Ca 1/ a1, V1

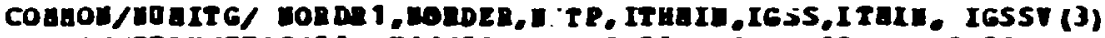

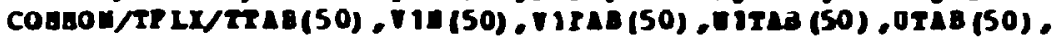

Pons 50

rons 55

Pous 60

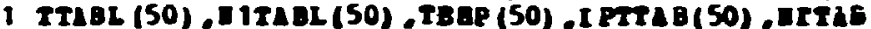

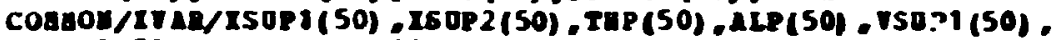

Pus 65

Pons 70

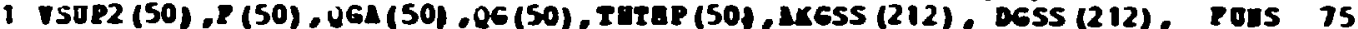

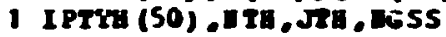
DATA IU01/0/

rous 60

Pons 85

c

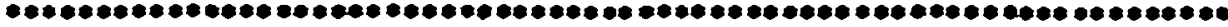

POES 90

c

EUTRI TLPOE (ALPG)

pous 100

rous 105

Fous 110

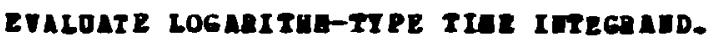

Pous 115

Pons 120

$\operatorname{ICSSV}(1)=\operatorname{ICSS}(1)+1$

IGSS=1GSSV (I)

AKSU=ARGS (IGSS)

Pous 125

rous 130

Pous 135

Pons 190

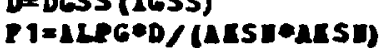

$Y 2=D L O C($ (AKII 11$) / U 1)$

pous 145

rous 150

$T L F U=P 1 * 22$

rous 155

Pons 160

c ReTUR:

Pous 165

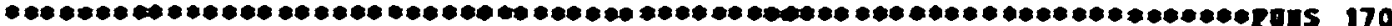

POUS 175

ETTAT TQPOE (ALPG)

POUS 180

Pous 185

Pous 190

DETEDIUE UOOTIETT-TIPE TIUE IGECAAD.

Puns 195

$\operatorname{IGSSV}(2)=\operatorname{IGSSV}(2)+1$

IGSS= IGSST (2)

Pous 200

Pous 205

AISU=ARCSS(IGSS)

rous 210

D=DESS (IESS)

pous 215

PI=LLPGED/ARSU

P2=1./(ARstedi)

Pous 220

TOPOT-P $1=22$

rous 225

esrons

pous 230

Pons 235

c

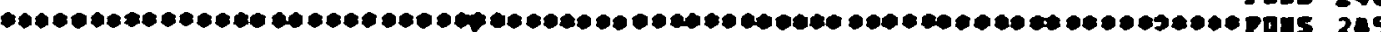

Pons 250

BUTET TOPOH (ALPA

PoIs 255

Pous 260

20ns 265

Puts 270

eos 275

POIS 200

2015205

Pons 290

Pons 295

reron

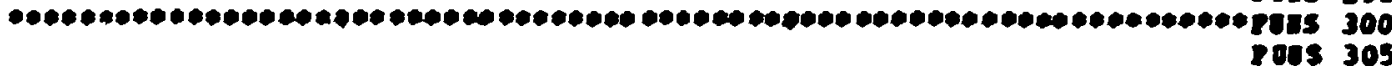

EuTER TIPODIALAO

Rons 310

rons 315

rons 320

7055325

Pous 330

Less $(3)=10397(3)+1$

ICSS-IGSSV (3)

irstentess (Less)

DoDess (z68s)

I00s 335

rous 340

TETD-NBES-D/ARE

pans 345

crove

Pous 35n

2008355

c

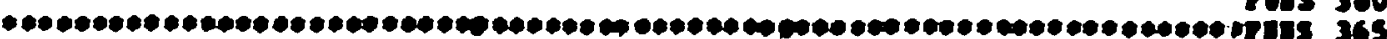

c

1008370 
EnTEY GPOA (ALPG)

2005375

c

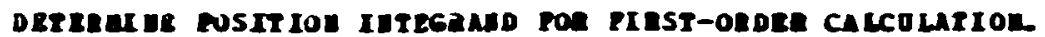

Fons 380

c

$I 65 s=1655+1$

ALSI=ARGSS (IGSS)

DEDESS (IGSS)

GPOD=D/(ACSU+D 1)

artoen

rous 305

rons 390

rous 395

rons 400

roLs cos

POus $\square 10$

rous 15

rons 20

c

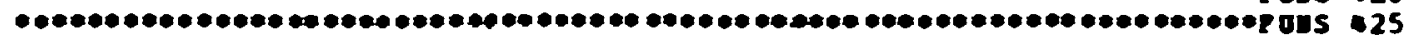

BHTET GAPOR (ALFG)

rous $\$ 30$

pons 435

rous 840

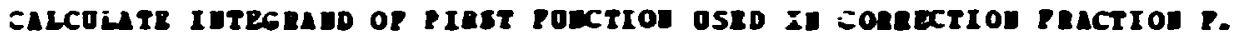

2653xI65S+1

AXSE=AKGSS (IGSS)

$D=D E S S$ (IGSS)

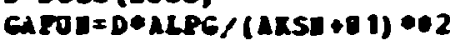

rous iss

pons iso

pons 55

poes 450

70.15465

eeturn

poes 71

pous 175

Pons $\$ 80$

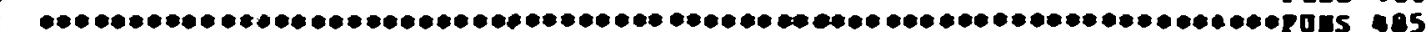

EUTRI GSTOD (ALPG)

Fous 490

Pous $\$ 95$

rons 500

c

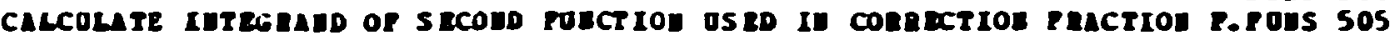

$165 S=165 S+1$

ARSERERES(ICSS)

$0=$ DGSS (IGSS)

GSPaE $* D /(A x S D+U 1) * \bullet 2$

netone

rous 510

rous 515

$7005 \$ 20$

pous 525

pans 530

rons 535

rous 540

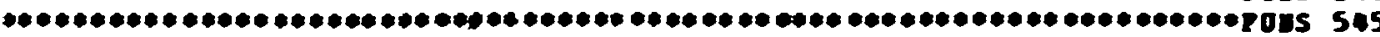

BUTEI G2TODIALPG

Pous 550

pous 555

ross 560

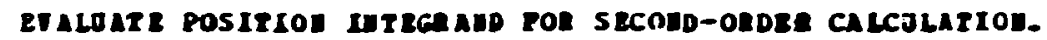

Pous 565

ICSS=ICSS+1

Pons 570

Pons 575

AxSD=AXGSS (16SS)

$D=$ DGSS (IGSS)

TP= ILLG (ALPG, ALP, R, INDI, DITE, ITHEIA, IRE, IRX)

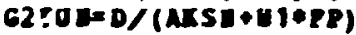

c

atron

Pons 580

rous 585

rous 590

pous 595

pous 600

Pors 605

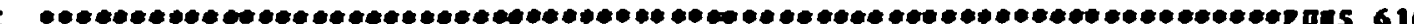

C

IIYAT DOEPOU (ALES)

rous 615

rous 620

C

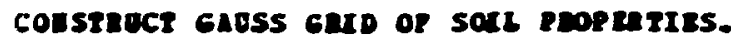

PoEs 625

Pous $\bullet 30$

rous 635

ICSS=ICSS $\bullet 1$

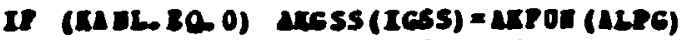

IP (RAUL IR O) MGSS (IGSS) -ARAK (ALPG)

rens 690

pons 645

rous 650

IP (KAUL- EO O) DESS (ICSS) = DROU (A LPG)

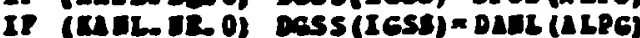

Donrever.

Puns 655

rons 660

POES 665

ntron

SUD

c

sobrode IUE paruse

2015670

Pots 675

Para 0

Pexi 5

pard 10

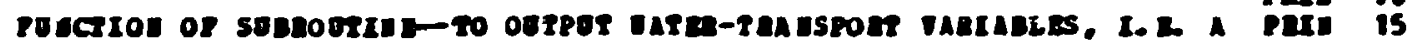

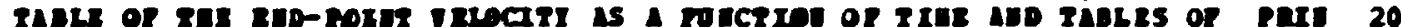

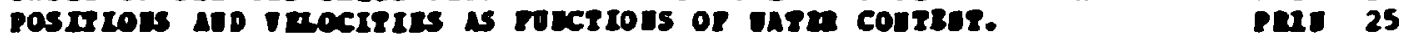

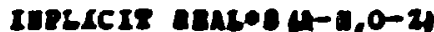

Petr 30

PaId 35

40

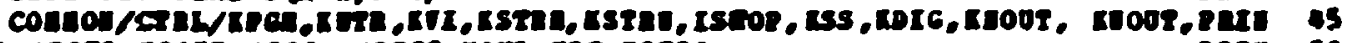

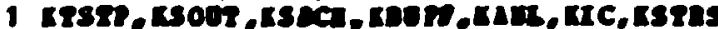

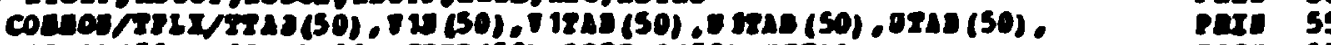

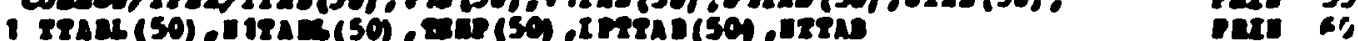

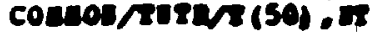

Para 6 


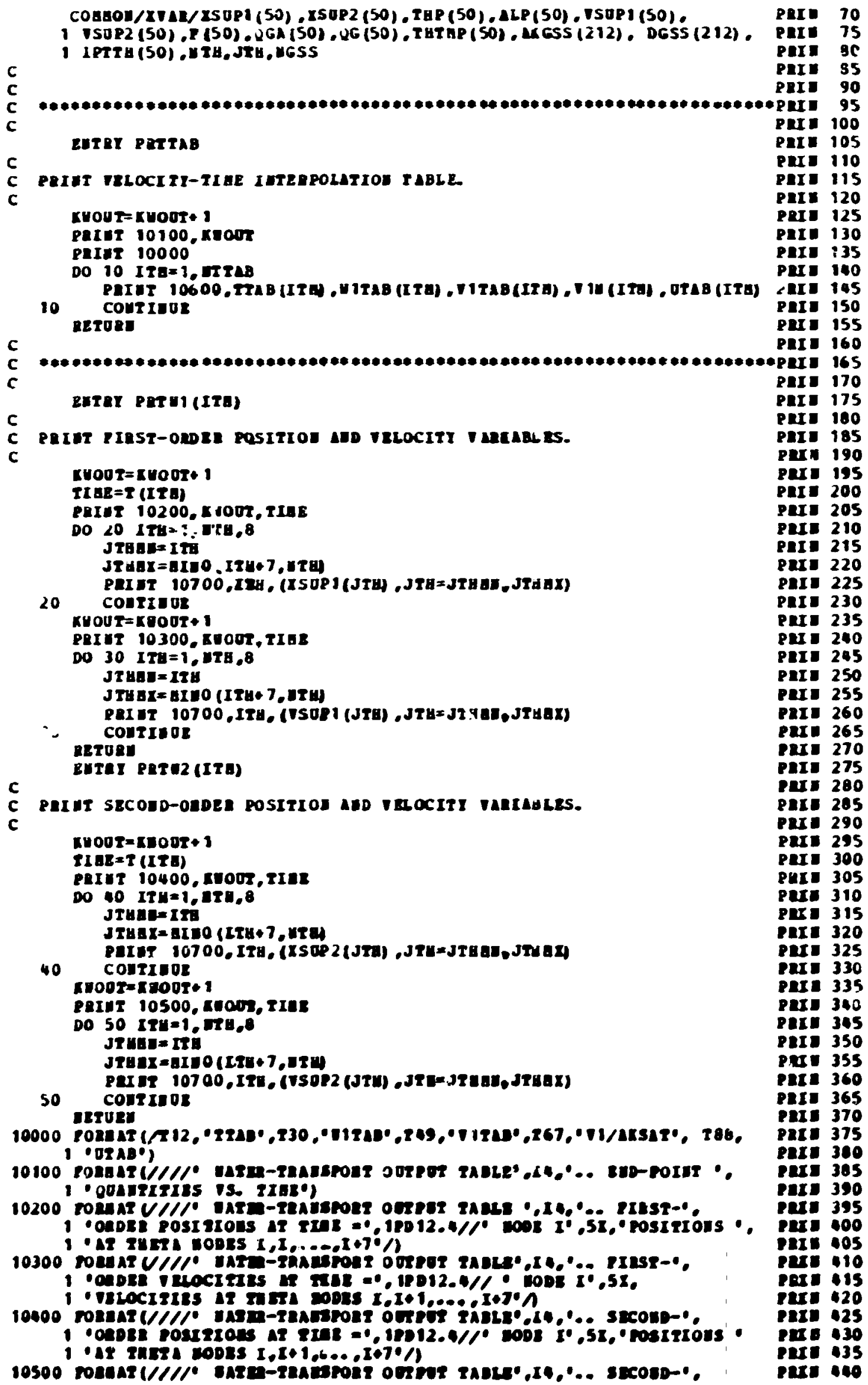




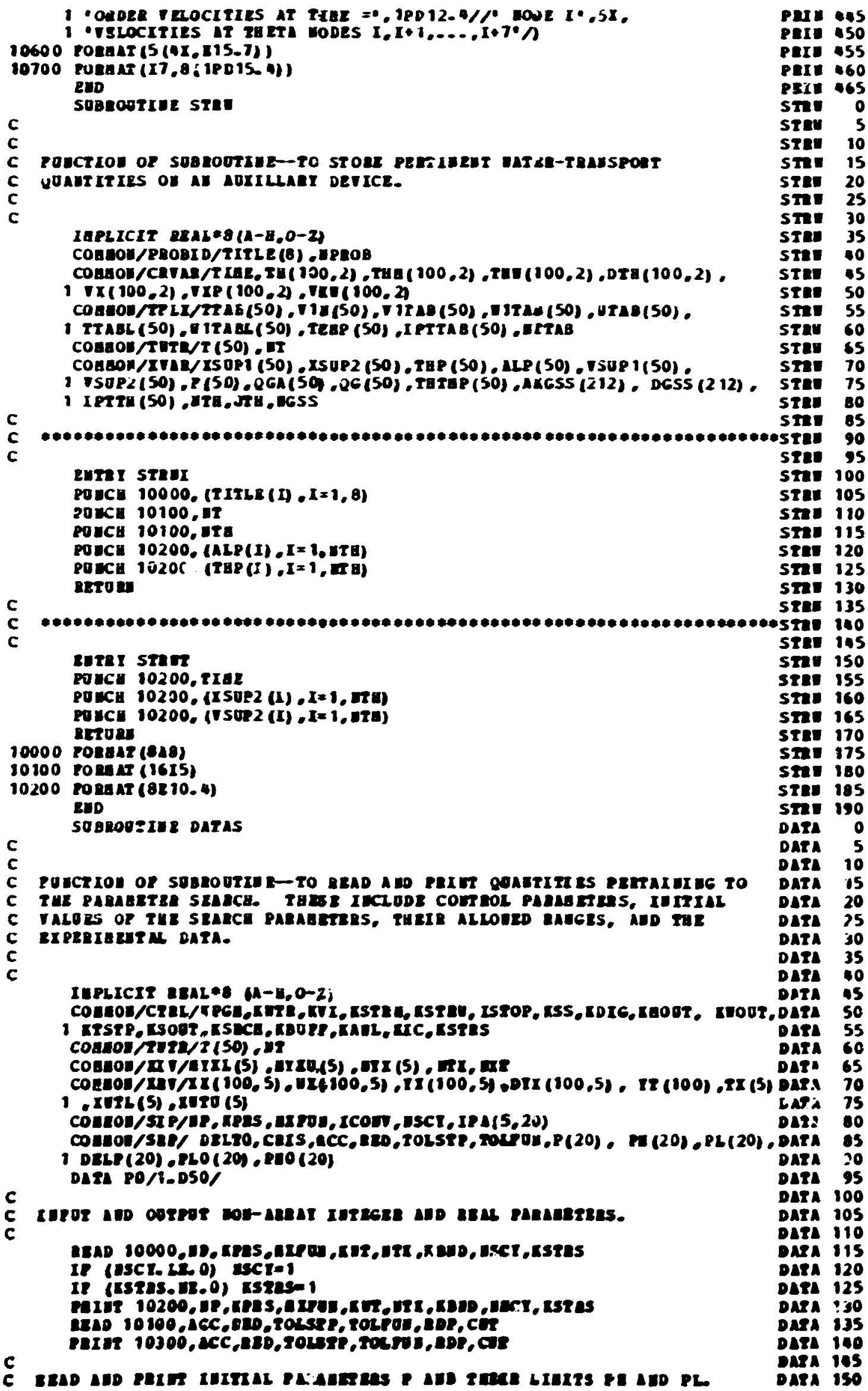


C

$c$
$c$
$c$
$c$

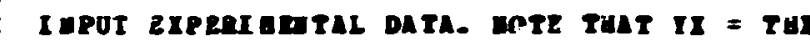

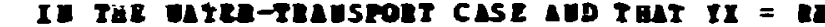
IE THE aATEIAL-TRASTOAT CASE.

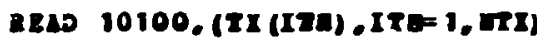

IP (KPCA. IE-S) 00 to 00

$\cot =1 \mathrm{~T}$

DO 70 ITE $=1, \mathrm{TT}$

10 T(ITU) $=$ TI (IT)

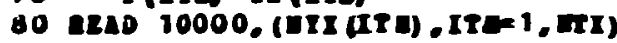

Do $\gg 0$ Ira $=1, \operatorname{Lr} x$

arIXL(xTa) $=1$

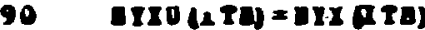

PaIIT 10600

DXT=0

DO 230 ITE $=1$, UIX

$\mathrm{II}=\operatorname{mix}(\mathrm{ITa})$

$8 x=1 \times x+1$

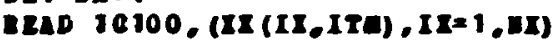

READ 10100, (II (II,ITU),II=I,EI)

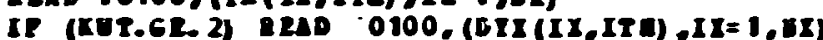

IF (KET.GR, 3) RBAD .0100,IUTL(ITA) TOTO(ITA)

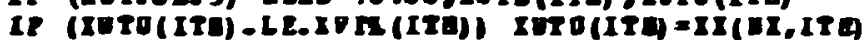

calcolute statistical hercars.

IF (KOR.G2.0) 60 TO 110

DO $100 \quad I I=1,1 \times$

DIL (II, ITA $=0$.

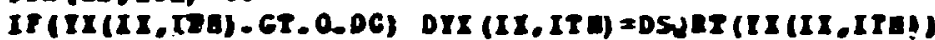

$n T=0$.

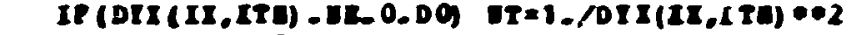
$\operatorname{II}(I \mathrm{II}, \mathrm{IA})=\mathrm{DT}$

6020190

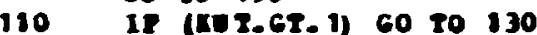

DO $120 \quad I x=1,0 x$

DIX (IX, Itrd) =cuT*II (IX,Ira)

$\Delta T=0$.

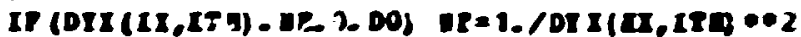

120 $U \mathrm{X}(\mathrm{IX}, \mathrm{ITI})=\mathrm{UT}$

60 ro 190

130 DO $180 \quad I I=1, \pi I$

$\mathrm{vT}=0$.

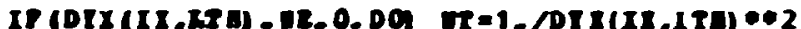

140

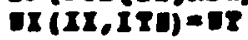

IP (IET. 20.2) 6020190

II: 0

DO $150 \quad I I=1, n$

$\mathrm{I}=\mathrm{n} x \cdot \mathrm{I}$

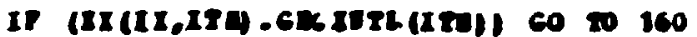

$0 x(I x, I T H)=0$.

150 merivos

160 aIIL(ITO)-

II=

DO $170 \mathrm{JI}=1, \mathrm{II}$
Data iss

oATa 160

onta 165

oara 170

data 175

Dara 100

oata 185

dara 190

data 195

Dara 200

DLTa 205

Dara 210

DATA 215

DATA 220

Dara 225

Data 230

dara 235

dara 240

DATA 2as

data 250

data 255

DATa 260

DATA 265

Dara 270

DATa 275

dara 2 a

Data 205

DLTI 290

Dara 295

olta 300

data 305

Dera 310

oAta 316

- ata 320

Data 325

DATa 330

oata 335

Dara 340

Dara 385

data 350

data 355

dara 360

dara 365

Data 370

Data 375

oAra 380

Dara 385

Data $\rightarrow 90$

Dara 392

Data 390

DLTa 398

dara $\$ 00$

Dara 402

dara 05

Data 10

dara is

Dara 920

Dara $\$ 22$

Dara 420

Data 926

Dara 30

Dara 935

Dara 30

DAFa 940

DLTL 482

Dara 95

I TA 050

DATa 55

Dara 460

Dara 45

Dara 170

Dara 975

Dara 980

dara cos

Dara oso 


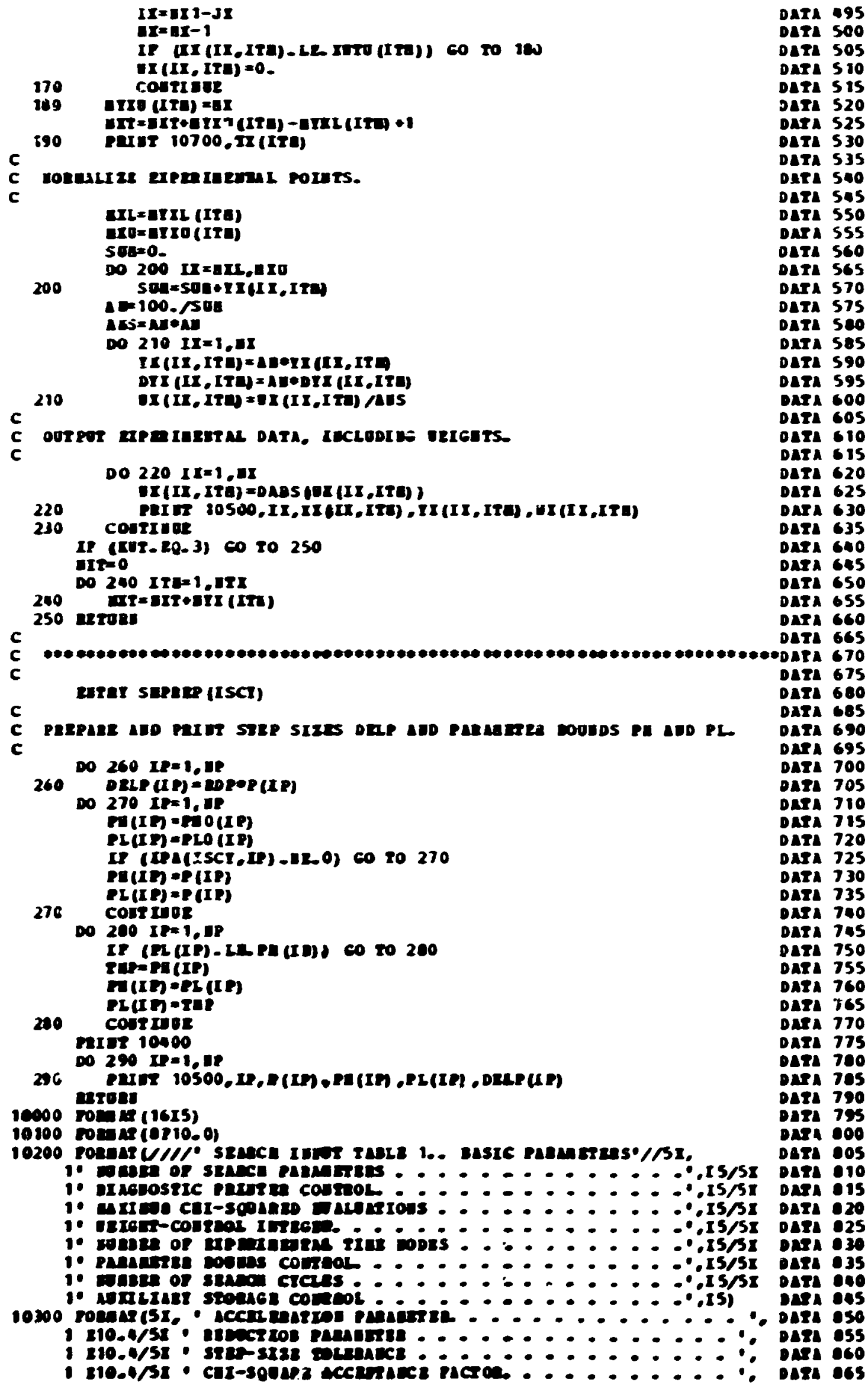




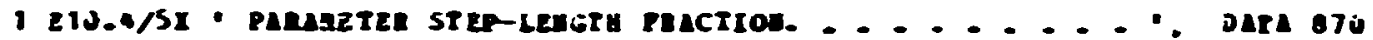

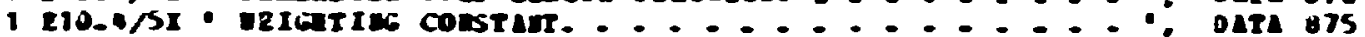

1 E10.d

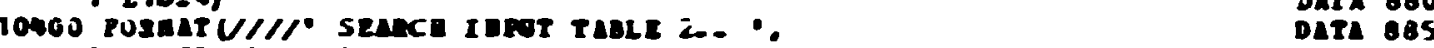

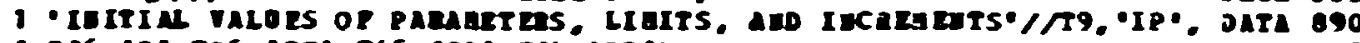

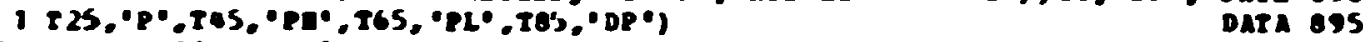

10500 ronarit(10,420.5)

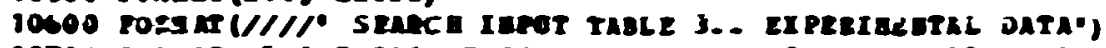
$\left.126 .^{\circ} \mathrm{ex}\right)$

EDD

c

subrodriue parms (ITE)

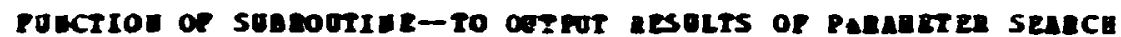

onta 900

Dara 980

DLIA 915

DATA 920

Peir 0

Pers 5

PII: 10

PaI. is

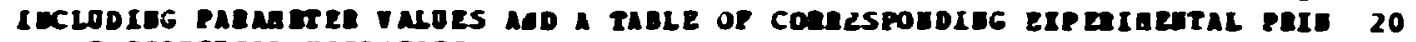

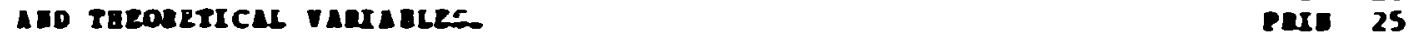

c

IAPLICIT LILE (L-B,0-Z

GeAlo PaAT

PaI. 30

pers 35

PII. 40

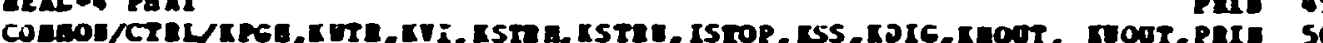

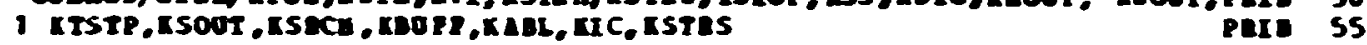

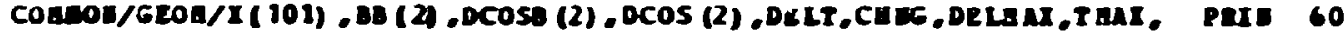

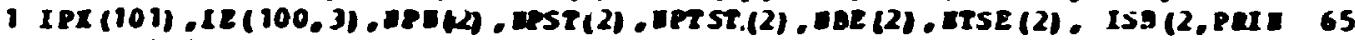

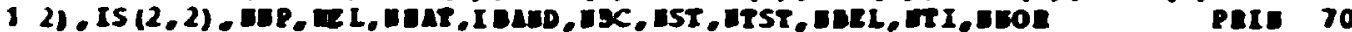

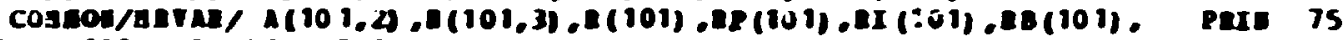

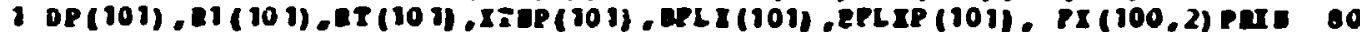

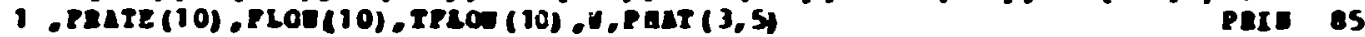

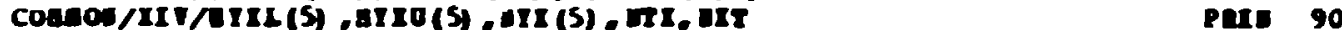

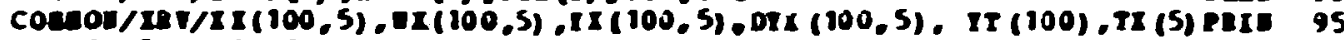

1 InTL (5) IIITO (5)

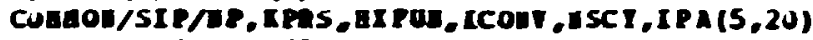

PaIs 100

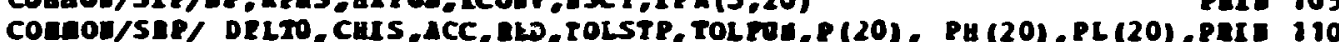

I DLLP(20), PLO (20), PEO (20)

$\mathrm{CSOQT}=\mathrm{KSOUT} \cdot \mathrm{I}$

PaIET 10100, RSOOT

c

par to pinal panagera taloes.

DO 10 IPE 1,18

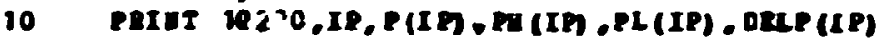

$c$

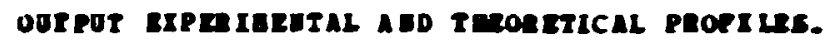

c

ISSOdT=RSOOT+I

Patex 10300, rsoot

$\operatorname{Mr}=\operatorname{six}(\operatorname{TTA})$

PaIET 10e00, II (ITB)

DO $20 I I=1,4 \mathrm{X}$

20 PALUT 10200,IX,IX(IX,ITa),IIII,ITE), IIII),DIX (IX,ITA)

IP (ITE.UR.GTI) 00 T0 30

c

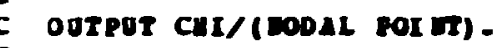

c

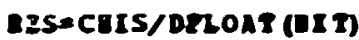

LES D DSORT (RES)

Paide 10500, es

30 extuan

10000 ponant (IS, 5x, E10, 4$)$

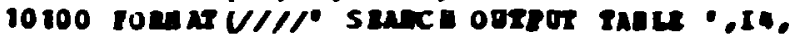

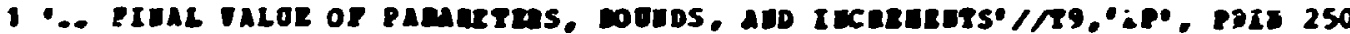

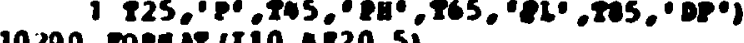

10200 rond ar $(210,4220.5)$

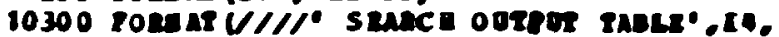

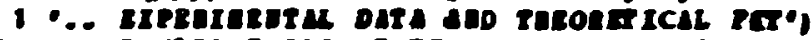

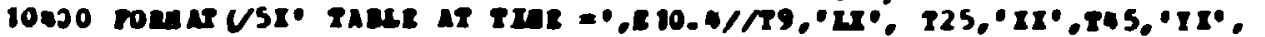
$\left.1765, \circ 19 \circ, 780^{\circ}, 01 \mathrm{C}^{\circ}\right)$

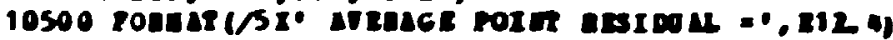

ISD

$c$

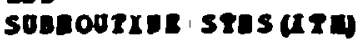

c

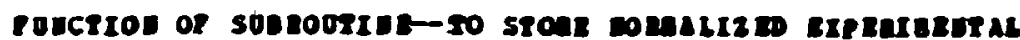

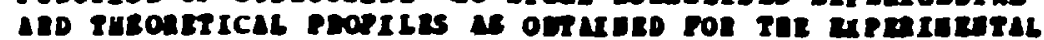

PeIs 115

P2II 120

PaI. 125

PII. 130

Pard 135

Par. 180

pers 145

PEI 150

paIE 155

PAIE 160

Para 165

Per. 170

PaId 175

PEI 180

Per. 185

paIa 190

para 195

Pard 200

PaI 205

PEI 210

PII 215

PEI 220

PAI 225

PRI 230

paru 235

Para 240

POIS 250

Para 255

Para 260

PaI. 265

Pero 270

pera 275

Pur 200

Per. 205

SnI 290

sres 0

sins:

squs 10

sres is

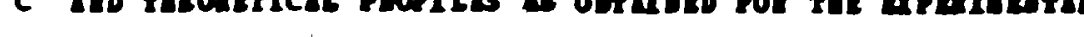

$\operatorname{sins} 20$ 


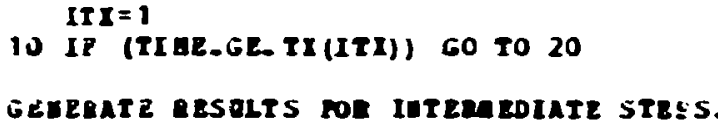

c c

Call ataa.

IP (KPGA. LE. 3) CALL PEUTE (ITA)

DELT=DELI* $(1 *$ CBIIG)

DELT= DEIE ! (DILT, DRLAR I)

TIAE =TIAE DELT

ITAxITa+1

c

co To 10

c

20 DELTP $=$ DELT

DELT = DELT - (TIAE-TX (ITX))

TIAE = TI (I TX)

CALL aTME

IF (XPGALE 3) CALL PEUTI (ITA)

$\| x=\operatorname{III}(\operatorname{IIX})$

$\operatorname{IIAL}=1$

sog $=0$.

aXLa AXXL(ITX)

EIO=GIXO(ITX)

DO $30 I I=1, \pi X$

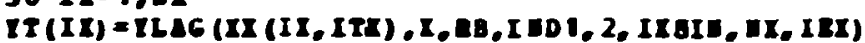

IF (IX.LT-EXL) GO TO 30

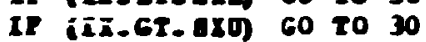

SOE-SOAPIT (IX)

$c$

30 Costinos

c

monghlze THEonetical potas.

$A I=100 . / 5$ of

DO $40 \quad I I=1,1 \mathrm{X}$

IT (II) = AD*IT (II)

c

COLlect CHI-SQOARER.

40

CUIS=CHIS UIIIX,ITi) $\bullet($ IT (IX) $-1 I(I X, I T I)) * 2$

$$
\text { consinaz }
$$

CuIS0=curs

IP (KPGE 6T. 3) 60 TO 50

CALL PEIETS (ITI)

IP (ISTES. D0.1) CALL gTIS(ITI)

50 If (ITX.GR. EII) 60 TO 60

$I T I=I T X+1$

DELT $=$ DELTP

TI HETI TI $\triangle D E L S$

ITH:ITn+1

Co 1010

60 RETORD

END

SUBROOTIME RERTAS (P.CHIS)

C

c

c

C

c

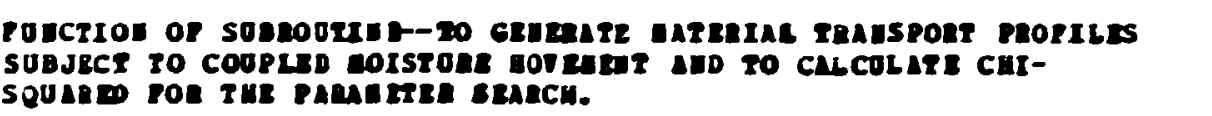

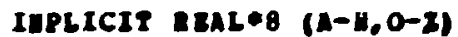

PrALAS PaAT

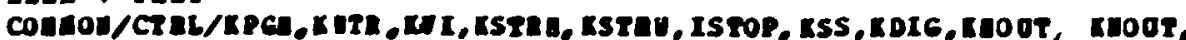

1 ITSTP, KSOOT, KSECU, KBORT, KAHL, KIC, KSTES

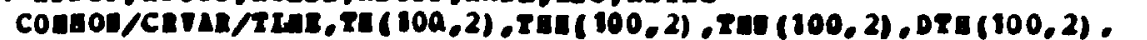

$1 \mathrm{~V}(100,2), \mathrm{T} \times \mathrm{P}(100,2), \mathrm{Ve} \times(100,2)$

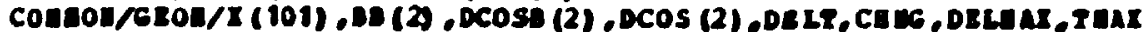

IPI 101$)$. 70

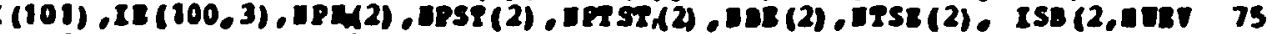

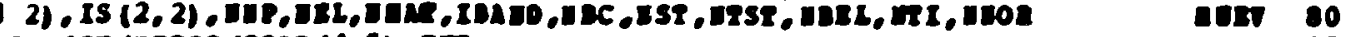

corton/areop/PRep $(1,5), \mathrm{en}$

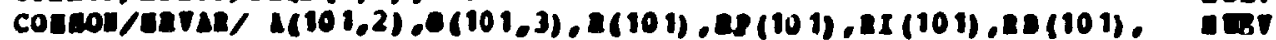

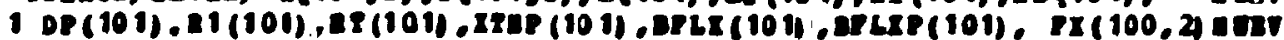

85

90

95 


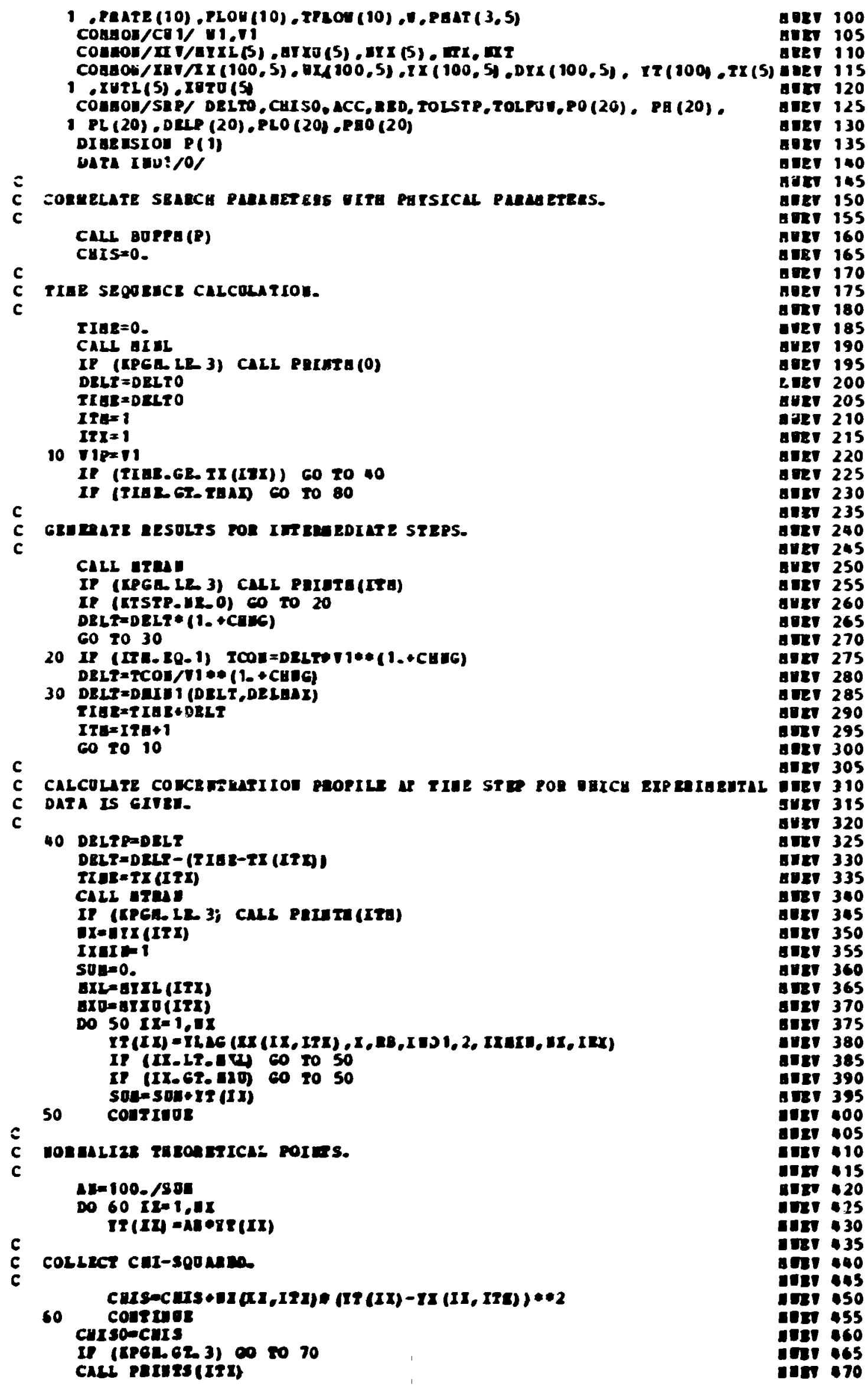




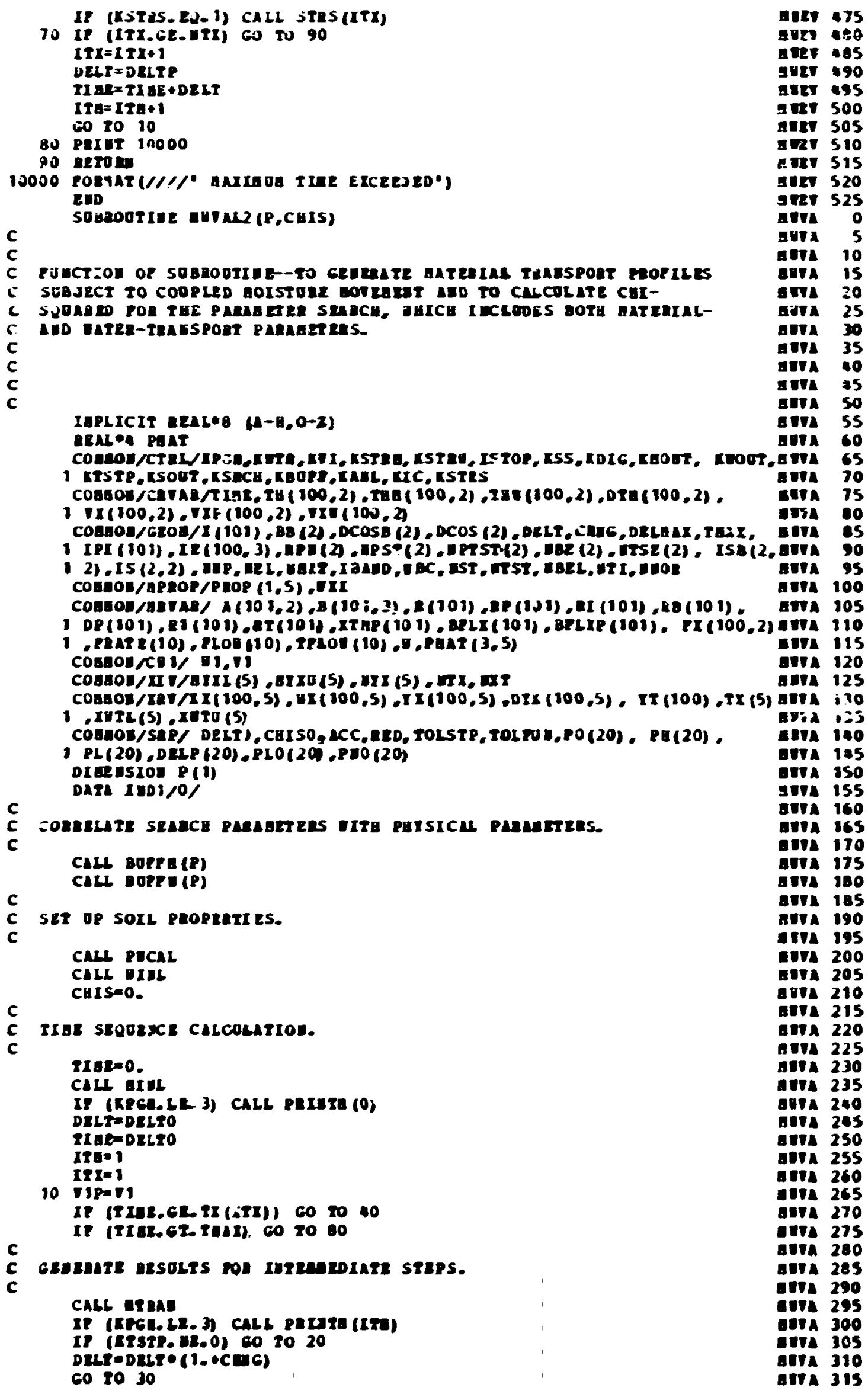




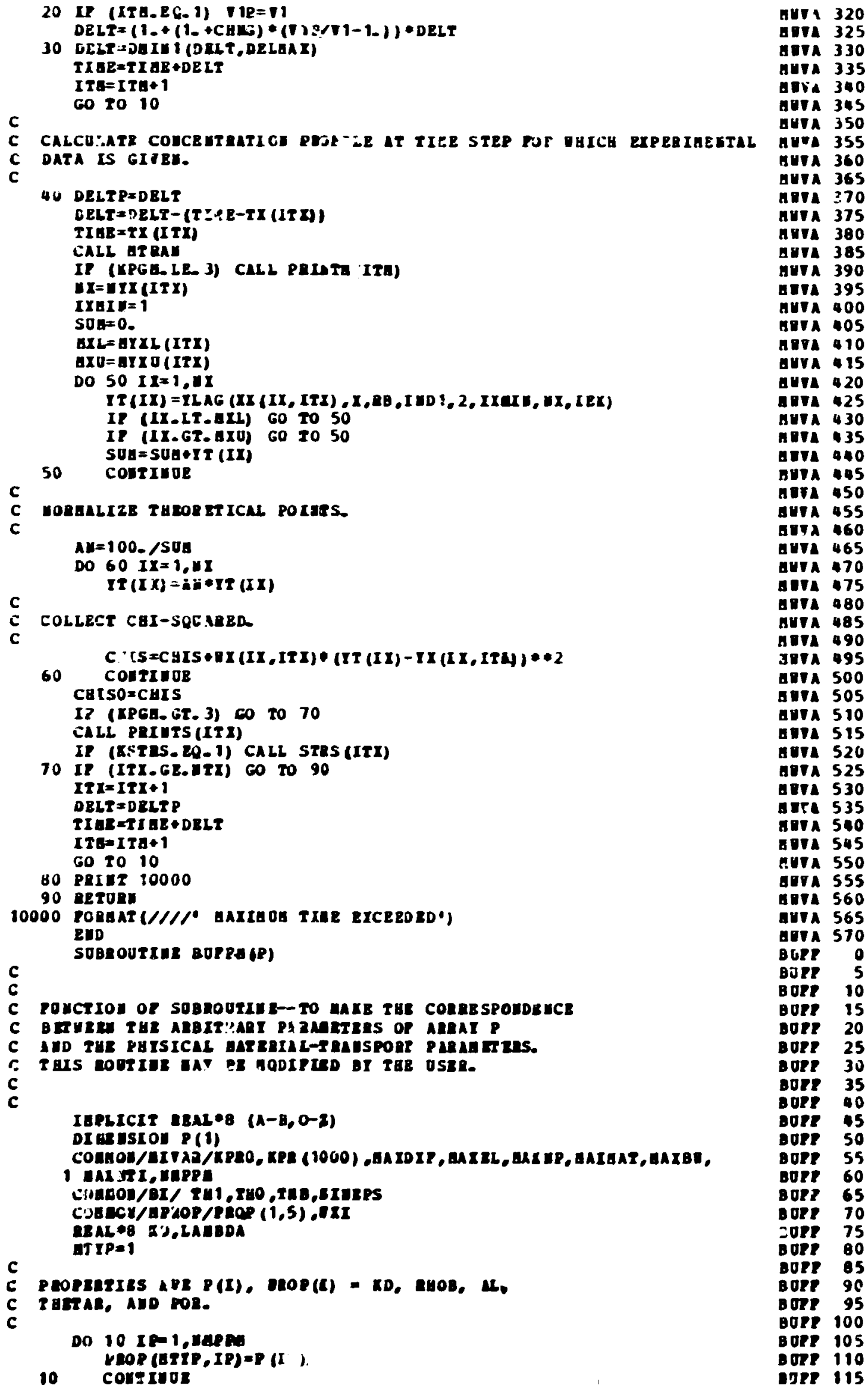

GDVA 325

avor 330

aria 335

aria 340

avia 345

auta 350

auda 355

nuta 360

MUTA 365

G074 370

ตบบ 375

avta 380

aUTA 385

MUTA 390

arTa 395

GUVA 400

MaTA 405

nova 410

aUva 15

auta 420

aDTa 425

ดบบ 430

ตถบน 35

avta 440

nUVA 405

neta 450

guta 455

geta 460

GUVA 465

auta 470

a DVA 475

aña 980

MUTA 485

nev1 490

307A 495

gata 500

- viva 505

aU7a 510

avia 515

aeva 520

avia 525

anva 530

are 535

anTa 540

BOTA 545

GUVA 550

aUVA 555

GDT4 560

aUva 565

avia 570

BUPR 0

BuRP 5

Bort 10

BOR2 15

DORP 20

BOPE 25

BOPR 30

sore 35

- 0r2 40

bore 45

bore 50

BORT 55

BUPR 60

BOP? 65

DOR 70

zORP 75

- opa 80

DOPR 85

BOPF 90

Bur 95

BOPR 100

BOPP 105

DORE 110

DDP 115 


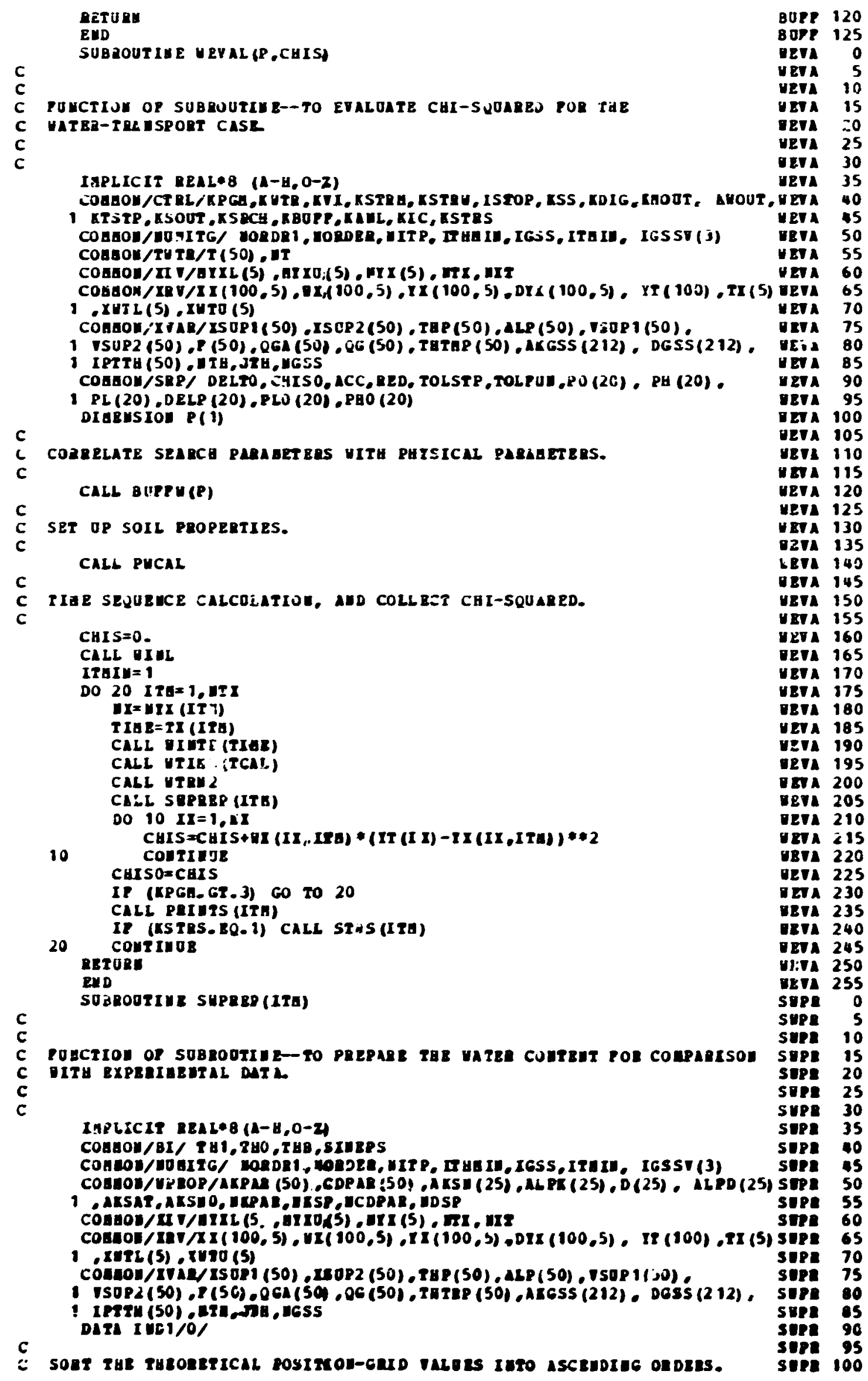


IIx IIX (ITE)

CALL DSORT (XSUR 2, IPITH, UTH)

$c$

C NADER ATEO-COHTER VALQES COREESTHDIJGLT.

C

DO $101 \mathrm{TH}=1, \mathrm{TL}$ JTH= IPTH (ITH) $\operatorname{THTAP}(\mathrm{JTH})=-2=$ (ITL)

10 costruoe

c

IHIERPCLATE ON TAE EXPERIAETTAL POSITIOU GID.

SUG $=0$.

GILZGIXL(ITR)

GXO= $\mathrm{AYXO}$ (ITA)

IAX $=x 50 P 2$ (DTH)

THSU THTOP (BTH)

IXIIE $=1$

vo $40 I x=1,4 x$

$X=X X(I X, I T 6)$

IF (X.LI.IEX) Go T2 20

IET= TH HI

60 Io 30

20

TEI = ILAG (I, ISOP 2, THTAP, IUD), ITP, IXUIU, UTH,IEI)

$30 \quad \mathrm{I} \mathbf{I}(\mathrm{IX})=\mathrm{TH} \mathrm{T}-\mathrm{THO}$

IF (IX-LI. AXL) GO TO 40

IP (II.GT_.XXO) GO TO $\$ 0$

SOA $=$ SUAPIT $(L X)$

C

40

COHT II UE

c

MORARLIZ THEORTILN POITIS.

50

$\Delta 1=100 . / 50 a$

DO $50 \quad I x=1,1 x$

$\operatorname{II}(I X)=A I * I T(I X)$

aETUR:

END

C

SUBLOOTIUE BURFE (P)

PUACTION OP SUB NOUTIUB-

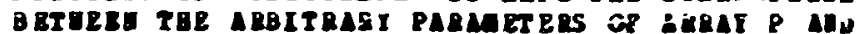

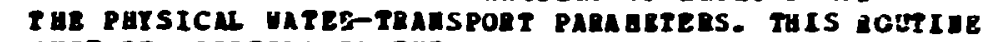

COST BS dODIPIID BI THE OSER SO IS TO MATCA AIS

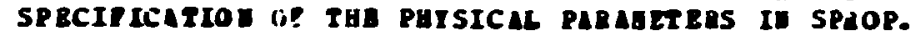

IAPLICIT LRALE $(4-4,0-3)$

DIAEUSIOU P(1)

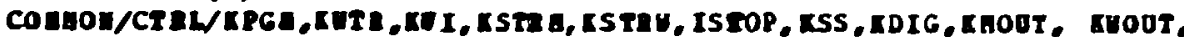

J ITSTP, KSOOR, ISECH, IBOPR, KAUL, IIC, ISTES

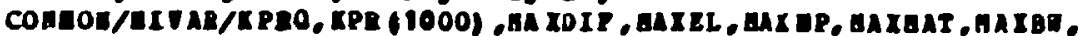

1 MAIDT , MAPP

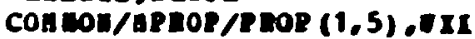

COMDE/AI, TE1, 2HO,THB,BIBRPS

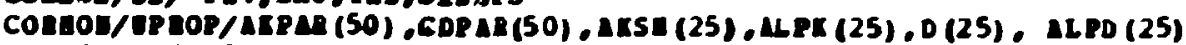

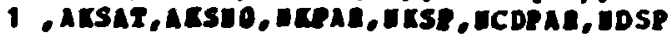

$I P P=0$

C

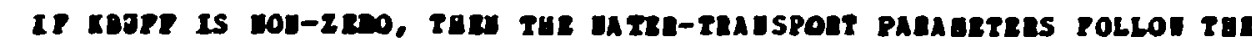

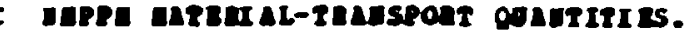

C
SUPE 105

SUPE 110

SUPR 115

SUPE 120

SUPE 125

SRPE 130

SUPE 135

SUPR 140

SUPR 145

SUR 150

SUPE 155

SEPR 160

SUPR 165

SUPE 170

SIPR 175

SEPR 180

SUPR 185

SUPE 190

cURe 195

SEPR 200

STPE 205

SUPR 210

SUPR 215

SEPR 220

SEPE 225

SUPE 230

SUPE 235

SUPR 240

SIPR 245

SUPA 250

SUPE 255

SUPE 260

SUPA 265

SUPR 270

SIPE 275

SOr 280

SUPR 285

SUPE 290

BOR? 0

BORT 5

DUR? 10

DuR2 15

BOR2 20

Dort 25

Bure 30

- ore 35

Burt 40

BORT 55

Bare 50

bort $5 \%$

60

Bor? 65

Bupr 70

BOPF 75

opr 80

80RP 05

bort 90

80T 95

cone 100

bore 105

Dore 110

aopr 115

Bore 120

Dore 125

Dort 130

BORE 135

eort 140

bort 145

corr 150

Dore 155

Bort 160

Dur 165

e0n 170

oor 175

bore 180 


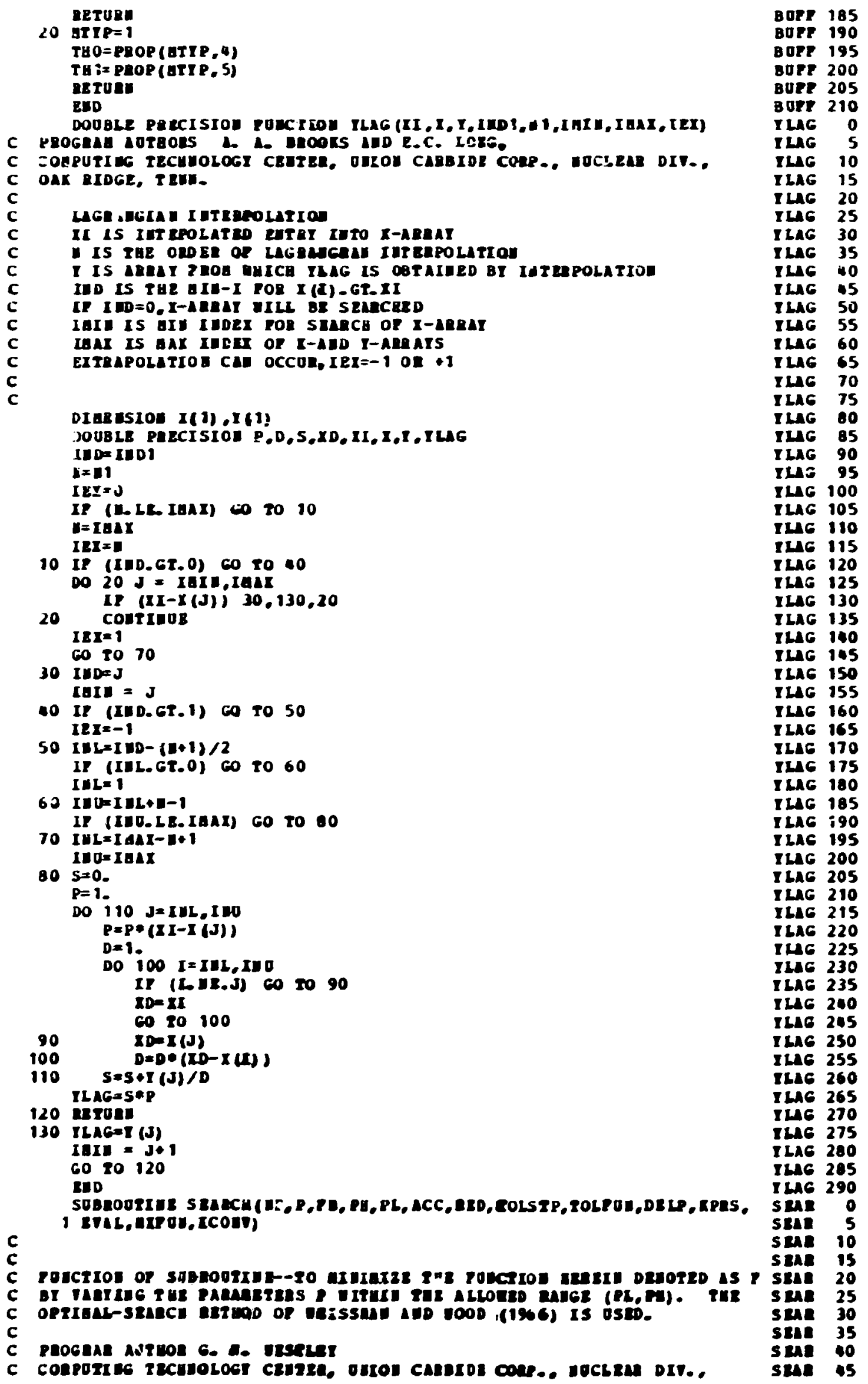


c

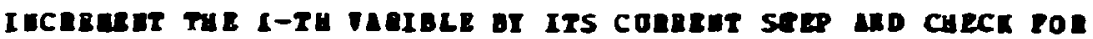

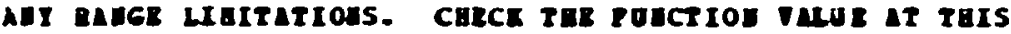

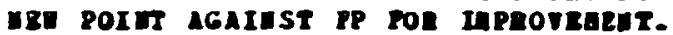

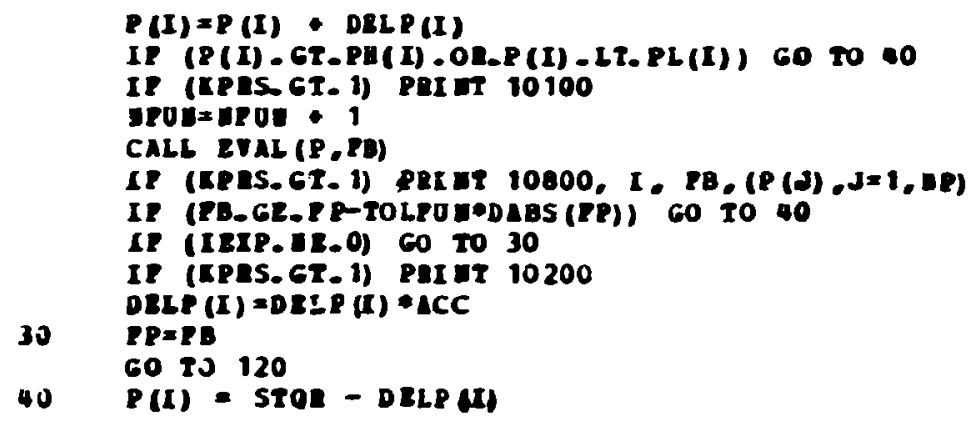




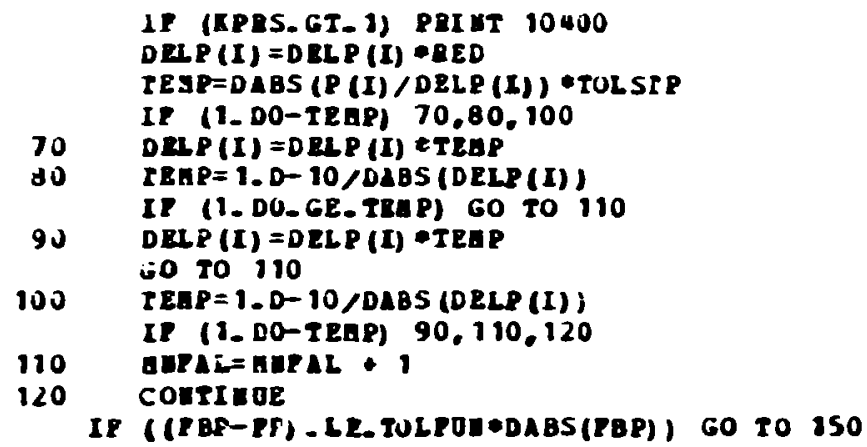


6020240

$220 \mathrm{ICONV}=1$

IP (KPAS. GT. 0) PAIET 11600, ar 0:

IF (XPAS GT, C) PeX Ut 10700, PaP, (BP (I), I=1,AP)

$F \mathbf{P B}=\mathbf{P B P}$

230

DO $230 \quad I=1,4 P$

c

$P(I)=B P(1)$

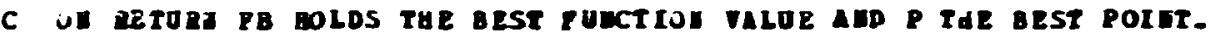

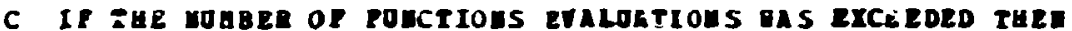

C OUE OP TAE Best poIETS IS aetoEred.

240 ezruas:

10000 POHAAT (" BEGIS EXPLORATORI LOOP')

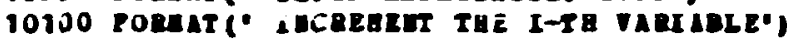

10200 PURAT (" .CCEL ERATE TUE STEP SIZI')

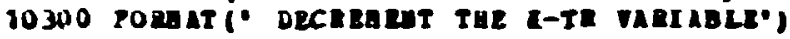

10300 POREAT (" RED DCE STEP SIZE')

10500 rota AT (" ACCEPT UED POInT')

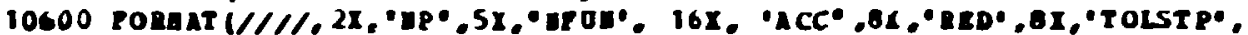

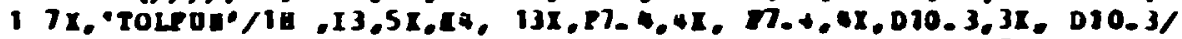

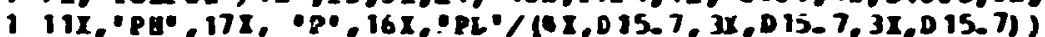

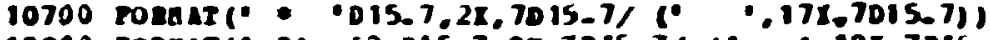

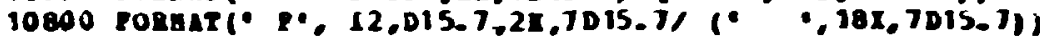

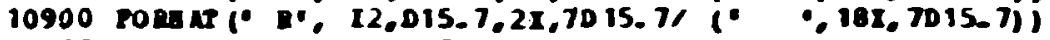

11000 ronat (. Bron=

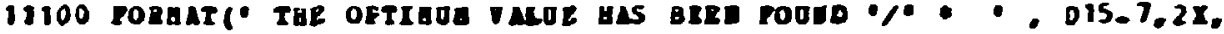
J $\left.\left.7015.7 / 1^{\circ} \cdot 172,7015.7\right)\right)$

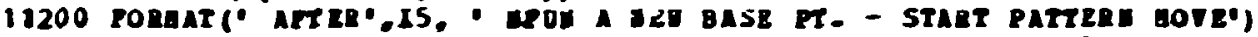

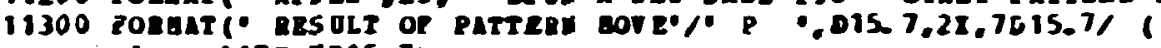
- $17 \times, 7015-7)$

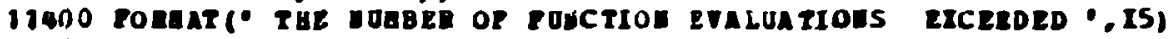

13500 FORAAT (" BASE PT. EXPLORATOAT GODE FAILOE')

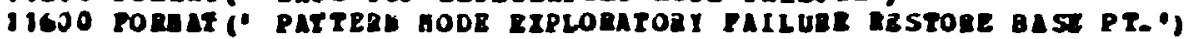

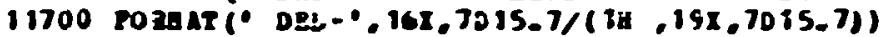

Eะ1)

c

SO jROUTIE GAOSS (A, E, RGAOSS,, , H)

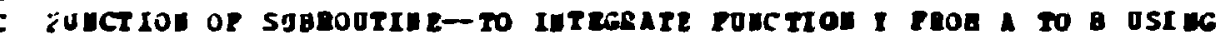

C AS T-TH ORDER GAOSS-LEGEUDE ALGORIYHA.

c

IBPLICIT REAL*B(H-H,0-Z)

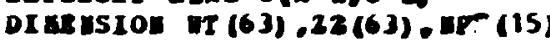

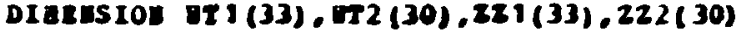

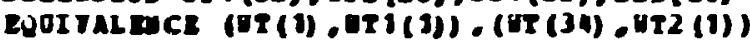

C

EQOI VALECE (22(1).221(3)) , (32)(34),222(1))

C SHOOLD BE IY (2, 16) EXCEPT E $=15$.

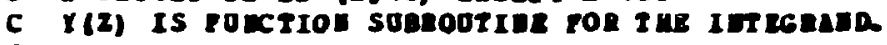

C GAOSS-zEGEDER ABscissks.

C

DATA $228, .577350269109630+00, .774596669241400+00$.

$1.000000000000000+00$. $.061136311594050+00, .339981043584850+00$.

$1.906379945930600000,-539469313105683400, .000000000000000+00$,

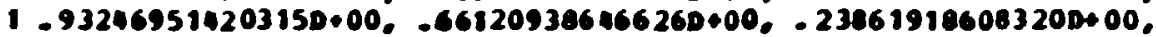

1. $.49107912362260+00, .741531185599390+00$. . $405845151377400+00$,

1.000000000000000400 . .6628985649754D400, .796666477413630*00,

$1.525532400916330+00$, - 183434642495650+00, . 960160239507630*00.

1.836031107326640000 . B13371432700590+06, . 324253423403810000,

$1.000000000000000 \times 00$, - $.973906528517170400, .865063366688900000$,

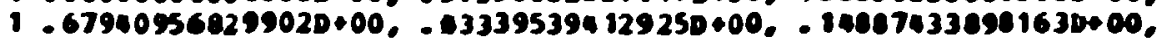

I. $-978226558146060+00,-887062589 \times 8100+00, .730152005574050020$.

1. $519096129206810.00 /$

DATA $822 / .269543155952340000$.000062000000000000,

$1.901560634246720000,-004177256370770 \bullet 00, .76990267$, 394308*0,

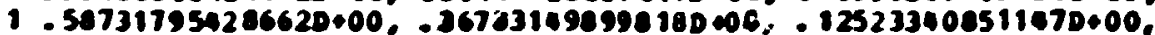

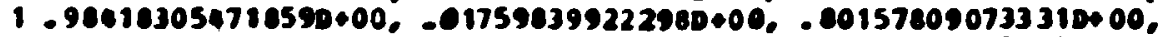

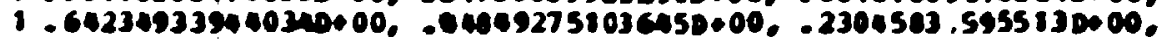

1.000000004000000000 . - .06203060696010000. . 920434003663570000.

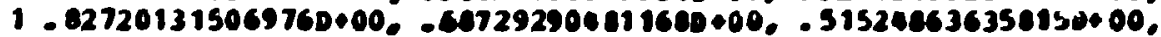

1. 31911236992785000 , . $900054940707340+00$. .98940093499165 0400.

SERE 800

SEAR 805

SER 810

sene 815

SEAR 820

SEAR 825

SENR 30

sere 835

5 ene 800

SEAR Bes

SEAR 850

sene ess

SELE 860

sena 865

SEAR 870

SEAR 875

SEAR 980

sear 085

SER 890

SEAR 895

sear 900

SEAR 905

SELR 910

SEAR 915

sene 920

sent 925

SER 930

sede 935

sene 940

SEAR 905

sene 950

SEA 955

SEAR 960

SELE 965

SEAR 970

sear 975

SRAR 980

cios 0

GAOS 5

GAOS 10

caOS 15

GAOS 20

G10s 25

Gios 30

GAOS 35

gaOs 40

GAOS as

Gás 50

gAOS 55

GLOS 60

GaOs 6:

caUs 70

GAOS 75

GAOS 80

GDOS 65

GAOS 90

gaOs 95

GaUs 100

GaOs 105

GaEs 110

GLes its

and 120

ches 125

c105 130

gaOs 135

Gass 140

Gass 145

cads 150

Gies 155

GAOS 160

cados 165

olos 170

G105 175

caos 100

ons is 


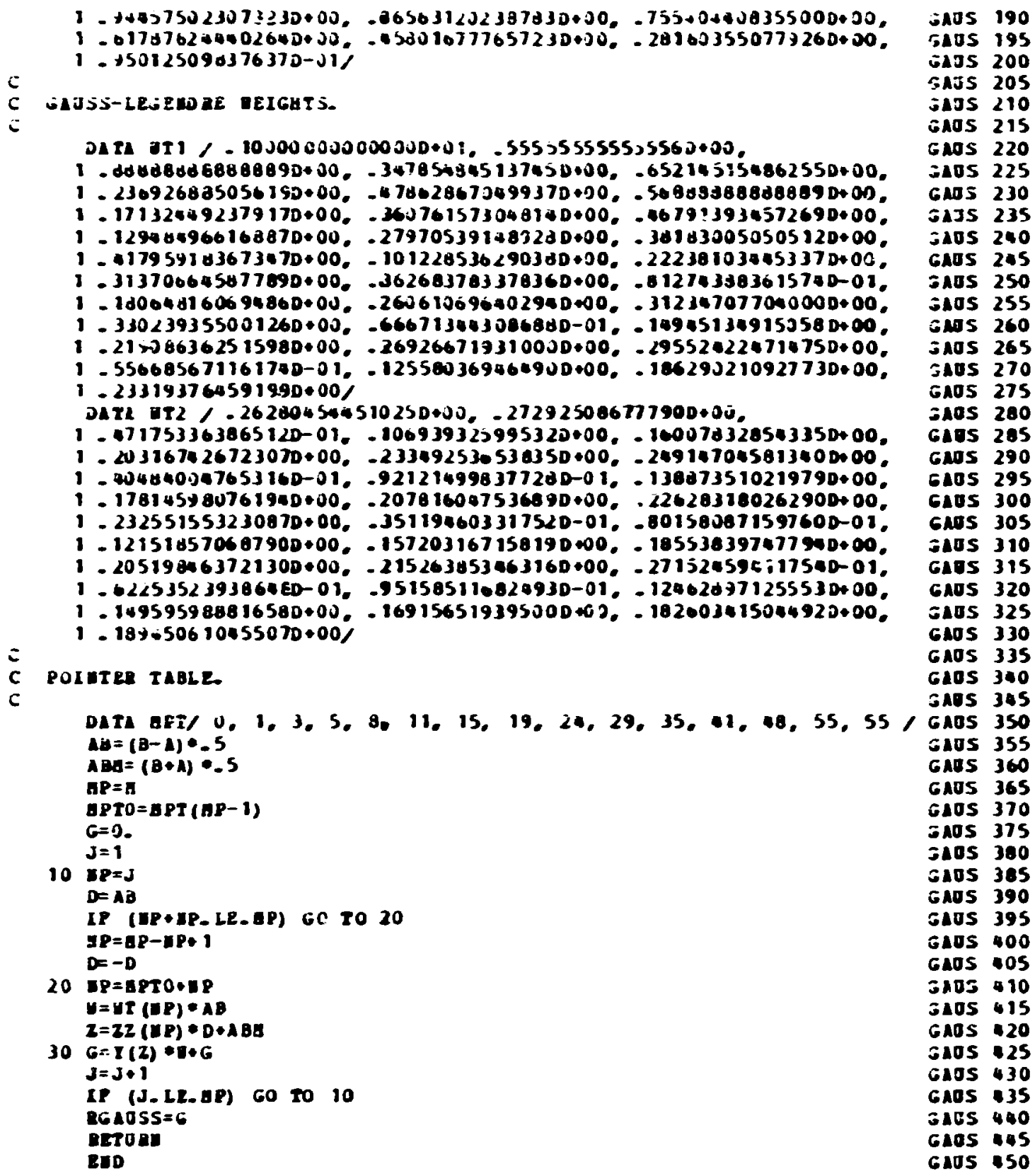




\section{APPENDIX C DEFINITION OF INPUT PARAMETERS}

Parameters are listed telou hy input data-set numbers in the order of their occurrence in the "Ibota Input (iuide." Such an sordering xheme lacilitates cass cross-referencing hetucen Appendices (" and $l)$. 
I. $N P(r)$

IPROB

IIIIII)

$2 N 1$

II

N311

I I

III

$\triangle H C$

ISI

KII

KSIRU

KSS

KisIP

III

.111

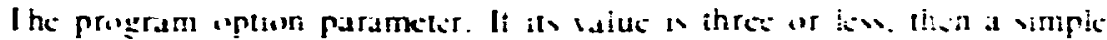

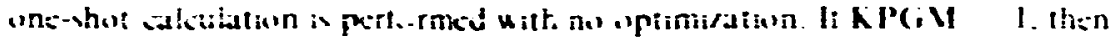

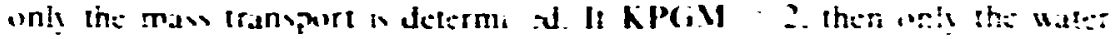
tanenort $w$ ohtaince li. hou ict KP(ill : then a coupled

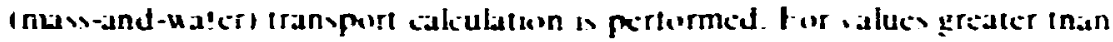
three. parameter ontemigation is perlormed. For KP(ill f. onis the mas

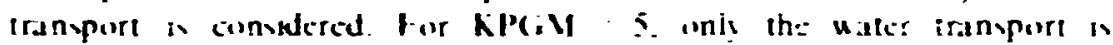
consulered for SPCill a coupied tran-port is connedered nut anl? the

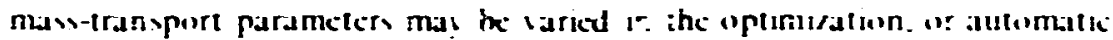

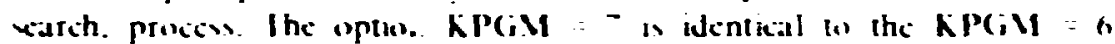
optuon with onit one exception. nargeh that an automatic varch of buth man- and ualter-transport incurs.

I problem adentiticatun number.

In arrat containing the llike of the problem

Vumber of nodial points.

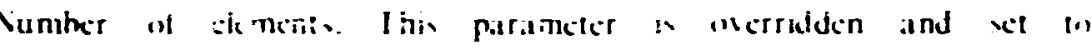
VII VII it entlier of the laller is nonzero.

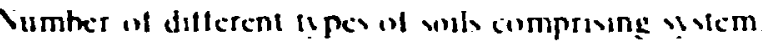

Vumber of correction matcriak

Sumber of the iricrements.

Vumber of l Mrrichlet houndars conduluns.

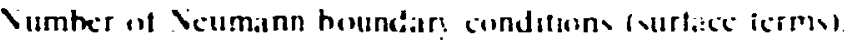

Velocilt in pert control parameter

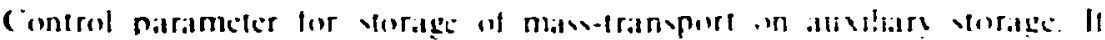

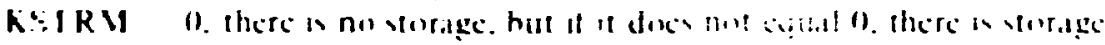

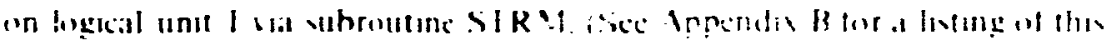
routunc.)

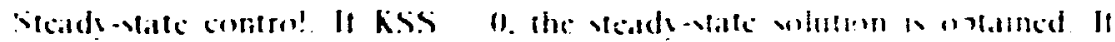

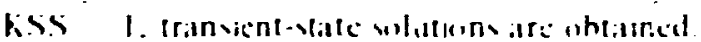

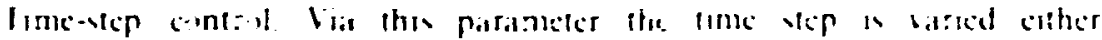

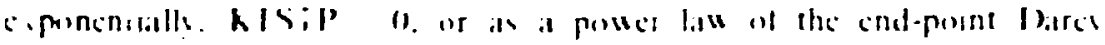
relocil! UI KIsIP' 0 .

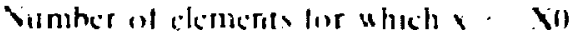

Vumber af clement bor which . Vo 
NTOR

KIC

KMESH

3. DELT

CHNG

DELMAX

TMAX

w

xi)

IMX

D.XI.I

DXI:I

VXI

4. KPRE

KPR(IIM)

5. PROP(1.J)

6. V.J

$X(X$.
Time integration parameter. If $\mathbf{X W O R}=1$, then integration proceeds as described in Chapier IV. Section 5. Otheruise Vorxelt integration OMJ**( $(\mathrm{NOR}-1))$ is used. Acceptable values are $. \mathrm{NOR}=1.2 .3$. and 5

Initial-condition control. If $\mathrm{KIC} \neq 0$. then the initui conditions are hulk concentrations. Oherwise !hey are fluid conceritrations.

Mesh control parameter. If KMFSH $=0$. then a free-form input is uxed with partial au:omatic generation. If K.MESH $=1$. then complete a utomatic generatio" is specified. If KMESH $=2$. then there is no automatis generation. and a compresed-form formai is uxed.

Initial time increment ... $T$.

Parameter used for changit. the time increment ... (dimensonnlew)

Maximum vaiuc of DE I.T ... T.

Maxim'sm vaiue of the time ... T.

Time-integrations parameter ... (dimensionkess).

Variable-mesh parameter. Position about which batible mesh is concentrated ... I..

Varable-mesh parameter. I.ength of chromatographic column ... I.

Varbable-mesh parameter. $X$-increment immediately heiou point $80 \ldots$.. I

Variable-mesh parameter. $X$-increntent im:nediately alxule point X0 ... I.

Space- and time-independent Darey velocity ... I. I.

Printer control for steady-state and initial conditions. It KPRO O. there is no output. If KPRO $=1$. only integrated flow variahles pertaining to the material balance are printed. If KPRO $=2$. then hoth huilh and fluid concentrations are oulput. If KPRO = ?. material fluxes and those variables mentioned presiously are printed. Finally. if KPRO $\equiv \mathcal{4}$. then waller contents and barcy velocitics are also output.

Printer control similar to KPRO used to control time dependent output.

Material property If for soil cype I. In terms of the fornal names given in the

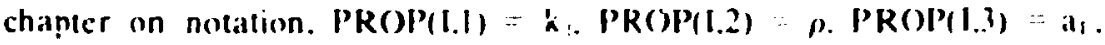
$P R O P(1.4)=\theta$. and $P R O P(1.5)=n$... (variable dimensions).

Yodal-point number.

X-coordinate of node ..I ... I. 


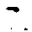

x. II

[EIMIII)

9. MI.MK

MITP

10. VI

$R(N)$

11.

12. N1

BHI

13. NI

I I

14. $1 \times 1.11 .10)$

15. IH(MI.1Q)

16.

17.

IX. KWTR

VI
Sec detinitions lor item 6.

foment number

Flement definition arrat. Fentrics IF( $\$ 11.1$ ) and IF(MII.2) are numbers of the two nodes which subtend :element MI. wheceas IE(MI.3) identities the matcrial tipe.

Element numbers.

Material-type inctex.

Viodal number.

Fluid or hulk concentration s or 8 .... MI $I * * 3$.

Sec definitions for itcm I0.

Vindal number.

Fluid concentration of houndary node $\$ 1 \ldots$ M!*?

Sidal number.

Material flux at boundary node. If th: direction is along the postuve $x$ axis.

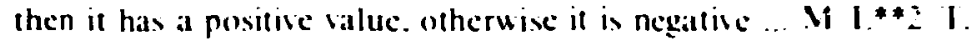

Darey velocity at node 10 of element MI ... I. I.

Water content at node IQ of element MI ... I**3 I**?.

Secitem 12.

See item 1.3.

Water-transport control parameter. This parameter is operative only if KP(iM $=2$. If $K W I R=0$. then only the tabular function $\| W_{\text {i }}$ ) is obtained. If $K W T R=1$, then, additionally, the firstarder calculations for $x^{\prime \prime}$ and $l "$ are determined.

Vumber of eagluations of the tahular function $\| \mathrm{W}$ ). 
NT

NTH

NKPAR

NCPAR

NORDER

NORDERI

NITP

KSTRW

KMESH

19. THO

THI

EPS

DALP1

20. AKPAR

21. CDPAR
The number of simulation times to be considered.

The number of values of $\theta$ to be used.

Number of conductivity parameters to be input.

Number $n$ ? capacity parameters to be input.

Order parameter for the Gauss quadrature algorithm when applied to the interval $(\theta, \ldots, \theta) . i<$.TH. NOR DER is the number of integration points to be inserted into each interval.

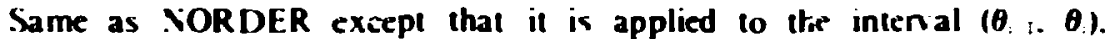
$i=$ NTH. Typically the diffusivity is a strongly varying lunction of water content in this region, and a higher-ordered Causs integration scheme must be used.

Number of lagrange interpolation points to be used in ail water-transport calculaticns requiring interpolation.

Control parameter for storage of hater-transpot output on auxiliary storage. If KSTRW $=0$. there is no storage. but if it does not eupual 0. there is storage on logical unit 2 via subroutil: STRW. (Sec Appendix B for a listing of this routine.)

Mesh control parameter. If $K M E S H=0$. then a uniformly spaced water-content grud is used. If KMESH $\neq 0$. then a variable grid is specified. Typically one desires to concentrate the mesh near the largest water content where $a(N T H)=1$. The next lower value is then $\alpha(N T H-1)=1$ - DALPI. where the laller is an input quantity.

Anaiytic soll-properties control. If KANI. $=0$, then tabular soil properties are used. If KA.NL $\neq 0$, then Gardner and King analytic properties are used.

Initial and residual moislure content ... L**3 L.*3.

Boundary moisture content and porosity ... $L * * 3 \quad 1 . * 3$.

Atıgle of inclination e ... (degrees).

Variable-mesh increment between $a=1$ and its nearest neighbor ... (dimensionless).

Conductivity parameters ... (variahle dimensions).

Diffusivity parameters ... (variable dimensions). 
22. 11

23. 1

24. NP

KPRS

MrFt:

KWI

IIX

KBNI

ISC

KS:ks

25. AC

RI:I)

I0I.SIP

IOI H.

RI)P

(WI)

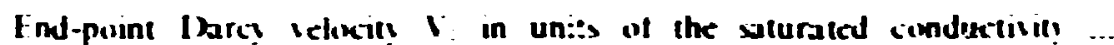
idimensionless).

The simulation time ... I.

Number ol search paramelers.

Output Rag. If KPRS $=0$. there is $\mathrm{m}$; in::rmediate search output. If KPRS $=1$. hax mints and current step sizes are printed. If KPRS = 2 . then there is cutput as for KPRS = I plus exphomtory search information. It KPRS = 3. then there is output as for KPKS $=2$ plus pattern seareh information.

Maximum number of funcioun craluations a!kowed in sarching for the maximum of the $\mathbb{X}$ surface.

Control parameter. for adjusting vtatistical ucights. It $\mathrm{kWT}: 0$. then the experimental error is taken to be the yuare roust of the experionental value. If $K \mathrm{KI}=$ I, a percentage error $\left({ }^{-} \mathrm{WI}\right)$ is taken. For $k \mathrm{KI}=-$ ? experimental errors ar: irput. For $\mathrm{KWJ}: 3$. the stafistial uciehts whtained from the experimental errors are set lo rere fior all $\mathrm{XX}$ - NWI.

Number of times tor which experimental data are li.pur.

If KBNI ) = 0. all porameter ranges are unkounded. If KBNI) 0 . then upper and louer hounds ate inpul lor each search parameler.

Vumber of xarch escles.

Control parameter for slorage of optimized profiks on auxilarg vtorage llape or dish). It KSIRS $=0$. there is no slurage on munched cards i ia subroutinc SIRS. (Sece Appendix $B$ for a tisling of this routine.)

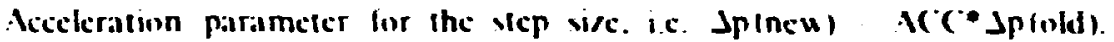
. $C C^{\circ}=1.2$ is 1 pical ... (dimensiuniew).

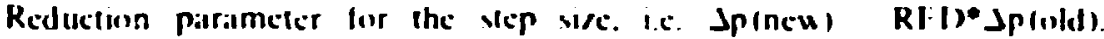
RF(I) -. (I. I is Ispical ... ddimensuinless).

Sicp-sise lolerance. (iencrally. the warch is lermenaled uhenceser

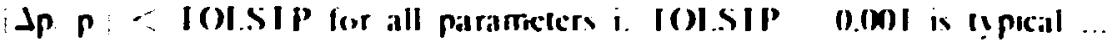
(dimensionless).

Iolerance in the function $X$. Cienctally. the wateh is terminated uhenever

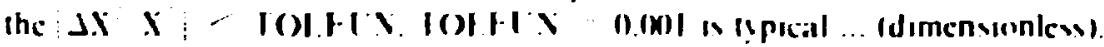

Sicp-sice parameter. Inilially the search step sies are laken lo he In RI)l*"p for all paramelers i ... (dimensionless)

Stalistical ucight parameter ... (dimensinn!ess). 
26. $P(I P)$

27. IPA(ISCY.IP)

28. $\mathbf{P H}(I \mathrm{P})$

29. PI.(IP)

30. $\mathbf{T X}(\mathrm{ITM})$

31. $\mathrm{NYX(1TM)}$

32. $\mathrm{XX}(\mathrm{IX} . \mathrm{ITM})$

33. $Y X(I X .1 T M)$

34. DYX(IX.ITM) Experimental error in the uater-content concent
po. ition IX and time IIM ... (varbable dimensions).

Startige salues for paratieter search The meaning of this serray depends on the progra:at option. If KPGiM $=4$. then $P$ contairs only the mass-transport

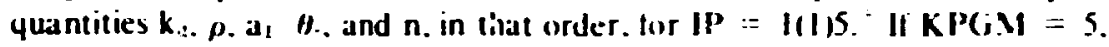
then $P$ contains only the uater-transport variahles $K . h . d . \beta^{*} h^{*} . d^{\prime}, \theta .=\theta$ and $\theta_{1}=\theta_{\text {r }}$ in that order. for $I P=I(I \mathrm{~K}$. Option KPC(BM = G requires onls the mass-transport input just as for $\mathrm{KPC} \mathbf{M}=4$. Option $\mathrm{KPC}: \mathrm{M}=7$. however, requires input appropriate for both mass and water transport. Thus

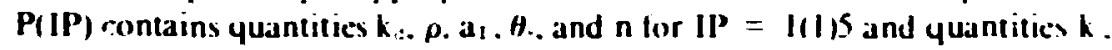
h... d. $\beta^{\prime}$. h'. and d' for IP = of I)ll ... (variable dimenuions).

Search parameter indices. A search is carried out on parameter IP on search cycle ISCY only if IPA(ISCY.IP) $\neq 0$ ).

Upper hounds for parameter P(IP). These parameters are operative only if KBNI) $\neq 0$... (variable dimensions).

Lower bounds for parameters IP(IP). These parameters are operatice only it KBNI) $\neq 0$... (variable dimensions).

Fexperimental times ... I.

Number of foints in experimental uaterecontent concentration profile at time ITM.

Fxperimental X-coordinate of point IX at time II M ... I.

Fxperimental witer-content coricentration value at point $I X$ and time IT.M ... (vartiah!• dimen.ions).

35. XWII.(ITM! The statistical wright is set to ero for all $\mathrm{XX}>\mathrm{XW}[\mathrm{l}$. .. 1 .

YWTU(ITM) Similarly the statistical weight is set to eero for all $\mathrm{XX} ; \mathrm{XWTI} \ldots \mathrm{L}$

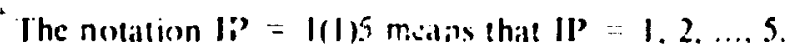


iói

\section{APPENDIX D \\ DATA INPUT GUIDE}

This appendix and Appendix (C hoth pertain to the data input. Here the in put data organization and format are prescribed. Appendix $C$ gives a definition of eush input parameter. 
1. Problem identification. One card per problem.

List: KPGiM.NPROB.(TITL.E(I).I=1.1.8)

Format: $215.8 \mathrm{AX}$

Mass-transport input. The following set of data should be included only if mass-transport is s,recified above. Specifically. only if KPGM = 1.3.4.6. or 7 should card seyuences 2 - 19 appear.

\section{Mass-trarsport integer control parameters. One card per problem.}

\section{List: NNP.NEL.NMAT.NCM.NTI.NBC.NST.KVI.KSTR.M.KSS.KTSTP.NELI. NELU.N.YOR.KIC.KMESH \\ Format: 1615}

Note on Darcy velecities and water contents. Five yuantities must be considered wheneter an uncoupled calculation (KPGM $=1$, or 4 ) is performed. They are KVI. the control integer listed above, the input velocity parameters VXI and VX(M.1Q). and porosity $n=$ PROP(I.S) and water content $\mathrm{TH}(\mathrm{M}, 1 Q)$. If $\mathrm{KVI}=\mathbf{0}$, then the Darcy velocity and water content are taken to be the spatial and temporal constant VXI (card-set 3) and n (card-set S), respectively. If KVI = I, then one spatially dependent array $V X(M, I Q)$ (card-set 12 ) and one spatialiy dependent array TH(IM.IQ) (card-set 13) are used for all time steps. Finally, if $\mathrm{KVI}=2$, time dependence is allowed. as well as space dependence. so that arrays VX(M.IQ) and TH(M.IQ) are input for each time step (card-sets 14 and (5).

Note on variable time mesh. By appropriately specifying control paramet:r KTSTP. the time step may he varied either exponentially

DELT $=$ DEI.T*(I.+CHN(i). KTSTP $=0$

or as a power law function of the endpoint Darcy velocity $V I$

DELT I. VI**(1.+CHNG). KTSTP $\neq 0$

The initial value of time step DEL.T and the value of parameter CHNC; appear in card-set 3. If an uncoupled calculation is called for hy the value of XPGM. then only the former eyuation is used. regardless of the value of KTSTP.

Nole on space mesh. Three different options are available here through control pa rameter KMESH. If KMESH $=0$, then nodal positions are input in free form via card-set 6 and elements are defined via card-set 8. If KMESH $=2$, then all nodal positions are prescribed by card-set 7. These positions may he in raidom order since they are subseyuently reordered and numbered in terms of ascending values. Eler .nt definitions are generated internally ano initial conditions are input (card-set 11 ) in the same order as their corresponding positions. If $\mathrm{KMESH}=1$. then both nodal positions and elements are generated automatically with the finer mesh concentrated about the point $\mathrm{x}=\mathrm{XO}$. Here integers NELL and NEL.U (above) and real quantities XO. XMX. DXI.I, and DXUI (card-set 3) are operative. Their meanings are apparent from the figure below.

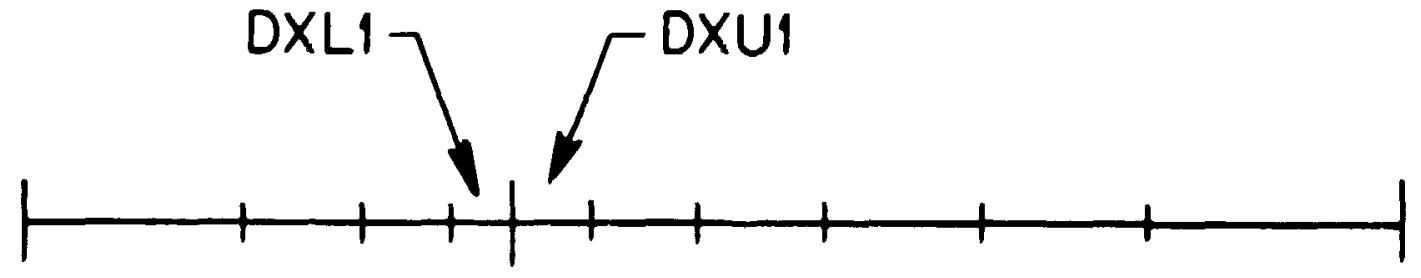




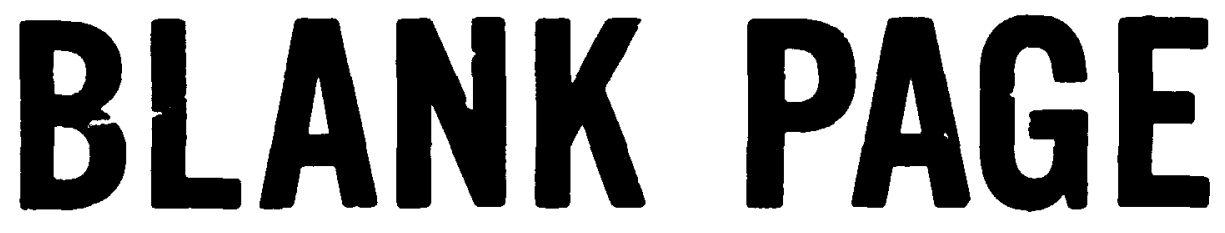


Niste on inisial conditisuns. If $K I C=0$. then $R=c$. the fluid concentration. in card-set 9. If. however. KIC $\neq 0$. :hen $R=$ in the bulk concentration in card-set 9.

3. Mass-transport real control parameters. I wo cards per problem.

I.ist: IDEI.T.CHX(i.DEI.MAX.TMAX.W.XO.X.MX.DXI.I.DXII.VXI

Format: $8 F 10.0$

Note im inme parameier $W$. If NXOR $=$ I. then $W$ has a dual mole of determining both the accuracy [OSIT: at most] and the intermediate time $t_{n}=1+$ ost 'or which time-dependent coefficients are evaluated. If. howeter. NXOR > I. then Norwett integration [Norselt. 1974] is used. which is

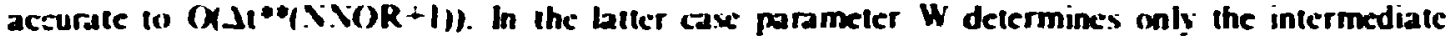
time.

Note on units. The enmputer code itself functions independently of the chooxen system of units. However. consistency of units is reyutred for the input. and dimensions (kngth. mass. and or time) are indialed in Appendix $C$ as an aid for the user.

4. Printer output control. The number of cards here depends on the number of time increments NTI.

l.ist: KPRO.(KPR(I).I=i..NII)

Formut: 8011

5. Material properties. A total of NMAT ards. one for each material.

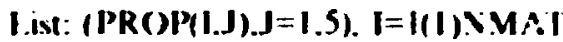

Format: XFIO.D

6. Free-form nodal-point positions. These cards are necessary uhenever K MFSH $=0$. 1 sually onc card per node is needed. a total of $\mathrm{Y}$ P cards.

I.ist: $\mathbf{N J} . \mathrm{X}(\mathrm{XJ})$

Format: 15.5X.F 10.0

However. some automatic generation may he employed in the following manner. If some of the nodes are equidistant. data for only the first and last points of the group are needed. Intermediate nodal positions are generated hy lincar interpolation.

7. Compressed-form nodal positions. These cards are used whenever KMFSII $=2$. There is no automatic generation of mesh points here. The number of cards depends on the value of SiP.

I.ist: $(X(X . J) . X . J=1 . X . X P)$

Format: RF10.? 
8. Element definitions. These cards are necessary whenever KMESH $=0$. I sually one card per ekment is needed. a total of NEL. cards.

L.ist: MI.(IE(MI.I).I=1,3).MOI)I.

Format: 1615

However. the last parameter of the above list is used to generate element detinitions automatically for a group of MODL. ekments containing seyuentially numbered nodes. In such a case MI designates the first number of the group of ekmen's. Field MODL is left blank whencier the automatic generation feature is not used.

9. Material correction. Cards are required there only if $\mathrm{YCM}>0$. : 2 many cases one card is rey!lired per material change. a total of NC:A cards.

\section{l.ist: MI.MTYP.MK}

Format: 1615

However. in those cases where numbers of the affecied elements range from a lower limit MI to an upper limit MK. automatic correction may he used. Field MK is left blank if the automatic correction facility is not used.

10. Free-form mass-transport initial conditions. Cards are required here whenever K MESH $\neq 2$. In the $n$ : 'st general case there is one card per node. a total of N.P eards.

I.ist: NJ.R(.NJ)

Format: 15.5X.F10.0

Ficyuently. however. groups of neighboring nodal points. $\mathrm{N} J$ have identical values $R(N)$ ). If a gap is recognized in the input seyuence of nodal numbers. the initial concentrations are arsumed to be identical to the concentration at the lower houndary of the gap.

11. Compressed-form mass-transport initial conditions. Cards are required here only if KMESH $=2$. The number of eards depends upon the value of XNP.

List: $(R(N J) . N J=I . N$.NP)

Here the order is assumed in correspond to that of the mesh points of eard-set 7 .

12. Dirichlet concentration-type boundary conditions. These cards are necessary only if NBC $>0$. Parameter NBC is the number of required cards.

I.ist: NI.BBI

Format: $15.5 \times . F 10.0$ 
13. Neumann flux-type boundary conditions. Cards of this type must be used if and only if NST $>0$ The value of parameter NST is the number of required cards.

List: NI,EI

Format: 15.5X.F10.0

14. Darcy velocities at time $t=0$. These cards are necessary if and only if the velocity control KVI $>0$. The number of cards depends on the number of ekments NEL.

List: ((VX(MJ,JQ),JQ=1.2), MJ=MI,MK) where $M K=\min (M I+3 . N E L)$ and $M I=\mid(4)$ MEL

Format: 8 F 10.0

It should be noted that the velocity input below, !ike the water-content input below, is ordered by elements.

15. Water contents at time $\mathrm{l}=0$. These cards are necessary whenever the Darcy-velocity cards are necessary, namely when KVI $>0$. The number of cards depends on the value of NEL.

List: ((TH(MJJQ).JQ=I.2).MJ=MI.MK)

where $M K=\min (M I+3 . N E L)$ and $M I=I(4) N E L$

Format: $8 F 10.0$

16. Darcy velocities for tirses $t>0$. Cards of : : is type must be used only whenever $K V I=2$. The number of cards depends on the value of NEL.

List: ( $V X(M J, J Q), J Q=1,2), M J=M I, M K)$

where $M K=\min (M I+3, N E L)$ and $M I=I(4) N E L$

Format: 8FI0.0

Note. Whenever KVI $=2$. card sequences of the form of sequences 14 and 15 below must appear for each time to be used in the simulation.

17. Water contents for times $t>0$. Cards of this $1:$ pe must be used only whenever $K V I=2$. The number of cards depends on the value of NEL.

List: ((TH(MJ,JQ),JQ=I,2),MJ=MI,MK) where $M K=\min (M I+3 . N E L)$ and $M I=1(4) N E L$.

Format: 8F10.0

Moisture-transport input. The following set of data should be included only if a moisturc-transport calculation is indicated by card I. Specifically, only if KPGM $=2,3,5,6$, or 7 , should card sequences 18 - 23 appear. 
18. Moisture-iranepent integer control parameters. Onc card per probkem.

LiST: KWTR.YT IAB.NT.NTH.NKPAR.NCDPAR.NORDER.NORIDERI.NIIP. KSTR W.K.MESH.KS.NL

Format: 16IS

Note on soil properties. Input paramers NKPAR. ICDPAR. and KANI. (ahove). and AKPAR(l) and CDPAR(I) (betow) all pertain to soil pripertics and are interretited. If. for exampk. KA.Y. $=0$. then array AKPAR contains the NKPAR entries $g_{i}, K_{i}, \theta_{2}, K_{:} \ldots$ and array CDPAR contains the NCDPAR entries $\theta_{1}, Q_{1}, \theta_{i}, Q_{-} . .$. . Ht:re $K$ is the conductivity. $Q$ is the diffusivity, and $\theta$ and $\theta^{\circ}$ are water content values. where $\theta$ is not ver: surily equal to $\theta$. If. on the other hand. KANL $\&$. then array AKPAR contains the parame $;: s \mathrm{Ks}$. hon and $d$. in that order. and CDPAR contains the parameters $\beta$. hin and $d^{*}$. Thus, in this c..e NKPAR $=3$ and NCDPAR $=3$.

Note on variable water-content mesh. Frequently a uniform distriblited set of $X$ I 4 water contents $\theta$ (or a) will be wufficient. Here KMESH = 0. Howerer. whenever computer time is a probsem. it is desirabl: to concentrate the mesh in the most active region near $a=1$. This may be done by specifyiag KMESH $\neq 0$ and supplying the first increment DAI.PI (below). The reculting mesh will begin a $a_{1 H}=1$. a IH-1 $=1$ - DAL.PI. The remaining points will then be distributed in accordance with an alacbraic progression of increment values.

19. Moisture-transport real control parameters. One card per probkem.

List: T H0.TH I.EPS.DAI.PI

Forinat: 8FIO.0

20. Conductivity para.seters. If $K A$ AI. $\neq 0$ (see note above), one card is sufficient. Otherw ise the rumber of cards is determined by NKPAR.

List: (AKPAR(I).I=I.NKPAR)

Format: $8 F 10.0$

21. Diffusivity parameters. If KAXI, $\neq 0$ (see note abnve), one card is sufficient. Otherwise the number of cards is determined by XCDPAR.

l.ist: $(\operatorname{CDPAR}(1) . \mathrm{J}=1 . \mathrm{N}$ (DPAR)

Format: $8 F 10.0$

22. End-point Darcy velocities. Tile number of cards depends on the value of NTTAB.

l.ist: (VI,V(I), I= I.NTTAB)

Format: 8 F 10.0 
23. Simulation times. This seyuence of ards is used if and onty if KPCM $=2$. The number of cards is a function of parameter. NT.

List: (T(I).I=I.NT)

Format: 8Fic.0

Optimization isput. The following set of deta shoult be included only if an optimintion. or parameter search. is indicated by cand I. Specifically. only if KPGM $>3$. should card seyuences 24 - 35 appar.

24. Search integer control variables. One cand per probkem.

Lis: NP.KPRS,MXFUX,KWT,NTX,KBND.NSCY,KSTRS

Format: 1615

Note on statistical weights. Variables $\mathrm{KWT}$ (above) and (WT. YX. DYX. XWTI.. and XWTU (below) are interrelated in the following manner: If the control intezer $K W T=0$. then the experimental error in a given measurement $Y X$ is taken to be $\sqrt{Y X}$ and the weizht. $W X=I Y X$ [see Eq. (5.1)]. is internally generated. If $K W T=1$. then $C W T$ is the rebtive error. the experimental error is $C W T \cdot Y X$, and again the statistical weight, $W X=1 / C W T T^{*} X^{* * 2}$, is intemally gencrated. If $K W T \geqslant 2$, then the experimental error is read into array IOYX(IX.ITM) as a function of both position index IX and time index ITM. These talues are then contened to statistical weights in accordance with the rebation $W X=1 D Y X * * 2$. If $K W I=3$. then $W X$ is wet to tero for all $X X<W X T L$ and for all XX $>$ XWTU.

Note on parameter constraints. If KB.ND $\neq 0$. then ineyuality constraints must he input in the form of an upper bound PH(IP) and a lower bound PI.(IP) for each parameter IP.

Nore on search cycles. In order to guard against unrealistic parameter values, it is sometimes desirable to search on the parameters seyuc. tially. This may be done hy selting NSCY cyual to the desired number of warch cycles and identifying the parameter groupings through the IPA array helow.

25. Search real control variables. One card per problem.

l.ist: ACC.RED.TOL.STP.TOI.FUN.RDP.CWT

Format: 8F10.0

26. Initial parameter values. The number of cards depends on the number of paramelers XP.

List: $(P(I P) . I P=I . N P)$

Format: $8 F 10.0$

27. Search-parameter identifiers. The number of zards depends on the number of parameters . YP.

l.ist: (IPA(ISCY.IP).IP=I.NP). ISCY=I NSCY

tormat: 1615 
28. Upper bounds. If KBND $\neq 0$, then the folkowing card seyuence must be prexent. the number of cards depends on the number of pararneters . $P$.

I ist: (PH(IP).IP=I.Xi')

Format: $8 F 10.0$

29. Lower bounds. If KBND $\neq 0$. then the following card seyuence must appear. The number of cards depends on the number of parameters. $\mathbf{X P}$.

list: (PI..IP).IP=I.NP)

Format: $8 F 10.0$

30. Experimental time measurements. The number of cards depends on variahk .TIX.

l.ist: (TX(ITM).ITM=I.NTX)

Format: $8+10.0$

31. Number of water-content / concentration profiles. The nuinher of cards depends on variable ITX.

l.ist: (.XYX(ITM).IT M=1.NTX)

Note on inpul of experimental profile measurements. The following three card seyucnces are nested within a loop over the time index II M=III) NTX.

32. Position variables for time ITM. The number of cards depends on the value of the index $\mathbf{X X}=$. YX(ITM).

I.ist: $(X X(1 X, 11 \mathrm{M}), 1 \mathrm{X}=1 . \mathrm{XX})$

Format: $X F 10.0$

33. Concentration/water-content variables for time ITM. The number of eards depends on the value of the index $\mathbf{X X}=$ IYX(ITM).

J.ist: $(Y X(I X, I T M), I X=I, X X)$

Format: $X+10.0$

34. Experimental errors for time ITM. This seyuence of cards should appcar only if $K W T \geqslant 2$. The number $n$ " eards depends on the value of the index $N X=$ NYX(ITM).

I.ist: (I)YXX(IX.ITM).IX=I.XX)

Format: XF 10.0 
35. Modification of statistical weights for time ITM. This s'quence of cards should a ppear only if $K W T=3$. One card per value of ITM.

List: XWTUITM).XWTU(TM)

Format: 8 F10.0 